Ricardo Augusto Souza Fernandes

\title{
Localização e Identificação de Consumidores com Alta Contribuição para a Distorção Harmônica de Tensão em Sistemas de Distribuição
}

Tese apresentada à Escola de Engenharia de São Carlos da Universidade de São Paulo, sendo parte dos requisitos para obtenção do título de Doutor em Ciências, Programa de Engenharia Elétrica.

Área de Concentração: Sistemas Dinâmicos Orientador: Prof. Dr. Ivan Nunes da Silva

São Carlos 
AUTORIZO A REPRODUÇÃO E DIVULGAÇ̃̃O TOTAL OU PARCIAL DESTE TRABALHO, POR QUALQUER MEIO CONVENCIONAL OU ELETRÔNICO, PARA FINS DE ESTUDO E PESQUISA, DESDE QUE CITADA A FONTE.

Ficha catalográfica preparada pela Seção de Tratamento da Informação do Serviço de Biblioteca - EESC/USP

$3631 \quad$ Localização e identificação de consumidores com alta contribuição para a distorção harmônica de tensão em sistemas de distribuição. / Ricardo Augusto Souza Fernandes ; orientador Ivan Nunes da Silva. São Carlos, 2011.

Tese (Doutorado - Programa de Pós-Graduação em Engenharia Elétrica e Área de Concentração em Sistemas Dinâmicos) -- Escola de Engenharia de São Carlos da Universidade de São Paulo, 2011.

1. Sistemas elétricos de potência. 2. Localização de fontes harmônicas. 3. Identificação de fontes harmônicas. 4. Componentes harmônicas. 5. Enxame de partículas. I. Título. 
FOLHA DE JULGAMENTO

Candidato: Engenheiro RICARDO AUGUSTO SOUZA FERNANDES

Título da tese: Localização e identificação de consumidores com alta contribuição para a distorção harmônica de tensão em sistemas de distribuição.

Data da defesa: 05/08/2011:

\section{Comissão Julgadora:}

Prof. Associado Ivan Nunes da Silva (Orientador)

(Escola de Engenharia de São Carlos/EESC)

Prof. Dr. Mário Oleskovicz

(Escola de Engenharia de São Carlos/EESC)

Prof. Dr. Paulo José Amaral Serni

(Universidade Estadual Paulista "Julio de Mesquita Filho"/UNESP/campus de Bauru)

Prof. Dr. Jesus Franklin Andrade Romero

(Universidade Federal do ABC/UFABC)

Prof. Titular Luis Carlos Origa de Oliveira

(Universidade Estadual Paulista "Julio de Mesquita Filho"/UNESP/campus de Ilha Solteira)
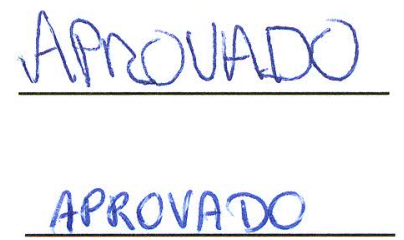

Resultado:

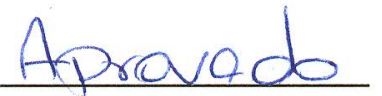

APRD ADO

Coordenador do Programa de Pós-Graduação em Engenharia Elétrica:

Prof. Titular Denis Vinicius Coury

Presidente da Comissão de Pós-Graduação:

Prof. Associado Paulo Cesar Lima Segantine 
"Porque dele e por meio dele, e para ele, são todas as coisas. Glória, pois a ele eternamente. Amém."

Romanos 11, 36

"A dog is the only thing on earth that loves you more than he loves himself."

Josh Billings (1818-1885) 



\section{Agradecimentos}

Esta tese contou com a colaboração de diversas pessoas, às quais gostaria de agradecer mesmo correndo o risco de esquecer algumas delas.

A princípio, faço especiais agradecimentos à minha família que forneceu suporte aos meus estudos. Ao grande homem que é meu pai por me ensinar a nunca pensar que algo não funcionará. Talvez seja esta a maior lição que levo deste doutorado, pois, tive que acreditar e seguir pesquisando mesmo quando o tempo já era curto e os resultados não eram favoráveis. À minha mãe pelo carinho, por estar ao meu lado quando mais preciso e também por sempre telefonar perguntando como estou. Ao meu irmão que por ser mais novo, faz-me lembrar que sempre há tempo para lazer e diversão. Aos meus avós que sempre contribuíram para formar meu caráter de um modo muito carinhoso. À minha namorada, Cíntia, pelo carinho, companheirismo, compreensão e por todo apoio dado em momentos difíceis, pois, quando ri ou chorei, ela sempre esteve ao meu lado.

Seguindo uma linha cronológica, gostaria de agradecer aos amigos que fiz antes mesmo da graduação e que continuam ao meu lado. Dentre estas pessoas, devo ressaltar o amigo Maurício Suzuki que me ajudou muito no aprendizado da lógica de programação e também por sempre tentar me mostrar que os problemas podem ser visualizados por ângulos diferentes.

Aos professores de graduação da FEB/Barretos, instituição na qual tive o privilégio em adquirir toda base de conhecimento científico. Em especial à Prof. ${ }^{a}$ MSc. Fernanda Maria da Cunha Santos, pelo auxílio dado desde o período da graduação até hoje, quando somos amigos e colegas de laboratório. Aos Prof. MSc. 
Sérgio Ricardo de Jesus Oliveira e Prof. MSc. Anderson Luiz Aguiar Vilaça pelos grandiosos ensinamentos.

A todos os amigos de graduação, em especial, a Yuri Andrey Olivato Assagra e Samuel Lourenço Nogueira pelo companheirismo e amizade, sem se esquecer das risadas que demos na antiga república, pois, isto é o que faz com que verdadeiras amizades sejam construídas.

Ao Prof. Dr. Rogério Andrade Flauzino que sempre fez sugestões com o intuito de contribuir com o projeto de doutorado.

Ao Prof. Dr. Mário Oleskovicz que atuou como co-orientador e, portanto, contribuiu de forma efetiva para o desenvolvimento do projeto.

Ao Prof. Dr. Ivan Nunes da Silva que, desde o início, quando ainda estava no mestrado, sempre deu liberdade para pesquisar assuntos que fossem de meu interesse; pela grandiosa contribuição para a conclusão do trabalho e pela confiança depositada nesta pesquisa de doutorado. Agradeço ainda pela orientação acadêmica e pelos ensinamentos para elaboração de projetos e artigos.

Aos amigos de laboratório (LAIPS): Danilo Hernane Spatti, Rodrigo Antonio Faccioli, Marcelo Suetake, Eduardo Sacogne Fraccaroli, Luciano Carli Moreira de Andrade, Sérgio Date Fugita e Fábbio Anderson Silva Borges.

Gostaria também de agradecer a alguns amigos que fiz na USP, campi São Carlos, aos quais tenho grande admiração e apreço: Pedro Luiz Lima Bertarini, Ricardo de Andrade Lira Rabêlo, Daniel Barbosa, Rafael Torres Maia, Guilherme Lage, Ulisses Chemin Netto, Marcelo Favoretto Castoldi, Fábio Toledo Bonemer de Salvi, Tatiane Cristina da Costa Fernandes e Camila dos Anjos Fantin. 
Aos funcionários da Universidade de São Paulo (USP/EESC/SEL), em especial às secretárias de Pós-Graduação, Marisa Fortulan, Rosane Aranda e Jussara Ramos Zoia.

À FAPESP (Fundação de Amparo à Pesquisa do Estado de São Paulo), Processo $\mathrm{N}^{\circ}$ 2008/09521-5, pelo auxílio financeiro concedido no período de realização desta pesquisa na forma de bolsa de estudos.

À Escola de Engenharia de São Carlos (EESC/USP) que acolheu este projeto de doutorado, por meio da destinação de espaço físico e apoio administrativo, traduzindo assim a grandiosidade da instituição e sua visão de futuro. 



\section{SUMÁRIO}

Resumo

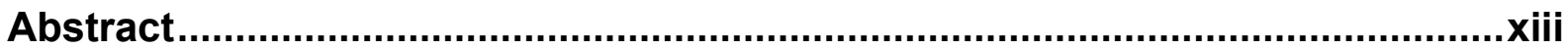

Lista de Siglas e Abreviaturas .......................................................................

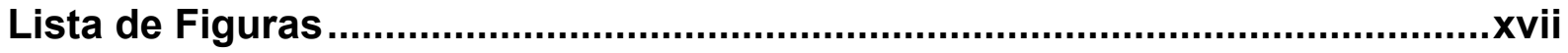

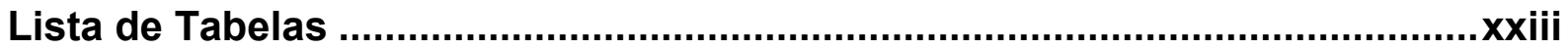

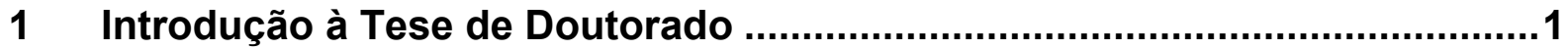

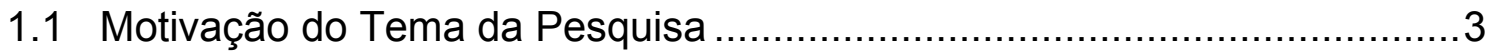

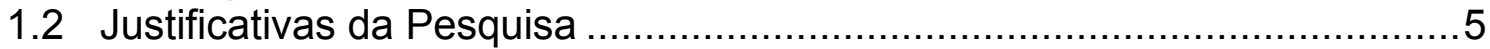

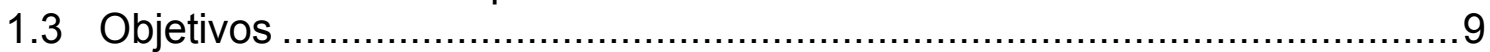

1.4 Principais Contribuições .................................................................. 10

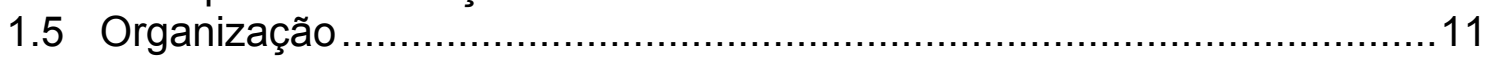

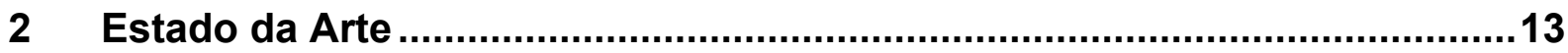

2.1 Modelagem de Sistemas de Distribuição e Dispositivos com Relação à Distorção Harmônica........................................................................13

2.2 Métodos Aplicados à Localização de Fontes Consumidoras de Potências Harmônicas ................................................................................. 14

2.3 Métodos Aplicados à Identificação de Fontes Consumidoras de Potências

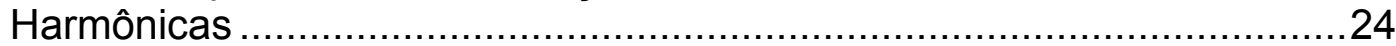

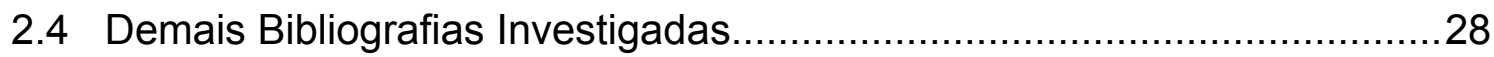

3 Modelagem e Simulação dos Estudos de Caso ..........................................29

3.1 Validação da Modelagem e Simulação Desenvolvida em ATP para o Sistema IEEE de 13 Barras..............................................................30

3.2 Sistema de 20 Barras Modelado para Testar e Validar a Proposta da Tese de Doutorado ................................................................................33

3.3 Sistema Real de 90 Barras Modelado para Testar e Validar a Proposta da

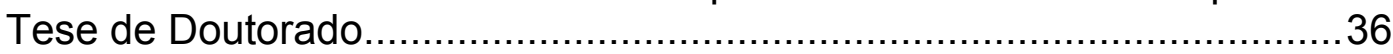

3.4 Cargas Não Lineares Modeladas no Software ATP ..............................42

3.5 Estudos de Caso Gerados para o Sistema de 20 Barras .........................45

3.5.1 Estudo de Caso 1 ............................................................. 47

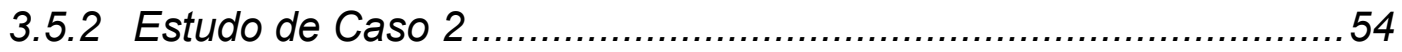

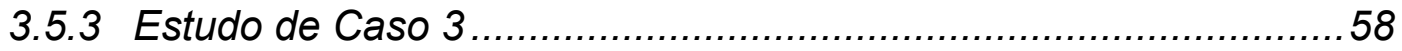

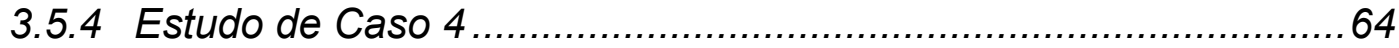

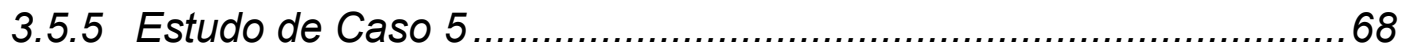

3.5.6 Estudo de Caso 6 ...................................................................... 75

3.6 Estudos de Caso Gerados para o Sistema de 90 Barras ..........................81

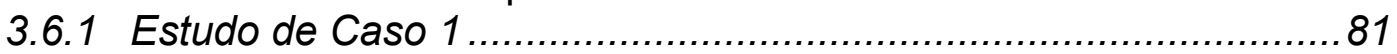

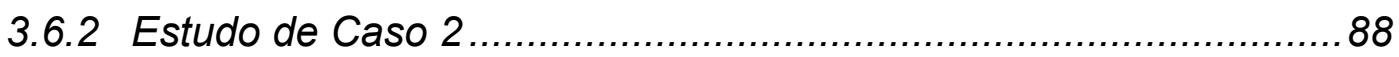

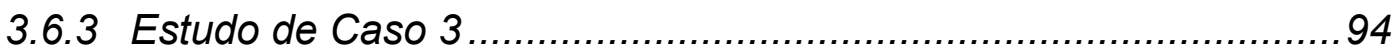

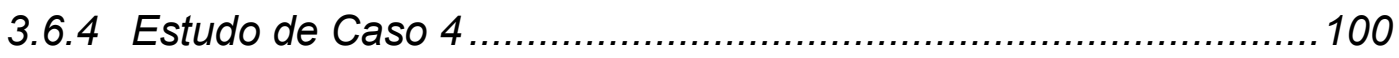


4 Método Proposto para Localização da Fonte Consumidora de Potências

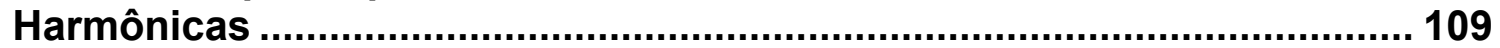

4.1 Aspectos do Sistema de Localização ................................................ 109

4.2 Resultados Obtidos pelo Localizador para Cada Estudo de Caso ......... 114

5 Método Proposto para Identificação da Fonte Consumidora de Potências

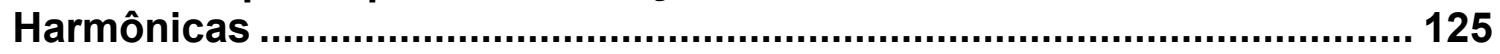

5.1 Aspectos do Sistema de Identificação ............................................... 125

5.2 Otimização por Enxame de Partículas (PSO)..................................... 128

5.3 Resultados Obtidos pelo Método de Identificação................................. 129

6 Método Proposto para Ajuste/Sintonia do Localizador de Fonte Consumidora de Potências Harmônicas ................................................... 135

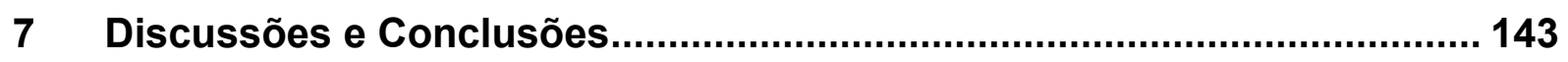

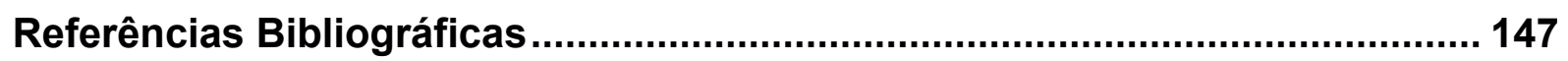

Anexo A - Sistema IEEE de 13 Barras ....................................................... 159

A.1. Configurações iniciais do modelo .................................................... 159

A.2. Algoritmo para injeção de corrente nas barras ..................................... 159

A.3. Modelagem do sistema de distribuição ................................................ 162

A.3.1. Impedância equivalente da fonte................................................. 162

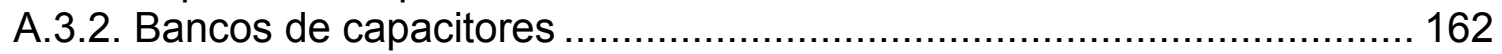

A.3.3. Transformador da subestação..................................................... 162

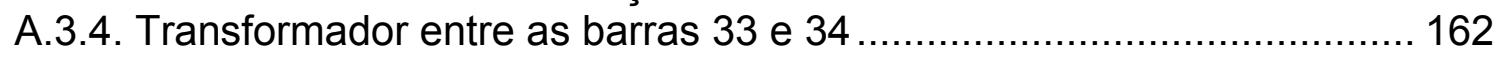

A.3.5. Impedâncias das cargas não lineares .............................................. 162

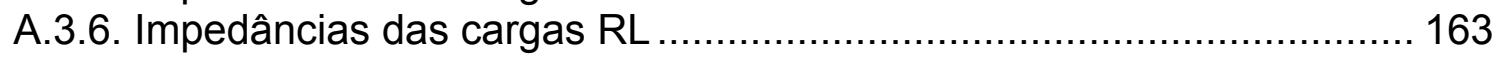

A.3.7. Impedâncias das linhas de distribuição ............................................. 164

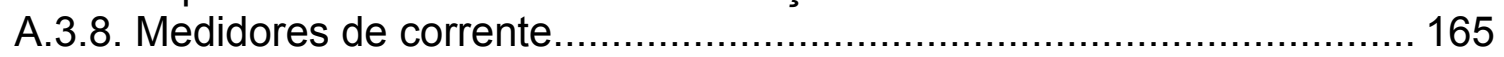

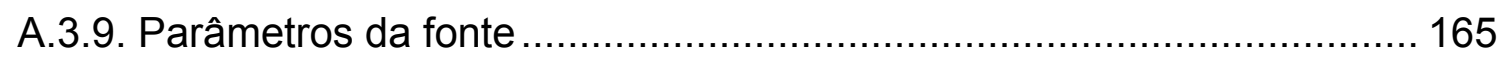

A.3.10. Barras com injeção de corrente harmônica ...................................... 165

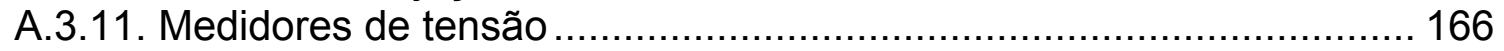

Anexo B - Sistema Fictício de 20 Barras..................................................... 167

B.1. Configurações iniciais do modelo ................................................. 167

B.2. Impedâncias das linhas de distribuição ................................................ 167

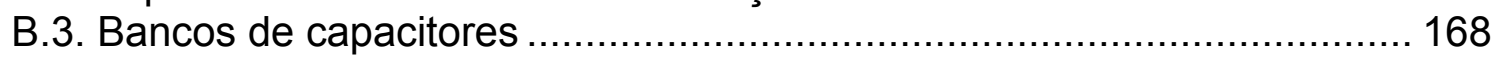

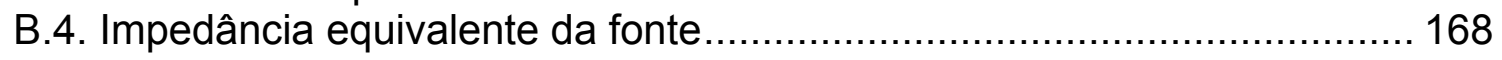

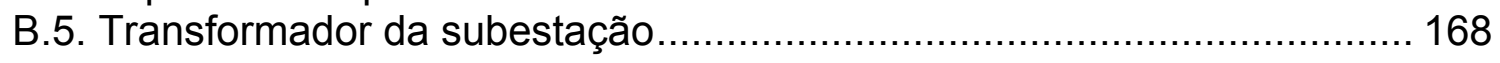

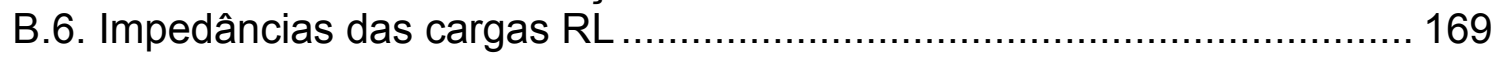

B.7. Chaves dos bancos de capacitores e seccionadoras ............................. 169

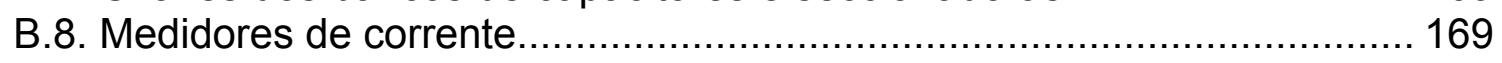

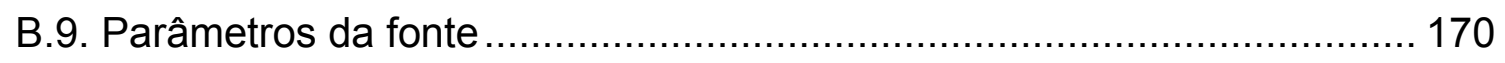

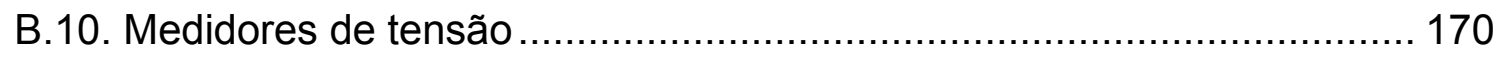




\section{Resumo}

FERNANDES, R. A. S. (2011). Localização e Identificação de Consumidores com Alta Contribuição para a Distorção Harmônica de Tensão em Sistemas de Distribuição. Tese (Doutorado) - Escola de Engenharia de São Carlos, Universidade de São Paulo, 2011.

Esta tese consiste em apresentar um método para localização e identificação de consumidores com alta contribuição para a distorção harmônica de tensão medida em subestações de sistemas de distribuição de energia elétrica. Cabe comentar que a etapa de localização visa obter uma lista das possíveis posições onde possa estar alocado o consumidor que possua cargas não lineares com grande consumo de potências harmônicas. Partindo-se desta lista, realiza-se a etapa de identificação, em que são estimadas as amplitudes de cada harmônica na posição selecionada. Por fim, um algoritmo para ajuste/sintonia do método de localização é empregado com o intuito de se realizar uma possível correção com relação à posição do consumidor. Desta forma, por meio de estudos de caso (simulados), os resultados obtidos procuram validar a metodologia proposta.

Palavras Chave: Localização de Fontes de Harmônicas, Identificação de Fontes de Harmônicas, Componentes Harmônicas, Enxame de Partículas. 



\section{Abstract}

FERNANDES, R. A. S. (2011). Location and Identification of Consumers with Larger Contribution to Harmonic Distortion of Voltage in Power Distribution Systems. Thesis (Ph.D. Degree) - Engineering School of São Carlos, University of São Paulo, 2011.

This thesis provides a method for location and identification of consumers with larger contribution to harmonic distortion of voltage in power distribution substations. It is worth to mention that the stage of consumers' location must furnish a list of possible positions where there may be consumers, who have nonlinear loads with high consumption of harmonic power. From this list, the identification stage is performed in order to estimate the amplitude of each harmonic from the location selected. Finally, a method for improve the location algorithm is employed in order to refine the consumer position. Therefore, by means of simulated case studies, the results obtained for these stages seek to validate the methodology proposed.

Keywords: Location of Harmonic Sources, Identification of Harmonic Sources, Harmonic Components, Particle Swarm Optimization. 



\section{Lista de Siglas e Abreviaturas}

$\begin{array}{ll}\text { ATP } & \text { Alternative Transients Program } \\ \text { BFS } & \text { Backward/Forward Sweep } \\ \text { DHT } & \text { Distorção Harmônica Total } \\ \text { GPS } & \text { Global Positioning System } \\ \text { IEEE } & \text { Institute of Electrical and Electronics Engineers } \\ \text { N.F. } & \text { Normalmente Fechadas } \\ \text { PRODIST } & \text { Procedimentos de Distribuição de Energia Elétrica no Sistema } \\ \text { PSO } & \text { Elétrico Nacional } \\ \text { QEE } & \text { Particle Swarm Optimization } \\ \text { RBF } & \text { Qualidade da Energia Elétrica } \\ \text { RNA } & \text { Radial Basis Function } \\ \text { TDF } & \text { Redes Neurais Artificiais }\end{array}$




\section{Lista de Figuras}

Figura 3.1 - Diagrama esquemático do sistema IEEE de 13 barras. ....................... 31

Figura 3.2 - Diagrama esquemático do sistema de 20 barras. ..........................34

Figura 3.3 - Diagrama esquemático do início do alimentador do sistema real de 90 barras.

Figura 3.4 - Diagrama esquemático da continuação do alimentador do sistema real de 90 barras a partir da chave seccionadora $3(\operatorname{Sec} 3)$.

Figura 3.5 - Diagrama esquemático da continuação do alimentador do sistema real de 90 barras a partir da chave seccionadora 4 (Sec 4).

Figura 3.6 - Diagrama do circuito retificador para conexão em $\Delta$ alimentando uma carga RL.

Figura 3.7 - Diagrama do circuito retificador para conexão em $\Delta$ alimentando uma carga RC.

Figura 3.8 - Tensão instantânea (fase-terra) característica do retificador de 6 pulsos alimentando uma carga $\mathrm{RL}$ (somente fase $\mathrm{A}$ ).

Figura 3.9 - Corrente instantânea (fase-terra) característica do retificador de 6 pulsos alimentando uma carga RL (somente fase $\mathrm{A}$ ).

Figura 3.10 - Tensão instantânea (fase-terra) característica do retificador de 6 pulsos alimentando uma carga RC (somente fase A).

Figura 3.11 - Corrente instantânea (fase-terra) característica do retificador de 6 pulsos alimentando uma carga RC (somente fase $A$ ).

Figura 3.12 - Exemplo de dados históricos da rede - corrente instantânea trifásica (fase-terra) medida na subestação.

Figura 3.13 - Exemplo de dados atuais da rede - corrente instantânea trifásica (fase-terra) medida na subestação.

Figura 3.14 - Tensão instantânea trifásica (fase-terra) medida na subestação para o estudo de caso 1 (dado histórico).

Figura 3.15 - Corrente instantânea trifásica (fase-terra) medida na subestação para o estudo de caso 1 (dado histórico).

Figura 3.16 - Tensão instantânea trifásica (fase-terra) medida no final do alimentador para o estudo de caso 1 (dado histórico). 
Figura 3.17 - Corrente instantânea trifásica (fase-terra) medida no final do alimentador para o estudo de caso 1 (dado histórico).

Figura 3.18 - Tensão instantânea trifásica (fase-terra) medida na subestação para o estudo de caso 1 (dado atual).

Figura 3.19 - Corrente instantânea trifásica (fase-terra) medida na subestação para o estudo de caso 1 (dado atual).

Figura 3.20 - Tensão instantânea trifásica (fase-terra) medida no final do alimentador para o estudo de caso 1 (dado atual).

Figura 3.21 - Corrente instantânea trifásica (fase-terra) medida no final do alimentador para o estudo de caso 1 (dado atual).

Figura 3.22 - Tensão instantânea trifásica (fase-terra) medida na subestação para o estudo de caso 2 (dado atual).

Figura 3.23 - Corrente instantânea trifásica (fase-terra) medida na subestação para o estudo de caso 2 (dado atual).

Figura 3.24 - Tensão instantânea trifásica (fase-terra) medida no final do alimentador para o estudo de caso 2 (dado atual).

Figura 3.25 - Corrente instantânea trifásica (fase-terra) medida no final do alimentador para o estudo de caso 2 (dado atual).

Figura 3.26 - Tensão instantânea trifásica (fase-terra) medida na subestação para o estudo de caso 3 (dado histórico).

Figura 3.27 - Corrente instantânea trifásica (fase-terra) medida na subestação para o estudo de caso 3 (dado histórico).

Figura 3.28 - Tensão instantânea trifásica (fase-terra) medida no final do alimentador para o estudo de caso 3 (dado histórico)....

Figura 3.29 - Corrente instantânea trifásica (fase-terra) medida no final do alimentador para o estudo de caso 3 (dado histórico).

Figura 3.30 - Tensão instantânea trifásica (fase-terra) medida na subestação para o estudo de caso 3 (dado atual).

Figura 3.31 - Corrente instantânea trifásica (fase-terra) medida na subestação para o estudo de caso 3 (dado atual).

Figura 3.32 - Tensão instantânea trifásica (fase-terra) medida no final do alimentador para o estudo de caso 3 (dado atual).

Figura 3.33 - Corrente instantânea trifásica (fase-terra) medida no final do alimentador para o estudo de caso 3 (dado atual). 
Figura 3.34 - Tensão instantânea trifásica (fase-terra) medida na subestação para o estudo de caso 4 (dado atual).

Figura 3.35 - Corrente instantânea trifásica (fase-terra) medida na subestação para o estudo de caso 4 (dado atual).

Figura 3.36 - Tensão instantânea trifásica (fase-terra) medida no final do alimentador para o estudo de caso 4 (dado atual).

Figura 3.37 - Corrente instantânea trifásica (fase-terra) medida no final do alimentador para o estudo de caso 4 (dado atual).....

Figura 3.38 - Tensão instantânea trifásica (fase-terra) medida na subestação para o estudo de caso 5 (dado histórico).

Figura 3.39 - Corrente instantânea trifásica (fase-terra) medida na subestação para o estudo de caso 5 (dado histórico).

Figura 3.40 - Tensão instantânea trifásica (fase-terra) medida no final do alimentador para o estudo de caso 5 (dado histórico).

Figura 3.41 - Corrente instantânea trifásica (fase-terra) medida no final do alimentador para o estudo de caso 5 (dado histórico).

Figura 3.42 - Tensão instantânea trifásica (fase-terra) medida na subestação para o estudo de caso 5 (dado atual).

Figura 3.43 - Corrente instantânea trifásica (fase-terra) medida na subestação para o estudo de caso 5 (dado atual).

Figura 3.44 - Tensão instantânea trifásica (fase-terra) medida no final do alimentador para o estudo de caso 5 (dado atual)...

Figura 3.45 - Corrente instantânea trifásica (fase-terra) medida no final do alimentador para o estudo de caso 5 (dado atual).

Figura 3.46 - Tensão instantânea trifásica (fase-terra) medida na subestação para o estudo de caso 6 (dado histórico).

Figura 3.47 - Corrente instantânea trifásica (fase-terra) medida na subestação para o estudo de caso 6 (dado histórico).

Figura 3.48 - Tensão instantânea trifásica (fase-terra) medida no final do alimentador para o estudo de caso 6 (dado histórico).

Figura 3.49 - Corrente instantânea trifásica (fase-terra) medida no final do alimentador para o estudo de caso 6 (dado histórico).

Figura 3.50 - Tensão instantânea trifásica (fase-terra) medida na subestação para o estudo de caso 6 (dado atual). 
Figura 3.51 - Corrente instantânea trifásica (fase-terra) medida na subestação para o estudo de caso 6 (dado atual).

Figura 3.52 - Tensão instantânea trifásica (fase-terra) medida no final do alimentador para o estudo de caso 6 (dado atual).

Figura 3.53 - Corrente instantânea trifásica (fase-terra) medida no final do alimentador para o estudo de caso 6 (dado atual).

Figura 3.54 - Tensão instantânea trifásica (fase-terra) medida na subestação para o estudo de caso 1 (dado histórico).

Figura 3.55 - Corrente instantânea trifásica (fase-terra) medida na subestação para o estudo de caso 1 (dado histórico).

Figura 3.56 - Tensão instantânea trifásica (fase-terra) obtida pelo medidor de ramificação para o estudo de caso 1 (dado histórico).

Figura 3.57 - Corrente instantânea trifásica (fase-terra) obtida pelo medidor de ramificação para o estudo de caso 1 (dado histórico).

Figura 3.58 - Tensão instantânea trifásica (fase-terra) medida na subestação para o estudo de caso 1 (dado atual).

Figura 3.59 - Corrente instantânea trifásica (fase-terra) medida na subestação para o estudo de caso 1 (dado atual).

Figura 3.60 - Tensão instantânea trifásica (fase-terra) obtida pelo medidor de ramificação para o estudo de caso 1 (dado atual)...

Figura 3.61 - Corrente instantânea trifásica (fase-terra) obtida pelo medidor de ramificação para o estudo de caso 1 (dado atual)...

Figura 3.62 - Tensão instantânea trifásica (fase-terra) medida na subestação para o estudo de caso 2 (dado histórico).

Figura 3.63 - Corrente instantânea trifásica (fase-terra) medida na subestação para o estudo de caso 2 (dado histórico).

Figura 3.64 - Tensão instantânea trifásica (fase-terra) obtida pelo medidor de ramificação para o estudo de caso 2 (dado histórico).

Figura 3.65 - Corrente instantânea trifásica (fase-terra) obtida pelo medidor de ramificação para o estudo de caso 2 (dado histórico).

Figura 3.66 - Tensão instantânea trifásica (fase-terra) medida na subestação para o estudo de caso 2 (dado atual).

Figura 3.67 - Corrente instantânea trifásica (fase-terra) medida na subestação para o estudo de caso 2 (dado atual). 
Figura 3.68 - Tensão instantânea trifásica (fase-terra) obtida pelo medidor de ramificação para o estudo de caso 2 (dado atual). ....

Figura 3.69 - Corrente instantânea trifásica (fase-terra) obtida pelo medidor de ramificação para o estudo de caso 2 (dado atual).

Figura 3.70 - Tensão instantânea trifásica (fase-terra) medida na subestação para o estudo de caso 3 (dado histórico).

Figura 3.71 - Corrente instantânea trifásica (fase-terra) medida na subestação para o estudo de caso 3 (dado histórico).

Figura 3.72 - Tensão instantânea trifásica (fase-terra) obtida pelo medidor de ramificação para o estudo de caso 3 (dado histórico).

Figura 3.73 - Corrente instantânea trifásica (fase-terra) obtida pelo medidor de ramificação para o estudo de caso 3 (dado histórico).

Figura 3.74 - Tensão instantânea trifásica (fase-terra) medida na subestação para o estudo de caso 3 (dado atual).

Figura 3.75 - Corrente instantânea trifásica (fase-terra) medida na subestação para o estudo de caso 3 (dado atual).

Figura 3.76 - Tensão instantânea trifásica (fase-terra) obtida pelo medidor de ramificação para o estudo de caso 3 (dado atual).

Figura 3.77 - Corrente instantânea trifásica (fase-terra) obtida pelo medidor de ramificação para o estudo de caso 3 (dado atual).

Figura 3.78 - Tensão instantânea trifásica (fase-terra) medida na subestação para o estudo de caso 4 (dado histórico).

Figura 3.79 - Corrente instantânea trifásica (fase-terra) medida na subestação para o estudo de caso 4 (dado histórico).

Figura 3.80 - Tensão instantânea trifásica (fase-terra) obtida pelo medidor de ramificação para o estudo de caso 4 (dado histórico).

Figura 3.81 - Corrente instantânea trifásica (fase-terra) obtida pelo medidor de ramificação para o estudo de caso 4 (dado histórico).

Figura 3.82 - Tensão instantânea trifásica (fase-terra) medida na subestação para o estudo de caso 4 (dado atual).

Figura 3.83 - Corrente instantânea trifásica (fase-terra) medida na subestação para o estudo de caso 4 (dado atual).

Figura 3.84 - Tensão instantânea trifásica (fase-terra) obtida pelo medidor de ramificação para o estudo de caso 4 (dado atual). 
Figura 3.85 - Corrente instantânea trifásica (fase-terra) obtida pelo medidor de ramificação para o estudo de caso 4 (dado atual).

Figura 4.1 - Mecanismo de funcionamento do localizador de fonte consumidora de potências harmônicas.

Figura 4.2 - Mecanismo de funcionamento do bloco "Gera Simulações".

Figura 5.1 - Mecanismo de funcionamento do método de identificação da fonte consumidora de potências harmônicas.

Figura 5.2 - Diagrama representativo da otimização realizada por PSO para estimação das amplitudes das harmônicas.

Figura 6.1 - Mecanismo de funcionamento do método de ajuste/sintonia da localização da fonte consumidora de potências harmônicas 


\section{Lista de Tabelas}

Tabela 3.1 - Valores de referência fornecidos pelo IEEE. ................................ 32

Tabela 3.2 - Valores obtidos pela simulação em ATP....................................... 32

Tabela 3.3 - Erros relativos médios percentuais calculados..............................33

Tabela 3.4 - Parâmetros dos elementos que compõem a rede de distribuição do sistema de 20 barras. ............................................................................ 35

Tabela 3.5 - Parâmetros dos elementos que compõem a rede de distribuição do sistema real de 90 barras.

Tabela 3.6 - Assinatura harmônica de corrente da carga não linear alocada na barra 21 para o estudo de caso 1.

Tabela 3.7 - Componentes fundamental e harmônicas de tensão medidas na subestação para o estudo de caso 1.

Tabela 3.8 - Assinatura harmônica de corrente da carga não linear alocada na barra 30 para o estudo de caso 2 .

Tabela 3.9 - Componentes fundamental e harmônicas de tensão medidas na subestação para o estudo de caso 2 .

Tabela 3.10 - Assinatura harmônica de corrente da carga não linear alocada na barra 34 para o estudo de caso 3.

Tabela 3.11 - Barras que sofreram variações de impedância durante a simulação dos dados que representam o estado atual da rede para o estudo de caso 3

Tabela 3.12 - Componentes fundamental e harmônicas de tensão medidas na subestação para o estudo de caso 3 .

Tabela 3.13 - Assinatura harmônica de corrente da carga não linear alocada na barra 53 para o estudo de caso 4 .

Tabela 3.14 - Barras que sofreram variações de impedância durante a simulação dos dados que representam o estado atual da rede para o estudo de caso 4 .

Tabela 3.15 - Componentes fundamental e harmônicas de tensão medidas na subestação para o estudo de caso 4 .

Tabela 3.16 - Assinatura harmônica de corrente da carga não linear alocada na barra 52 para o estudo de caso 5 . 
Tabela 3.17 - Barras que sofreram variações de impedância durante a simulação dos dados que representam o estado atual da rede para o estudo de caso 5 .

Tabela 3.18 - Componentes fundamental e harmônicas de tensão medidas na subestação para o estudo de caso 5 .

Tabela 3.19 - Assinatura harmônica de corrente da carga não linear alocada na barra 42 para o estudo de caso 6 .

Tabela 3.20 - Barras que sofreram variações de impedância durante a simulação dos dados que representam o estado atual da rede para o estudo de caso 6 .

Tabela 3.21 - Componentes fundamental e harmônicas de tensão medidas na subestação para o estudo de caso 6 .

Tabela 3.22 - Assinatura harmônica de corrente da carga não linear alocada na barra B45 para o estudo de caso 1 .

Tabela 3.23 - Componentes fundamental e harmônicas de tensão medidas na subestação para o estudo de caso 1

Tabela 3.24 - Assinatura harmônica de corrente da carga não linear alocada na barra B49 para o estudo de caso 2.

Tabela 3.25 - Componentes fundamental e harmônicas de tensão medidas na subestação para o estudo de caso 2 .

Tabela 3.26 - Assinatura harmônica de corrente da carga não linear alocada na barra B14 para o estudo de caso 3 .

Tabela 3.27 - Componentes fundamental e harmônicas de tensão medidas na subestação para o estudo de caso 3 .

Tabela 3.28 - Assinatura harmônica de corrente da carga não linear alocada na barra B05 para o estudo de caso 4.

Tabela 3.29 - Barras que sofreram variações de impedância durante a simulação dos dados que representam o estado atual da rede para o estudo de caso 4.

Tabela 3.30 - Componentes fundamental e harmônicas de tensão medidas na subestação para o estudo de caso 4

Tabela 3.31 - Limites recomendados pelo IEEE para distorções harmônicas individuais e totais de tensão.

Tabela 3.32 - Limites fornecidos pelo PRODIST para as distorções harmônicas individuais de tensão. 
Tabela 3.33 - Limites fornecidos pelo PRODIST para as distorções harmônicas totais de tensão

Tabela 4.1 - Erros obtidos para cada uma das barras no estudo de caso 1 do sistema de 20 barras.

Tabela 4.2 - Erros obtidos para cada uma das barras no estudo de caso 2 do sistema de 20 barras.

Tabela 4.3 - Erros obtidos para cada uma das barras no estudo de caso 3 do sistema de 20 barras.

Tabela 4.4 - Erros obtidos para cada uma das barras no estudo de caso 4 do sistema de 20 barras.

Tabela 4.5 - Erros obtidos para cada uma das barras no estudo de caso 5 do sistema de 20 barras.

Tabela 4.6 - Erros obtidos para cada uma das barras no estudo de caso 6 do sistema de 20 barras.

Tabela 4.7 - Erros obtidos para cada uma das barras no estudo de caso 1 do sistema de 90 barras.

Tabela 4.8 - Erros obtidos para cada uma das barras no estudo de caso 2 do sistema de 90 barras.

Tabela 4.9 - Erros obtidos para cada uma das barras no estudo de caso 3 do sistema de 90 barras.

Tabela 4.10 - Erros obtidos para cada uma das barras no estudo de caso 4 do sistema de 90 barras.

Tabela 5.1 - Quadro resumo dos resultados obtidos pelo método de localização para os sistemas de 20 e 90 barras.

Tabela 5.2 - Resultados obtidos pelo método de identificação para a estimação das amplitudes das correntes harmônicas da carga no estudo de caso 1.

Tabela 5.3 - Resultados obtidos pelo método de identificação para a estimação das amplitudes das correntes harmônicas da carga no estudo de caso 2 .

Tabela 5.4 - Resultados obtidos pelo método de identificação para a estimação das amplitudes das correntes harmônicas da carga no estudo de caso 3 .

Tabela 5.5 - Resultados obtidos pelo método de identificação para a estimação das amplitudes das correntes harmônicas da carga no estudo de caso 4 .

Tabela 5.6 - Resultados obtidos pelo método de identificação para a estimação das amplitudes das correntes harmônicas da carga no estudo de caso 5 . 
Tabela 5.7 - Resultados obtidos pelo método de identificação para a estimação das amplitudes das correntes harmônicas da carga no estudo de caso 6.... 132

Tabela 5.8 - Resultados obtidos pelo método de identificação para a estimação das amplitudes das correntes harmônicas da carga no estudo de caso 1 ..... 133

Tabela 5.9 - Resultados obtidos pelo método de identificação para a estimação das amplitudes das correntes harmônicas da carga no estudo de caso 2..... 133

Tabela 5.10 - Resultados obtidos pelo método de identificação para a estimação das amplitudes das correntes harmônicas da carga no estudo de caso 3 .

Tabela 5.11 - Resultados obtidos pelo método de identificação para a estimação das amplitudes das correntes harmônicas da carga no estudo de caso 4 .

Tabela 6.1 - Probabilidades de a carga estar alocada em cada barra selecionada para o estudo de caso 1 do sistema de 20 barras..................... 138

Tabela 6.2 - Probabilidades de a carga estar alocada em cada barra selecionada para o estudo de caso 3 do sistema de 20 barras..................... 138

Tabela 6.3 - Probabilidades de a carga estar alocada em cada barra selecionada para o estudo de caso 4 do sistema de 20 barras..................... 138

Tabela 6.4 - Probabilidades de a carga estar alocada em cada barra selecionada para o estudo de caso 5 do sistema de 20 barras...................... 138

Tabela 6.5 - Probabilidades de a carga estar alocada em cada barra selecionada para o estudo de caso 6 do sistema de 20 barras...................... 139

Tabela 6.6 - Probabilidades de a carga estar alocada em cada barra selecionada para o estudo de caso 1 do sistema de 90 barras.

Tabela 6.7 - Probabilidades de a carga estar alocada em cada barra selecionada para o estudo de caso 2 do sistema de 90 barras.

Tabela 6.8 - Probabilidades de a carga estar alocada em cada barra selecionada para o estudo de caso 3 do sistema de 90 barras. 


\section{Introdução à Tese de Doutorado}

Atualmente, nota-se a crescente proliferação de cargas não lineares que em consumidores de médio e grande porte (principalmente indústrias) são ainda mais predominantes. Desta forma, verifica-se também a crescente degradação da Qualidade da Energia Elétrica (QEE) entregue pelas concessionárias. Neste contexto, pode-se destacar a degradação das tensões harmônicas presentes nos alimentadores dos sistemas de distribuição de energia elétrica, as quais podem ser medidas por equipamentos analisadores de qualidade de energia ou oscilógrafos. É importante observar que as distorções harmônicas em sistemas de distribuição podem acarretar em falhas de equipamentos (IEEE Task Force on Harmonic Impacts, 1993; Sankaran, 2002; Rosa, 2006), a saber:

- Falhas em transformadores de distribuição associadas à presença de tensões harmônicas, pois, estas geram perdas adicionais no núcleo do transformador;

- Falhas em bancos de capacitores e até condições de ressonância. Sendo sua reatância inversamente proporcional à freqüência, o banco de capacitores passa a absorver correntes harmônicas e, portanto, esta situação pode resultar numa possível sobrecorrente;

- Falhas em cabos também podem ser observadas, pois, o efeito pelicular é maximizado quanto maiores forem as amplitudes das correntes harmônicas de alta frequência; 
- Falhas nos dispositivos de proteção, os quais podem operar de forma errônea e comprometer grande parte do sistema de distribuição de energia elétrica;

- Falhas em equipamentos baseados nos componentes da eletrônica digital.

No entanto, apesar de ser conhecida a presença das tensões harmônicas nos alimentadores dos sistemas de distribuição, bem como as falhas que podem ser acarretadas por estas situações de distorção harmônica, pouco é retratado na literatura a respeito de métodos que possam ser aplicados à localização dos consumidores que tenham alta contribuição para a degradação do sistema. Neste sentido, grande parte das pesquisas encontra-se direcionada à estimação de estado de correntes e tensões harmônicas (Heydt, 1989; Najjar e Heydt, 1991; Du et al., 1999; D'Antona, Muscas e Sulis, 2009), sendo que algumas das pesquisas retratam a importância da alocação ótima de medidores junto à estimação de estados (Farach, Grady e Arapostathis, 1993; Ma e Girgis, 1996; Kumar, Das e Sharma, 2005a, 2005b). A partir destas pesquisas, surgiram outras com o mesmo objetivo, utilizando-se para tanto de sistemas inteligentes (Hong e Chen, 1999; Lin et al., 2005).

Partindo-se da estimação de estados das correntes e tensões harmônicas, surgiram ainda pesquisas com o objetivo de caracterizar as fontes consumidoras de potências harmônicas e identificar a composição harmônica destas fontes. Dentre as pesquisas destinadas à caracterização das fontes consumidoras de potências harmônicas, estas podem ser divididas em duas categorias, a saber:

- Fundamentadas em classes de cargas que retratam uma visão geral, onde as cargas são divididas em dispositivos ferromagnéticos, 
dispositivos baseados em componentes da eletrônica de potência e dispositivos a arco (Varadan e Makram, 1994, 1996; Alammari, Soliman e El-Hawary, 2004);

- Fundamentadas na classificação da carga propriamente dita. No entanto, estes métodos de caracterização são retratados na literatura somente para cargas de menor potência, normalmente cargas residenciais (Umeh e Mohamed, 2004, 2005; Mohamed et al., 2006; Srinivasan, Ng e Liew, 2006; Fernandes, Silva e Oleskovicz, 2010).

Já com relação às pesquisas que têm como objetivo principal a identificação da composição harmônica, estas fazem uso de medidas de tensão e corrente de modo a obter as amplitudes e/ou ângulos de fase para cada uma das harmônicas a ser estimada (Hartana e Richards, 1990, 1993; Zhao, Li e Xia, 2004; Al-Kandari et al., 2006; Gursoy e Niebur, 2009).

Após uma breve introdução à temática desta pesquisa de doutorado (localização e identificação da fonte consumidora de potências harmônicas), na sequência serão apresentados os fatos que motivaram tal pesquisa (Seção 1.1), as justificativas para as motivações comentadas (Seção 1.2), os objetivos a serem atingidos ao final da pesquisa (Seção 1.3), as principais contribuições advindas desta pesquisa (Seção 1.4) e, por fim, a organização do texto (Seção 1.5).

\subsection{Motivação do Tema da Pesquisa}

De acordo com as pesquisas correlatas encontradas na literatura, verifica-se que, com relação aos métodos já desenvolvidos para localização de fontes consumidoras de potências harmônicas em sistemas de distribuição de energia elétrica (Najjar e Heydt, 1991; Farach, Grady e Arapostathis, 1993; Ma e Girgis, 
1996; Hong e Chen, 1999; Won et al., 2006; D'Antona, Muscas e Sulis, 2009), estes são baseados em estimadores de estado e, portanto, sua aplicabilidade não é viável ao sistema elétrico brasileiro, pois, necessitam de um grande conjunto de medidas. Assim, seria necessária a alocação de uma grande quantidade de equipamentos medidores de correntes e/ou tensões harmônicas, fato este que demandaria altos investimentos financeiros por parte das concessionárias.

Além disso, há uma diversidade de pesquisas que apresentam resultados considerados satisfatórios desde que algumas restrições sejam garantidas, a saber:

- Métodos aplicados somente a sistemas de transmissão de energia elétrica, isto é, sistemas malhados contendo medidas redundantes e pseudo-medidas $^{1}$ (Heydt, 1989; Du et al., 1999; Kumar, Das e Sharma, 2005a, 2005b; Lin et al., 2005);

- Métodos aplicados a sistemas de distribuição fortemente malhados (Najjar e Heydt, 1991);

- Métodos aplicados a sistemas de distribuição radiais, os quais não são submetidos a situações onde haja variações no carregamento da rede (alterações nos perfis de consumo de potência ativa e reativa) e erros nas medidas (Farach, Grady e Arapostathis, 1993; D’Antona, Muscas e Sulis, 2009);

Cabe comentar que todos estes métodos já propostos na literatura têm normalmente medidores alocados com base no conhecimento especialista ou empregam ferramentas de otimização para a tarefa de alocação.

\footnotetext{
${ }^{1}$ Pseudo-medidas representam valores calculados que podem substituir medidas quando da ocorrência de falha em medidores, presença de erros grosseiros, etc; além disso, as pseudo-medidas podem ser utilizadas para fornecer informações dos pontos onde não existam medidores.
} 
No entanto, para todos estes métodos, a alocação dos medidores torna-se fortemente dependente do comprimento do sistema de distribuição (topologia), motivo este que impede a aplicação de tais metodologias a grandes redes de distribuição de energia elétrica. Assim, visto que os métodos de localização (baseados em estimadores de estado de correntes e tensões harmônicas) não são viáveis de serem aplicados ao sistema elétrico brasileiro, nota-se que, por consequência, os métodos de identificação da composição harmônica da fonte causadora de distorções não podem ser empregados, pois, têm como pré-requisito a tarefa de estimação de estados. Desta forma, cabe a esta pesquisa, além de localizar a fonte consumidora de potências harmônicas, identificar a composição harmônica da mesma, assim como garantir que o método proposto atenda, com poucos investimentos, o sistema elétrico brasileiro.

De forma a ressaltar as características das pesquisas já encontradas na literatura (localização das fontes) e contrastá-las com a pesquisa de doutorado retratada neste documento, na sequência (Seção 1.2), tais pesquisas são devidamente explanadas em maior nível de detalhamento com o intuito de justificarem o tema proposto.

\subsection{Justificativas da Pesquisa}

As motivações desta tese são justificadas com base nos relatos publicados pela comunidade científica, os quais são provenientes de revistas renomadas da área. Desta forma, a princípio, são apresentadas as principais pesquisas que mais se assemelham à proposta desta tese de doutorado. Estas pesquisas serão devidamente comentadas, explanadas e discutidas seguindo uma ordem cronológica (da mais antiga para a mais recente). 
Assim, tem-se o trabalho de Heydt (1989) como o lastro das pesquisas voltadas à localização e identificação de fontes consumidoras de potências harmônicas. A proposta do autor é baseada na estimação de estado das tensões e correntes harmônicas para sistemas de transmissão de energia elétrica. Portanto, subentende-se que o sistema de transmissão possui uma diversidade de medidores, os quais fornecem medidas redundantes e que auxiliam ainda mais no processo de estimação. De posse destas medidas, o autor propõe um estimador baseado no método dos mínimos quadrados para calcular o espectro de frequências em cada barra do sistema de transmissão. Os resultados obtidos foram satisfatórios, entretanto, faz-se necessário comentar que, para um sistema de 75 barras, empregaram-se 20 medidores de tensão e 11 medidores de corrente. Além disso, por se tratar de um sistema de transmissão, este é interconectado (totalmente malhado). O autor comenta também que a metodologia proposta pode apresentar resultados imprecisos em certos casos, principalmente onde haja perdas de potência reativa, perdas de potência ativa, erros do estimador baseado em mínimos quadrados e erros que podem ser acarretados pela modelagem imprecisa das linhas de transmissão.

Partindo-se da pesquisa de Heydt (1989), a mesma foi expandida para sistemas de distribuição, onde em Najjar e Heydt (1991) um novo estimador de tensões e correntes harmônicas foi proposto para melhor aderir ao propósito de estimação de estados em sistemas de distribuição. O estimador desenvolvido foi considerado híbrido por agregar o método dos mínimos quadrados ponderados junto à lei de Kirchhoff das correntes. No entanto, a metodologia proposta necessita de tantos medidores quanto naquela proposta de Heydt (1989), sendo que cada medidor deve utilizar uma taxa de amostragem tal que permita a obtenção de 1024 
pontos por ciclo. Por este motivo, os autores deixam claro que o método proposto somente poderia vir a ser aplicado com o avanço da instrumentação.

Analisando-se a pesquisa de Najjar e Heydt (1991), de maneira mais aprofundada, é possível verificar que mesmo com a melhora da instrumentação e a queda no valor agregado à aquisição destes equipamentos, ainda não era realidade de muitos países a instalação de grandes quantidades de medidores em sistemas de distribuição.

Após a análise da pesquisa supracitada, foi possível notar que uma possibilidade deste tipo de pesquisa ser aplicada em sistemas de distribuição se torna então viável com a utilização de smart meters, porém, os smart meters (Mannikoff e Nilsson, 2009) são tecnologias ainda consideradas muito recentes. Desta forma, pode-se afirmar que apesar de a pesquisa de Najjar e Heydt (1991) apresentar bons resultados, esta não pode ser aplicada aos sistemas de distribuição brasileiros a menos que altos investimentos financeiros sejam realizados.

Visto a grande quantidade de medidores que devem ser alocados para a estimação de estado das correntes e tensões harmônicas, em Farach, Grady e Arapostathis (1993) é proposta a alocação ótima destes medidores com o intuito de se manter a menor quantidade e de se obter uma estimação de estado satisfatória. Neste caso, foram realizados testes sobre três sistemas de distribuição, os quais continham respectivamente 7, 9 e 18 barras. Para cada um destes sistemas se realizou a alocação dos medidores, a qual se baseia num algoritmo exaustivo (todas as possíveis posições são verificadas). Desta alocação, observou-se que para aqueles sistemas de 7 e 9 barras, as melhores configurações necessitariam de pelo menos 3 medidores. Para o sistema de 18 barras, no entanto, seria necessário no 
mínimo 5 medidores a fim de se garantir uma boa estimação do estado das harmônicas.

Em Hong e Chen (1999), os autores fazem uso de um sistema Fuzzy Cmeans $^{2}$ de forma a dividir a rede de distribuição em regiões (clusters), onde para cada uma das regiões determinadas é alocado um medidor. Assim, uma Rede Neural Artificial (RNA) recebe os dados obtidos por cada um dos medidores e fornece como saída a barra onde se encontra a carga consumidora de potências harmônicas. No entanto, visto que há a necessidade de se treinar as RNAs, os autores pressupõem que o fluxo de potência harmônico da rede, bem como o carregamento da mesma, não sofre forte variação. Desta forma, nota-se que o método proposto não empregou um modelo de rede de distribuição com características mais próximas quanto possível de uma rede de distribuição real.

Mais recentemente, Won et al. (2006) propuseram um método que considera uma rede de distribuição com alimentador de grande comprimento (sistema IEEE de 34 barras), além de considerarem um leve carregamento da rede e também situações de desbalanceamento. Assim, nota-se que o sistema modelado apresenta características que se assemelham àquelas encontradas em redes de distribuição reais. Porém, neste caso, os autores realizam o cálculo do fluxo de potência e para isto necessita-se da alocação de medidores. Cabe comentar que, para o sistema de distribuição proposto, empregaram-se um total de 26 medidores, portanto, quase todas as barras do sistema possuíam monitoramento.

\footnotetext{
${ }^{2}$ Fuzzy C-means é uma ferramenta de agrupamento (cluster) que emprega sistemas Fuzzy, os quais são responsáveis por ponderar se um determinado dado pode ou não fazer parte de mais do que um cluster, isto é, por meio desse sistema pode-se definir o grau de pertinência de um dado para cada um dos clusters.
} 
Por fim, em D’Antona, Muscas e Sulis (2009), os autores propõem um método Bayesiano que utiliza pseudo-medidas de tensão e corrente. Neste trabalho, a metodologia proposta é testada sobre um sistema IEEE de 13 barras, o qual é modificado de forma a não possuir desbalanceamento e, portanto, pode ser representado de modo unifilar. Para que o método apresentasse bons resultados foram utilizados 5 medidores ( 3 medidores de corrente e 2 medidores de tensão). No entanto, após a modificação do sistema de 13 barras, este tornou-se um sistema com somente 8 barras. Portanto, houve a necessidade de alocar medidores em quase todas as barras que constituem o sistema de distribuição modelado.

Verificada a literatura supracitada, nota-se que os métodos até então propostos para a localização de fontes consumidoras de potências harmônicas em sistemas de distribuição de energia elétrica não conseguem proporcionar uma boa localização sem que sejam alocados muitos medidores de tensão e/ou corrente. Além disso, observa-se também que esta grande quantidade de medidores somente deve ser alocada devido ao fato de que todas as metodologias propostas necessitam do cálculo do fluxo de potência das correntes e tensões harmônicas.

Portanto, justifica-se esta tese de doutorado com a investigação e implementação de uma nova metodologia que possa ser empregada aos sistemas de distribuição brasileiros. Desta forma, será também proposta aqui uma metodologia de identificação que suporte o método de localização proposto. Assim, a Seção 1.3 destina-se a apresentar os objetivos desta tese de doutorado.

\subsection{Objetivos}

Os objetivos gerais desta tese de doutorado consistem na investigação, desenvolvimento, projeto, implementação e validação de uma nova metodologia que 
possa ser empregada à localização e identificação de consumidores com alta contribuição para a distorção harmônica de tensão medida em subestações de sistemas de distribuição de energia elétrica.

Já os objetivos específicos, estes podem ser definidos conforme apresentado na sequência:

- Modelar sistemas de distribuição de energia elétrica de maneira a considerar, quando possível, modelos mais detalhados;

- Simular os sistemas de distribuição, depois de modelados, com o intuito de se obter medidas elétricas, principalmente de tensão, que possuam distorções harmônicas;

- Investigar métodos que possam ser empregados à localização e identificação da fonte consumidora de potências harmônicas, os quais podem ser tanto convencionais como baseados em sistemas inteligentes;

- Formular e implementar uma solução que seja viável ao problema da localização e identificação da fonte consumidora de potências harmônicas, sendo aqui importante que o método tenha viabilidade e aplicabilidade ao sistema elétrico brasileiro;

- Discutir e comparar a metodologia proposta nesta tese com algumas metodologias já existentes e que são retratadas na literatura correlata.

\subsection{Principais Contribuições}

Em consonância com as abordagens encontradas na literatura, este projeto de doutorado pretende fornecer as seguintes contribuições:

- Desenvolvimento de uma ferramenta que possibilite a localização mais precisa quanto possível da fonte consumidora de potências harmônicas, 
a qual leve em consideração a utilização de poucos medidores alocados no sistema de distribuição; além de se obter robustez mesmo quando houver variações na tensão e carregamento da rede;

- Desenvolvimento de uma ferramenta para a identificação da fonte consumidora de potências harmônicas. Identificação esta que visa a estimação dos níveis das correntes harmônicas absorvidas pelas cargas no ponto previamente selecionado pelo método de localização;

- Desenvolvimento de uma ferramenta que possibilite a melhoria do método de localização, a qual será nomeada por método de ajuste/sintonia do localizador.

\subsection{Organização}

A tese está organizada em sete capítulos principais de modo a proporcionar ao leitor uma apropriada compreensão tanto do estado da arte como da metodologia proposta. Desta forma, o Capítulo 1 foi direcionado a introduzir o tema desta pesquisa, bem como apresentar as motivações e justificativas que levaram à realização desta tese de doutorado.

O Capítulo 2 destina-se ao estado da arte e permeia os procedimentos de localização e identificação das fontes consumidoras de potências harmônicas. Neste capítulo, dar-se-á destaque tanto às técnicas consideradas convencionais como àquelas técnicas que empregam sistemas inteligentes (redes neurais artificiais, sistemas de inferência fuzzy, algoritmos evolutivos, dentre outros).

A partir do Capítulo 3, os aspectos intrínsecos a esta pesquisa de doutorado serão devidamente reportados. Portanto, no Capítulo 3, tratam-se as características inerentes às simulações computacionais. Neste capítulo, também são feitos 
comentários sobre os estudos de caso, os quais serão utilizados até o final da tese em cada uma das etapas (localização, identificação e ajuste/sintonia da localização).

No Capítulo 4, realiza-se uma explanação detalhada sobre o método proposto para a localização da fonte consumidora de potências harmônicas. Além disso, são reportados os resultados obtidos para cada um dos estudos de caso.

No Capítulo 5, tratam-se dos aspectos relacionados à identificação da fonte consumidora de potências harmônicas. Portanto, a compreensão deste capítulo é dependente do entendimento do Capítulo 4, pois, a posição selecionada pelo método de localização é utilizada para se identificar a assinatura harmônica de corrente da carga. Ao final deste capítulo, os resultados obtidos por meio do método de identificação são então fornecidos.

O Capítulo 6 tem por objetivo apresentar o sistema que realiza o ajuste/sintonia do método de localização. Por fim, cabe ao Capítulo 7 a apresentação das discussões e conclusões obtidas ao final desta pesquisa de doutorado. 


\section{Estado da Arte}

Conforme apresentado no capítulo introdutório, esta tese de doutorado tem por objetivos principais a localização e identificação de consumidores que estejam contribuindo para a degradação da QEE em termos de distorção harmônica. Neste contexto, foram investigados diversos trabalhos correlatos com a finalidade de justificar a proposta desta tese. Assim, este capítulo apresenta ao leitor uma revisão desta bibliografia correlata, a qual forneceu uma base sólida para que a tese pudesse ser devidamente realizada. Neste sentido, dividiu-se este capítulo em seções, as quais irão mostrar uma análise dos métodos empregados para a modelagem de sistemas e dispositivos (Seção 2.1) com relação à distorção harmônica de tensão e/ou corrente, assim como para a localização (Seção 2.2) e identificação (Seção 2.3) das fontes consumidoras de potências harmônicas.

\subsection{Modelagem de Sistemas de Distribuição e Dispositivos com Relação à Distorção Harmônica}

Atualmente, a modelagem de sistemas de distribuição de energia elétrica tem sido realizada, principalmente, com base no relatório emitido pelo IEEE (IEEE Distribution Planning Working Group Report, 1991). Portanto, grande parte dos elementos que compõem um sistema de distribuição de energia elétrica (capacitores, cargas, transformadores, reguladores de tensão, linhas áreas, linhas subterrâneas, etc) são também modelados em conformidade com o referido relatório supracitado. Entretanto, a proposta do relatório emitido pelo IEEE é de fornecer 
modelos de sistemas de distribuição, os quais não consideram os efeitos das distorções harmônicas. Assim, surge então a proposta do próprio IEEE de desenvolver uma Task Force (IEEE Task Force on Harmonics Modeling and Simulation, 1996a, 1996b) que justamente forneça embasamento para a modelagem de sistemas de distribuição, considerando-se para tanto as distorções harmônicas.

Todavia, as pesquisas não se restringiram somente à modelagem de sistemas de distribuição de energia elétrica (IEEE Task Force on Harmonics Modeling and Simulation, 1996a, 1996b; Thunberg e Soder, 1999) e, portanto, podem ser encontrados na literatura alguns trabalhos que buscam a modelagem de cargas (Xu et al., 1994; Mayordomo et al., 1998; Lima, Semlyen e Iravani, 2003; Plata e Tacca, 2005; Sun et al., 2007; Chang, Chen e Liu, 2010), bem como a modelagem de sistemas elétricos industriais (Yan et al., 1994).

Cabe comentar que, mesmo a modelagem não sendo o foco principal da presente tese de doutorado, houve aqui a necessidade de se modelar e também de se simular sistemas de distribuição para que fossem obtidas suas tensões e correntes harmônicas. No entanto, apesar de esta ser uma breve revisão sobre modelagem, a mesma fez-se necessária para garantir a evolução da pesquisa, a fim de tornar claro ao leitor que os modelos apresentados no Capítulo 3 somente foram possíveis de serem desenvolvidos após adquirido este embasamento.

\subsection{Métodos Aplicados à Localização de Fontes Consumidoras de Potências Harmônicas}

Desde os primeiros trabalhos voltados à localização de fontes consumidoras de potências harmônicas (Heydt, 1989; Najjar e Heydt, 1991) até os trabalhos mais recentes (Lin et al., 2005; D’Antona, Muscas e Sulis, 2009), nota-se que as pesquisas foram todas direcionadas a desenvolver métodos de estimação de 
estado, seja no contexto de sistemas de transmissão (Heydt, 1989; Hartana e Richards, 1990, 1993; Meliopoulos, Zhang e Zelingher, 1994; Du et al., 1999; Kumar, Das e Sharma, 2004; Lin et al., 2005; Gursoy e Niebur, 2005; Arruda, Kagan e Ribeiro, 2010) ou de distribuição de energia elétrica (Najjar e Heydt, 1991; Teshome, 1991; Cronje e Rens, 2004; Pyzalski, Lukomski e Wilkosz, 2004; D’Antona, Muscas e Sulis, 2009).

Visto que a grande parte dos métodos aplicados à localização de fontes consumidoras de potências harmônicas está atrelada aos estimadores de estado, na sequência são então abordadas as propostas que mais se destacam na literatura.

Com o intuito de se fornecer uma abrangente visão sobre as técnicas de localização, a princípio, as técnicas empregadas em sistemas de transmissão de energia elétrica serão brevemente abordadas e, em maior profundidade, serão tratadas as técnicas até então desenvolvidas e que podem ser aplicadas a sistemas de distribuição de energia elétrica.

No que tange às metodologias aplicadas aos sistemas de transmissão de energia elétrica, pode-se destacar o trabalho de Heydt (1989), o qual é considerado como um dos precursores da área. Na pesquisa de Heydt (1989), faz-se uma alocação de medidores baseada em conhecimento especialista. Portanto, alguns pontos do sistema de transmissão são contemplados com estes medidores, para assim obter um conjunto de medidas que possa fornecer boa resposta por parte do estimador. É importante frisar que, neste caso, faz-se necessário até mesmo a obtenção de medidas redundantes e pseudo-medidas. Conforme esperado pelos autores, bons resultados foram alcançados nesta pesquisa; portanto, outras poucas pesquisas surgiram com o intuito de localizar fontes consumidoras de potências harmônicas em sistemas de transmissão de energia elétrica empregando-se 
estimadores de estado convencionais (por convencionais consideram-se os estimadores baseados em mínimos quadrados, mínimos quadrados ponderados, Newton-Raphson, etc). Assim, já no início da década de 90, Hartana e Richards (1990) propõem um método de estimação de estado das correntes harmônicas baseado em RNAs. Neste trabalho, os autores utilizam um conjunto de RNAs a fim de se estimar as correntes harmônicas de cada barra do sistema de transmissão.

Ao final da década de 90, Du et al. (1999) propõem um estimador de estado baseado em medidas sincronizadas por GPS (do inglês - Sistema de Posicionamento Global). Nota-se que, na pesquisa de Du et al. (1999), a contribuição está toda direcionada para as medidas sincronizadas e não para o método de estimação de estado.

As pesquisas mais recentes, voltadas para estimação de estado das correntes e/ou tensões harmônicas em sistemas de transmissão de energia elétrica, podem ser verificadas em Kumar, Das e Sharma (2004) e também Lin et al. (2005).

No trabalho desenvolvido por Kumar, Das e Sharma (2004), todos os testes são realizados sobre sistemas de transmissão IEEE de 14 e 30 barras, onde somente as harmônicas de ordem ímpar são consideradas durante o processo de estimação. Entretanto, um diferencial que as pesquisas atuais têm apresentado quando comparadas com aquelas desenvolvidas no final da década de 80 , e durante a década de 90 , é a localização de múltiplas fontes consumidoras de potências harmônicas. Desta forma, nota-se que nos métodos recentemente propostos, os estimadores de estado podem ser considerados mais precisos. Na pesquisa realizada por Kumar, Das e Sharma (2004), os autores empregam num primeiro estágio a estimação de estado por meio do método de mínimos quadrados ponderados e, num segundo estágio, calcula-se a norma Euclidiana entre as 
medidas obtidas pelos medidores alocados no sistema e as medidas estimadas. Assim, o método proposto consegue identificar a presença de múltiplas barras contendo fontes consumidoras de potências harmônicas. Cabe comentar que tal cálculo somente é realizado após a obtenção do estado harmônico (correntes e tensões) de cada barra que compõe o sistema de transmissão sob estudo.

Seguindo a mesma ideologia, em Lin et al. (2005), os autores empregam RNAs para a detecção da presença de fontes consumidoras de potências harmônicas, onde para cada medidor alocado no sistema há uma RNA responsável por identificar ou não a presença de uma fonte causadora de distorção harmônica. É importante comentar que, neste caso, o sistema de transmissão foi dividido em regiões, em que para cada região há um medidor alocado. No entanto, após uma análise mais detalhada desta bibliografia, nota-se que a metodologia proposta somente tem validade caso as RNAs sejam constantemente treinadas, ou ainda, em casos onde a dinâmica do sistema de transmissão não apresente variações bruscas em suas tensões e correntes.

Com base nos primeiros trabalhos feitos com o objetivo de se localizar fontes consumidoras de potências harmônicas em sistemas de transmissão, surgem propostas de métodos novos ou modificados para atender ao mesmo propósito em sistemas de distribuição de energia elétrica (Najjar e Heydt, 1991; Islam e Samra, 1997; Hong e Chen, 1999; Rens e Swart, 2001; Cronje e Rens, 2004; Pyzalski, Lukomski e Wilkosz, 2004; Barbaro et al., 2007; Schau e Novitskiy, 2008; D’Antona, Muscas e Sulis, 2009). Dentre estes trabalhos, as contribuições de Najjar e Heydt (1991), Hong e Chen (1999) e D'Antona, Muscas e Sulis (2009) podem ser destacadas. 
Em Najjar e Heydt (1991), os autores propõem um estimador de estados para sistemas de distribuição, o qual é baseado no método dos mínimos quadrados ponderados e na lei de Kirchhoff das correntes. No entanto, para que o método proposto apresente precisão considerável, deve-se garantir que a taxa de amostragem dos medidores a serem alocados no sistema seja de no mínino 1024 pontos por ciclo. Nota-se que tal metodologia necessita de muitos medidores a serem alocados no sistema para que a devida estimação seja realizada. Os autores deixam também claro que o método proposto apresenta a vantagem de utilizar medidas redundantes durante a estimação de estados, garantindo-se assim uma melhor resposta do estimador. Entretanto, como principal desvantagem, os autores destacam o custo atrelado à aquisição dos muitos medidores que devem ser alocados ao sistema de distribuição. Além disso, os autores empregaram durante a etapa de testes do estimador somente redes de distribuição fortemente malhadas. Por este motivo, para esta topologia de sistema de distribuição, torna-se mais conveniente e coerente a obtenção de medidas redundantes do que para sistemas de distribuição totalmente radiais ou fracamente malhados.

Já em Hong e Chen (1999), os autores propõem a divisão do sistema de distribuição em pequenas regiões. Desta forma, para cada uma destas regiões, há um medidor alocado. Além disso, para cada um destes medidores, utilizam-se RNAs que têm como função a identificação da presença ou não de uma fonte consumidora de potências harmônicas. Portanto, o método proposto não localiza a posição precisa da fonte, mas apresenta uma resposta que sugere que a fonte encontra-se dentro da região, a qual a RNA juntamente com o medidor são responsáveis por monitorar. Entretanto, alguns questionamentos poderiam ser levantados com relação a esta metodologia, visto que podem haver casos onde a dinâmica da rede de 
distribuição apresenta grandes variações. Nestas situações, pode acontecer de a RNA não fornecer boa resposta, pois, tais dados provavelmente se encontrariam fora do domínio da solução para a qual a rede neural foi previamente treinada. Além disso, diversos estudos de caso devem ser gerados para que sejam obtidos os dados necessários ao treinamento de cada rede neural. Portanto, é importante comentar que a maior contribuição do trabalho de Hong e Chen (1999) é a divisão dos conjuntos por meio de um sistema Fuzzy C-means, o qual garante o bom monitoramento da rede de distribuição.

Por fim, em D’Antona, Muscas e Sulis (2009), é proposto um método Bayesiano que necessita de conhecimento prévio a respeito das incertezas contidas nas medidas de carregamento. Além disso, o método Bayesiano também faz uso de medidas redundantes e pseudo-medidas, isto porque tais medidas, assim como mostrado em outros trabalhos (Hong e Chen, 1999; Najjar e Heydt, 1991), são um diferencial para que os estimadores de estados apresentem resultados satisfatórios. Neste trabalho, os autores utilizam um sistema IEEE de 13 barras modificado; porém, as modificações realizadas favorecem o método de estimação de estado, pois, adaptou-se o sistema de distribuição de forma a não possuir desbalanceamento e, portanto, o mesmo pode ser representado em um formato unifilar (considera-se um sistema monofásico). Por meio das adaptações/modificações realizadas sobre o sistema IEEE de 13 barras, os autores consideraram somente 8 pontos para alocação de cargas, sendo que um total de 5 medidores foram utilizados no sistema (2 medidores de tensão e 3 medidores de corrente). Portanto, nota-se que o espaço de busca pela solução foi restrito e que o método proposto somente consegue boa estimação devido a estes ajustes. 
Dada a grande quantidade de medidores que se fazem necessários de serem alocados para que as três metodologias supracitadas tenham a devida validade e forneçam resultados satisfatórios, surgiram-se então algumas pesquisas (Farach, Grady e Arapostathis, 1993; Ma e Girgis, 1996; Nguyen e Lee, 2000; Sahni e Lee, 2004; Won et al., 2006) com a finalidade de otimizar a alocação de tais medidores com o intuito de se obter um conjunto reduzido de medidas que garantisse um equilíbrio razoável entre o custo agregado à aquisição de equipamentos e a boa resposta dos estimadores de estado.

Assim, Farach, Grady e Arapostathis (1993) apresentam uma das primeiras propostas relacionadas à alocação ótima de medidores, a fim de se equilibrar o custo atrelado à aquisição de medidores e o grau de satisfação da resposta produzida por métodos de estimação de estado de correntes e tensões harmônicas. Neste sentido, os autores realizam testes de alocação ótima para três sistemas, contendo respectivamente 7,9 e 18 barras. Para tanto, uma fonte consumidora de potências harmônicas foi introduzida no sistema de distribuição a fim de se executar o estimador de estado e aplicar o método de otimização. No entanto, devido ao emprego de um método estatístico para a otimização da alocação dos medidores, os autores verificaram que, apesar da minimização do número de medidores alocados quando comparado a outros trabalhos da época, o método não considera a dinâmica do sistema de distribuição. Porém, obteve-se para o sistema de 7 e 9 barras um total de 3 medidores alocados. Já para o sistema de 18 barras, somente 5 medidores foram alocados.

Em meados da década de 90, Ma e Girgis (1996) propõem também um método para a alocação ótima de medidores, onde tal método considera a dinâmica do sistema de distribuição e, portanto, esta seria a contribuição do trabalho 
desenvolvido, visto que em Farach, Grady e Arapostathis (1993) esta dinâmica não foi considerada. Além disso, Ma e Girgis (1996) empregaram um estimador de estado baseado no filtro de Kalman que não necessita de medidas redundantes para melhorar o processo de estimação de estado das correntes e tensões do sistema de distribuição. Entretanto, nada é retratado com relação à topologia da rede de distribuição testada, nem mesmo com relação ao carregamento e desequilíbrio da rede, pois, os autores somente afirmam que empregaram um sistema de 11 barras e que foram necessários 3 medidores alocados ao sistema. Desta forma, torna-se difícil a reprodução dos resultados, bem como a averiguação da validade da metodologia proposta, pois, não se sabe o local onde a fonte consumidora de potências harmônicas encontra-se alocada e nem mesmo o local onde cada medidor deve ser alocado.

Já em Nguyen e Lee (2000) é apresentado um método capaz de se sobrepor a algumas desvantagens encontradas nos métodos tradicionais. As desvantagens dos métodos tradicionais comentadas pelos autores são as seguintes:

- Necessidade de desconectar bancos de capacitores para que o cálculo do fluxo de potência harmônico não seja afetado;

- O sistema pode sofrer uma queda acentuada da tensão devida à desconexão dos bancos de capacitores;

- Os fenômenos ocorridos devido à ressonância serão ocultados/abstraídos.

De acordo com estas desvantagens, os autores propõem um método capaz de lidar com tais obstáculos. Entretanto, para que o método proposto por Nguyen e Lee (2000) possa ser executado, há a necessidade de que um medidor de corrente seja alocado em cada ramificação do sistema de distribuição. Desta forma, nota-se 
que apesar de se desvencilhar dos problemas mencionados, o método tende a maximizar os custos relacionados à aquisição de medidores.

Em Sahni e Lee (2004), um método para localização da fonte consumidora de potências harmônicas é proposto, onde há a necessidade de informações provenientes do cálculo do fluxo de potência harmônico da rede de distribuição. Partindo-se destas medidas, é possível uma verificação gráfica dos dados em que se mostra claramente a posição da fonte, isto é, a barra onde ela se encontra. Apesar de ser um método bastante compacto, sua efetividade com relação à localização da fonte consumidora de potências harmônicas pode ser notada. Entretanto, assim como a maioria dos métodos encontrados na literatura, este também depende do cálculo do fluxo de potência das correntes e tensões harmônicas que por sua vez necessita das medidas de corrente nos pontos que existam cargas conectadas.

Por fim, Won et al. (2006) apresentam um método destinado a localizar eventos de QEE, em que dentre eles se encontram as distorções harmônicas. Porém, somente um caso contendo distorções harmônicas foi testado, onde se empregou um sistema IEEE de 34 barras. Cabe comentar que o sistema de distribuição utilizado considera um alimentador de maior comprimento, levemente carregado e desbalanceado. Portanto, pode-se dizer que os autores consideraram um sistema de distribuição bastante semelhante a sistemas reais. Entretanto, para que a fonte consumidora de potências harmônicas fosse devidamente localizada, houve então a necessidade de se alocar um total de 26 medidores. Além disso, quando da análise da distribuição dos medidores pela rede, nota-se que um dos medidores foi alocado junto à fonte consumidora de potências harmônicas. Também 
é importante frisar que o método proposto apresenta forte dependência do cálculo do fluxo de potência harmônico.

Além dos estimadores de estado supracitados, outras pesquisas destinaramse à investigação, adaptação e desenvolvimento de métodos para o cálculo do fluxo de potência das correntes e tensões harmônicas em sistemas de distribuição de energia elétrica (Hong, Lin e Liu, 2000; Ziari e Jalilian, 2004; Teng e Chang, 2007; Sun et al., 2008; Variz et al., 2008). Dentre os métodos encontrados, pode-se destacar o Backward/Forward Sweep (BFS), o qual foi modificado por Teng e Chang (2007) de forma a atender sistemas de distribuição com distorção harmônica. No trabalho realizado por Teng e Chang (2007), tem-se como uma das principais contribuições a modificação no método BFS, de forma que o mesmo apresente melhor resposta quando há bancos de capacitores conectados no sistema. Desta maneira, verifica-se a relevância da pesquisa de Teng e Chang (2007), pois, em casos onde há bancos de capacitores, deve-se considerar a ressonância que pode ocorrer entre determinadas harmônicas e o elemento capacitivo.

Além disso, é importante destacar o método de injeção de correntes, o qual se baseia no método de Newton-Raphson para obter o fluxo de potência. Neste caso, Variz et al. (2008) propõem modificações no método a fim de que este possa ser aplicado a sistemas de distribuição trifásicos contendo distorções harmônicas. Ressalta-se que, devido à capacidade deste método de calcular o fluxo de potência para sistemas trifásicos, há então a possibilidade da análise de redes de distribuição desbalanceadas. 


\subsection{Métodos Aplicados à Identificação de Fontes Consumidoras de Potências Harmônicas}

Os métodos empregados para identificação de fontes consumidoras de potências harmônicas normalmente são voltados à identificação de uma carga propriamente dita ou de uma classe de cargas. Devido a esta tese tratar da identificação de fontes consumidoras de potências harmônicas em sistemas de distribuição de energia elétrica, torna-se mais interessante a identificação das componentes harmônicas da carga.

Seguindo o contexto acima delineado, realizou-se aqui uma investigação da literatura correlata, onde se verificou que as pesquisas no sentido de identificar as classes de cargas se iniciaram em meados da década de $90 \mathrm{com}$ os trabalhos de Cristaldi e Ferrero (1994), Varadan e Makram (1994, 1996).

No trabalho proposto por Cristaldi e Ferrero (1994) é desenvolvido um sistema embarcado em hardware para a identificação de fontes causadoras de distorção harmônica. Devido às pesquisas nesta área ainda se encontrarem no início (durante a realização de tal trabalho), os autores somente realizaram testes de identificação num sistema compacto que possuía uma fonte e duas cargas, sendo uma das cargas linear e a outra não linear. Portanto, o sistema embarcado foi responsável por adquirir as tensões e correntes do sistema, bem como aplicar a Transformada Rápida de Fourier. Assim, com base nas componentes harmônicas obtidas, o sistema embarcado forneceu como resposta um sinal binário que representava a presença ou não da carga não linear.

Em Varadan e Makram (1994) surge a primeira pesquisa empregando-se sistemas inteligentes ao propósito da identificação das fontes consumidoras de potências harmônicas. Neste caso, os autores empregaram RNAs do tipo Perceptron 
de Múltiplas Camadas, onde as mesmas utilizaram o algoritmo de Backpropagation durante a etapa de treinamento. As redes neurais foram responsáveis por classificar/identificar o tipo de carga conectada ao sistema de acordo com três classes de cargas, a saber: Tipo A (dispositivos baseados na eletrônica de potência); Tipo B (dispositivos a arco); Tipo C (dispositivos ferromagnéticos). Cada um destes três tipos de cargas têm suas correntes harmônicas características. Portanto, as RNAs tinham como função principal conhecer tais características de modo a apresentar como saída a classe (A, B ou C) da carga.

Em 1996, com o trabalho de Varadan e Makram (1996), surge uma nova proposta, em que os autores, além de identificar o tipo de carga consumidora de potências harmônicas, também determinam a sua composição harmônica. Durante o processo de determinação da composição harmônica da carga, os autores estimam a forma de onda da corrente e, consequentemente, as componentes harmônicas da carga podem ser obtidas pela aplicação da Transformada Discreta de Fourier (TDF).

Após a década de 90, as pesquisas nesta área se intensificaram, assim, diversos trabalhos podem ser encontrados (Niekerk, Rens e Hoffman, 2002; Zhao, Li e Xia, 2004; Alammari, Soliman e El-Hawary, 2004; Morimoto et al., 2007; Ferrero, Salicone e Todeschini, 2007; Gursoy e Niebur, 2009).

Em Niekerk, Rens e Hoffman (2002) são utilizadas RNAs do tipo Perceptron de Múltiplas Camadas, e também redes do tipo RBF (Radial Basis Function), para a identificação das mesmas classes de cargas apresentadas em Varadan e Makram (1994, 1996). No entanto, para que as RNAs fossem devidamente validadas, os autores empregaram, como dispositivo baseado na eletrônica de potência, um retificador de seis pulsos trifásico; para os dispositivos a arco, empregaram-se três fornos a arco com diferentes potências; e como dispositivo ferromagnético foi 
utilizado um transformador. As redes neurais foram então treinadas e validadas, onde se verificou que os erros de identificação variaram entre $2 \%$ e $10 \%$.

No trabalho desenvolvido por Alammari, Soliman e El-Hawary (2004), a contribuição fornecida está em uma nova categoria de cargas, em que, ao invés de serem categorizadas por tipos de dispositivos, são classificadas pelas harmônicas predominantes. Deste modo, determinam-se três categorias de cargas, onde na Classe A se encontram cargas com predominância das harmônicas de $5^{\mathrm{a}}, 7^{\mathrm{a}}, 11^{\mathrm{a}} \mathrm{e}$ $13^{\mathrm{a}}$ ordens; a Classe B é definida por cargas, onde predominam as componentes harmônicas de $3^{a}, 5^{a}$ e $7^{a}$ ordens; e a Classe $C$ suporta as cargas com predominância de harmônicas de $3^{\mathrm{a}}$ e $5^{\mathrm{a}}$ ordens. É importante verificar que apesar de as três classes de cargas definidas pelos autores serem parecidas com aquelas definidas pelo IEEE, as magnitudes das harmônicas (relativas à componente fundamental), quando comparadas, são distintas das sugeridas pelo IEEE.

A partir de Zhao, Li e Xia (2004), as pesquisas tornam-se mais direcionadas à identificação de fontes consumidoras de potências harmônicas em sistemas de distribuição de energia elétrica. Assim, por meio da estimação dos coeficientes $a_{h}$ e $b_{h}$ da Transformada de Fourier, é então estimada a composição harmônica das barras que compõem o sistema de distribuição.

Em meio às pesquisas voltadas para identificação de classes de cargas e estimação de composição harmônica das cargas, algumas pesquisas surgem direcionadas a estimar tanto a impedância das linhas como a admitância das cargas (Zhang, Ahmed e Xu, 1999; Sumner et al., 2002; Xu et al. 2002; Al-Kandari e ElNaggar, 2006; Yonghai, Shun e Yingying, 2006). Dentre estas pesquisas, destacamse as publicações de Xu et al. (2002) e Al-Kandari e El-Naggar (2006). 
No trabalho de Xu et al. (2002), os autores propõem um método para estimação da impedância harmônica das redes (distribuição ou transmissão de energia elétrica). Para que a estimação da impedância seja devidamente realizada, necessita-se da obtenção dos sinais de corrente e tensão em regime permanente para os períodos de pré e pós-distúrbio. Adquiridos tais dados, calcula-se a impedância harmônica com base na obtenção das componentes harmônicas dos sinais de corrente e tensão de pré e pós-distúrbio, onde tais componentes são calculadas via TDF. Os autores ressaltam que para aplicações práticas, seria então necessário garantir o sincronismo das medidas de corrente e tensão nos períodos de pré e pós-distúrbio. Além deste fato, também seria importante a estimação da frequência da rede, visto que a frequência nominal pode sofrer variações e, por consequência, prejudicar a estimação da impedância harmônica da rede.

Já em Al-Kandari e El-Naggar (2006) é proposto um algoritmo baseado em filtro de Kalman, o qual tem por objetivo estimar os parâmetros de admitância da fonte consumidora de potências harmônicas. Durante a etapa de testes do algoritmo proposto, foi analisado o desempenho do estimador sobre sinais de corrente e tensão adquiridos com distintas taxas de amostragem. Cabe comentar que também foram realizados alguns testes sobre dados contendo sinais ruidosos.

Além das pesquisas já comentadas, Ferrero, Salicone e Todeschini (2007) empregaram Sistemas de Inferência Fuzzy para identificar fontes consumidoras de potências harmônicas em sistemas elétricos industriais. Por fim, Gursoy e Niebur (2009) desenvolveram um método baseado na Análise de Componentes Independentes (somente pode ser aplicado em sistemas com grande quantidade de medidores), onde são estimadas as partes reais e imaginárias das componentes 
harmônicas em cada uma das 14 barras de um sistema de transmissão fornecido pelo IEEE.

A seguir, na Seção 2.4, são apresentadas outras bibliografias que não são fortemente relacionadas ao tema da tese de doutorado, porém, forneceram embasamento e proporcionaram idéias para trabalhos futuros.

\subsection{Demais Bibliografias Investigadas}

Durante o levantamento bibliográfico desta tese de doutorado, uma diversidade de produções científicas foram investigadas. Assim, uma das áreas proeminentes no contexto da análise de distorções harmônicas em sistemas de distribuição de energia elétrica tem por objetivo a avaliação, identificação e estimação da contribuição harmônica tanto por parte do consumidor (carga) quanto por parte da concessionária (Xu e Liu, 2000; Xu, Liu e Liu, 2003; Hamzah, Mohamed e Hussain, 2003, 2004; Li, Xu e Tayjasanant, 2004; Chen et al., 2004; Vlahinic, Vlahinic e Brnobic, 2004; Wilkosz, 2007; Pfajfar, Blazic e Papic, 2008; Santos, Costa e Oliveira, 2009; Farhoodnea, Mohamed e Shareef, 2011).

Portanto, estas bibliografias são recomendadas para leitura, visto que fornecem uma visão bastante detalhista com relação aos métodos que têm como objetivo principal a obtenção da contribuição harmônica entre concessionária e consumidor. 


\section{Modelagem e Simulação dos Estudos de Caso}

Conforme comentado ao final da Seção 2.1, a modelagem e simulação de alguns estudos de caso foram extremamente necessárias para validar a metodologia proposta.

A princípio, idealizou-se a implementação de modelos de sistemas de distribuição empregando o software ATP (Alternative Transients Program), porém, seria necessário garantir que este software forneceria medidas de tensões e correntes harmônicas coerentes. Desta forma, o sistema IEEE de 13 barras foi previamente modelado, pois, é o único sistema de distribuição encontrado na literatura (IEEE Task Force on Harmonics Modeling and Simulation, 1996a, 1996b) que possui informações sobre as correntes e tensões harmônicas devidamente documentadas. Assim, somente após garantida a validade da modelagem e simulação realizados pelo ATP sobre o sistema IEEE de 13 barras, dois novos sistemas de distribuição foram implementados, pois, o sistema IEEE de 13 barras apresenta um alimentador de pequeno comprimento. Estes dois novos sistemas de distribuição possuem 20 (sistema fictício) e 90 (sistema real) barras, onde suas características são explanadas em maiores detalhes nas Seções 3.2 e 3.3.

Este capítulo foi dividido de forma a apresentar na Seção 3.1 a validação do software ATP aplicado à modelagem e simulação do sistema IEEE de 13 barras; na

Seção 3.2 são apresentados os aspectos do sistema fictício constituído por 20 barras; a Seção 3.3 se destina a mostrar os aspectos do sistema real, o qual possui 
um alimentador com 90 barras; na Seção 3.4 são apresentados os modelos das cargas não lineares empregadas nesta tese; as Seções 3.5 e 3.6 destinam-se a apresentar os estudos de caso gerados para validar a metodologia proposta; por fim, a Seção 3.7 apresenta os aspectos normativos relacionados às tensões harmônicas.

\subsection{Validação da Modelagem e Simulação Desenvolvida em ATP para o Sistema IEEE de 13 Barras}

Conforme previamente explanado, devido ao sistema IEEE de 13 barras ser o único que apresenta os dados das DHTs de tensão e componente fundamental das tensões reportados na literatura, o mesmo foi modelado e simulado via o software ATP com o intuito de garantir que o modelo e simulação tanto do sistema de 20 barras (fictício) como do sistema de 90 barras (real) apresentassem medidas de tensões e correntes coerentes. Portanto, cabe frisar que a modelagem e simulação do sistema IEEE de 13 barras foi somente desenvolvida para verificar se era cabível utilizar o software ATP para fins de simulação de sistemas com distorções harmônicas, visto que este software foi criado com a finalidade de modelar e simular transitórios eletromagnéticos.

Na sequência, pode-se visualizar o diagrama esquemático do sistema IEEE de 13 barras, bem como as características das linhas, transformadores, fonte e bancos de capacitores (Figura 3.1).

Cabe comentar também que os dados referentes tanto às cargas não lineares como os dados que se referem às cargas $\mathrm{RL}$ podem ser verificados em maiores detalhes no IEEE Task Force (IEEE Task Force on Harmonics Modeling and Simulation, 1996a, 1996b). Além disso, o modelo desenvolvido em ATP encontra-se no Anexo $A$, o qual também fornece as informações necessárias para o desenvolvimento do sistema IEEE de 13 barras. 


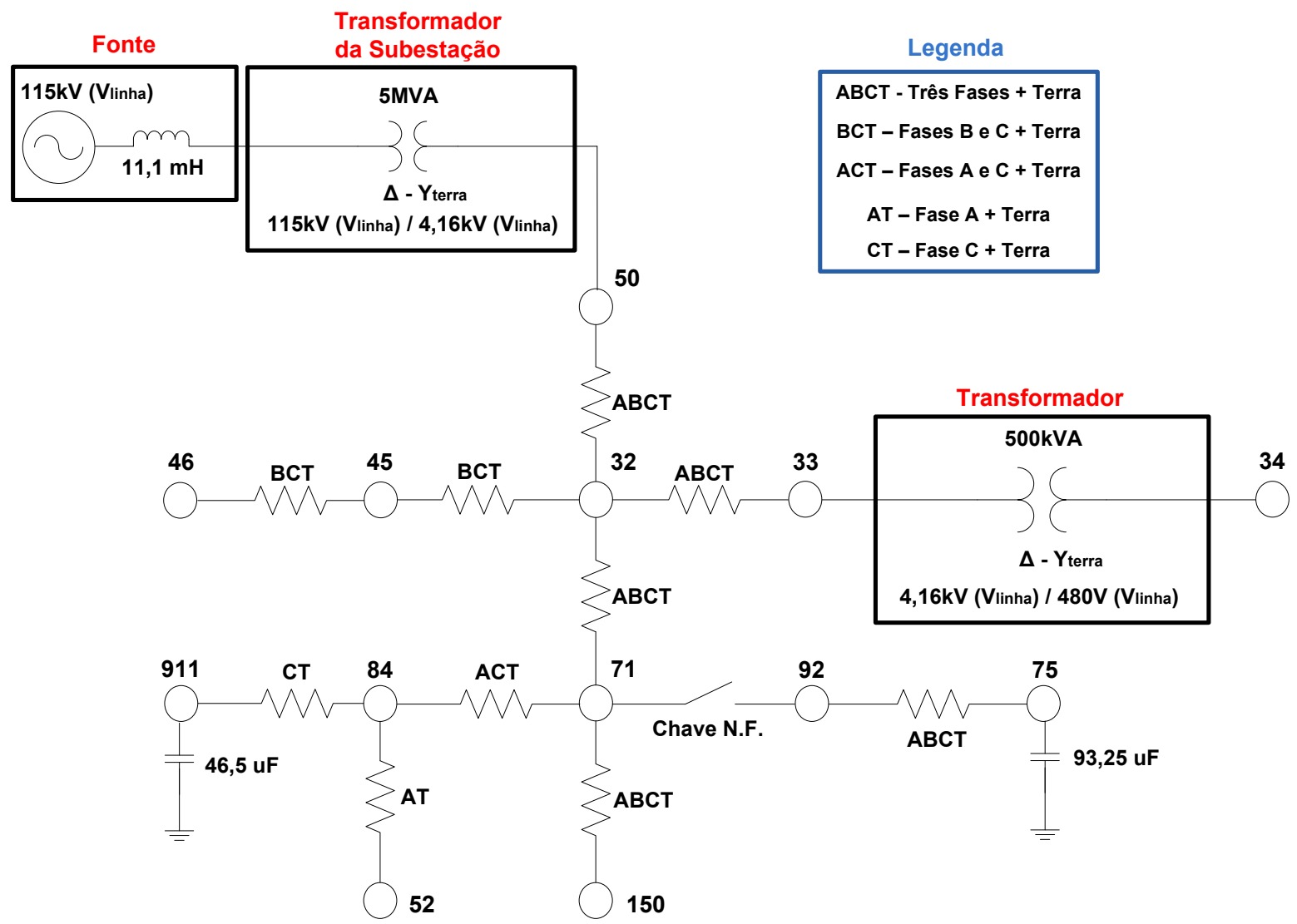

Figura 3.1 - Diagrama esquemático do sistema IEEE de 13 barras.

Feita a modelagem do sistema de distribuição de 13 barras fornecido pelo IEEE, o software ATP foi executado com o intuito de simular o sistema em regime permanente. Assim, as tensões e correntes harmônicas de cada uma das barras que compõem o sistema puderam ser obtidas e as amplitudes destas componentes harmônicas foram comparadas com os valores fornecidos pelo IEEE. Deste modo, por meio da Tabela 3.1 , os valores tidos como referência podem ser verificados, sendo que na Tabela 3.2 são mostrados os valores obtidos pela simulação via ATP. 
Tabela 3.1 - Valores de referência fornecidos pelo IEEE.

\begin{tabular}{|c|c|c|c|c|c|c|}
\hline & \multicolumn{2}{|c|}{ Fase A } & \multicolumn{2}{c|}{ Fase B } & \multicolumn{2}{c|}{ Fase C } \\
\hline Barra & $\begin{array}{c}\text { DHT } \\
(\%)\end{array}$ & $\begin{array}{c}\text { Fundamental } \\
\text { (p.u.) }\end{array}$ & $\begin{array}{c}\text { DHT } \\
\text { (\%) }\end{array}$ & $\begin{array}{c}\text { Fundamental } \\
\text { (p.u.) }\end{array}$ & $\begin{array}{c}\text { DHT } \\
(\%)\end{array}$ & $\begin{array}{c}\text { Fundamental } \\
\text { (p.u.) }\end{array}$ \\
\hline 32 & 1,96 & 1,034 & 1,76 & 1,038 & 1,69 & 1,007 \\
\hline 33 & 1,96 & 1,034 & 1,76 & 1,038 & 1,69 & 1,007 \\
\hline 34 & 0,96 & 1,018 & 0,96 & 1,030 & 1,04 & 1,022 \\
\hline 71 & 3,23 & 1,010 & 2,76 & 1,045 & 2,86 & 0,969 \\
\hline 75 & 3,35 & 1,003 & 2,82 & 1,048 & 2,95 & 0,967 \\
\hline 52 & 3,30 & 1,008 & - & - & - & - \\
\hline 911 & - & - & - & - & 3,00 & 0,965 \\
\hline
\end{tabular}

Tabela 3.2 - Valores obtidos pela simulação em ATP.

\begin{tabular}{|c|c|c|c|c|c|c|}
\hline & \multicolumn{2}{|c|}{ Fase A } & \multicolumn{2}{c|}{ Fase B } & \multicolumn{2}{c|}{ Fase C } \\
\hline Barra & $\begin{array}{c}\text { DHT } \\
(\%)\end{array}$ & $\begin{array}{c}\text { Fundamental } \\
\text { (p.u.) }\end{array}$ & $\begin{array}{c}\text { DHT } \\
(\%)\end{array}$ & $\begin{array}{c}\text { Fundamental } \\
\text { (p.u.) }\end{array}$ & $\begin{array}{c}\text { DHT } \\
\text { (\%) }\end{array}$ & $\begin{array}{c}\text { Fundamental } \\
\text { (p.u.) }\end{array}$ \\
\hline 32 & 1,98 & 0,948 & 1,86 & 0,978 & 1,70 & 0,931 \\
\hline 33 & 1,98 & 0,948 & 1,86 & 0,978 & 1,70 & 0,931 \\
\hline 34 & 1,01 & 1,018 & 1,01 & 1,032 & 1,10 & 1,029 \\
\hline 71 & 3,12 & 0,928 & 2,80 & 0,985 & 2,77 & 0,899 \\
\hline 75 & 3,12 & 0,928 & 2,80 & 0,985 & 2,77 & 0,899 \\
\hline 52 & 3,12 & 0,928 & - & - & - & - \\
\hline 911 & - & - & - & - & 2,77 & 0,899 \\
\hline
\end{tabular}

Tendo em mãos os valores obtidos por meio da simulação em ATP, tornouse então possível calcular o erro relativo médio para cada uma das fases do sistema IEEE de 13 barras (considerando somente aquelas barras que possuem valores de referência). Portanto, o erro relativo médio percentual pode ser visualizado por meio da Tabela 3.3. 
Tabela 3.3 - Erros relativos médios percentuais calculados.

\begin{tabular}{|c|c|c|}
\hline & \multicolumn{2}{|c|}{ Erro Relativo Médio (\%) } \\
\hline & DHT & Fundamental \\
\hline Fase A & 3,829 & 6,695 \\
\hline Fase B & 3,746 & 4,702 \\
\hline Fase C & 3,978 & 6,146 \\
\hline
\end{tabular}

Visto que os valores percentuais dos erros relativos médios foram de no máximo $6,695 \%$ para a componente fundamental da tensão e de $3,978 \%$ para a DHT, garante-se então aqui que o ATP é capaz de gerar simulações coerentes quando comparado aos dados fornecidos pelo IEEE.

\subsection{Sistema de 20 Barras Modelado para Testar e Validar a Proposta da Tese de Doutorado}

Verificada a integridade do software ATP para se desenvolver modelos que possibilitem a obtenção de sinais de tensões e correntes harmônicas, iniciou-se então a modelagem de um sistema fictício composto por 20 barras, com o intuito de verificar o desempenho da metodologia proposta para localização e identificação de fontes consumidoras de potências harmônicas. Na sequência, o diagrama esquemático deste sistema é mostrado por meio da Figura 3.2.

Nota-se que o sistema de 20 barras mostrado na Figura 3.2 possui dois medidores de corrente e tensão alocados. Desta forma, tanto o medidor de corrente alocado (em série) entre a barra 10 e P1 como o medidor de tensão alocado na barra 10 (entre fase e terra) são responsáveis por adquirirem as medidas da subestação. Já o segundo conjunto de medidas é obtido por um medidor de tensão alocado na barra 50 e um medidor de corrente alocado entre a barra 50 e P2. É importante comentar que somente os medidores de tensão e corrente que se 
encontram longe da subestação (barras 50 e P2) foram alocados de forma aleatória. No entanto, a idéia de alocá-los mais longe da subestação foi a de garantir que houvesse uma melhor cobertura da rede, pois, estes seriam menos sensibilizados pelas harmônicas quando a fonte consumidora de potências harmônicas estivesse mais próxima da subestação.

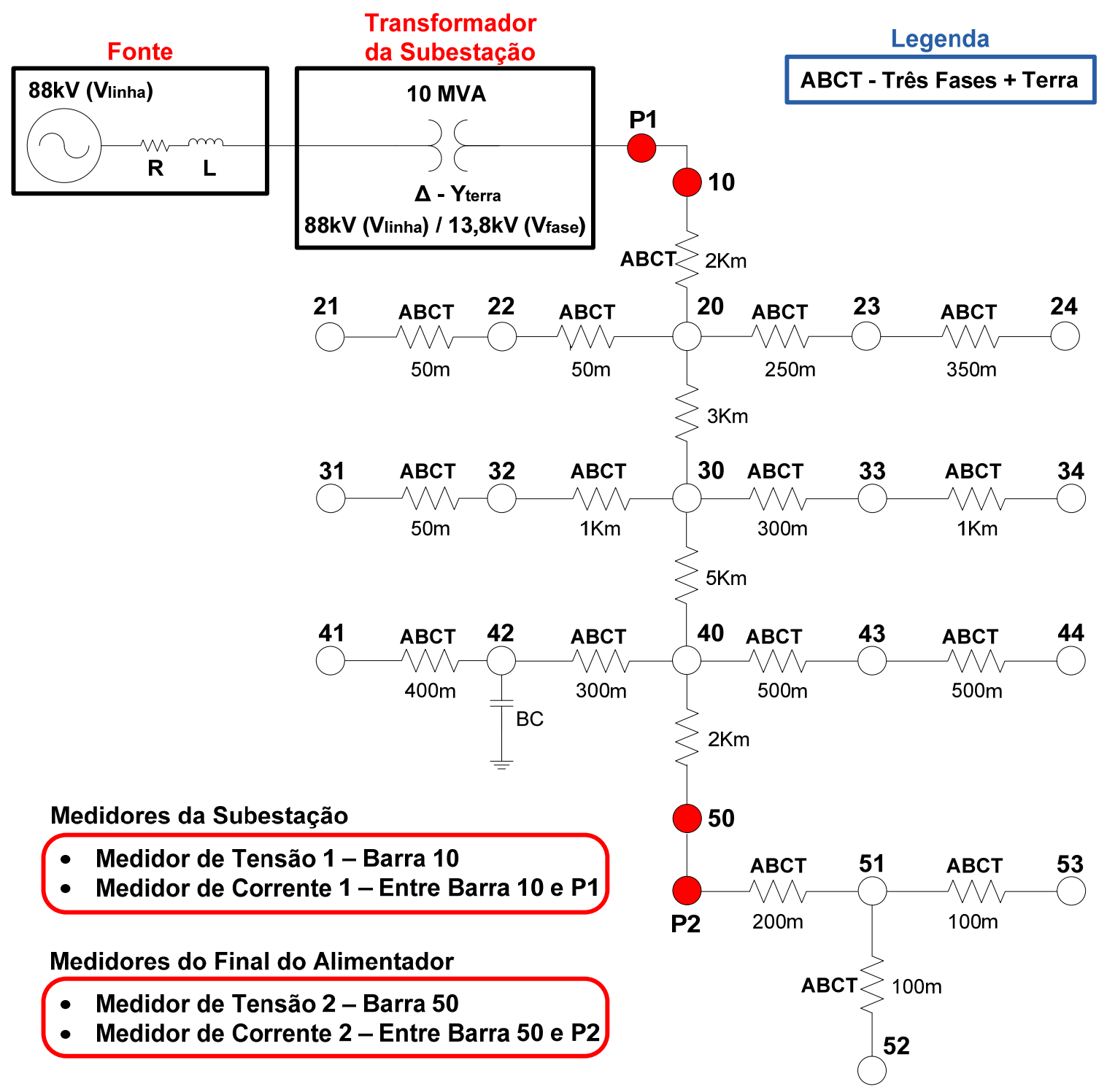

Figura 3.2 - Diagrama esquemático do sistema de 20 barras.

Com relação à configuração e parametrização desta rede de distribuição, a seguir, apresenta-se a Tabela 3.4 , na qual podem ser visualizados os dados 
referentes ao transformador da subestação, à fonte, ao banco de capacitores e aos medidores.

Tabela 3.4 - Parâmetros dos elementos que compõem a rede de distribuição do sistema de 20 barras.

\begin{tabular}{|c|c|}
\hline \multicolumn{2}{|l|}{ Fonte } \\
\hline Tensão de Linha Nominal (kV) & 88 \\
\hline Resistência de Sequência Zero Equivalente $(\Omega)$ & 20,805 \\
\hline Resistência de Sequência Positiva Equivalente $(\Omega)$ & 4,062 \\
\hline Indutância de Sequência Zero Equivalente (mH) & 203,721 \\
\hline Indutância de Sequência Positiva Equivalente (mH) & 52,5397 \\
\hline Frequência Nominal da Rede $(\mathrm{Hz})$ & 60 \\
\hline \multicolumn{2}{|c|}{ Transformador da Subestação } \\
\hline Tipo de Conexão & $\Delta$-Y aterrado \\
\hline Tensão de Linha no Primário (kV) & 88 \\
\hline Tensão de Fase no Secundário (kV) & 13,8 \\
\hline Resistência do Primário $(\Omega)$ & 0,054695 \\
\hline Resistência do Secundário $(\Omega)$ & 0,79376 \\
\hline Indutância do Primário (mH) & 1,628 \\
\hline Indutância do Secundário (mH) & 23,6258 \\
\hline Potência Aparente (MVA) & 10 \\
\hline \multicolumn{2}{|c|}{ Banco de Capacitores } \\
\hline Tipo de Conexão & $\Delta$-Y aterrado \\
\hline Capacitância (uF) & 5,9652 \\
\hline \multicolumn{2}{|c|}{ Medidores de Tensão e Corrente } \\
\hline Amostras por Ciclo & 256 \\
\hline Taxa de Amostragem (Hz) & 15360 \\
\hline
\end{tabular}

Cabe comentar que devido à grande quantidade de parâmetros desta rede, os dados das linhas de distribuição e das cargas RL são disponibilizados no Anexo B, onde estes são apresentados junto ao modelo do sistema de 20 barras desenvolvido via o software ATP.

Informadas as configurações básicas que permearam o desenvolvimento do sistema fictício de 20 barras, na sequência, são apresentadas as particularidades do sistema real de 90 barras. 


\subsection{Sistema Real de 90 Barras Modelado para Testar e Validar a Proposta da Tese de Doutorado}

Além do sistema de 20 barras previamente modelado, vislumbrou-se a modelagem do alimentador de uma rede de distribuição nacional. Desta forma, obteve-se junto a uma concessionária de energia elétrica brasileira todos os dados de um alimentador composto por 90 barras. Assim, pôde-se modelar o alimentador via o software ATP, o qual seguiu as mesmas diretrizes empregadas na concepção do modelo desenvolvido para o sistema de 20 barras. De forma a melhor ilustrar o alimentador do sistema real modelado, as Figuras $3.3,3.4$ e 3.5 apresentam os diagramas esquemáticos do mesmo.

A Figura 3.3 representa o início do alimentador, onde podem ser visualizados a fonte e o transformador da subestação, bem como os medidores da subestação (medidor de corrente entre P01 e a barra B01; medidor de tensão na barra B01). Além disso, verifica-se que há uma chave seccionadora do tipo N.F. (Sec1) logo após o transformador, a qual possibilita a desconexão de todas as linhas de distribuição que fazem parte do alimentador sob análise. Mais a frente encontrase alocado um banco de capacitores que é chaveado por ChBC1. Todas as linhas de distribuição são mostradas com seus respectivos comprimentos, onde é possível notar que este primeiro trecho do alimentador possui um comprimento total de pouco menos que 8 Km (sem contabilizar a ramificação entre as barras B09 e B10). Ao final deste trecho, outras três chaves seccionadoras ( $\operatorname{Sec} 2$, Sec 3 e $\operatorname{Sec} 4$ ) podem ser visualizadas, em que todas elas são do tipo N.F. (normalmente fechadas). Portanto, a continuação do alimentador partindo-se da chave seccionadora $3(\operatorname{Sec} 3)$ pode ser visualizada por meio da Figura 3.4. 
Xं

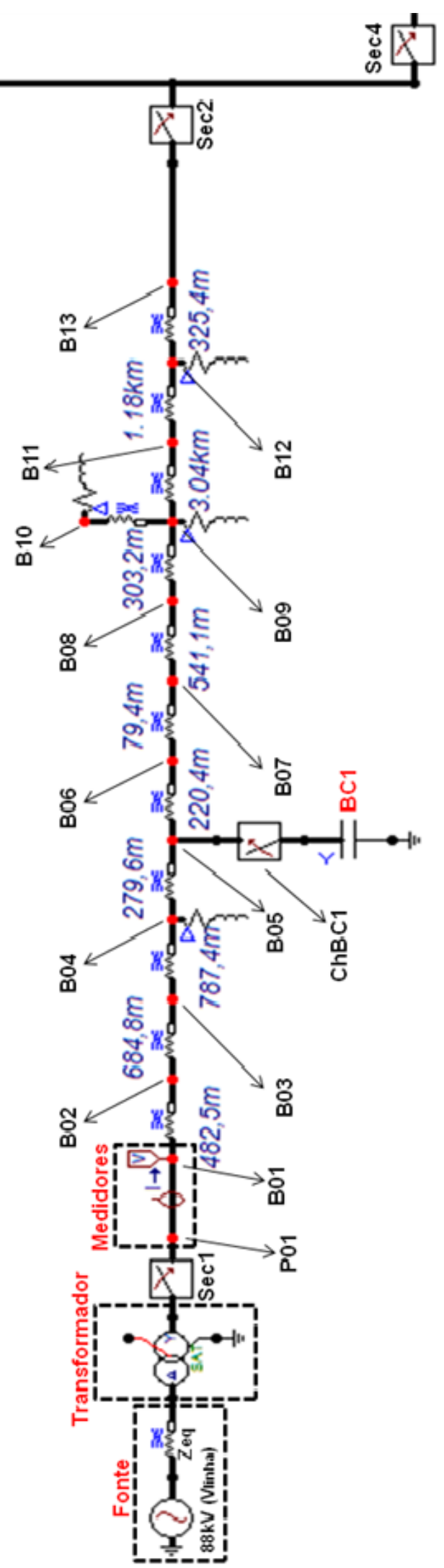

Figura 3.3 - Diagrama esquemático do início do alimentador do sistema real de 90 barras. 


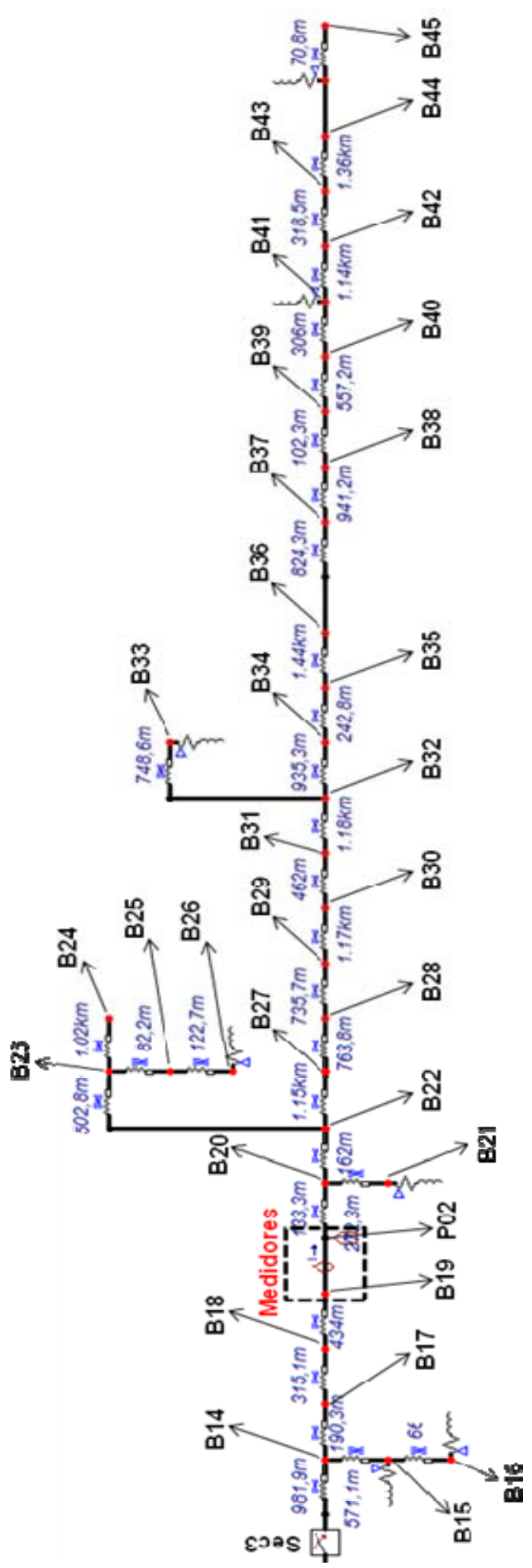

Figura 3.4 - Diagrama esquemático da continuação do alimentador do sistema real de 90 barras a partir da chave seccionadora 3 (Sec 3). 
Mediante a análise da Figura 3.4, observa-se então que um segundo conjunto de medidas pode ser obtido por meio do medidor de tensão alocado em P02 e pelo medidor de corrente alocado entre P02 e a barra B19. Conforme já comentado na Seção 3.2, os medidores responsáveis por adquirirem este segundo conjunto de medidas foram alocados de forma aleatória, onde, neste caso, estes foram alocados no início da ramificação de maior comprimento.

Além disso, nota-se que as linhas de distribuição que comportam este trecho do alimentador totalizam um comprimento de aproximadamente $15 \mathrm{Km}$ (somente as linhas que compõem uma reta foram somadas, partindo-se da chave seccionadora 3, com término na barra B45), portanto, este trecho do alimentador possui comprimento de quase o dobro do primeiro trecho de linhas previamente mostrado na Figura 3.3.

$\mathrm{Na}$ sequência, o trecho final do alimentador que parte da chave seccionadora $4(\operatorname{Sec} 4)$ é ilustrado por meio da Figura 3.5. Este último trecho do alimentador é composto por diversas linhas de distribuição que, quando somados seus respectivos comprimentos, chega-se a um total de aproximadamente $8 \mathrm{Km}$ (somando-se somente uma linha reta que se inicia na chave seccionadora 4 e termina na barra B90, isto é, as ramificações não são incluídas na soma). 


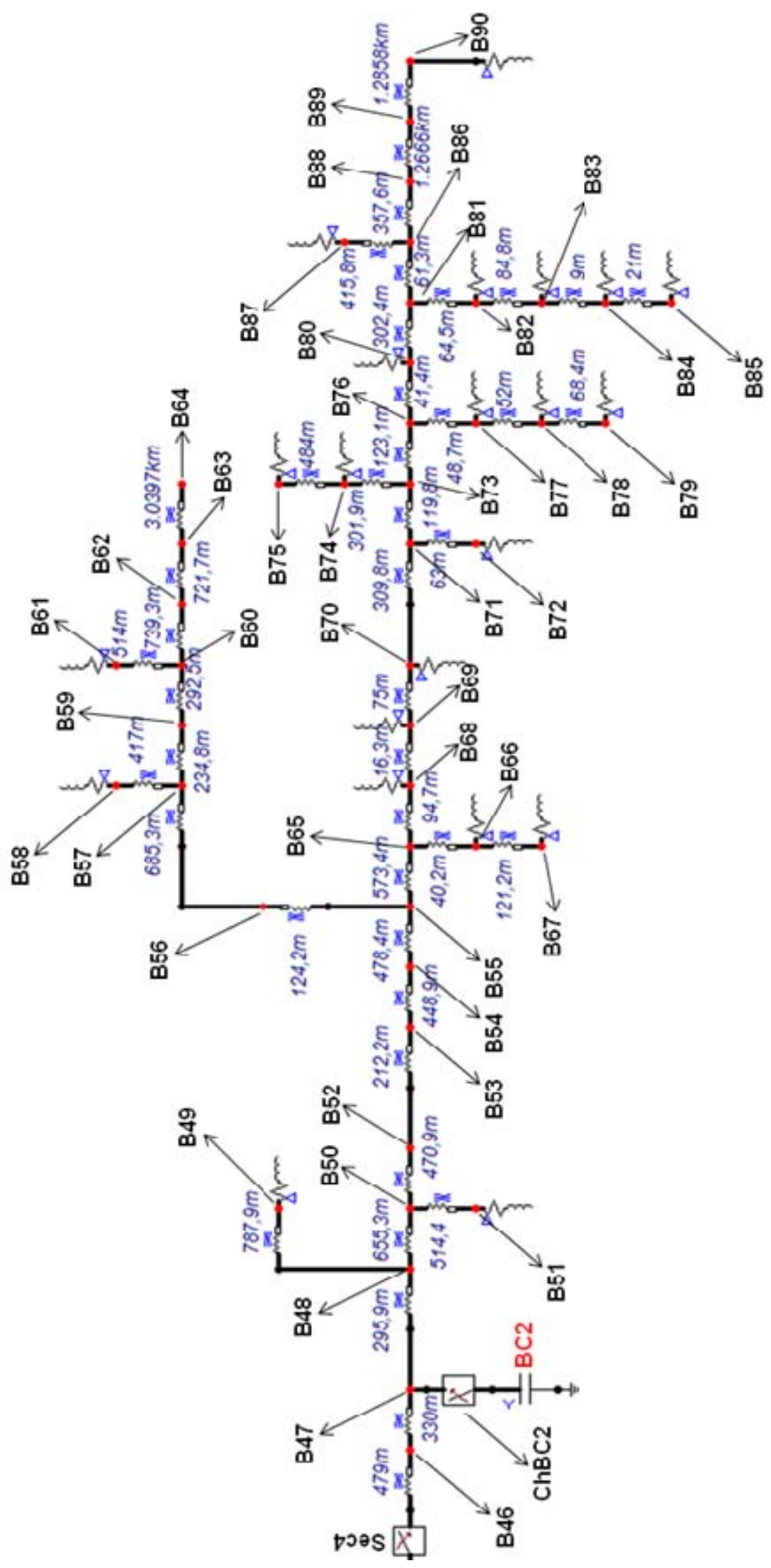

Figura 3.5 - Diagrama esquemático da continuação do alimentador do sistema real de 90 barras a partir da chave seccionadora 4 (Sec 4). 
Ainda com relação à Figura 3.5, pode-se observar a presença de um banco de capacitores $(\mathrm{BC} 2)$ que é chaveado à rede por meio de $\mathrm{ChBC2}$. Todos os elementos destacados nas figuras supracitadas têm seus parâmetros descritos na Tabela 3.5.

Tabela 3.5 - Parâmetros dos elementos que compõem a rede de distribuição do sistema real de 90 barras.

\begin{tabular}{|c|c|}
\hline \multicolumn{2}{|l|}{ Fonte } \\
\hline Tensão de Linha Nominal (kV) & 88 \\
\hline Resistência de Sequência Zero Equivalente $(\Omega)$ & 20,805 \\
\hline Resistência de Sequência Positiva Equivalente $(\Omega)$ & 4,062 \\
\hline Indutância de Sequência Zero Equivalente (mH) & 203,721 \\
\hline Indutância de Sequência Positiva Equivalente (mH) & 52,5397 \\
\hline Frequência Nominal da Rede (Hz) & 60 \\
\hline \multicolumn{2}{|c|}{ Transformador da Subestação } \\
\hline Tipo de Conexão & $\Delta-Y$ aterrado \\
\hline Tensão de Linha no Primário (kV) & 88 \\
\hline Tensão de Fase no Secundário (kV) & 13,8 \\
\hline Resistência do Primário $(\Omega)$ & 0,054695 \\
\hline Resistência do Secundário $(\Omega)$ & 0,79376 \\
\hline Indutância do Primário $(\mathrm{mH})$ & 1,628 \\
\hline Indutância do Secundário (mH) & 23,6258 \\
\hline Potência Aparente (MVA) & 10 \\
\hline \multicolumn{2}{|c|}{ Banco de Capacitores } \\
\hline Tipo de Conexão & $\Delta-Y$ aterrado \\
\hline Capacitância de BC1 (uF) & 5,9652 \\
\hline Capacitância de BC2 (uF) & 5,9652 \\
\hline \multicolumn{2}{|c|}{ Medidores de Tensão e Corrente } \\
\hline Amostras por Ciclo & 256 \\
\hline Taxa de Amostragem (Hz) & 15360 \\
\hline
\end{tabular}

É importante mencionar que, para todas as linhas de distribuição deste sistema, encontram-se disponíveis três fases e terra. No entanto, todas as cargas alocadas (sejam cargas RL ou cargas não lineares) são conectadas a três fios $(\Delta)$. A 
modelagem desta rede foi implementada seguindo as mesmas diretrizes adotadas para modelar o sistema de 20 barras apresentado no Anexo B (em formato ATP).

A seguir, por meio da Subseção 3.4, os aspectos da modelagem das cargas não lineares serão devidamente apresentados.

\subsection{Cargas Não Lineares Modeladas no Software ATP}

Devido ao propósito desta pesquisa estar focado na localização e identificação de fontes consumidoras de potências harmônicas, fez-se necessário a modelagem e simulação de cargas não lineares. Seguindo este contexto, um circuito retificador de 6 pulsos foi modelado para alimentar dois tipos de cargas, isto é, cargas RL e RC. Portanto, subentende-se que duas cargas não lineares foram modeladas, visto que suas assinaturas harmônicas de corrente são distintas. Os diagramas que representam as cargas $R L$ e RC, as quais foram modeladas via ATP, são apresentados respectivamente por meio das Figuras 3.6 e 3.7.

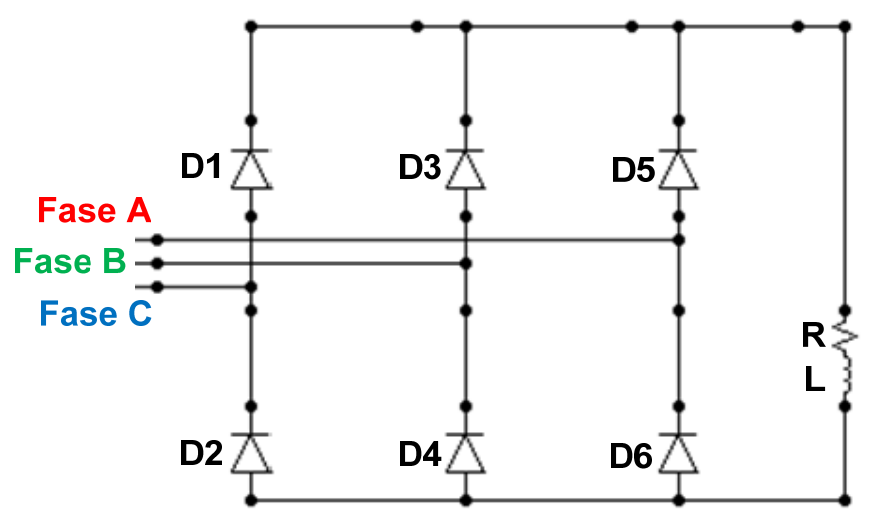

Figura 3.6 - Diagrama do circuito retificador para conexão em $\Delta$ alimentando uma carga $R L$. 


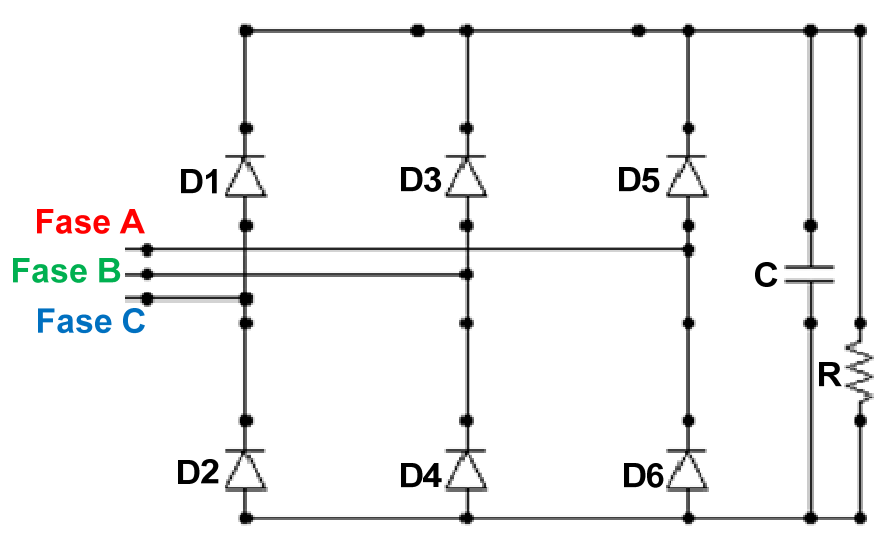

Figura 3.7 - Diagrama do circuito retificador para conexão em $\Delta$ alimentando uma carga $R C$.

Os modelos dos retificadores junto às suas cargas são desenvolvidos tendo como base algumas publicações encontradas na literatura correlata (Gohr Jr. e Perin, 1991; Batista, 2004). Desta forma, aplicando-se a tensão nominal de linha $(23,9 \mathrm{kV})$ na entrada destes retificadores, as seguintes formas de onda de corrente e tensão puderam ser obtidas (Figuras de 3.8 a 3.11).

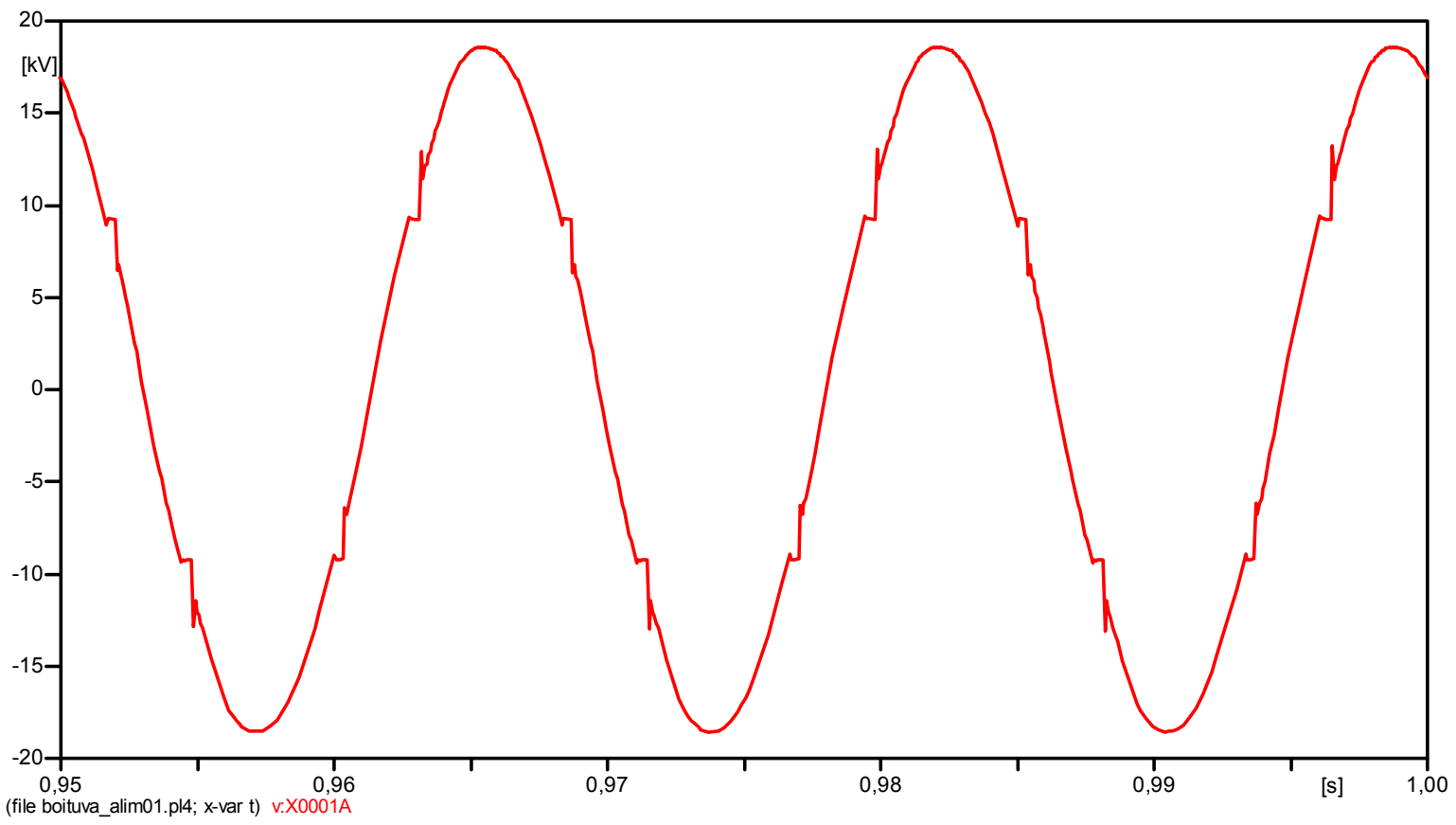

Figura 3.8 - Tensão instantânea (fase-terra) característica de um retificador de 6 pulsos alimentando uma carga $R L$ (somente fase $A$ ). 


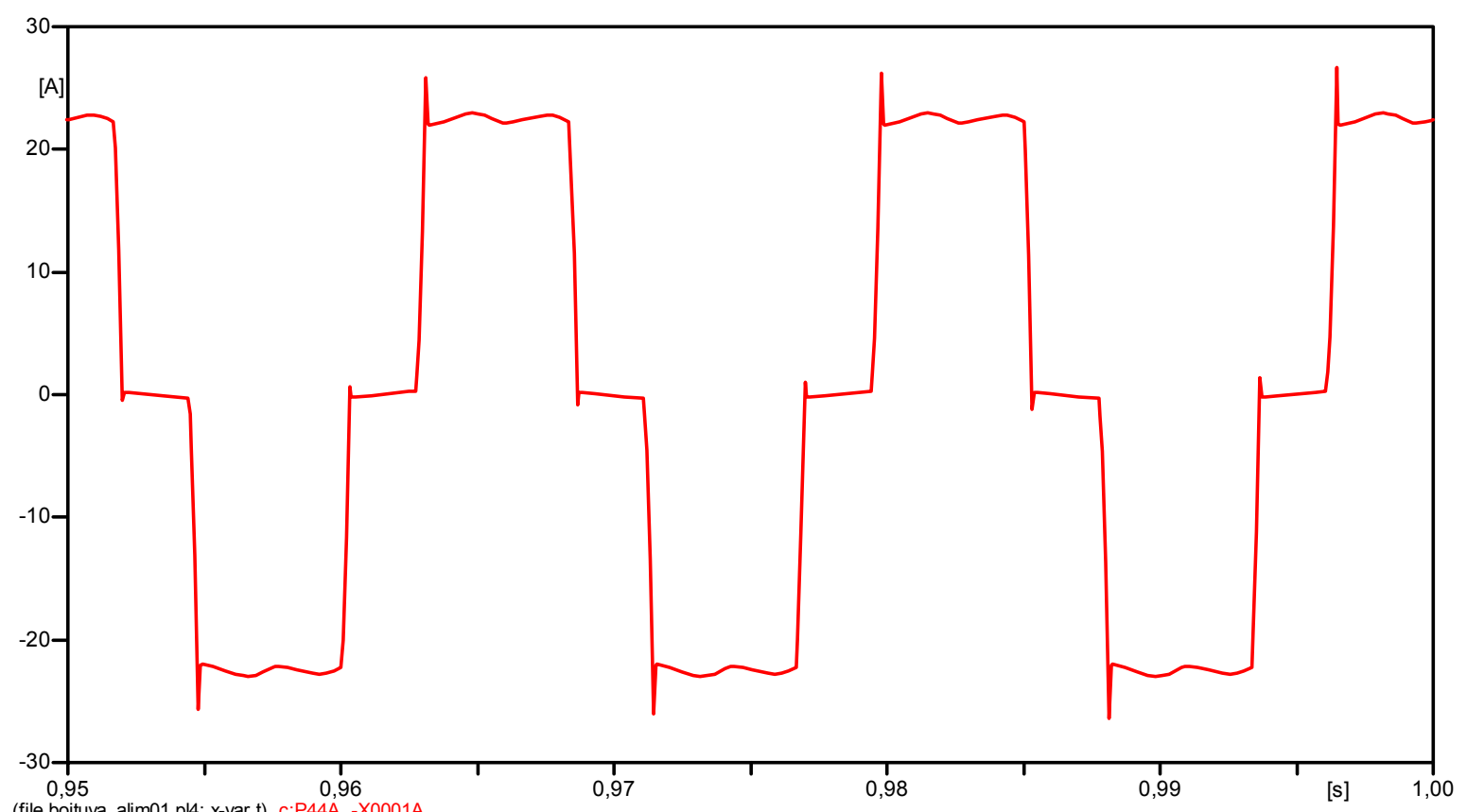

Figura 3.9 - Corrente instantânea (fase-terra) característica de um retificador de 6 pulsos alimentando uma carga $R L$ (somente fase $A$ ).

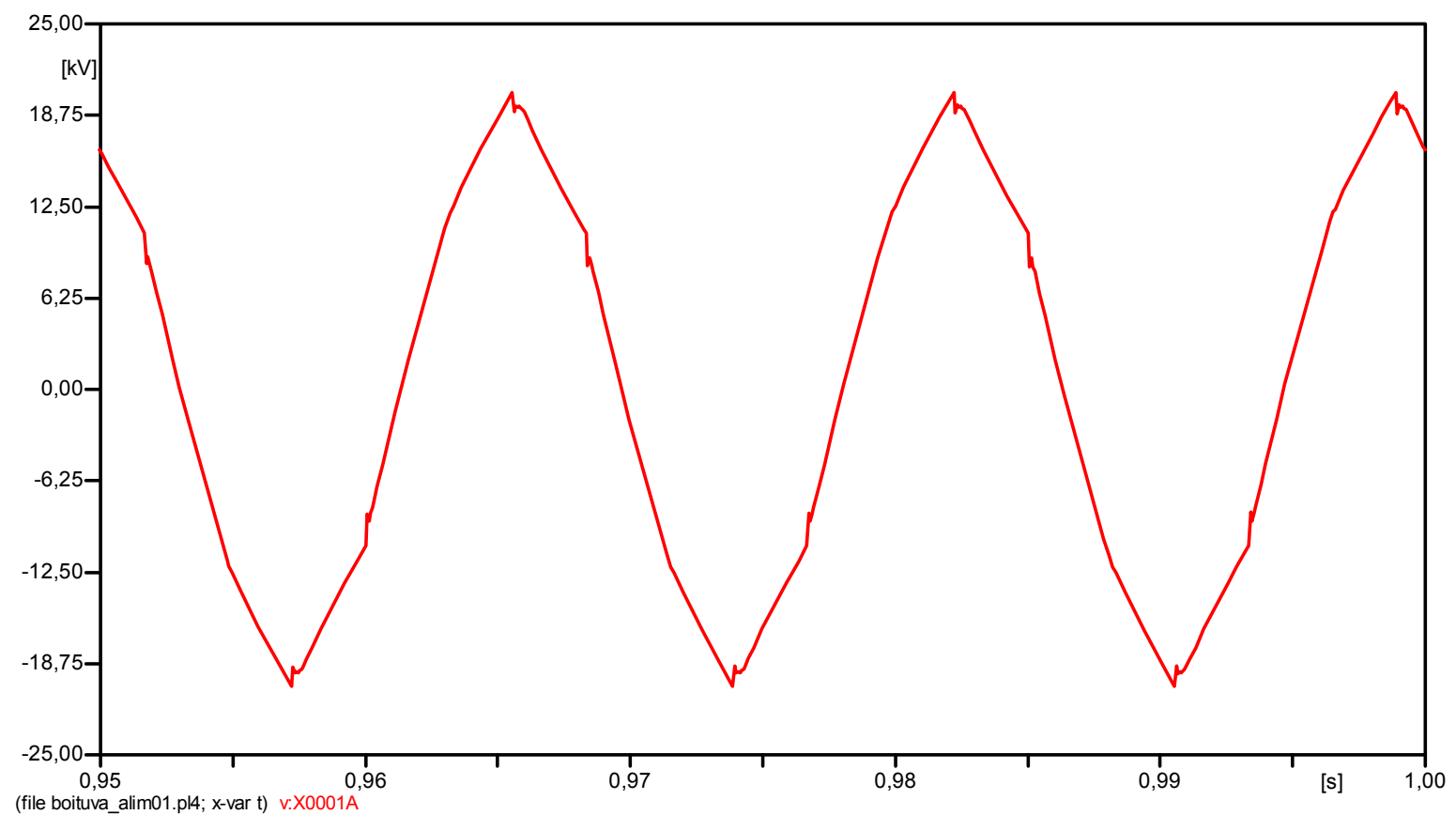

Figura 3.10 - Tensão instantânea (fase-terra) característica de um retificador de 6 pulsos alimentando uma carga $R C$ (somente fase $A$ ). 


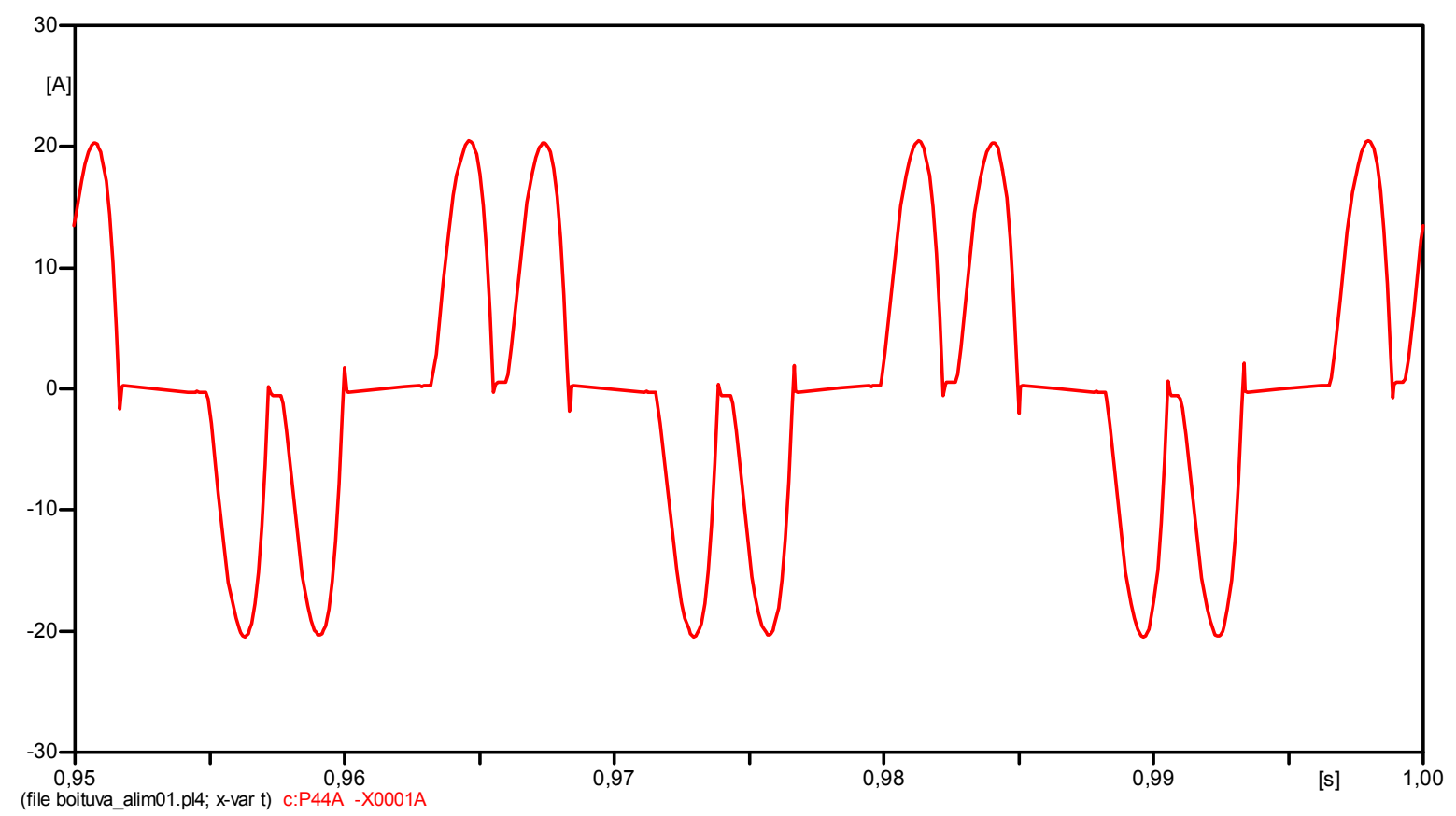

Figura 3.11 - Corrente instantânea (fase-terra) característica de um retificador de 6 pulsos alimentando uma carga $R C$ (somente fase $A$ ).

Torna-se importante observar que todos os gráficos que representam sinais de tensão e corrente são apresentados com seus valores instantâneos.

\subsection{Estudos de Caso Gerados para o Sistema de 20 Barras}

De modo a validar a metodologia proposta nesta pesquisa, houve a necessidade de gerar alguns estudos de caso tanto para o sistema de 20 barras como para o de 90 barras. Assim, para o sistema de 20 barras, seis estudos de caso foram realizados e suas particularidades serão devidamente tratadas na sequência (Subseções de 3.5.1 a 3.5.6). Cada um destes estudos de caso contou com a alocação das cargas não lineares apresentadas na Seção 3.4 (retificadores). Para cada estudo de caso, foram adquiridos os sinais de tensão e corrente que correspondem ao histórico do sistema, isto é, sinais em regime permanente antes da entrada da carga não linear, a qual se pretende localizar e identificar. Além disso, 
foram também adquiridos os dados que correspondem ao estado atual do sistema, isto é, os sinais em regime permanente após a entrada da carga não linear. Com o intuito de melhor ilustrar os dados históricos e atuais dos estudos de caso, exemplos destes sinais podem ser visualizados por meio das Figuras 3.12 e 3.13 .

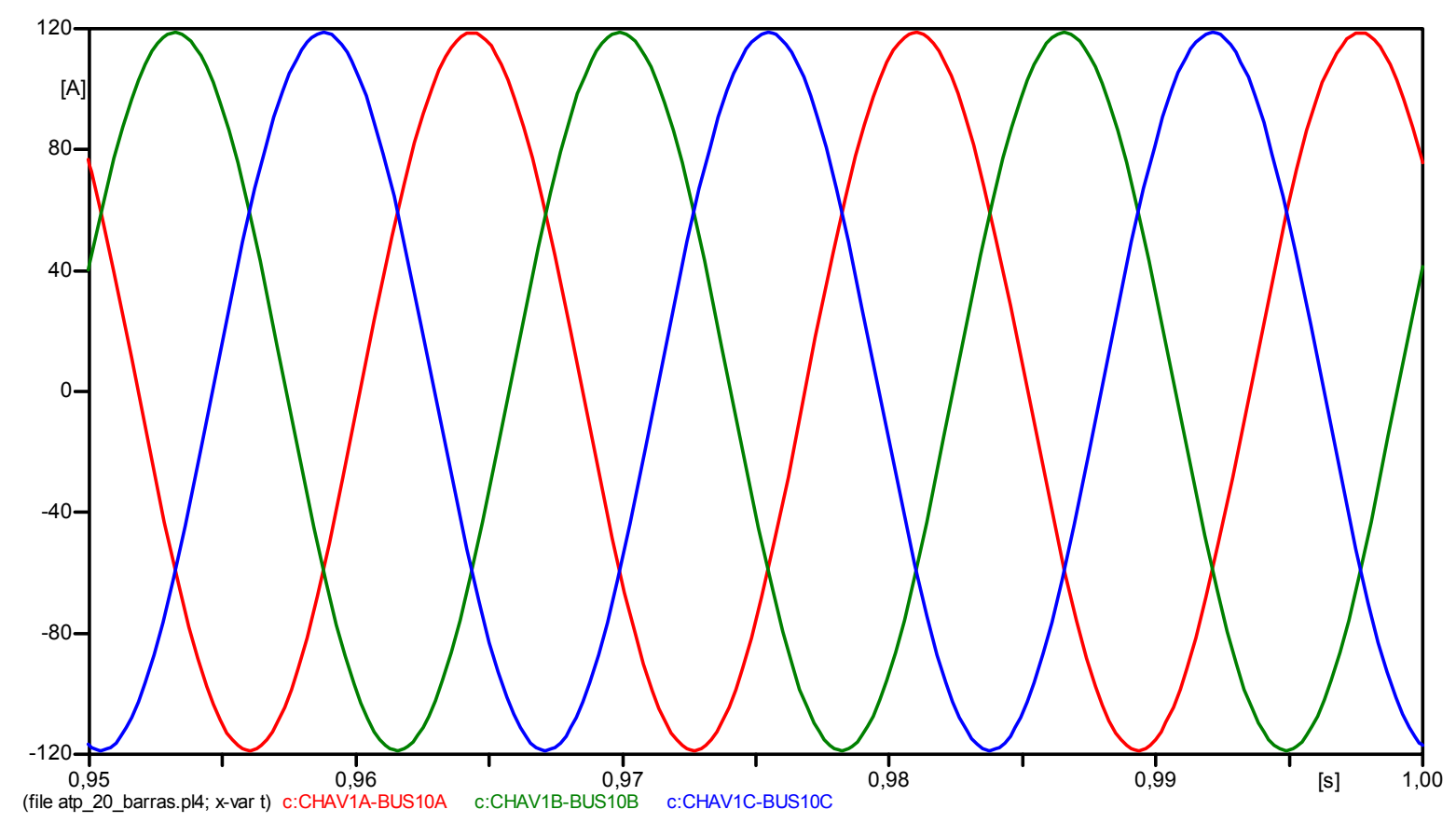

Figura 3.12 - Exemplo de dados históricos da rede - corrente instantânea trifásica (faseterra) medida na subestação.

Na Figura 3.12 é possível visualizar as correntes de fase trifásicas históricas medidas junto à subestação (entre P1 e a barra 10). Neste caso, nota-se claramente que a rede não apresentava qualquer distorção harmônica. Entretanto, num próximo intervalo temporal, mostrado na Figura 3.13 (dados atuais da rede), nota-se o aparecimento de correntes harmônicas que surgiram devido à entrada de uma carga não linear. Desta forma, estabelecem-se para a sequência deste texto as nomenclaturas de "dados históricos" e "dados atuais", seguindo as explanações supra comentadas. 


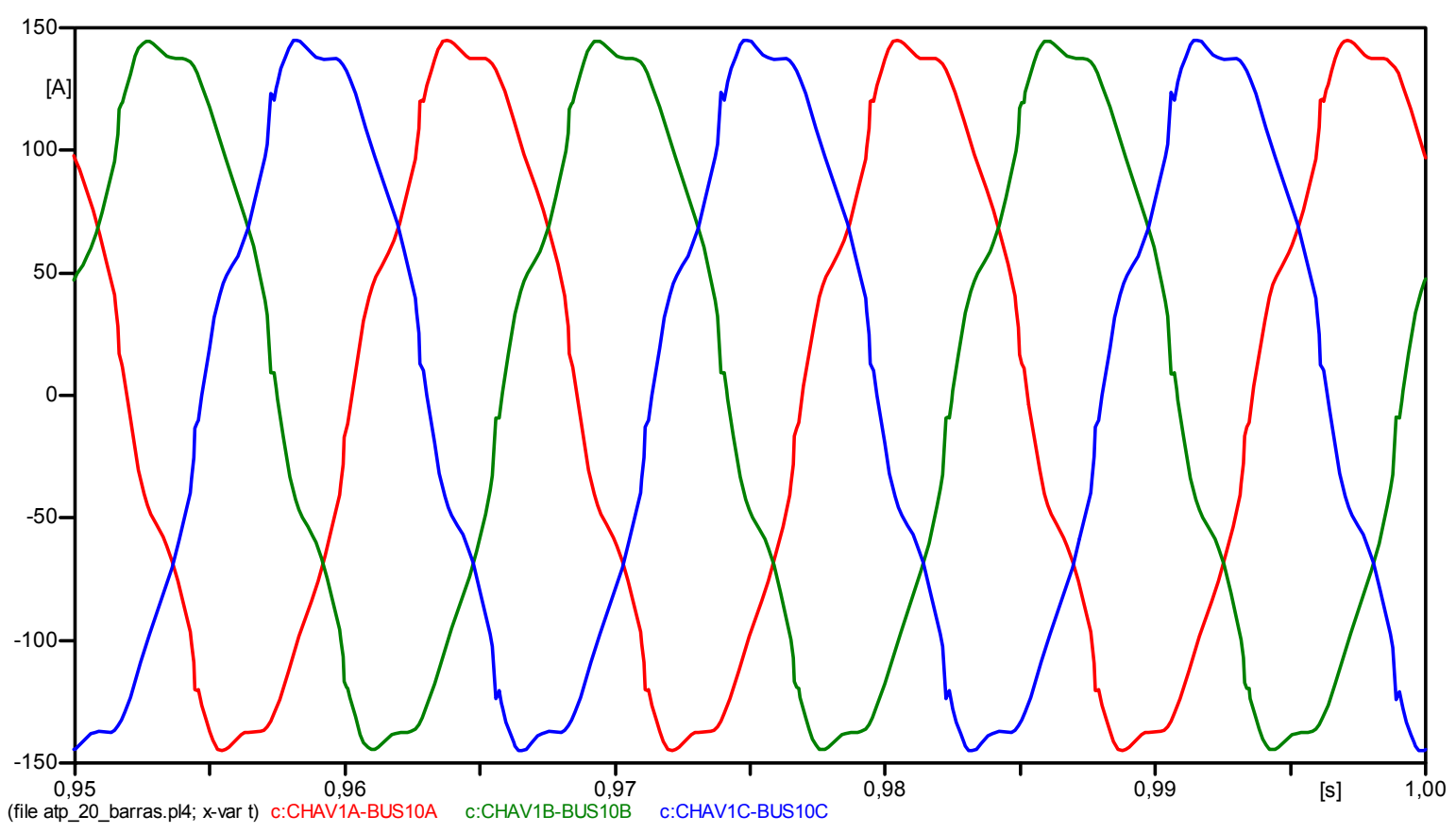

Figura 3.13 - Exemplo de dados atuais da rede - corrente instantânea trifásica (fase-terra) medida na subestação.

Além disso, é importante frisar que estes dados históricos e atuais são obtidos não somente pelos medidores da subestação, mas também pelos medidores responsáveis por adquirir o segundo conjunto de medidas (no sistema de 20 barras, estes medidores encontram-se alocados mais próximos ao final do alimentador; no sistema de 90 barras, encontram-se alocados numa das ramificações da rede).

\subsubsection{Estudo de Caso 1}

Conforme pode ser verificado na Figura 3.2, quatro medidores foram alocados, sendo 2 para tensão e 2 para corrente. Portanto, a partir deste momento, os medidores de tensão (na barra 10) e de corrente (entre P1 e a barra 10) serão referidos como medidores da subestação. Já os medidores de tensão (na barra 50) e de corrente (entre P2 e a barra 50) serão tratados como medidores do final do alimentador. Estas nomenclaturas serão empregadas para todos os casos que se referem ao sistema de 20 barras. 
Neste primeiro estudo de caso, o sistema de 20 barras foi simulado para se ter medidas históricas sem distorções harmônicas, sendo este considerado um caso ideal (normalmente não encontrado na prática). Portanto, esta simulação foi realizada para gerar os dados históricos corresponde ao sistema de 20 barras, da mesma forma como apresentado na Seção 3.2 e no Anexo B. As formas de onda das tensões e correntes históricas medidas na subestação e no final do alimentador podem ser visualizadas por meio das Figuras de 3.14 a 3.17.

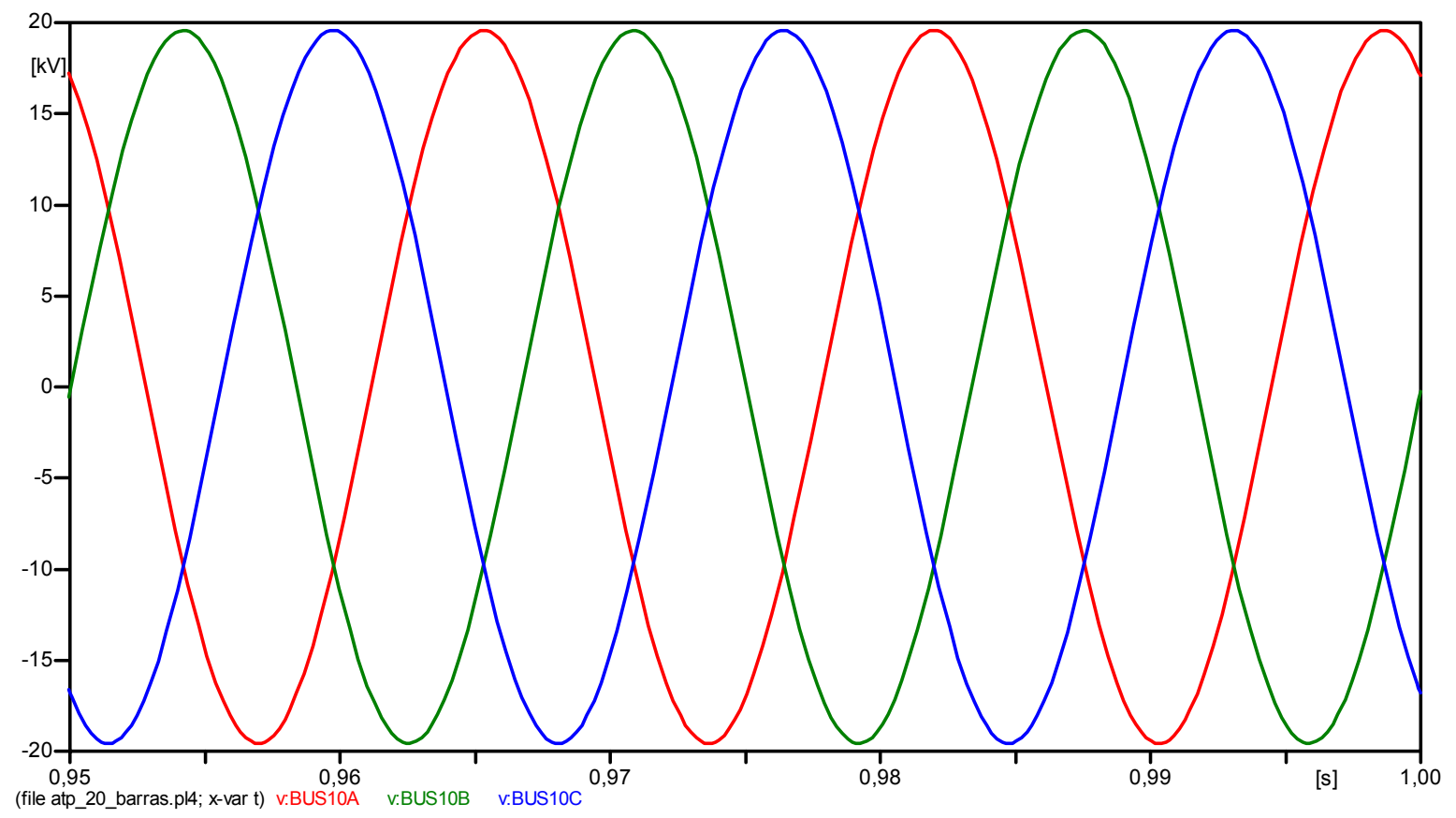

Figura 3.14 - Tensão instantânea trifásica (fase-terra) medida na subestação para o estudo de caso 1 (dado histórico). 


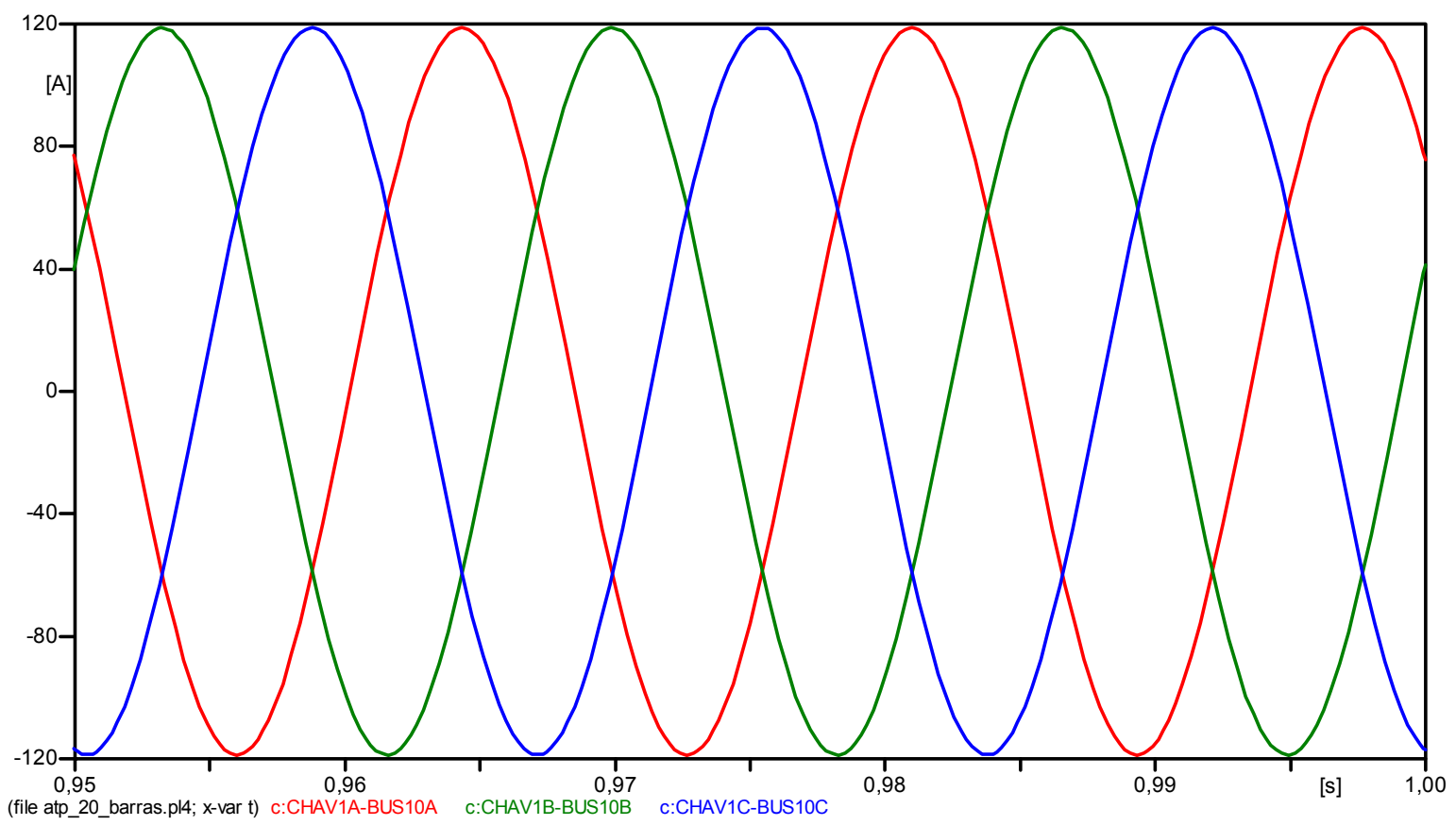

Figura 3.15 - Corrente instantânea trifásica (fase-terra) medida na subestação para o estudo de caso 1 (dado histórico).

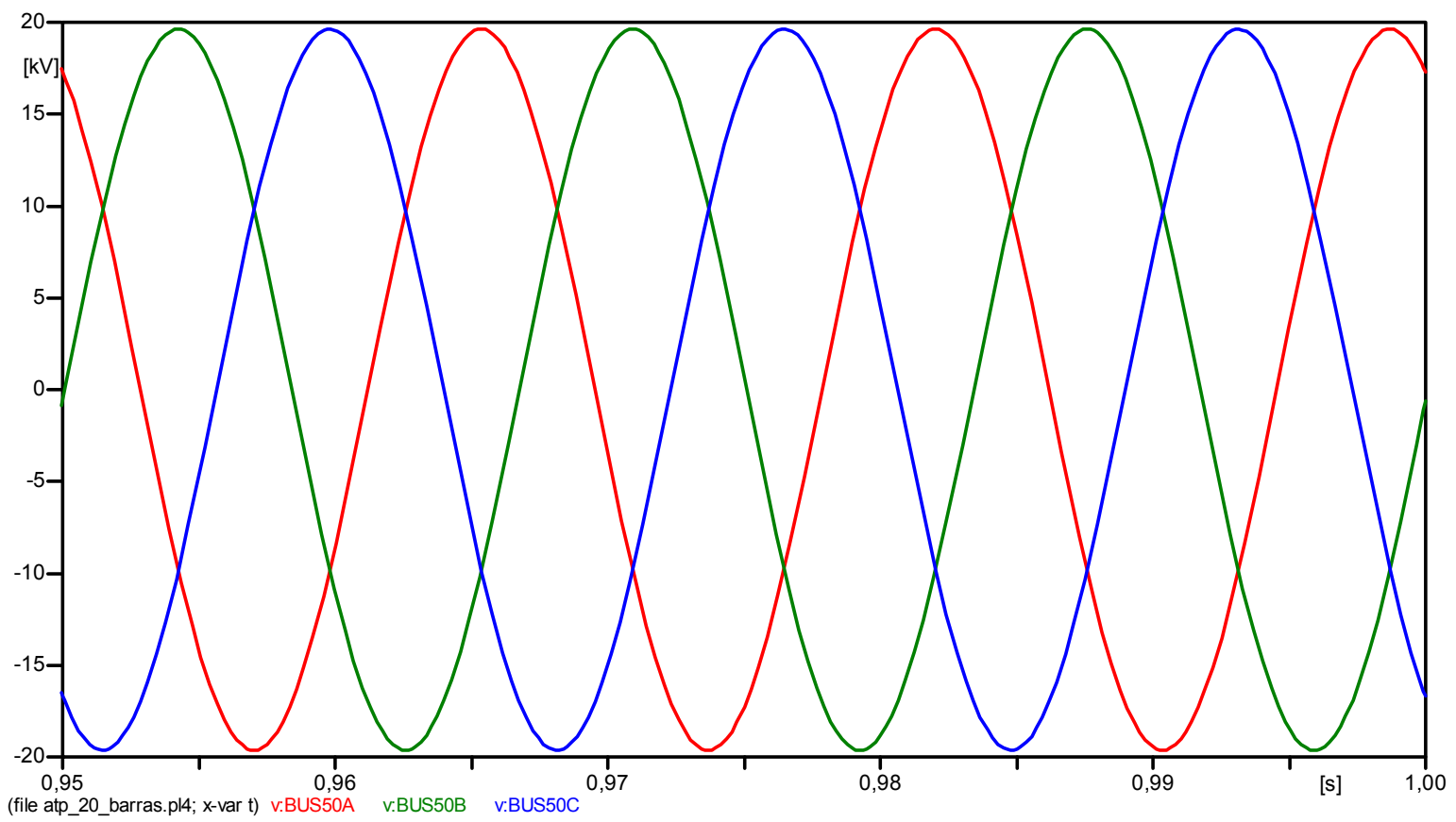

Figura 3.16 - Tensão instantânea trifásica (fase-terra) medida no final do alimentador para o estudo de caso 1 (dado histórico). 


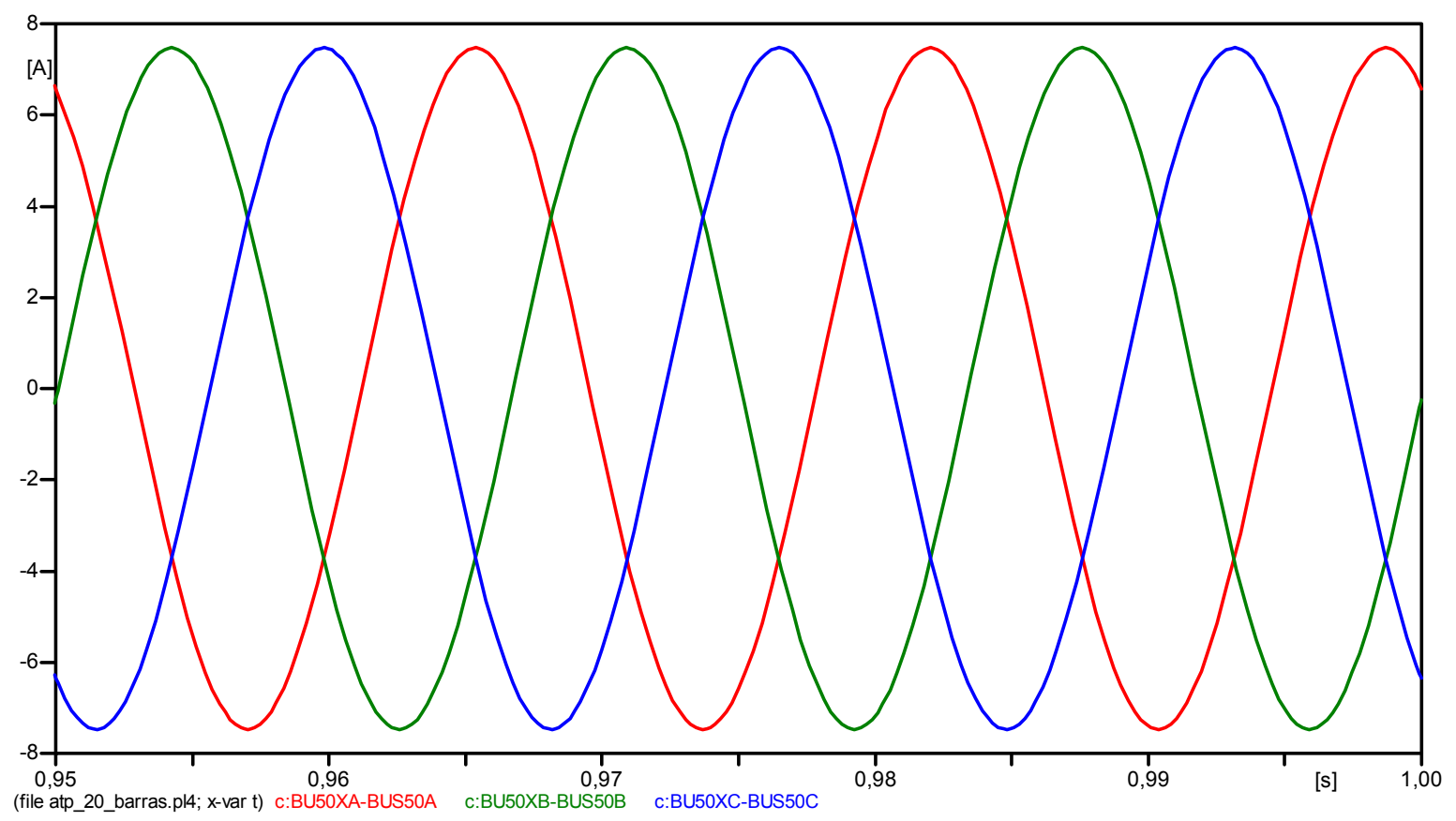

Figura 3.17 - Corrente instantânea trifásica (fase-terra) medida no final do alimentador para o estudo de caso 1 (dado histórico).

A partir das medidas que correspondem ao histórico da rede, verifica-se claramente que estas não sofrem com distorções harmônicas, pois, as cargas alocadas na rede durante a obtenção destes dados históricos eram todas lineares. Entretanto, a simulação que representa o estado atual deste estudo de caso conta com uma carga não linear (retificador) alocada na barra 21. Este retificador foi alocado no sistema a fim de alimentar uma carga $\mathrm{RL}(600 \Omega$ e $200 \mathrm{mH})$, sendo o mesmo responsável por requerer os níveis das correntes fundamental e harmônicas apresentados na Tabela 3.6. 
Tabela 3.6 - Assinatura harmônica de corrente da carga não linear alocada na barra 21 para o estudo de caso 1.

\begin{tabular}{|c|c|c|c|}
\hline Fundamental e Harmônicas & $\begin{array}{c}\text { Amplitude (Ipico) } \\
\text { Fase A [A] }\end{array}$ & $\begin{array}{c}\text { Amplitude (Ipico) } \\
\text { Fase B [A] }\end{array}$ & $\begin{array}{c}\text { Amplitude (Ipico) } \\
\text { Fase C [A] }\end{array}$ \\
\hline 1 & 59,935 & 60,165 & 59,922 \\
\hline 3 & 0,14789 & 0,26817 & 0,12101 \\
\hline 5 & 13,332 & 13,183 & 13,316 \\
\hline 7 & 6,8956 & 7,1166 & 6,799 \\
\hline 9 & 0,15505 & 0,24416 & 0,12224 \\
\hline 11 & 5,3141 & 5,2254 & 5,275 \\
\hline 13 & 4,055 & 4,2602 & 3,9178 \\
\hline
\end{tabular}

Apenas como informação adicional, todas as tabelas que apresentam as assinaturas harmônicas de corrente das cargas não lineares, as quais são apresentadas no decorrer deste e de outros capítulos, mostram os valores de pico das correntes.

Portanto, depois de realizada a alocação da carga não linear na barra 21, o estudo de caso 1 foi devidamente simulado para gerar os dados que correspondem ao estado atual da rede. Desta forma, os sinais medidos tanto na subestação como no final do alimentador puderam ser obtidos e encontram-se ilustrados por meio das Figuras de 3.18 a 3.21 . 


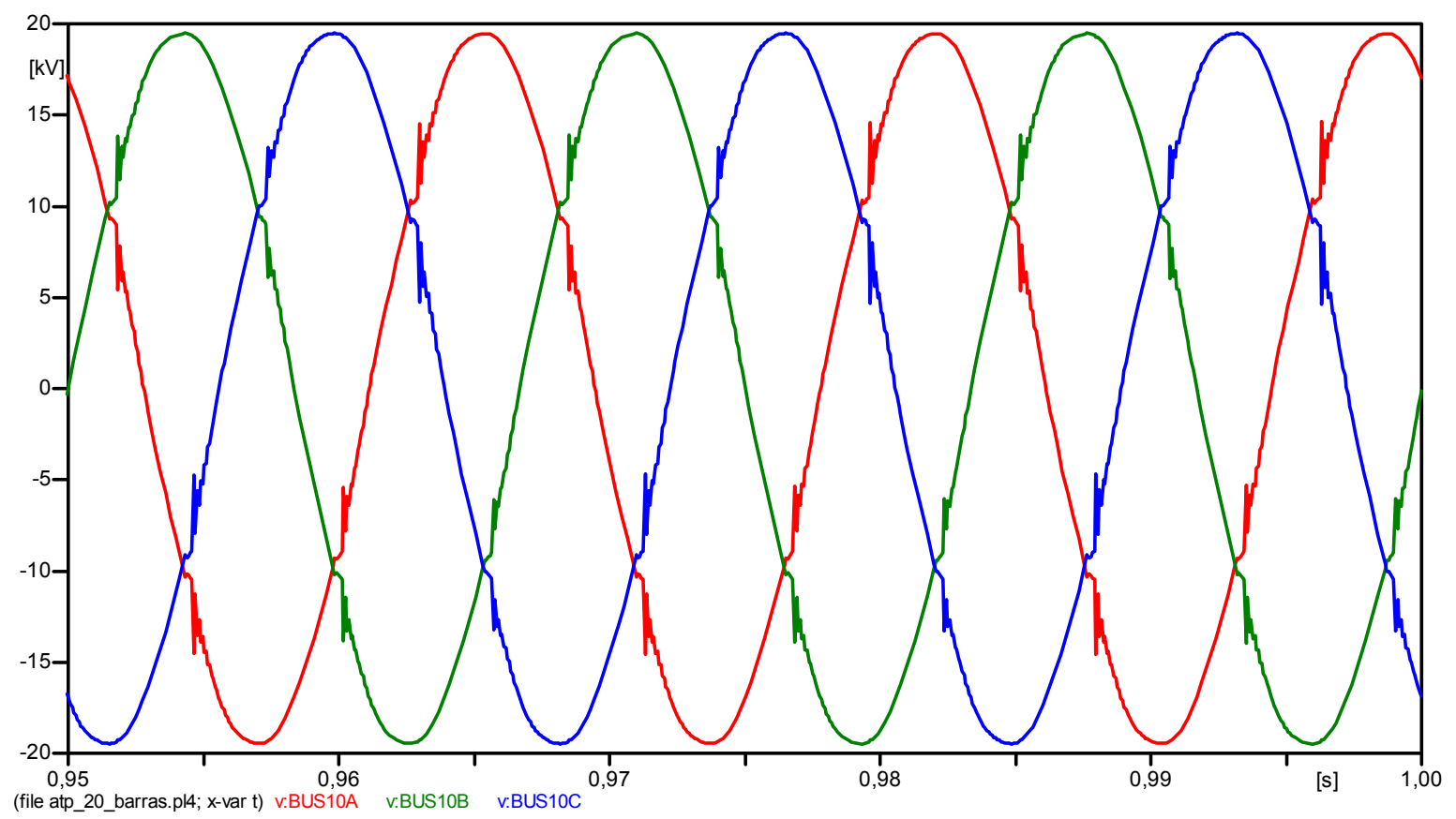

Figura 3.18 - Tensão instantânea trifásica (fase-terra) medida na subestação para o estudo de caso 1 (dado atual).

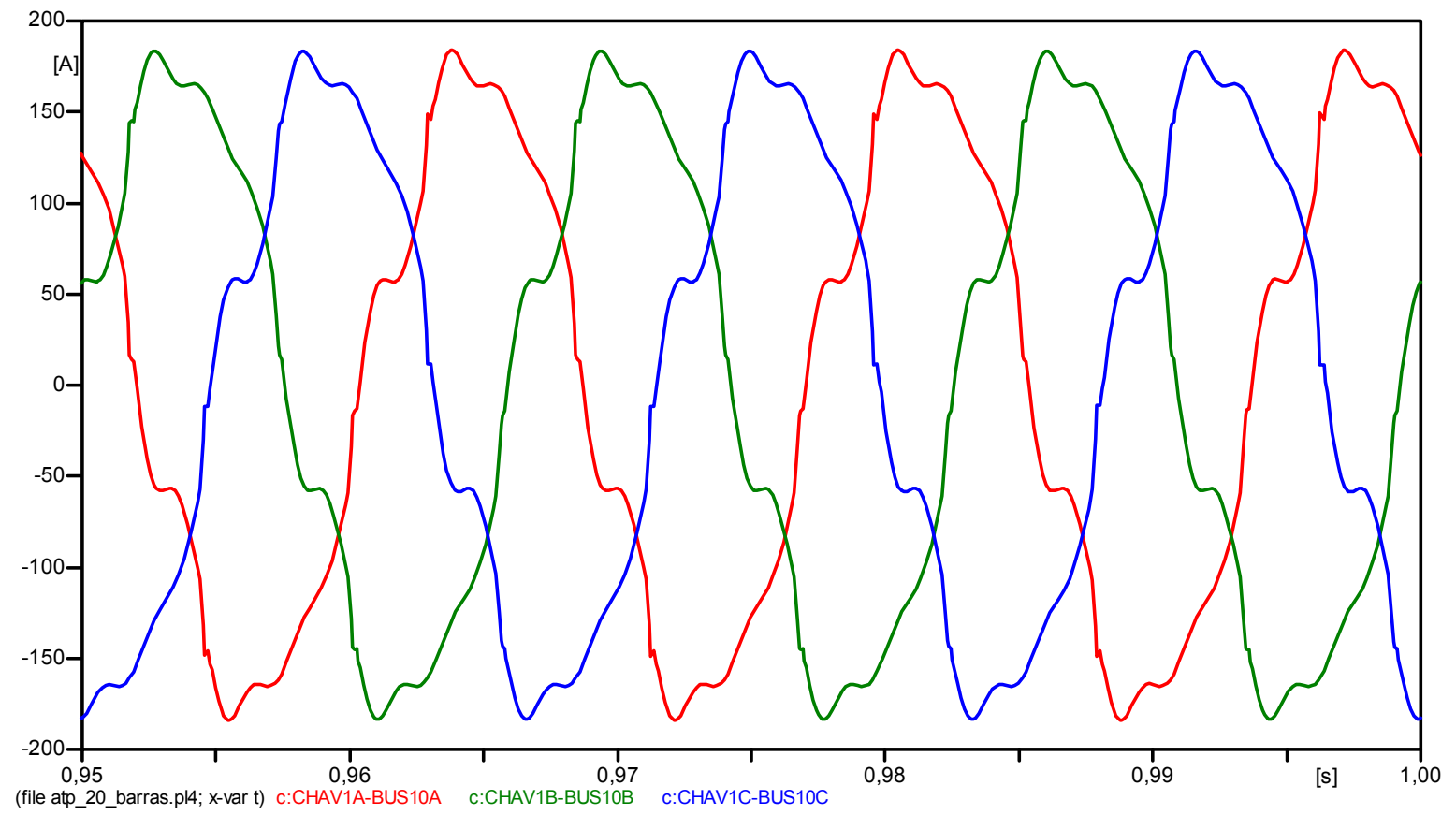

Figura 3.19 - Corrente instantânea trifásica (fase-terra) medida na subestação para o estudo de caso 1 (dado atual). 


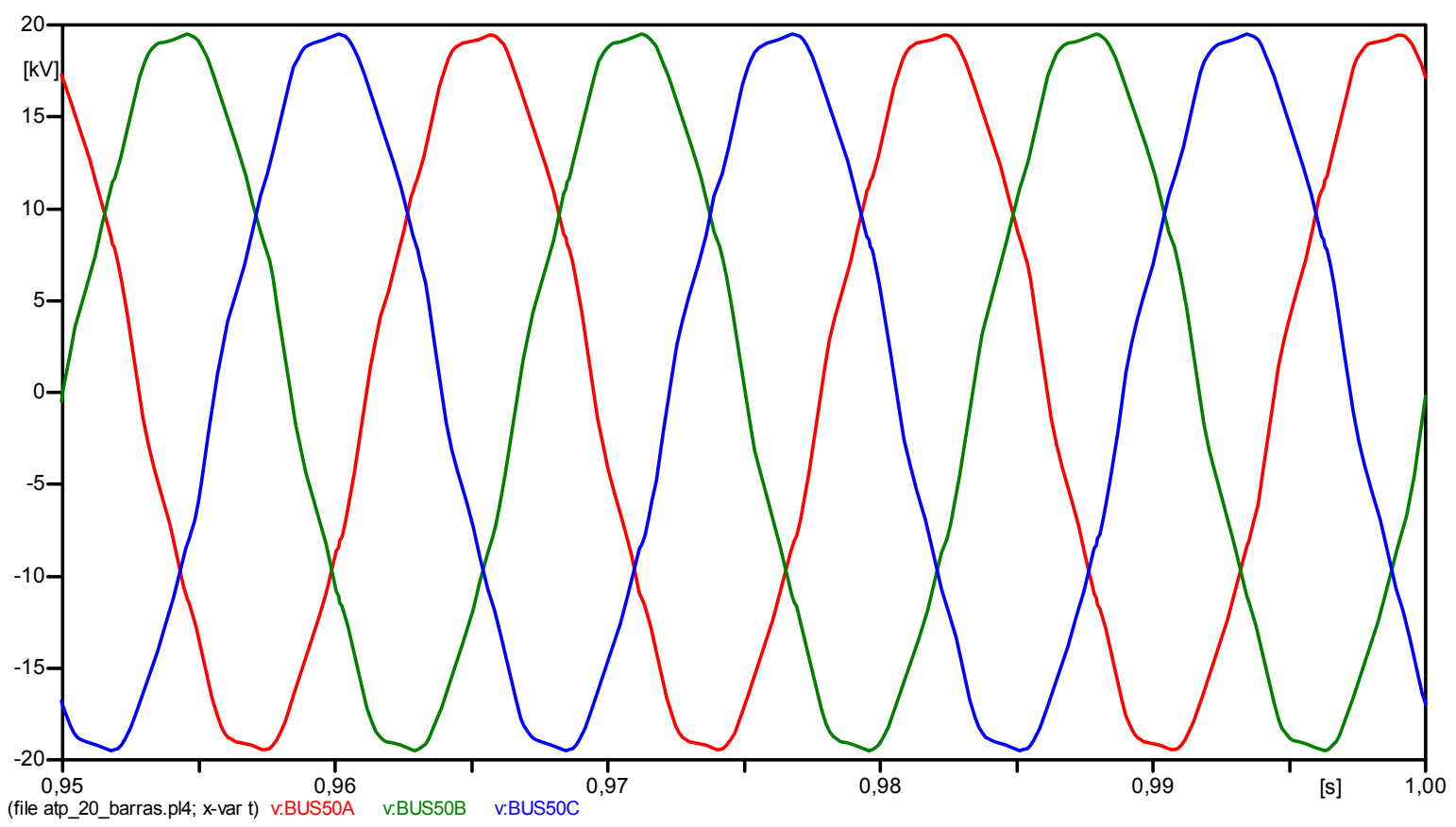

Figura 3.20 - Tensão instantânea trifásica (fase-terra) medida no final do alimentador para o estudo de caso 1 (dado atual).

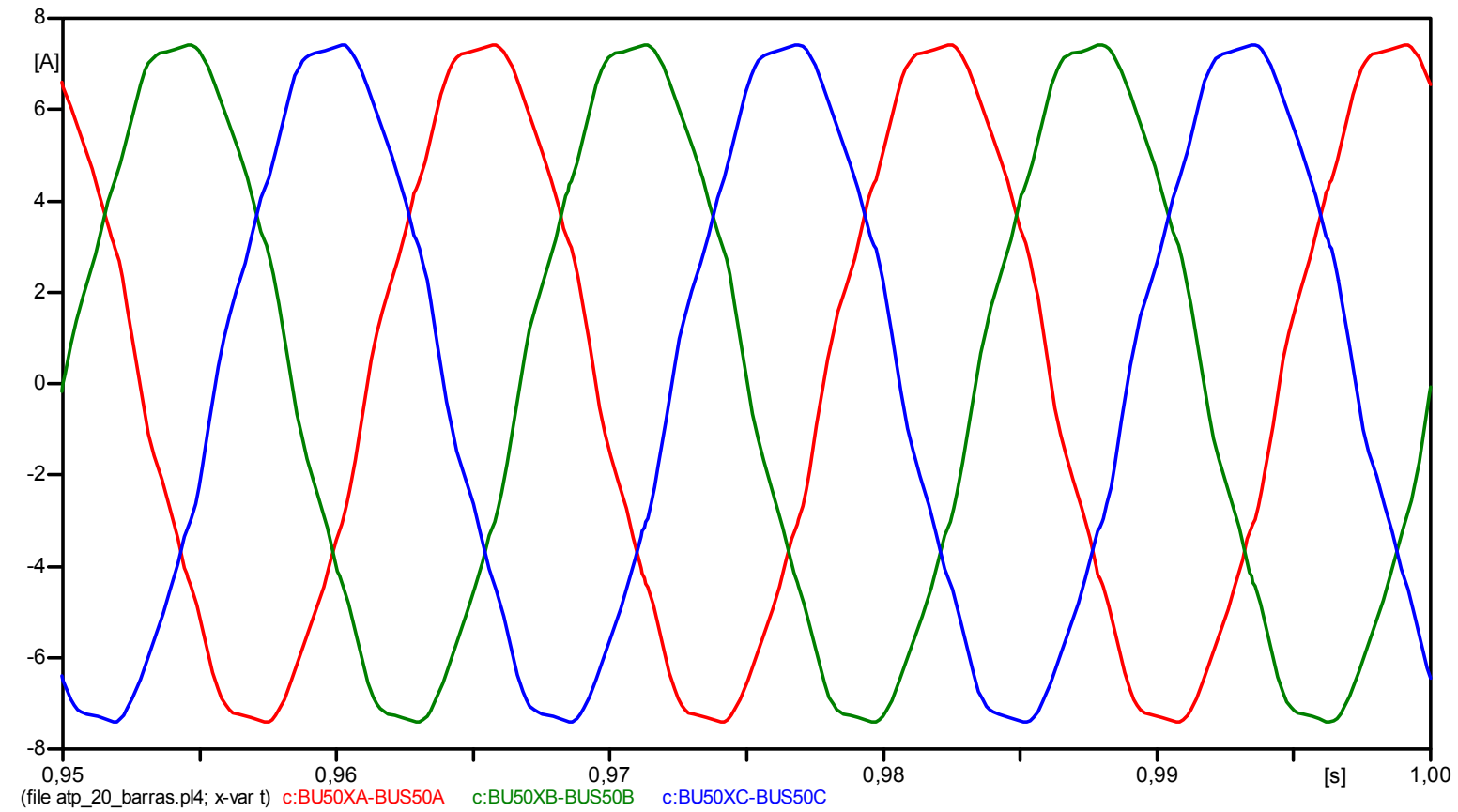

Figura 3.21 - Corrente instantânea trifásica (fase-terra) medida no final do alimentador para o estudo de caso 1 (dado atual).

Um fator a ser verificado é que todos os gráficos mostrados nesta tese, os quais representam os sinais de tensões e correntes, têm seu início temporal em 0,95 
$\mathrm{s}$ ao invés de se iniciar em $0,0 \mathrm{~s}$, pois, o período transitório do sistema não é aqui considerado.

Após uma rápida análise sobre os sinais de tensão e corrente que representam o estado atual da rede, verifica-se o surgimento de componentes harmônicas e, desta forma, calculou-se a DHT para a tensão de fase trifásica medida na subestação, onde foram encontrados os seguintes valores: $1,71 \%$ (fase A), $1,91 \%$ (fase B) e 1,74\% (fase C). Na Tabela 3.7 são mostrados os níveis de tensão tanto da fundamental como das harmônicas (somente ímpares até $13^{a}$ ordem) medidas na subestação para cada uma das fases.

Tabela 3.7 - Componentes fundamental e harmônicas de tensão medidas na subestação para o estudo de caso 1.

\begin{tabular}{|c|c|c|c|}
\hline Fundamental e Harmônicas & $\begin{array}{c}\text { Amplitude (Vpico) } \\
\text { Fase A [V] }\end{array}$ & $\begin{array}{c}\text { Amplitude (Vpico) } \\
\text { Fase B [V] }\end{array}$ & $\begin{array}{c}\text { Amplitude (Vpico) } \\
\text { Fase C [V] }\end{array}$ \\
\hline 1 & 19516 & 19572 & 19516 \\
\hline 3 & 32,108 & 54,284 & 30,854 \\
\hline 5 & 182,56 & 208,91 & 206,78 \\
\hline 7 & 225,92 & 237,12 & 216,13 \\
\hline 9 & 8,0549 & 18,462 & 11,766 \\
\hline 11 & 11,109 & 22,157 & 26,779 \\
\hline 13 & 21,141 & 14,243 & 22,325 \\
\hline
\end{tabular}

Torna-se importante comentar que todas as tabelas apresentadas nesta tese, as quais representam as componentes fundamentais e harmônicas de tensão medidas na subestação, têm seus valores mostrados em tensão de pico.

\subsubsection{Estudo de Caso 2}

O segundo estudo de caso foi gerado de modo a apresentar os mesmos dados históricos obtidos para o estudo de caso 1. Portanto, consideram-se as 
formas de onda apresentadas nas Figuras de 3.14 a 3.17 (sem distorção harmônica).

Já a simulação que representa o estado atual deste estudo de caso conta com uma carga não linear (retificador) alocada na barra 30. Este retificador foi alocado no sistema a fim de alimentar uma carga $\mathrm{RL}$, sendo esta parametrizada com $900 \Omega$ e $900 \mathrm{mH}$. Desta forma, foram medidas as correntes fundamental e harmônicas na entrada do retificador, as quais podem ser visualizadas por meio da Tabela 3.8.

Tabela 3.8 - Assinatura harmônica de corrente da carga não linear alocada na barra 30 para o estudo de caso 2.

\begin{tabular}{|c|c|c|c|}
\hline Fundamental e Harmônicas & $\begin{array}{c}\text { Amplitude (Ipico) } \\
\text { Fase A [A] }\end{array}$ & $\begin{array}{c}\text { Amplitude (Ipico) } \\
\text { Fase B [A] }\end{array}$ & $\begin{array}{c}\text { Amplitude (Ipico) } \\
\text { Fase C [A] }\end{array}$ \\
\hline 1 & 40,183 & 40,495 & 40,276 \\
\hline 3 & 0,26221 & 0,34026 & 0,078471 \\
\hline 5 & 8,4262 & 8,1579 & 8,3561 \\
\hline 7 & 5,2202 & 5,5296 & 5,2661 \\
\hline 9 & 0,25976 & 0,33712 & 0,087809 \\
\hline 11 & 3,717 & 3,4775 & 3,6429 \\
\hline 13 & 2,8919 & 3,2209 & 2,9527 \\
\hline
\end{tabular}

Além disso, para a obtenção dos dados atuais deste estudo de caso, a tensão nominal da fonte foi mantida na fase $A$, variada em $-5 \%$ na fase $B$ e $+10 \%$ na fase C. Portanto, entre os dados históricos e os dados atuais pode-se observar tal variação de tensão. É importante comentar que os percentuais de variação de tensão foram gerados de maneira aleatória.

De forma breve, pode-se dizer que o estado atual deste estudo de caso conta com variações na tensão e também com uma carga não linear alocada na barra 30. Assim, as formas de onda medidas tanto na subestação como no final do alimentador puderam ser obtidas e são mostradas nas Figuras de 3.22 a 3.25. 


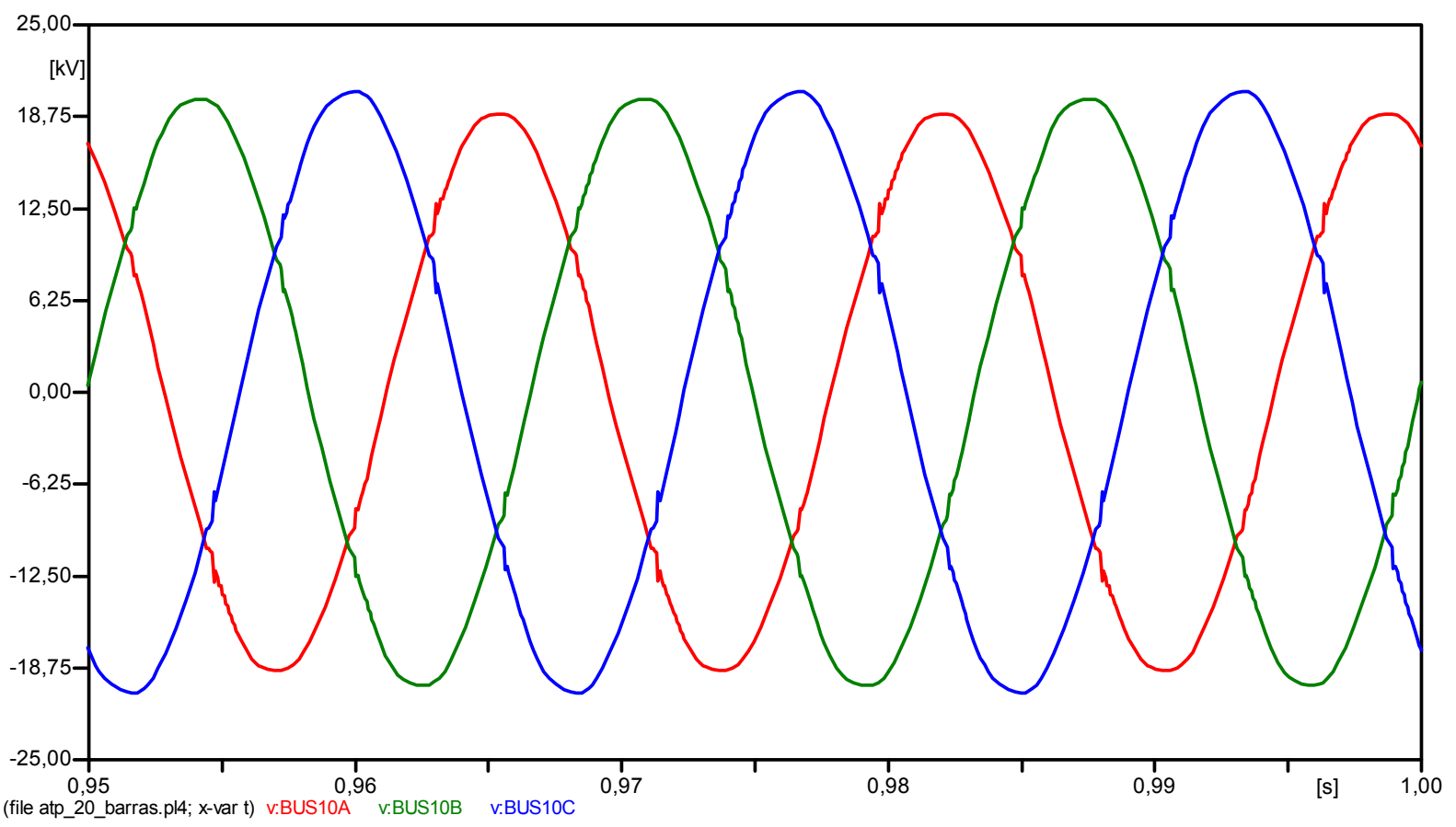

Figura 3.22 - Tensão instantânea trifásica (fase-terra) medida na subestação para o estudo de caso 2 (dado atual).

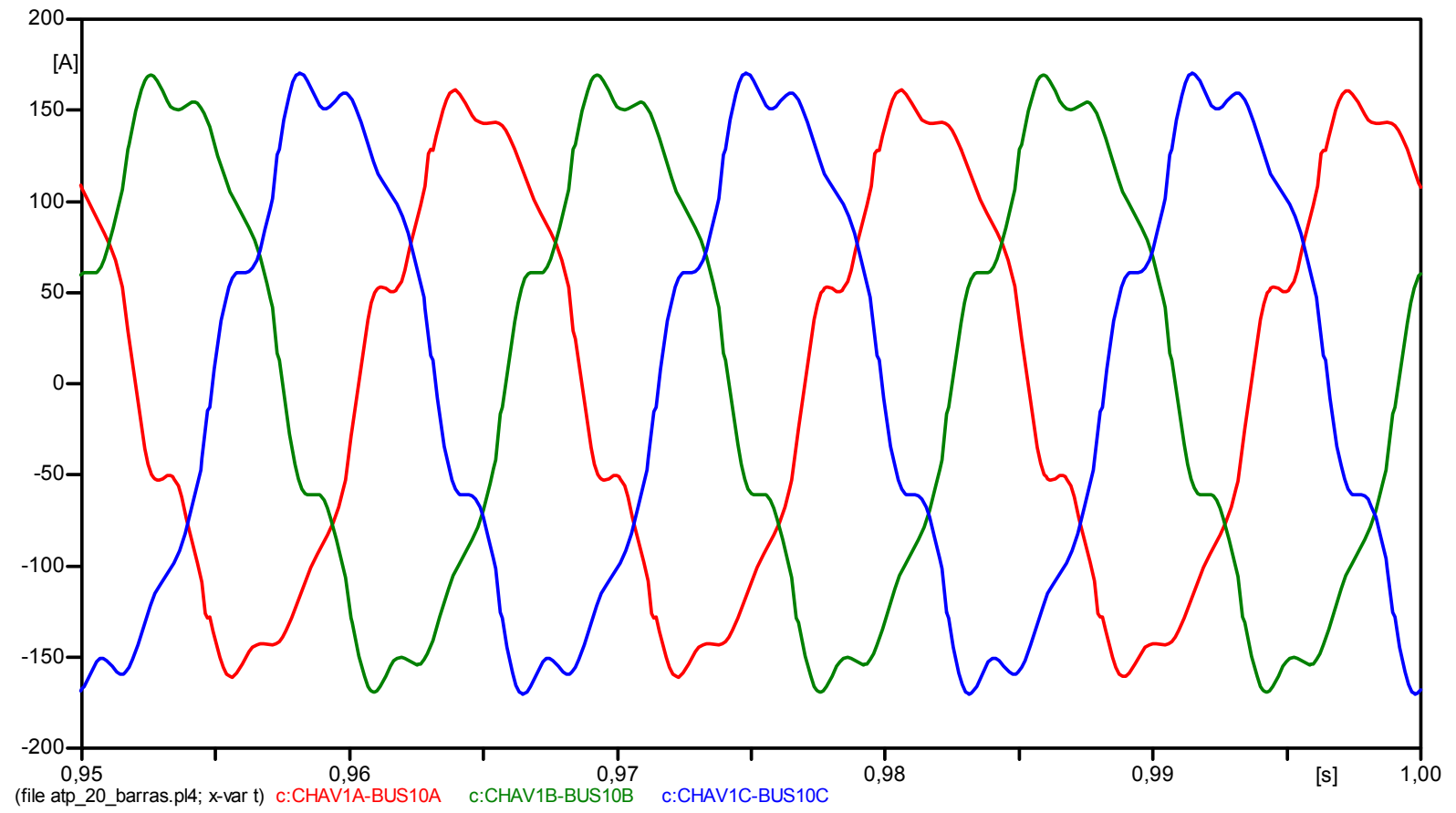

Figura 3.23 - Corrente instantânea trifásica (fase-terra) medida na subestação para o estudo de caso 2 (dado atual). 


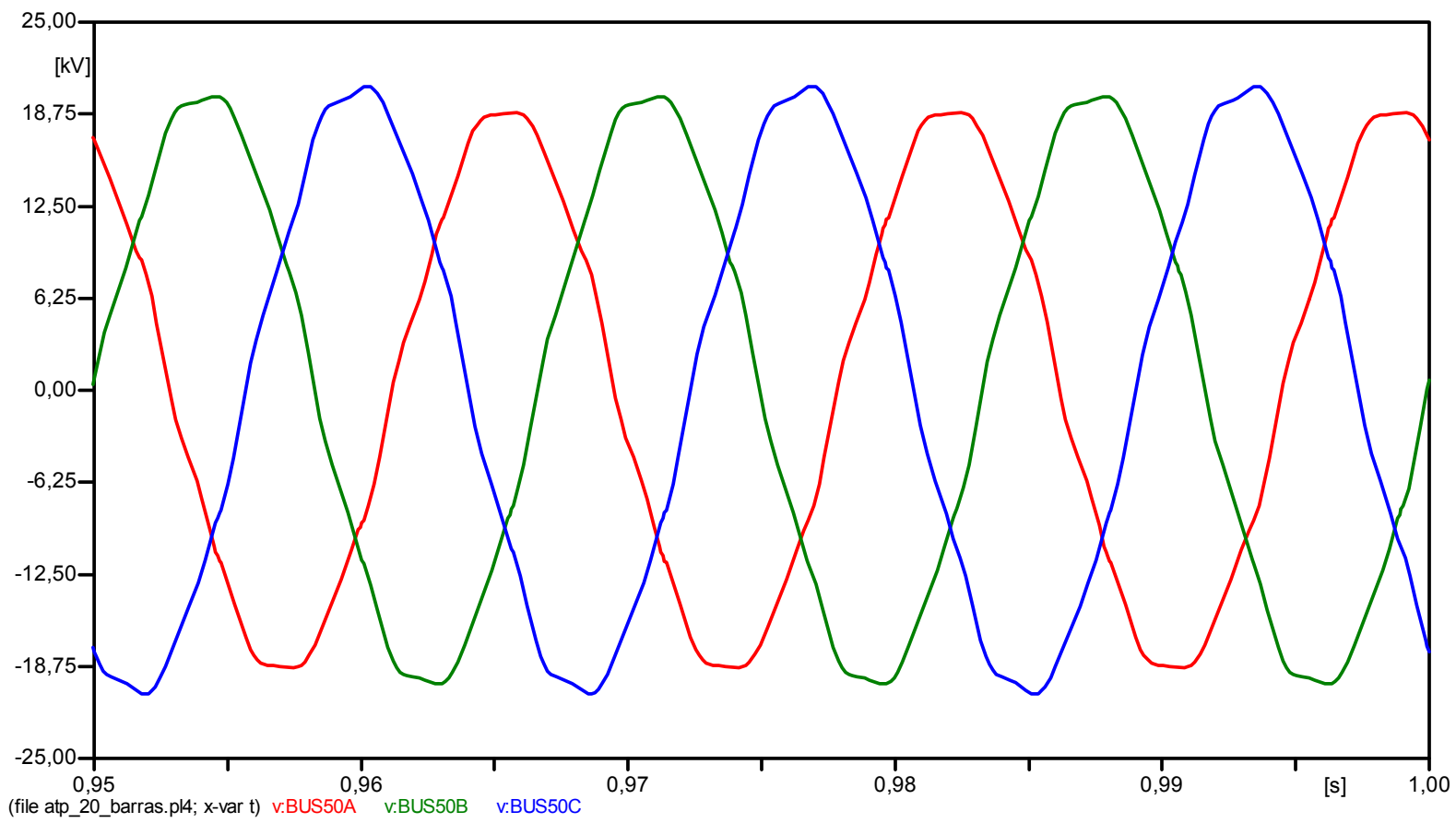

Figura 3.24 - Tensão instantânea trifásica (fase-terra) medida no final do alimentador para o estudo de caso 2 (dado atual).

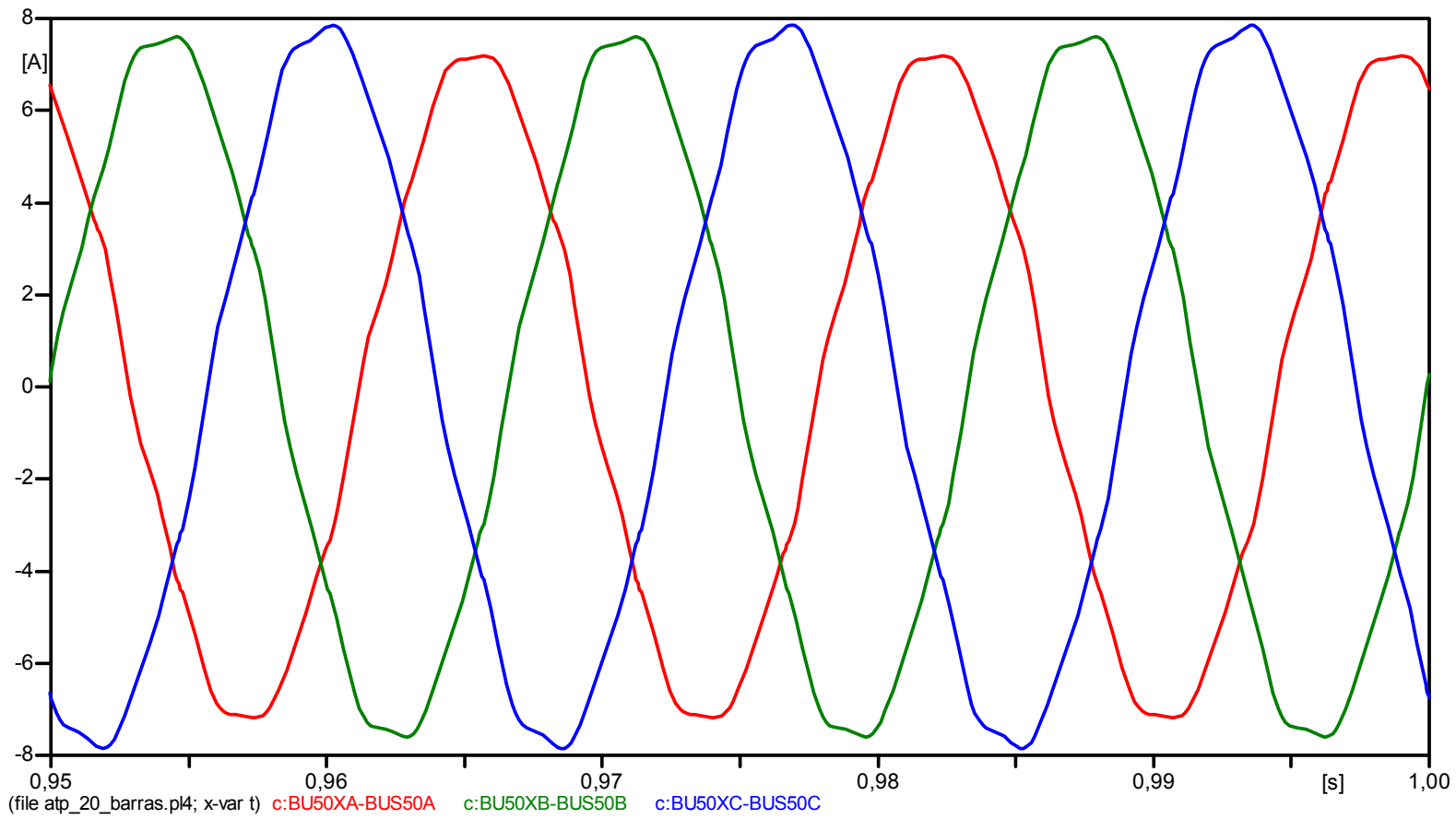

Figura 3.25 - Corrente instantânea trifásica (fase-terra) medida no final do alimentador para o estudo de caso 2 (dado atual).

Neste estudo de caso 2, verificou-se que as DHTs calculadas para as tensões medidas na subestação foram de 1,36\% (fase A), 1,54\% (fase B) e 1,39\% 
(fase C). A seguir, apresenta-se a Tabela 3.9, em que são mostrados os níveis de tensão tanto da fundamental como das harmônicas (somente ímpares até $13^{a}$ ordem) medidas na subestação para cada uma das fases.

Tabela 3.9 - Componentes fundamental e harmônicas de tensão medidas na subestação para o estudo de caso 2.

\begin{tabular}{|c|c|c|c|}
\hline Fundamental e Harmônicas & $\begin{array}{c}\text { Amplitude (Vpico) } \\
\text { Fase A [V] }\end{array}$ & $\begin{array}{c}\text { Amplitude (Vpico) } \\
\text { Fase B [V] }\end{array}$ & $\begin{array}{c}\text { Amplitude (Vpico) } \\
\text { Fase C [V] }\end{array}$ \\
\hline 1 & 19040 & 20092 & 20513 \\
\hline 3 & 34,45 & 54,119 & 39,328 \\
\hline 5 & 135,07 & 143,9 & 139,22 \\
\hline 7 & 179,05 & 225,62 & 221,12 \\
\hline 9 & 68,192 & 22,013 & 56,914 \\
\hline 11 & 44,984 & 48,105 & 42,474 \\
\hline 13 & 12,023 & 19,438 & 12,789 \\
\hline
\end{tabular}

\subsubsection{Estudo de Caso 3}

Este terceiro estudo de caso, assim como os estudos de caso 1 e 2, foi gerado de modo a apresentar dados históricos sem distorções harmônicas. No entanto, o banco de capacitores previamente alocado na barra 42 foi retirado da rede. Assim, as formas de onda medidas na subestação e no final do alimentador são ilustradas nas Figuras de 3.26 a 3.29 . 


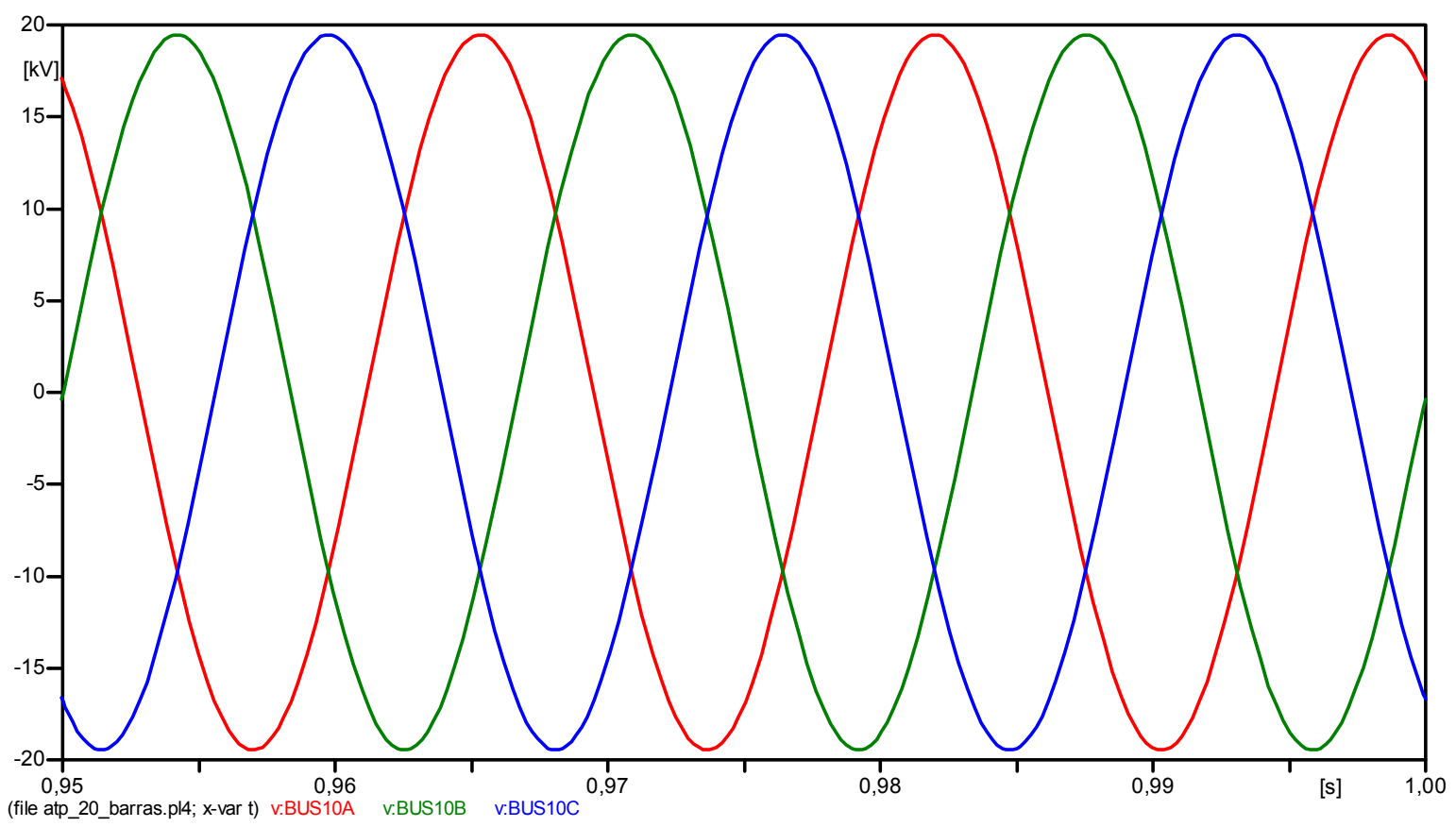

Figura 3.26 - Tensão instantânea trifásica (fase-terra) medida na subestação para o estudo de caso 3 (dado histórico).

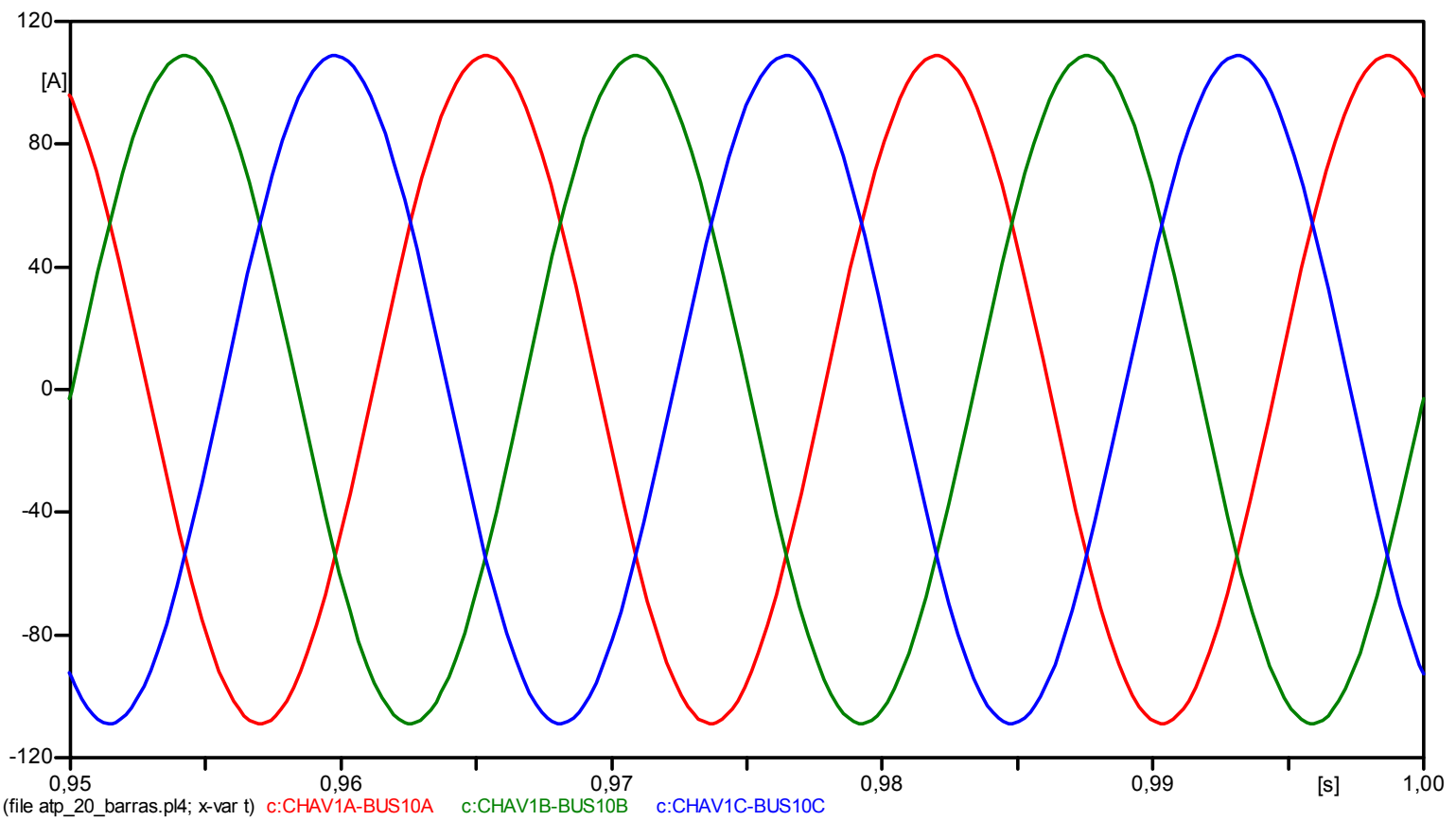

Figura 3.27 - Corrente instantânea trifásica (fase-terra) medida na subestação para o estudo de caso 3 (dado histórico). 


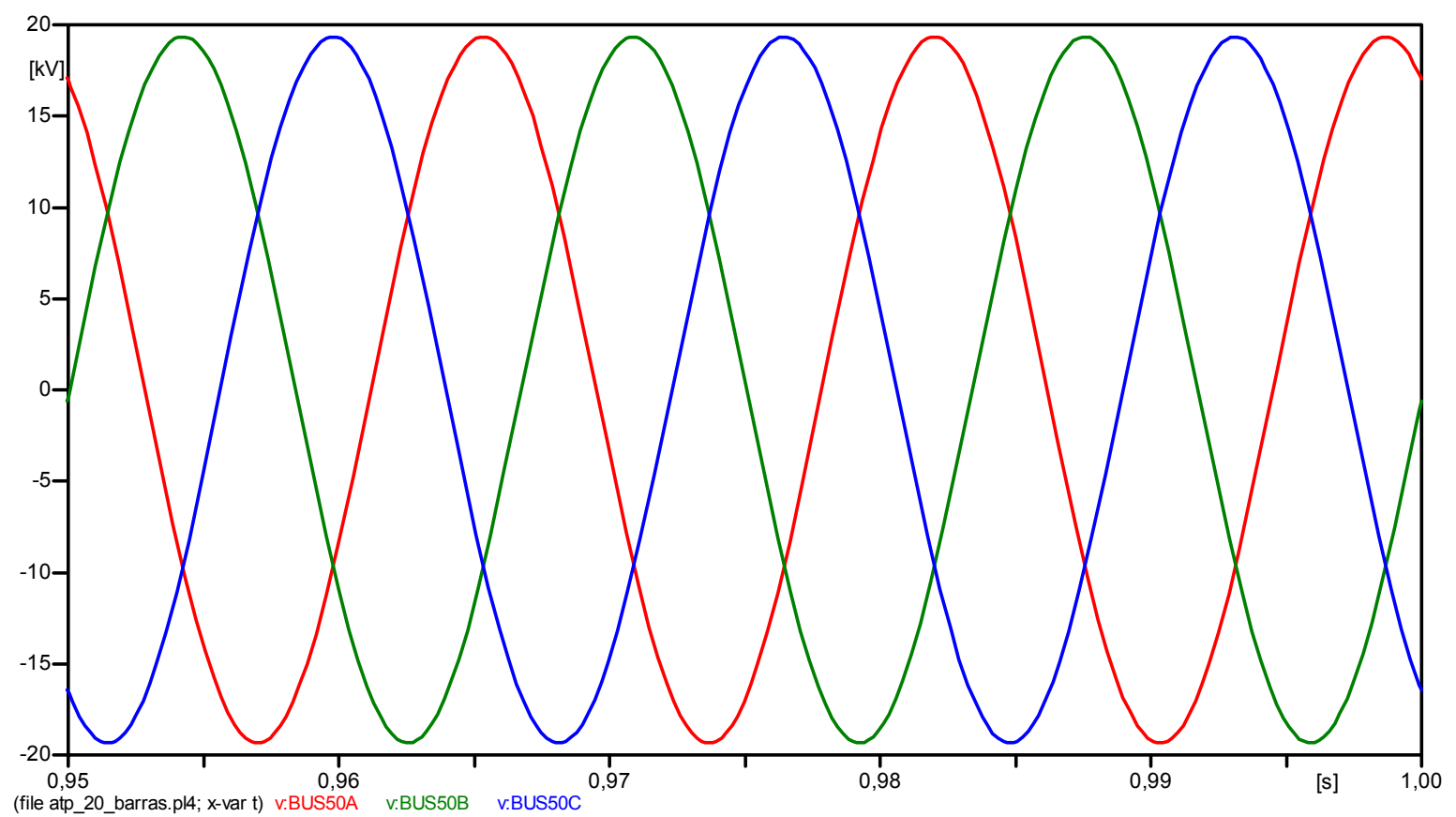

Figura 3.28 - Tensão instantânea trifásica (fase-terra) medida no final do alimentador para o estudo de caso 3 (dado histórico).

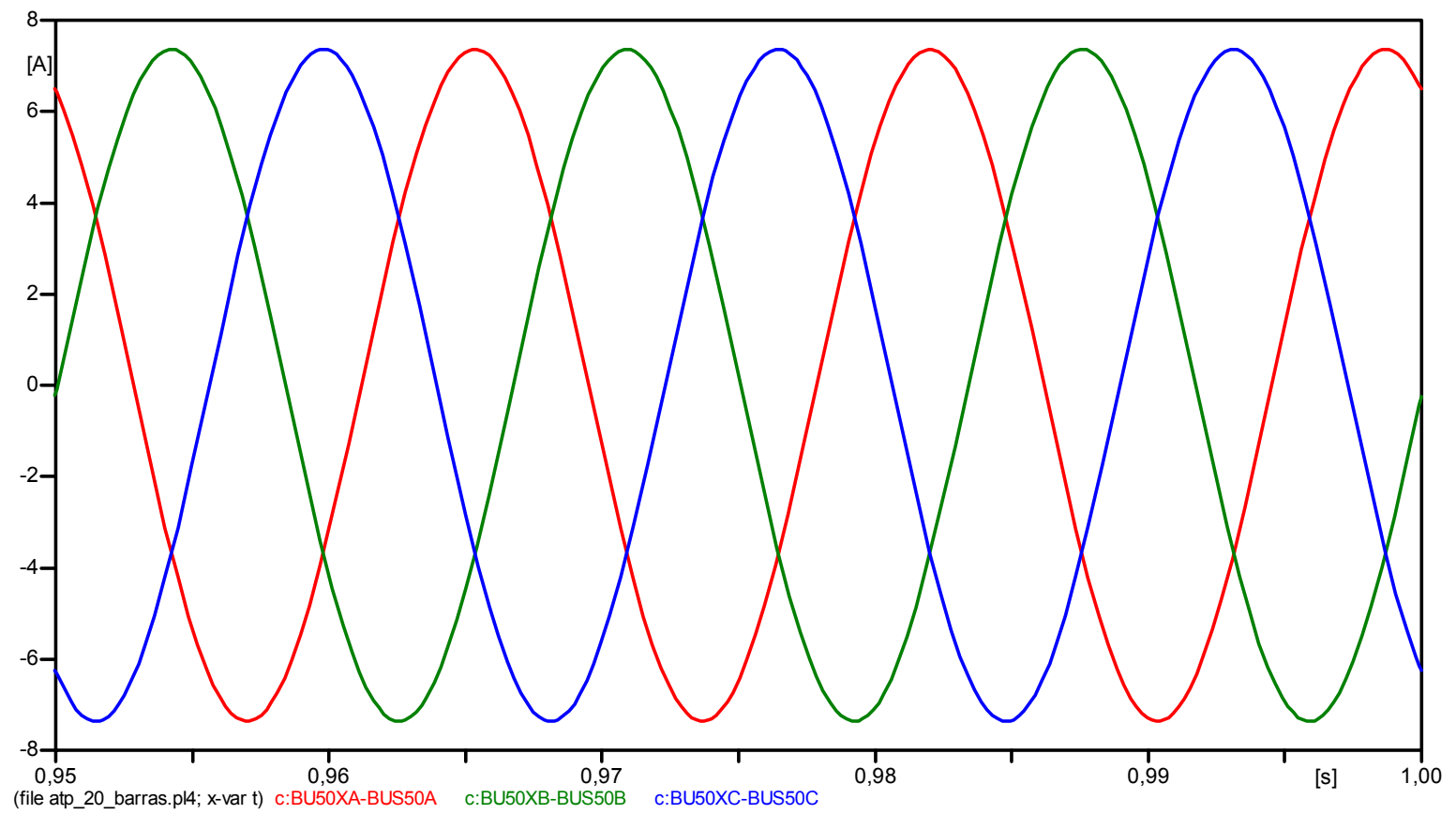

Figura 3.29 - Corrente instantânea trifásica (fase-terra) medida no final do alimentador para o estudo de caso 3 (dado histórico).

A simulação que representa o estado atual deste estudo de caso conta com uma carga não linear (retificador) alocada na barra 34. Este retificador foi alocado no 
sistema a fim de alimentar uma carga RL, sendo esta parametrizada com $1300 \Omega$ e $200 \mathrm{mH}$. Desta forma, foram medidas as correntes fundamental e harmônicas na entrada do retificador, as quais podem ser visualizadas por meio da Tabela 3.10.

Tabela 3.10 - Assinatura harmônica de corrente da carga não linear alocada na barra 34 para o estudo de caso 3.

\begin{tabular}{|c|c|c|c|}
\hline Fundamental e Harmônicas & $\begin{array}{c}\text { Amplitude (Ipico) } \\
\text { Fase A [A] }\end{array}$ & $\begin{array}{c}\text { Amplitude (Ipico) } \\
\text { Fase B [A] }\end{array}$ & $\begin{array}{c}\text { Amplitude (Ipico) } \\
\text { Fase C [A] }\end{array}$ \\
\hline 1 & 27,922 & 28,085 & 27,96 \\
\hline 3 & 0,083991 & 0,17505 & 0,093931 \\
\hline 5 & 6,2727 & 6,1661 & 6,2899 \\
\hline 7 & 3,0053 & 3,1771 & 3,0538 \\
\hline 9 & 0,094306 & 0,18167 & 0,091193 \\
\hline 11 & 2,5111 & 2,4162 & 2,5642 \\
\hline 13 & 1,686 & 1,8692 & 1,7534 \\
\hline
\end{tabular}

Além disso, para a obtenção dos dados atuais deste estudo de caso, algumas cargas RL tiveram suas impedâncias alteradas com o intuito de gerar variações no carregamento da rede. Assim, apresenta-se a Tabela 3.11, onde são mostradas as barras que sofreram com variações de impedância.

Tabela 3.11 - Barras que sofreram variações de impedância durante a simulação dos dados que representam o estado atual da rede para o estudo de caso 3.

\begin{tabular}{|c|c|c|c|}
\hline Barra & Fase A & Fase B & Fase C \\
\hline 30 & $-15 \%$ & $+15 \%$ & $-15 \%$ \\
\hline 31 & $-10 \%$ & $-10 \%$ & $+10 \%$ \\
\hline 40 & $+5 \%$ & $+5 \%$ & $+5 \%$ \\
\hline 52 & $+8 \%$ & $-8 \%$ & $+8 \%$ \\
\hline
\end{tabular}

Cabe comentar que os percentuais de variação de carregamento foram gerados de forma aleatória e que estas variações foram feitas somente na parte resistiva das cargas, isto é, somente a potência ativa consumida foi modificada. 
As formas de onda medidas tanto na subestação como no final do alimentador foram obtidas e são mostradas nas Figuras de 3.30 a 3.33 .

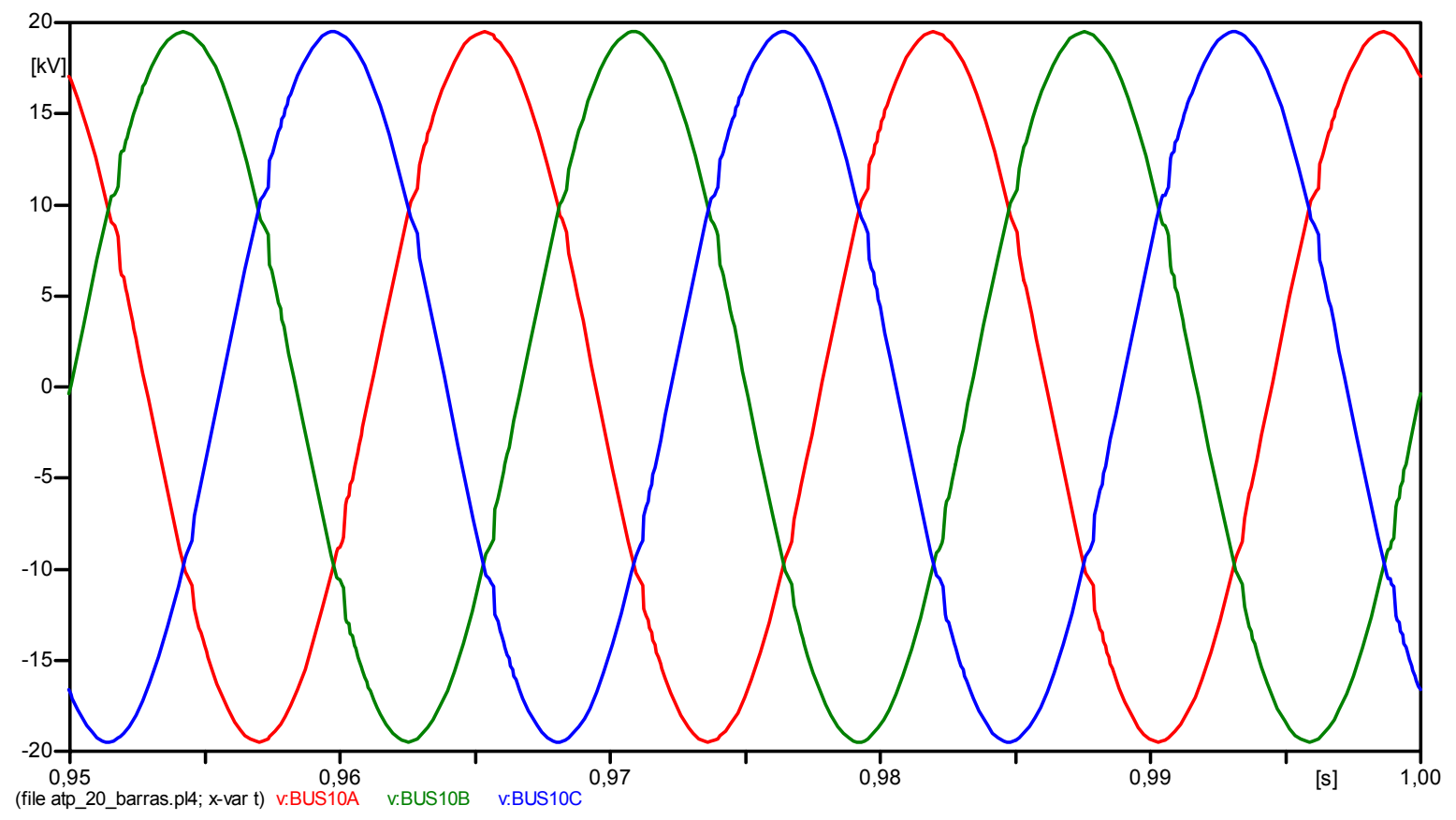

Figura 3.30 - Tensão instantânea trifásica (fase-terra) medida na subestação para o estudo de caso 3 (dado atual).

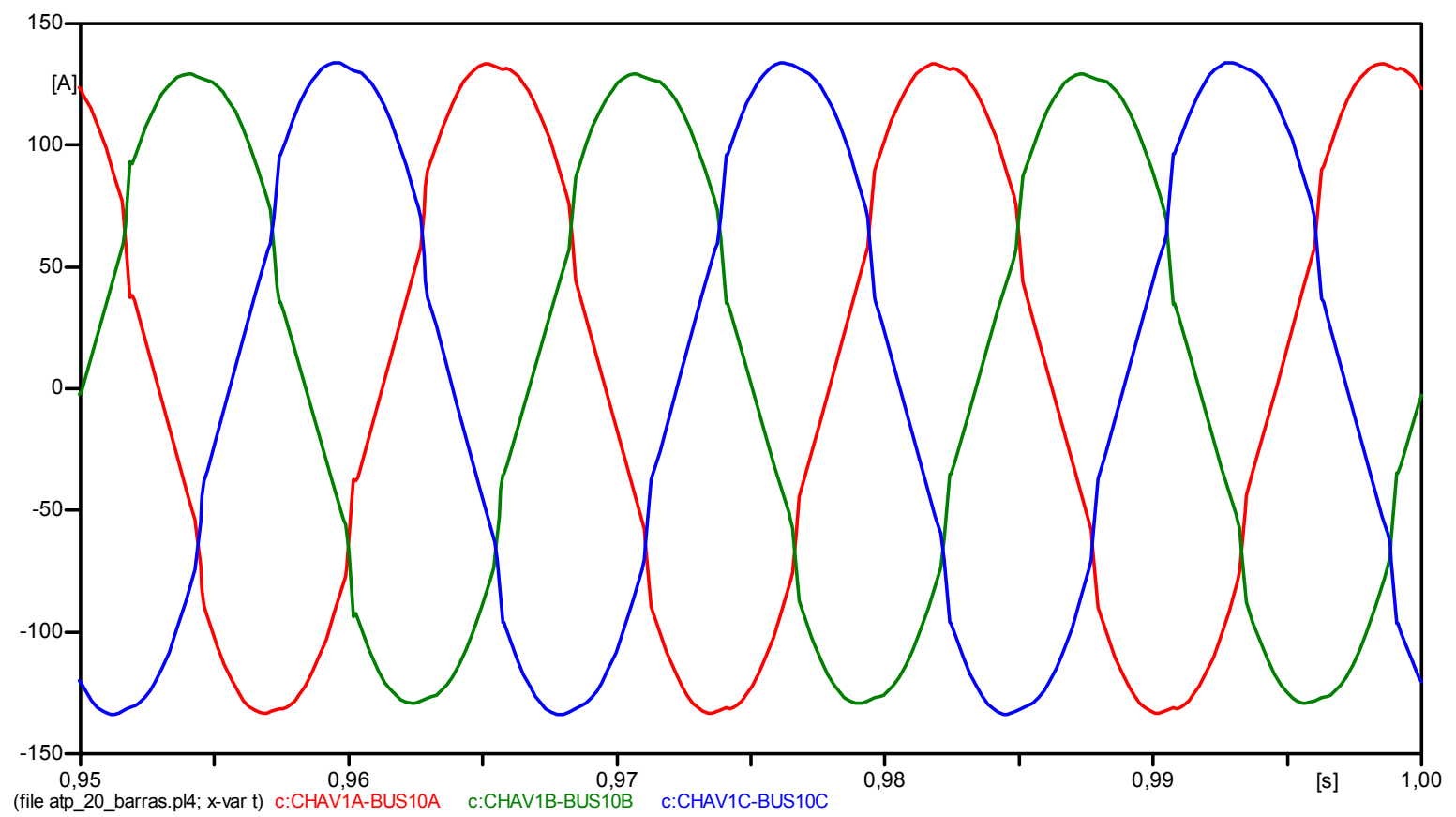

Figura 3.31 - Corrente instantânea trifásica (fase-terra) medida na subestação para o estudo de caso 3 (dado atual). 


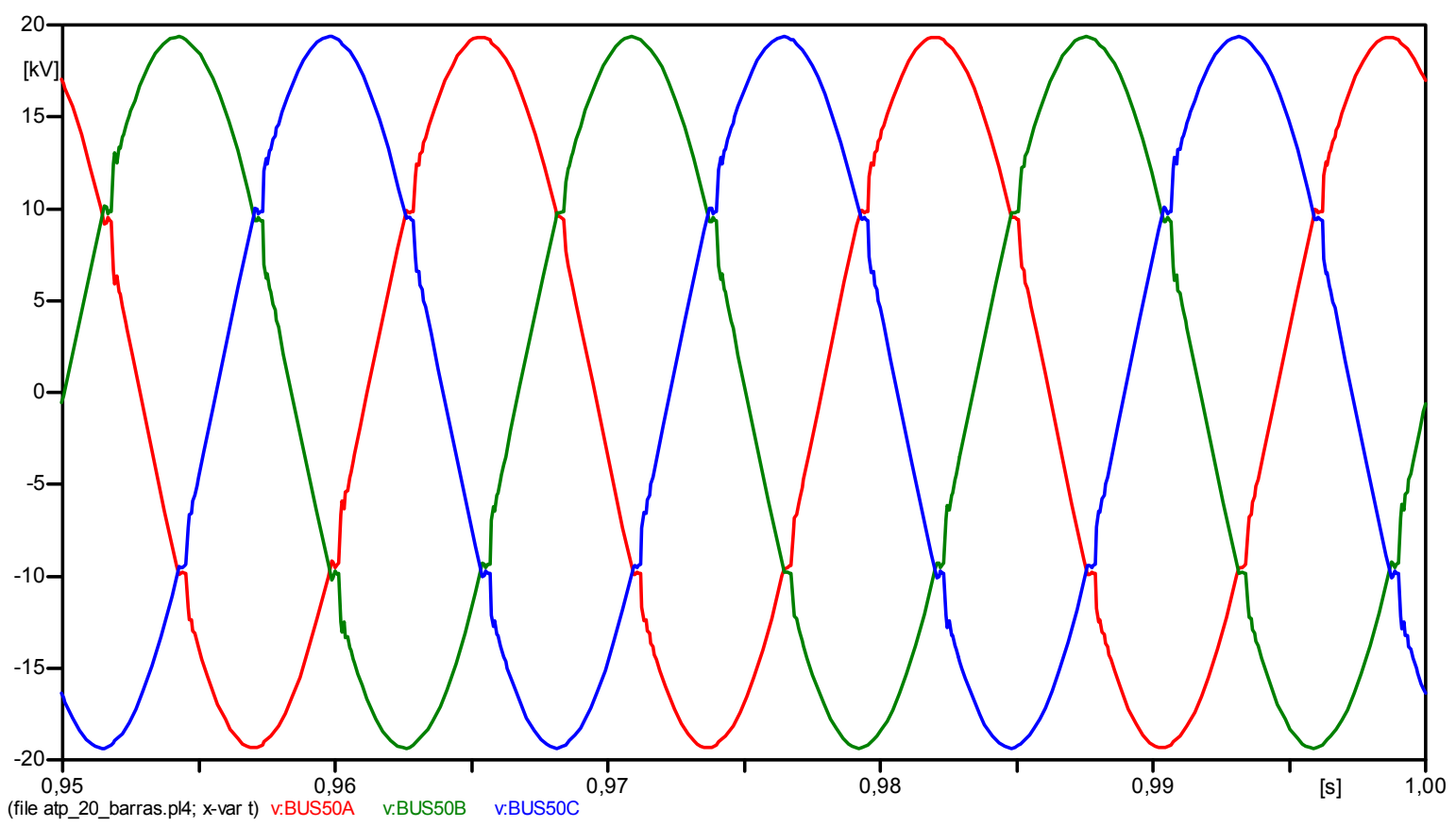

Figura 3.32 - Tensão instantânea trifásica (fase-terra) medida no final do alimentador para o estudo de caso 3 (dado atual).

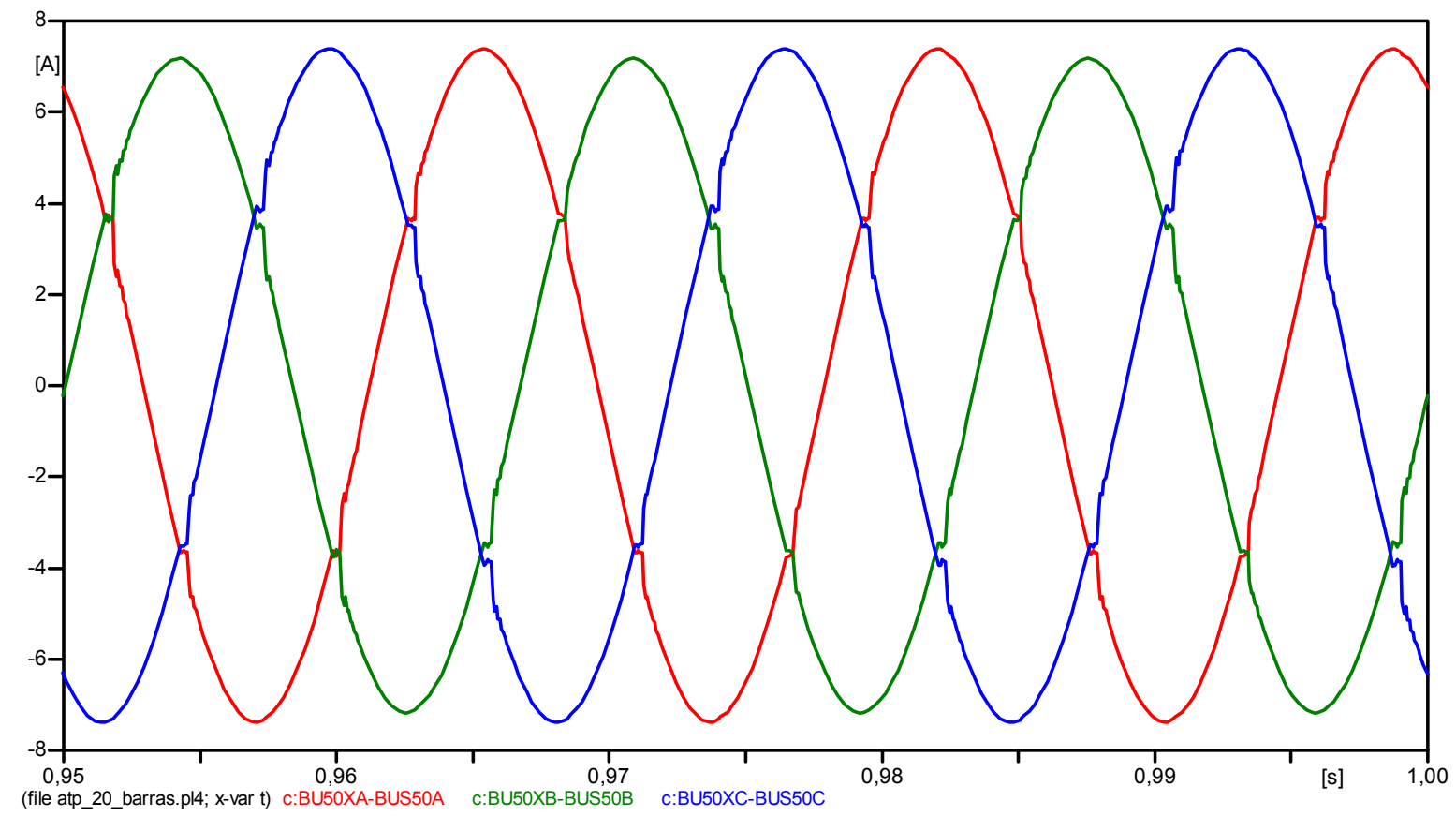

Figura 3.33 - Corrente instantânea trifásica (fase-terra) medida no final do alimentador para o estudo de caso 3 (dado atual).

Em relação ao estudo de caso 3, verificou-se que as DHTs calculadas para as tensões medidas na subestação foram de $0,92 \%$ (fase $A$ ), 1,11\% (fase B) e 
0,99\% (fase C). A seguir, apresenta-se a Tabela 3.12, onde são mostrados os níveis de tensão tanto da fundamental como das harmônicas (somente ímpares até $13^{a}$ ordem) medidas na subestação para cada uma das fases.

Tabela 3.12 - Componentes fundamental e harmônicas de tensão medidas na subestação para o estudo de caso 3.

\begin{tabular}{|c|c|c|c|}
\hline Fundamental e Harmônicas & $\begin{array}{c}\text { Amplitude (Vpico) } \\
\text { Fase A [V] }\end{array}$ & $\begin{array}{c}\text { Amplitude (Vpico) } \\
\text { Fase B [V] }\end{array}$ & $\begin{array}{c}\text { Amplitude (Vpico) } \\
\text { Fase C [V] }\end{array}$ \\
\hline 1 & 19430 & 19492 & 19444 \\
\hline 3 & 30,352 & 53,065 & 31,12 \\
\hline 5 & 61,72 & 90,749 & 86,432 \\
\hline 7 & 57,84 & 67,173 & 50,549 \\
\hline 9 & 8,7688 & 18,835 & 10,239 \\
\hline 11 & 61,992 & 46,923 & 59,103 \\
\hline 13 & 44,576 & 42,944 & 47,359 \\
\hline
\end{tabular}

\subsubsection{Estudo de Caso 4}

O quarto estudo de caso foi gerado de modo a apresentar os mesmos dados históricos obtidos para o estudo de caso 3. Portanto, consideram-se as formas de onda apresentadas nas Figuras de 3.26 a 3.29 (sem distorção harmônica).

Já a simulação que representa o estado atual deste estudo de caso conta com uma carga não linear (retificador) alocada na barra 53. Este retificador foi alocado no sistema a fim de alimentar uma carga $R C$, sendo esta parametrizada com $800 \Omega$ e 1000 uF. Desta forma, foram medidas as correntes fundamental e harmônicas na entrada do retificador, as quais podem ser visualizadas por meio da Tabela 3.13. 
Tabela 3.13 - Assinatura harmônica de corrente da carga não linear alocada na barra 53 para o estudo de caso 4.

\begin{tabular}{|c|c|c|c|}
\hline Fundamental e Harmônicas & $\begin{array}{c}\text { Amplitude (Ipico) } \\
\text { Fase A [A] }\end{array}$ & $\begin{array}{c}\text { Amplitude (Ipico) } \\
\text { Fase B [A] }\end{array}$ & $\begin{array}{c}\text { Amplitude (Ipico) } \\
\text { Fase C [A] }\end{array}$ \\
\hline 1 & 44,446 & 45,61 & 44,898 \\
\hline 3 & 0,35875 & 0,44443 & 0,7948 \\
\hline 5 & 21,303 & 21,523 & 21,765 \\
\hline 7 & 10,675 & 10,304 & 10,4 \\
\hline 9 & 0,43704 & 0,14895 & 0,45499 \\
\hline 11 & 3,6088 & 3,7039 & 3,8396 \\
\hline 13 & 2,481 & 2,4422 & 2,457 \\
\hline
\end{tabular}

Além disso, para a obtenção dos dados atuais deste estudo de caso, a tensão nominal da fonte foi variada em $-7 \%$ na fase $A, 7 \%$ na fase $B$ e $-4 \%$ na fase C. Os dados atuais também contam com variações no carregamento da rede, sendo que as suas variações percentuais podem ser visualizadas na Tabela 3.14.

Tabela 3.14 - Barras que sofreram variações de impedância durante a simulação dos dados que representam o estado atual da rede para o estudo de caso 4.

\begin{tabular}{|c|c|c|c|}
\hline Barra & Fase A & Fase B & Fase C \\
\hline 30 & $+15 \%$ & $+15 \%$ & $-15 \%$ \\
\hline 31 & $+10 \%$ & $+10 \%$ & $-10 \%$ \\
\hline 40 & $+5 \%$ & $+5 \%$ & $+5 \%$ \\
\hline 52 & $+8 \%$ & $+8 \%$ & $-8 \%$ \\
\hline
\end{tabular}

De forma breve, pode-se dizer que o estado atual deste estudo de caso, conta com variações na tensão, variações no carregamento e também com uma carga não linear alocada na barra 53. Assim, as formas de onda medidas tanto na subestação como no final do alimentador foram obtidas e são mostradas nas Figuras de 3.34 a 3.37 . 


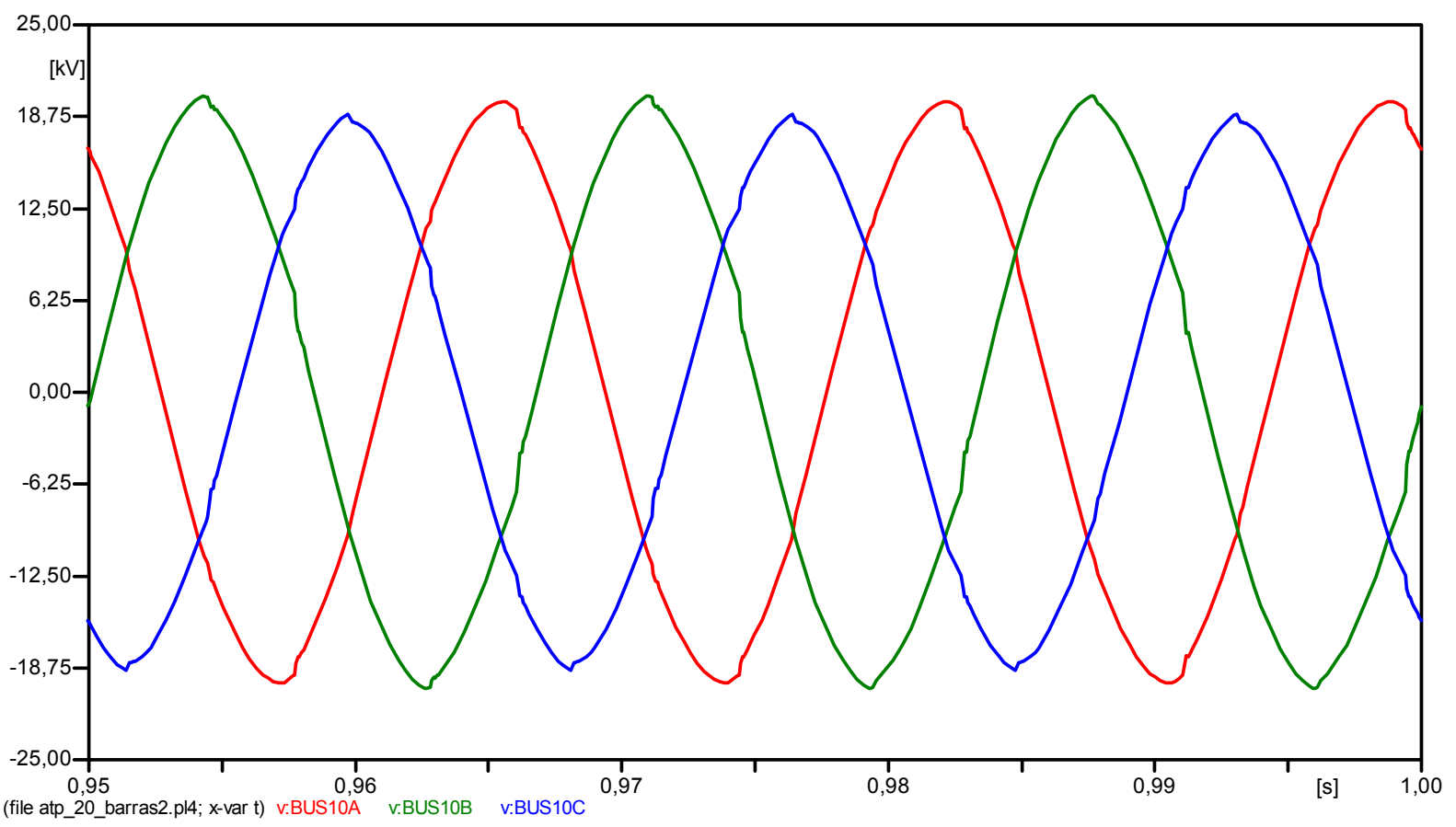

Figura 3.34 - Tensão instantânea trifásica (fase-terra) medida na subestação para o estudo de caso 4 (dado atual).

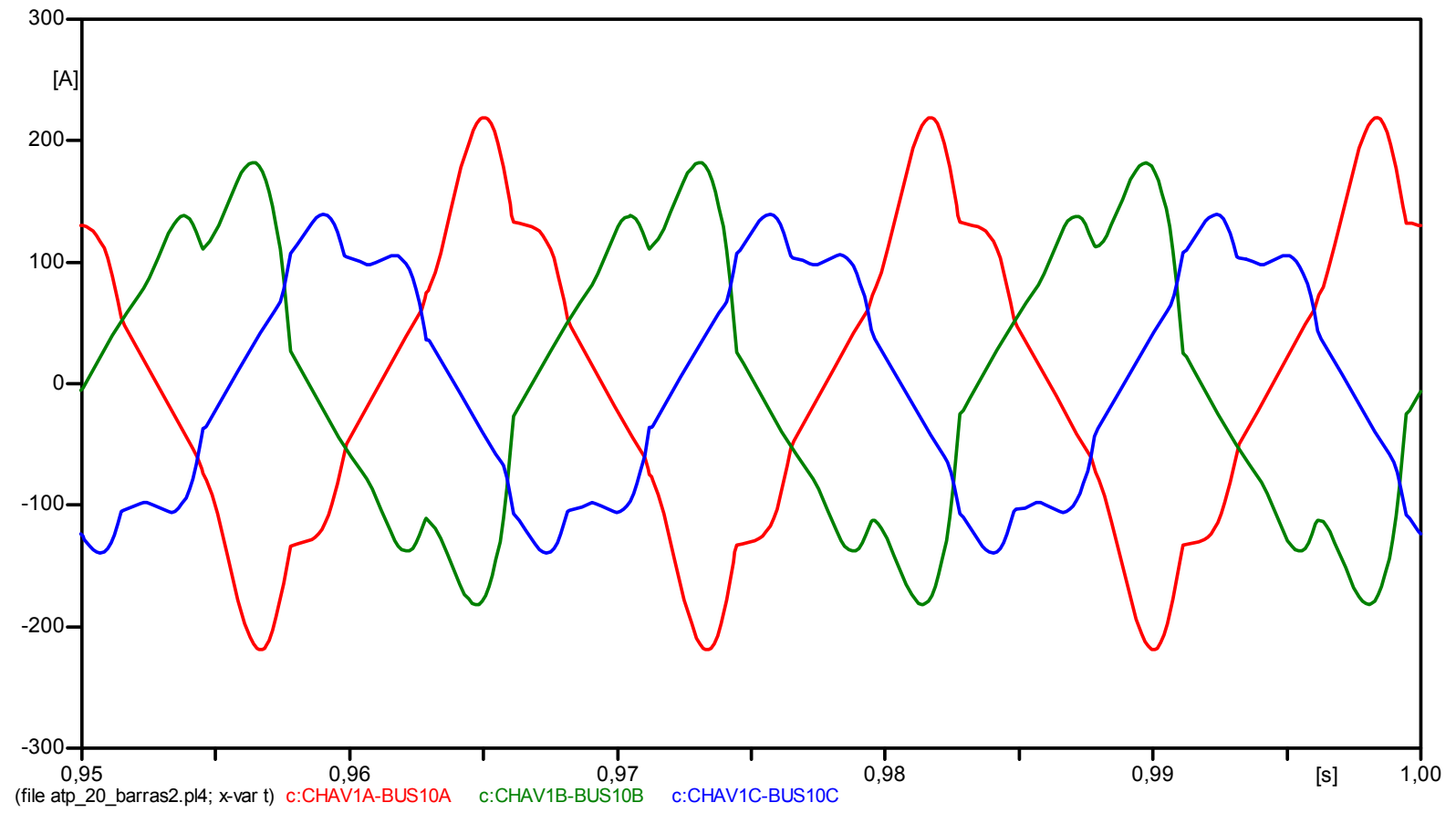

Figura 3.35 - Corrente instantânea trifásica (fase-terra) medida na subestação para o estudo de caso 4 (dado atual). 
67

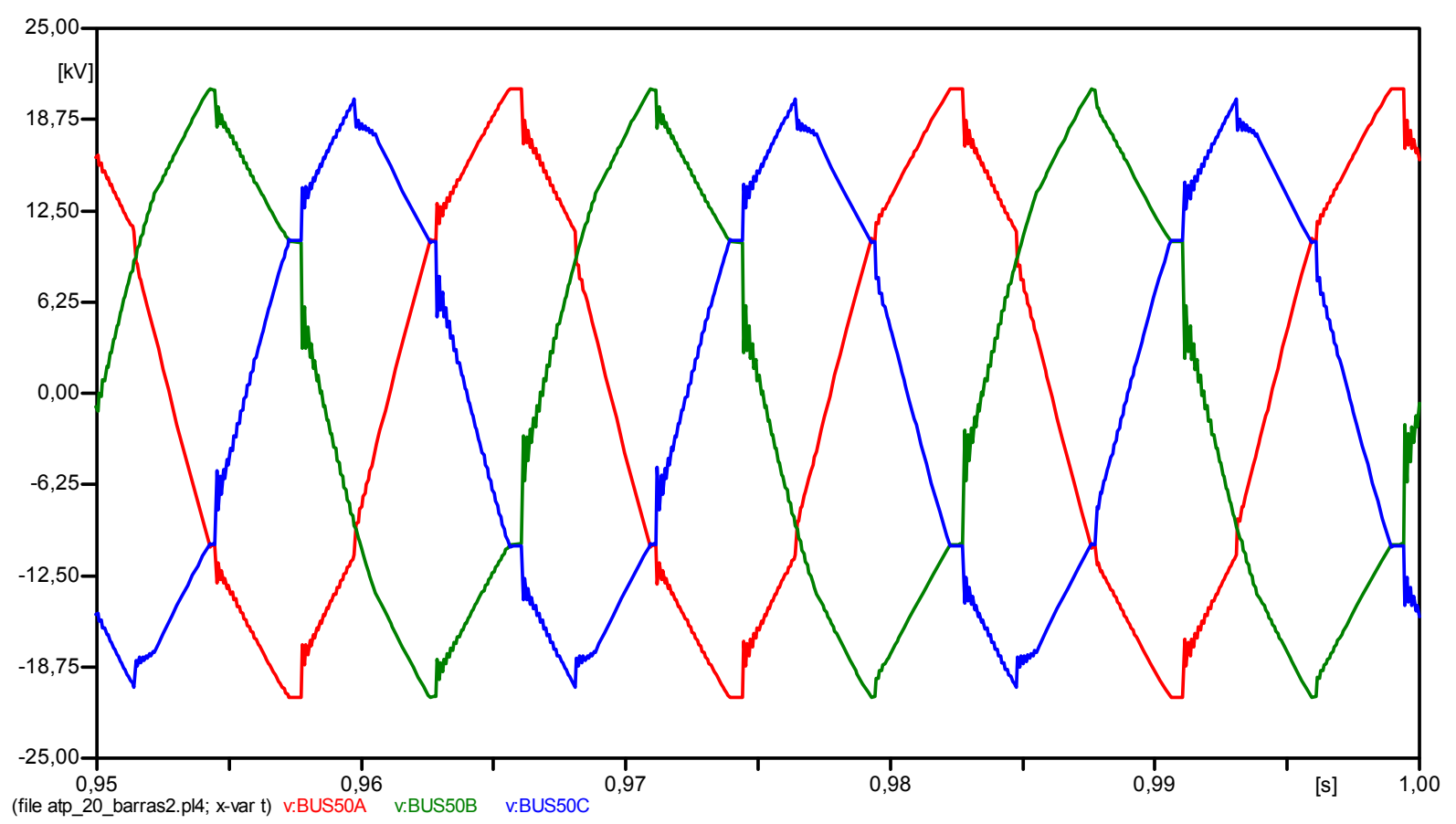

Figura 3.36 - Tensão instantânea trifásica (fase-terra) medida no final do alimentador para o estudo de caso 4 (dado atual).

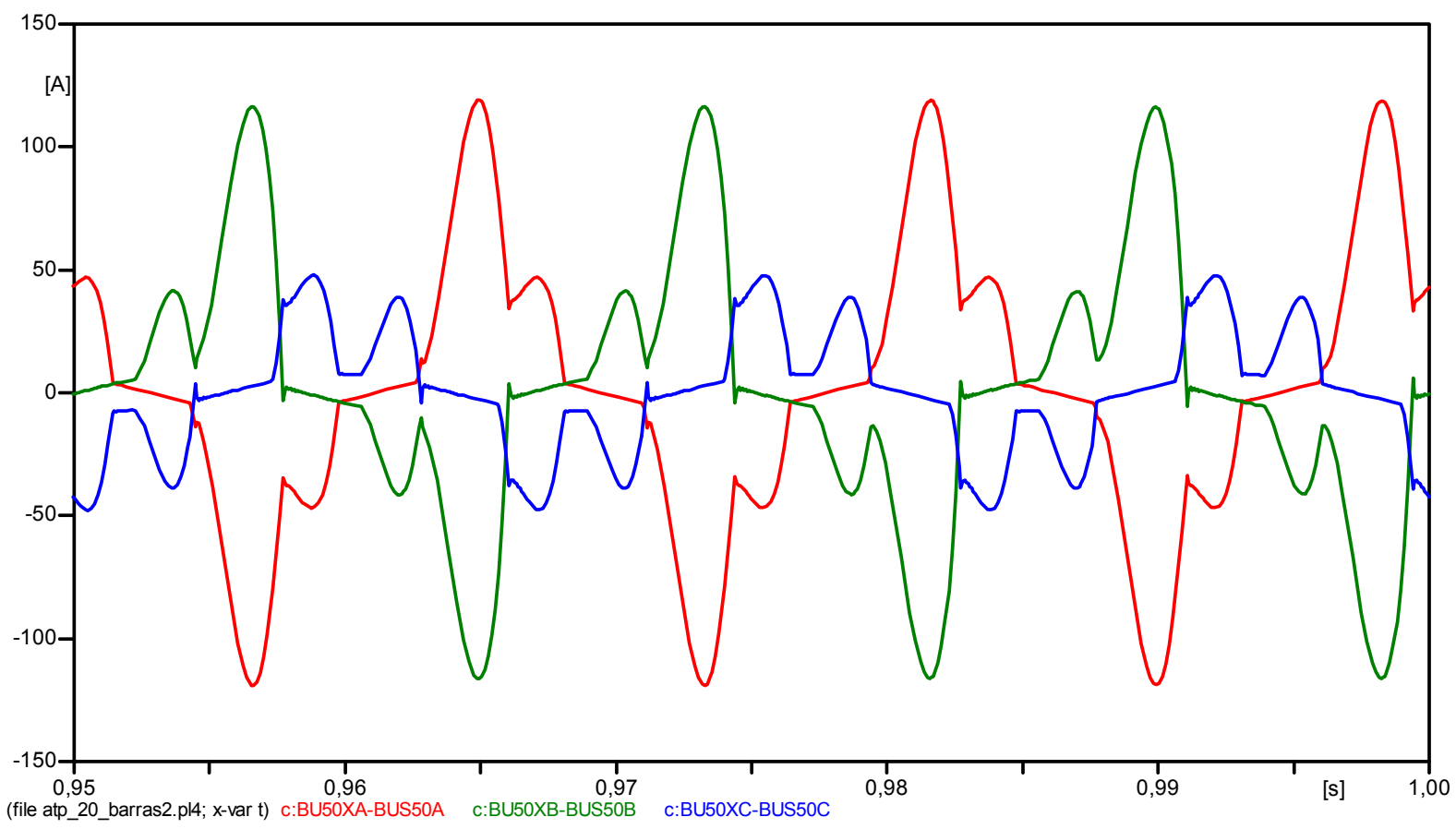

Figura 3.37 - Corrente instantânea trifásica (fase-terra) medida no final do alimentador para o estudo de caso 4 (dado atual).

Verificou-se para o estudo de caso 4 que as DHTs calculadas para as tensões medidas na subestação foram de 1,90\% (fase A), 2,46\% (fase B) e 1,46\% 
(fase C). A seguir, apresenta-se a Tabela 3.15, onde são mostrados os níveis de tensão tanto da fundamental como das harmônicas (somente ímpares até $13^{a}$ ordem) medidas na subestação para cada uma das fases.

Tabela 3.15 - Componentes fundamental e harmônicas de tensão medidas na subestação para o estudo de caso 4.

\begin{tabular}{|c|c|c|c|}
\hline Fundamental e Harmônicas & $\begin{array}{c}\text { Amplitude (Vpico) } \\
\text { Fase A [V] }\end{array}$ & $\begin{array}{c}\text { Amplitude (Vpico) } \\
\text { Fase B [V] }\end{array}$ & $\begin{array}{c}\text { Amplitude (Vpico) } \\
\text { Fase C [V] }\end{array}$ \\
\hline 1 & 19439 & 19718 & 18383 \\
\hline 3 & 215,72 & 225,81 & 82,503 \\
\hline 5 & 191,99 & 324,94 & 191,79 \\
\hline 7 & 159,47 & 120,66 & 44,41 \\
\hline 9 & 107,24 & 134,33 & 50,834 \\
\hline 11 & 44,688 & 96,638 & 67,707 \\
\hline 13 & 23,89 & 43,149 & 45,125 \\
\hline
\end{tabular}

\subsubsection{Estudo de Caso 5}

O quinto estudo de caso, diferente dos quatro primeiros previamente comentados, teve dados históricos gerados com distorções harmônicas, portanto, pressupõe-se que a rede já conta com cargas não lineares. Além disso, foi mantida a retirada do banco de capacitores da barra 42. Para gerar estes dados históricos com distorções harmônicas, alocou-se uma carga não linear na barra 34, a qual é composta por um retificador que alimenta uma carga $\mathrm{RL}$ com $1500 \Omega$ e $400 \mathrm{mH}$. Assim, as formas de onda medidas na subestação e no final do alimentador são mostradas nas Figuras de 3.38 a 3.41. 


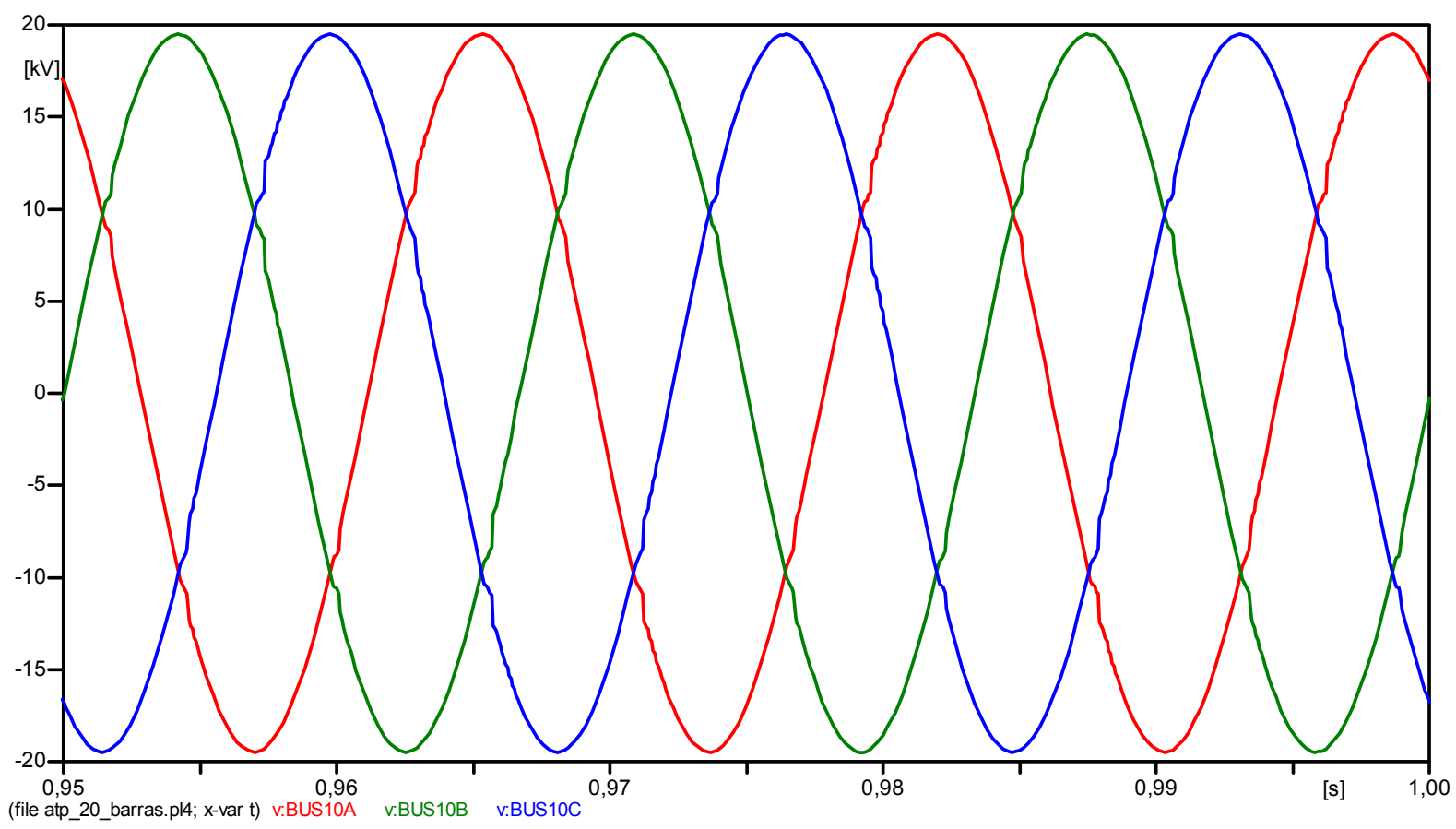

Figura 3.38 - Tensão instantânea trifásica (fase-terra) medida na subestação para o estudo de caso 5 (dado histórico).

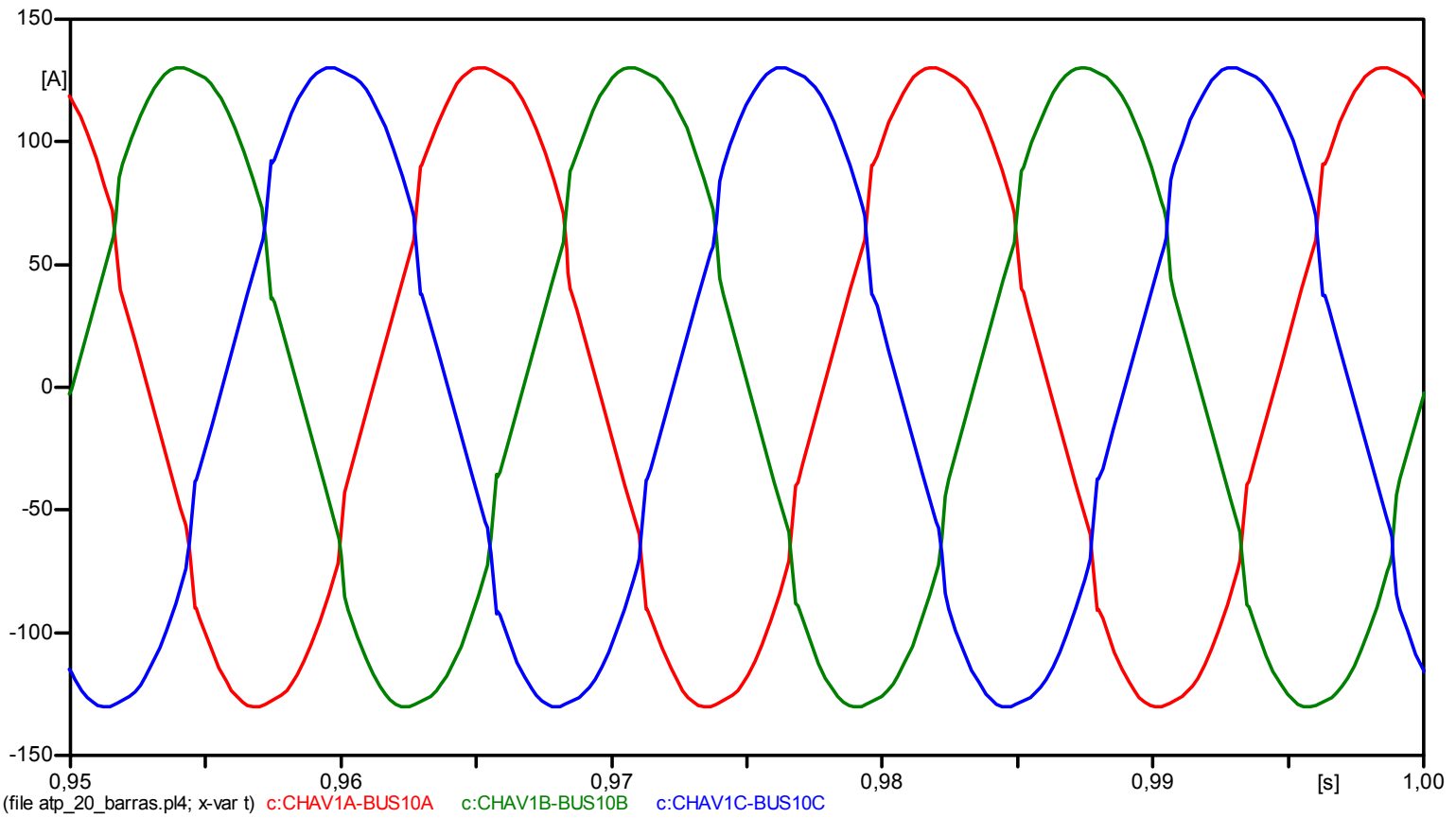

Figura 3.39 - Corrente instantânea trifásica (fase-terra) medida na subestação para o estudo de caso 5 (dado histórico). 


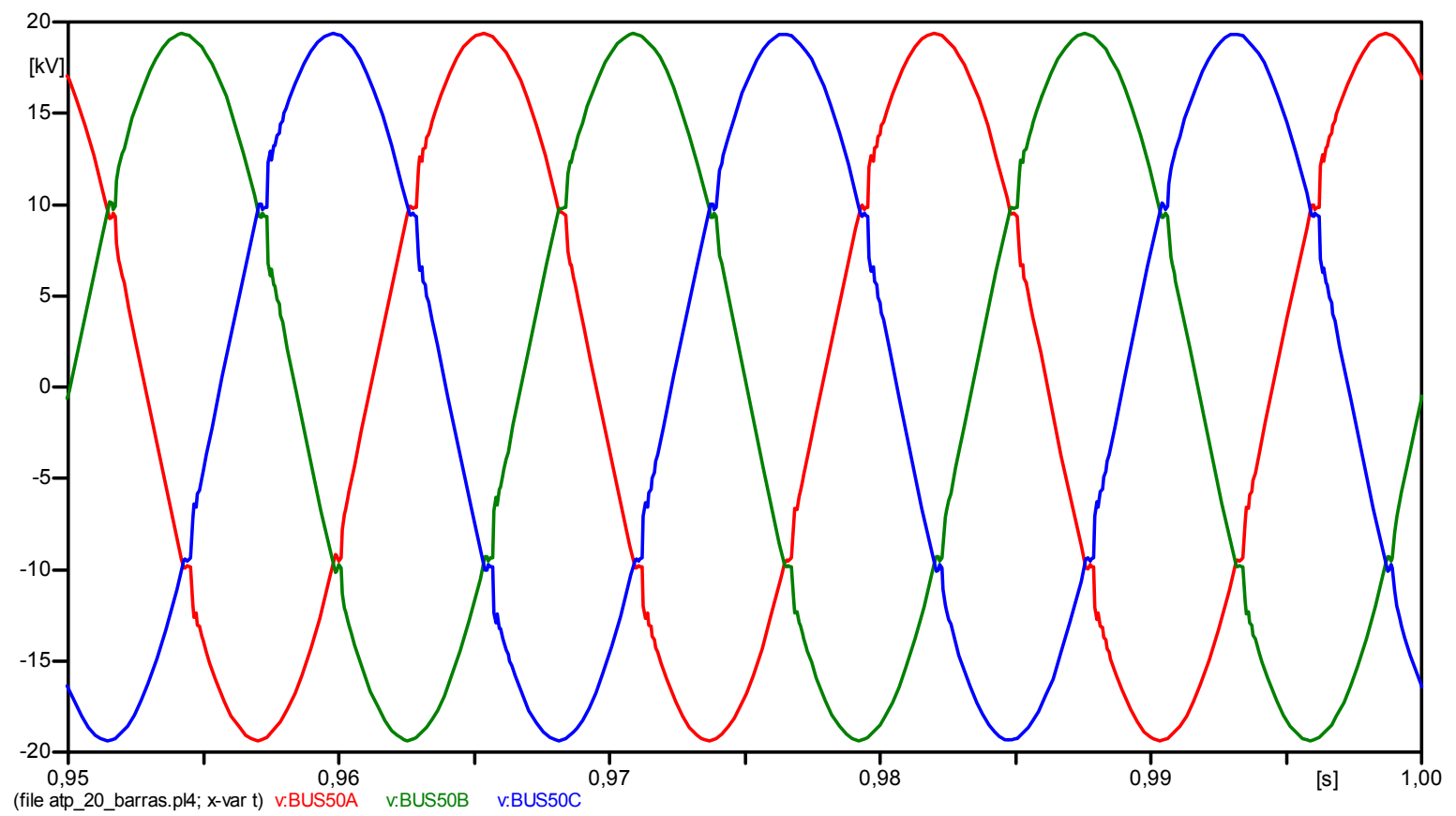

Figura 3.40 - Tensão instantânea trifásica (fase-terra) medida no final do alimentador para o estudo de caso 5 (dado histórico).

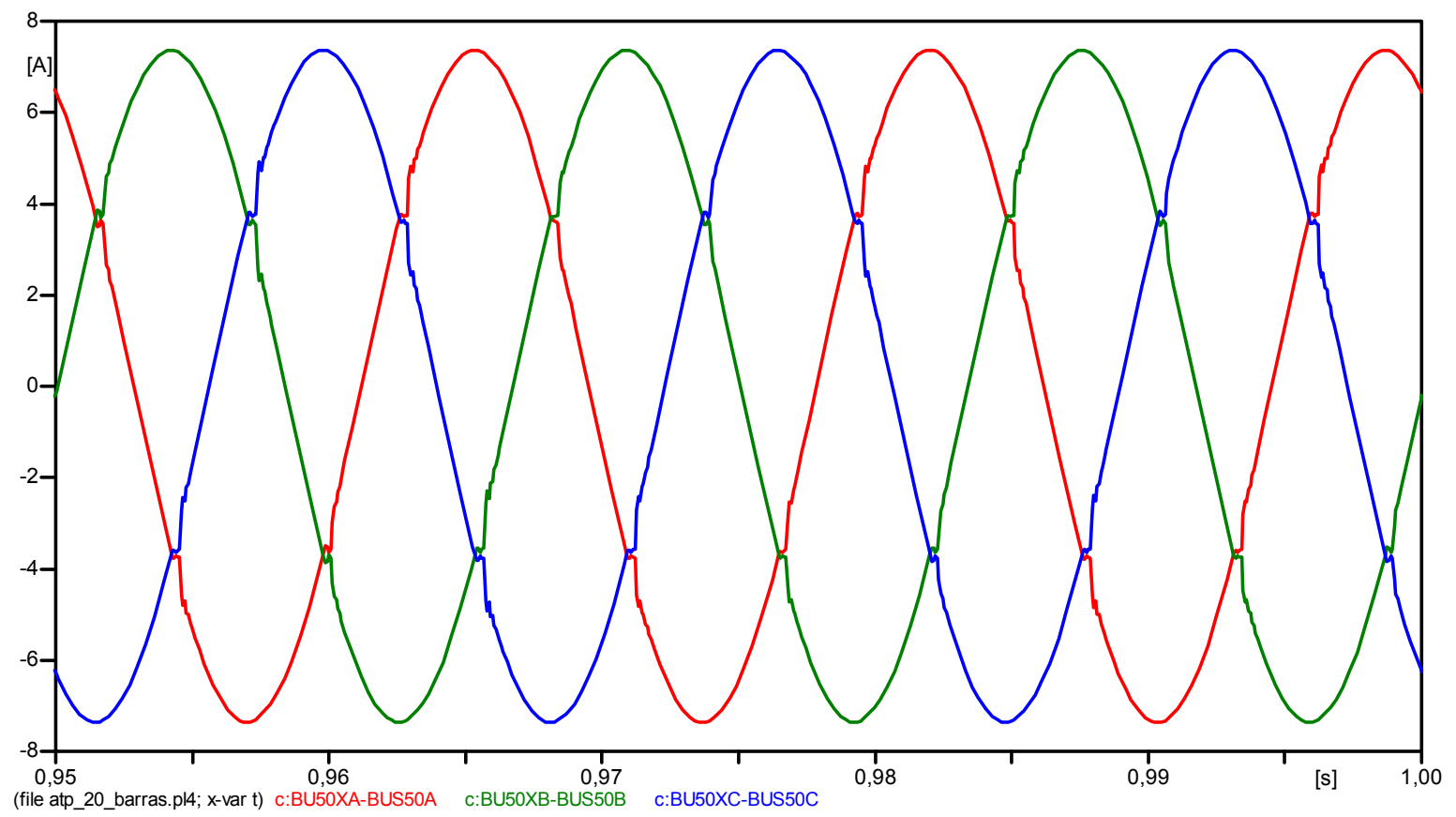

Figura 3.41 - Corrente instantânea trifásica (fase-terra) medida no final do alimentador para o estudo de caso 5 (dado histórico). 
Depois de obtidas as medidas de tensão da subestação, verificou-se que suas DHTs foram de 0,88\% (fase A), 1,04\% (fase B) e 0,88\% (fase C).

A simulação que representa o estado atual deste estudo de caso conta com uma carga não linear (retificador) alocada na barra 52. Este retificador foi alocado no sistema a fim de alimentar uma carga RL, sendo esta parametrizada com $1400 \Omega$ e $600 \mathrm{mH}$. Desta forma, foram medidas as correntes fundamental e harmônicas na entrada do retificador, as quais podem ser visualizadas por meio da Tabela 3.16.

Tabela 3.16 - Assinatura harmônica de corrente da carga não linear alocada na barra 52 para o estudo de caso 5.

\begin{tabular}{|c|c|c|c|}
\hline Fundamental e Harmônicas & $\begin{array}{c}\text { Amplitude (Ipico) } \\
\text { Fase A [A] }\end{array}$ & $\begin{array}{c}\text { Amplitude (Ipico) } \\
\text { Fase B [A] }\end{array}$ & $\begin{array}{c}\text { Amplitude (Ipico) } \\
\text { Fase C [A] }\end{array}$ \\
\hline 1 & 25,762 & 25,801 & 25,852 \\
\hline 3 & 0,084949 & 0,022207 & 0,08719 \\
\hline 5 & 5,5588 & 5,5617 & 5,5175 \\
\hline 7 & 2,8655 & 2,9506 & 2,9904 \\
\hline 9 & 0,076775 & 0,066179 & 0,085823 \\
\hline 11 & 2,1524 & 2,176 & 2,15 \\
\hline 13 & 1,541 & 1,647 & 1,6853 \\
\hline
\end{tabular}

Além disso, para a obtenção dos dados atuais deste estudo de caso, a tensão nominal da fonte foi variada em $+3 \%$ na fase $A,-6 \%$ na fase $B$ e $+9 \%$ na fase C. Os dados atuais também contam com variações no carregamento da rede e, desta forma, as variações percentuais nas impedâncias de determinadas barras podem ser visualizadas na Tabela 3.17. 
Tabela 3.17 - Barras que sofreram variações de impedância durante a simulação dos dados que representam o estado atual da rede para o estudo de caso 5.

\begin{tabular}{|c|c|c|c|}
\hline Barra & Fase A & Fase B & Fase C \\
\hline 41 & $-9 \%$ & $-9 \%$ & $-9 \%$ \\
\hline 23 & $-15 \%$ & $-15 \%$ & $-15 \%$ \\
\hline 21 & $-10 \%$ & $-10 \%$ & $-10 \%$ \\
\hline 34 & $-12 \%$ & $-12 \%$ & $+12 \%$ \\
\hline
\end{tabular}

Portanto, o estado atual deste estudo de caso conta com variações no carregamento e tensão da rede, além de uma carga não linear alocada na barra 52 . As formas de onda medidas tanto na subestação como no final do alimentador são mostradas nas Figuras de 3.42 a 3.45 .

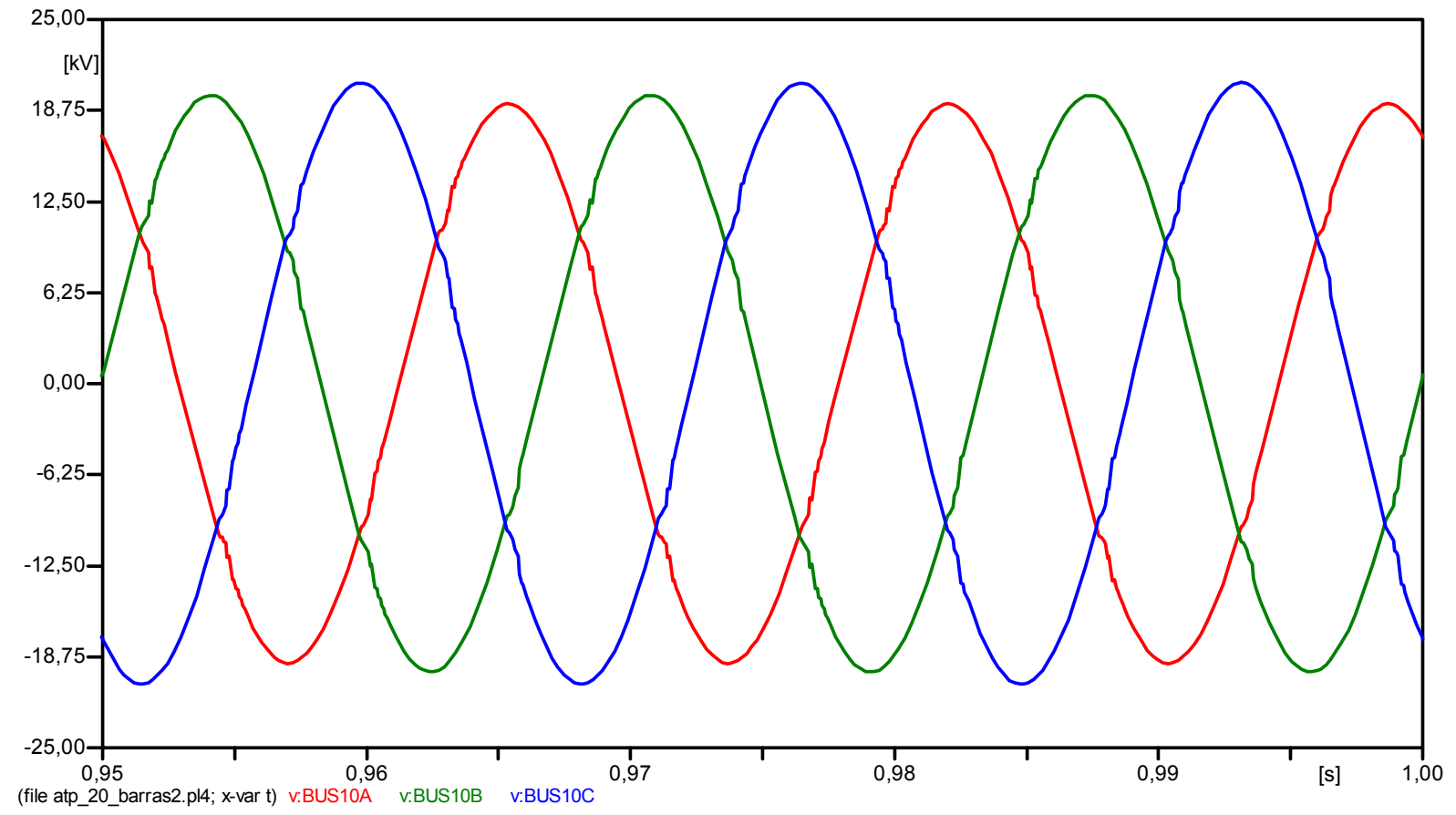

Figura 3.42 - Tensão instantânea trifásica (fase-terra) medida na subestação para o estudo de caso 5 (dado atual). 


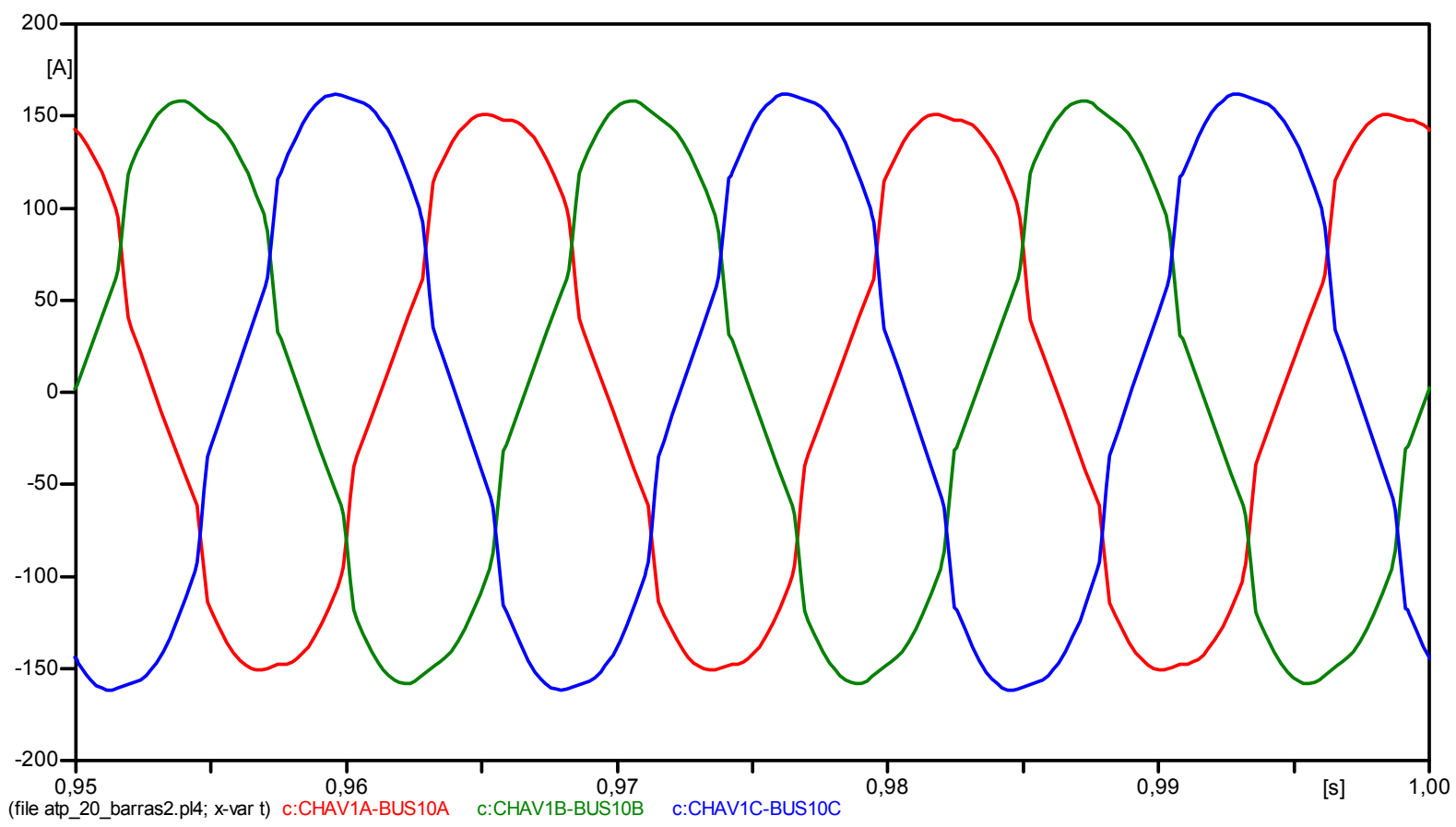

Figura 3.43 - Corrente instantânea trifásica (fase-terra) medida na subestação para o estudo de caso 5 (dado atual).

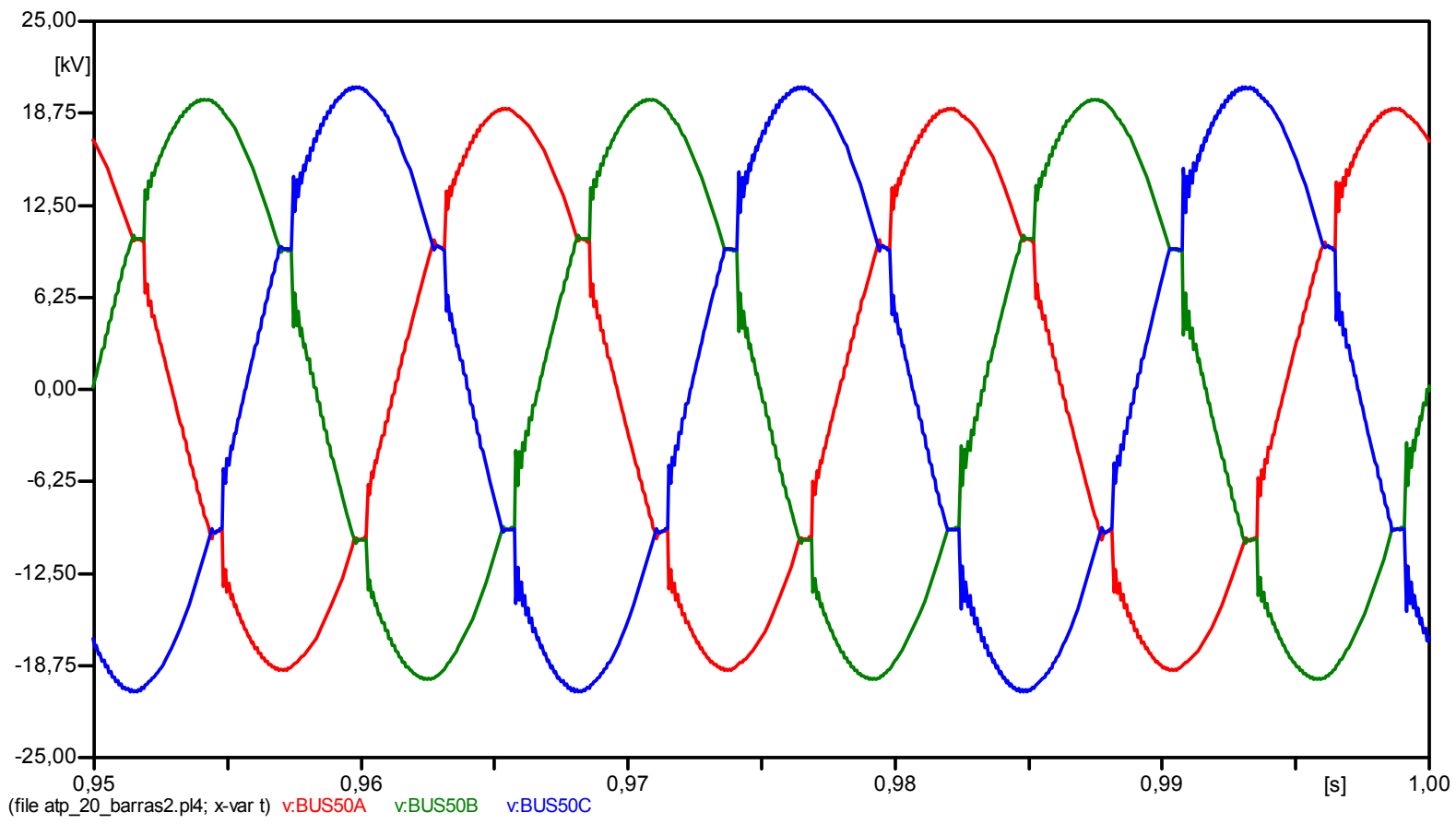

Figura 3.44 - Tensão instantânea trifásica (fase-terra) medida no final do alimentador para o estudo de caso 5 (dado atual). 


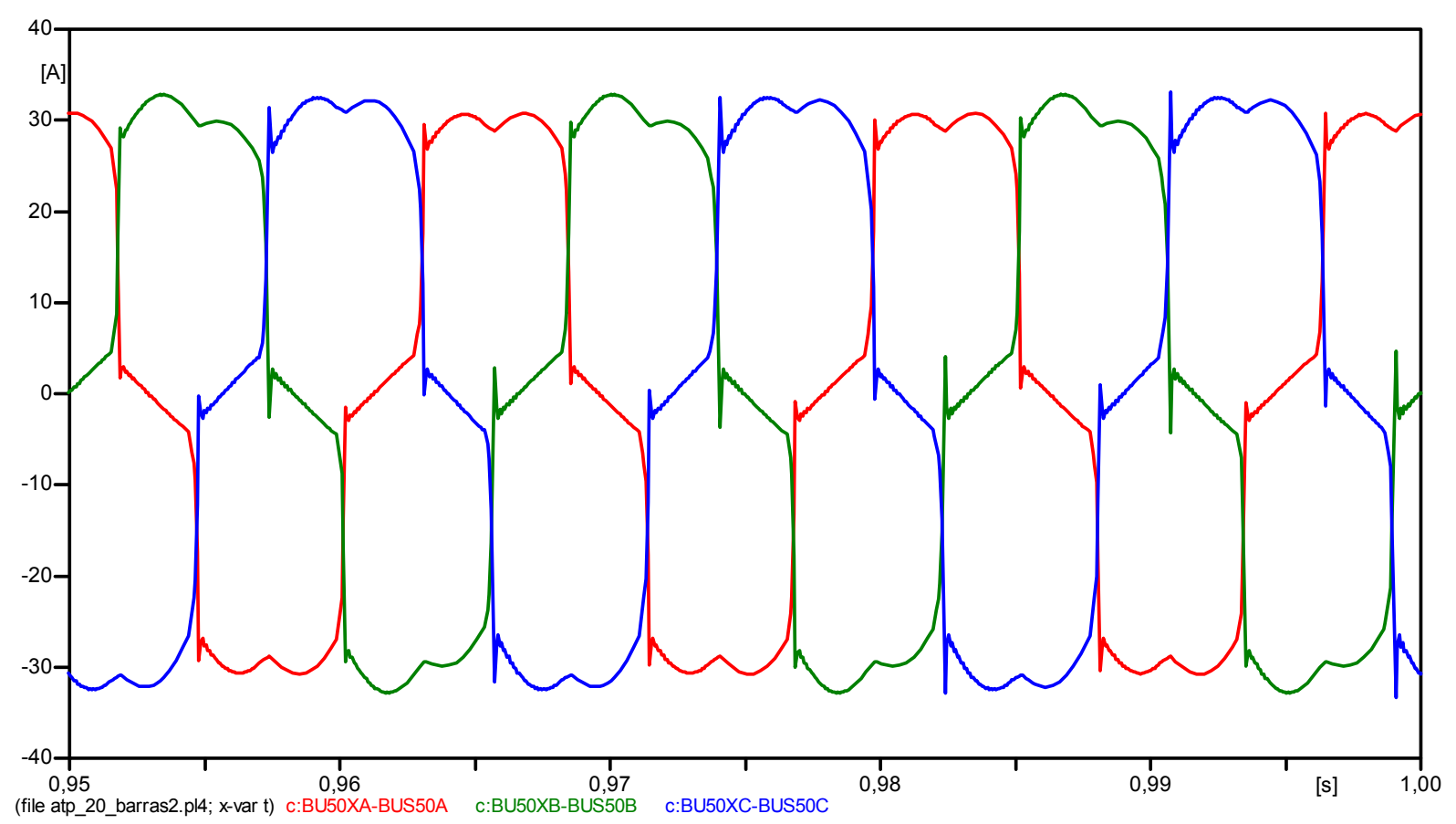

Figura 3.45 - Corrente instantânea trifásica (fase-terra) medida no final do alimentador para o estudo de caso 5 (dado atual).

Em relação ao estudo de caso 5, verificou-se que as DHTs calculadas para as tensões medidas na subestação durante o estado atual da rede foram de $1,38 \%$ (fase A), 1,45\% (fase B) e 1,28\% (fase C). A Tabela 3.18 mostra os níveis de tensão tanto da fundamental como das harmônicas (somente ímpares até $13^{a}$ ordem) medidas na subestação para cada uma das fases.

Tabela 3.18 - Componentes fundamental e harmônicas de tensão medidas na subestação para o estudo de caso 5.

\begin{tabular}{|c|c|c|c|}
\hline Fundamental e Harmônicas & $\begin{array}{c}\text { Amplitude (Vpico) } \\
\text { Fase A [V] }\end{array}$ & $\begin{array}{c}\text { Amplitude (Vpico) } \\
\text { Fase B [V] }\end{array}$ & $\begin{array}{c}\text { Amplitude (Vpico) } \\
\text { Fase C [V] }\end{array}$ \\
\hline 10 & 19134 & 19784 & 20591 \\
\hline 3 & 25,624 & 46,616 & 39,655 \\
\hline 5 & 124,85 & 144,79 & 128,95 \\
\hline 7 & 85,014 & 105,9 & 102,2 \\
\hline 9 & 36,217 & 17,479 & 22,987 \\
\hline 11 & 111,53 & 85,923 & 74,565 \\
\hline 13 & 58,568 & 72,944 & 92,72 \\
\hline
\end{tabular}




\subsubsection{Estudo de Caso 6}

O sexto estudo de caso tem certa semelhança com o estudo de caso 5; no entanto, o banco de capacitores volta a ser alocado no sistema, porém, na barra 20 . A dita semelhança entre os estudos de caso 5 e 6 pode ser observada na obtenção dos dados históricos que já possuem algum conteúdo harmônico, bem como na variação de carga e tensão quando da obtenção dos dados atuais da rede.

A fim de gerar os dados que correspondem ao histórico da rede, um retificador foi alocado na barra 34, o qual alimentou uma carga $R L$ com $500 \Omega$ e 200 $\mathrm{mH}$. As formas de onda medidas na subestação e no final do alimentador são mostradas nas Figuras de 3.46 a 3.49 .

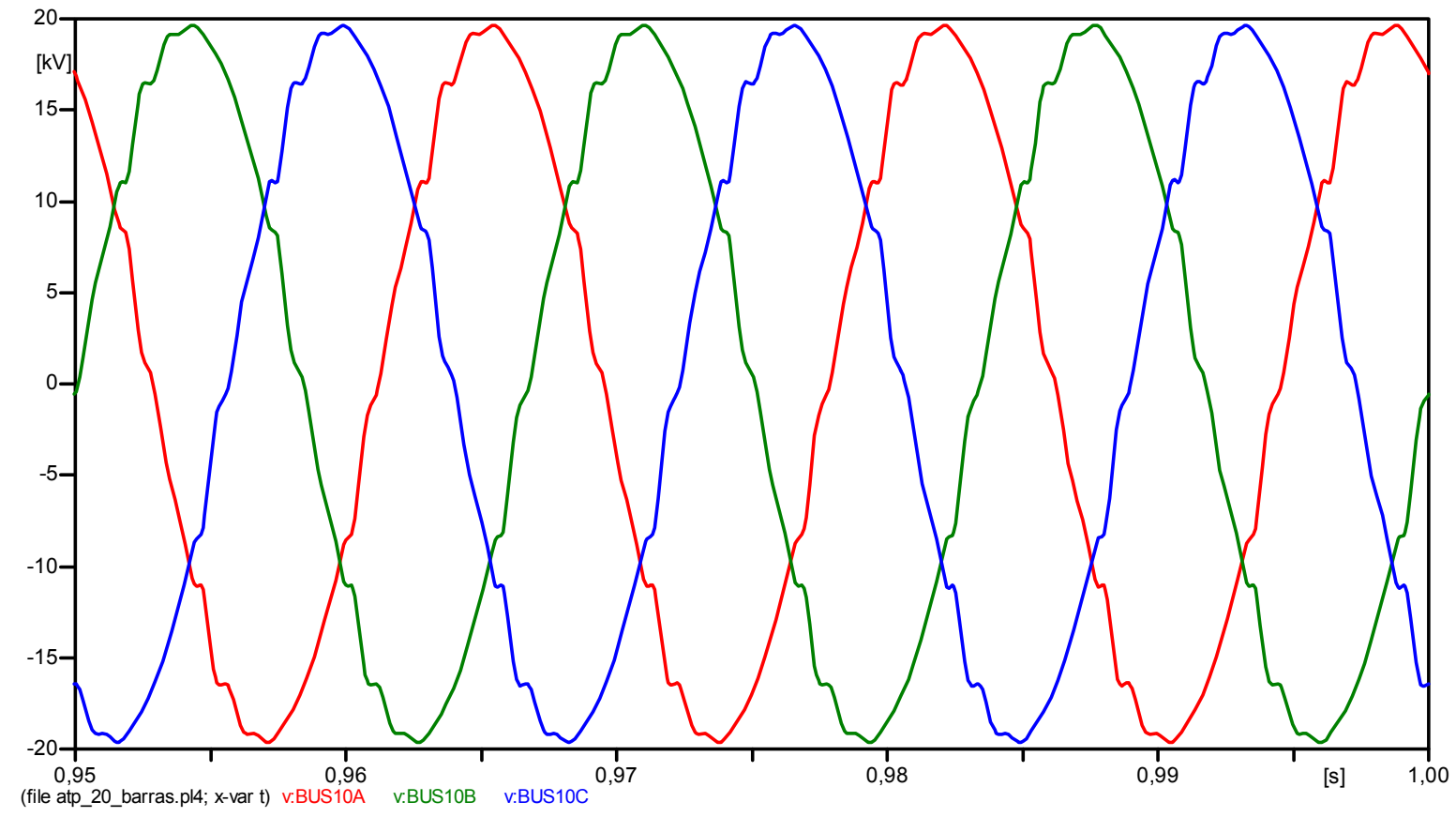

Figura 3.46 - Tensão instantânea trifásica (fase-terra) medida na subestação para o estudo de caso 6 (dado histórico). 


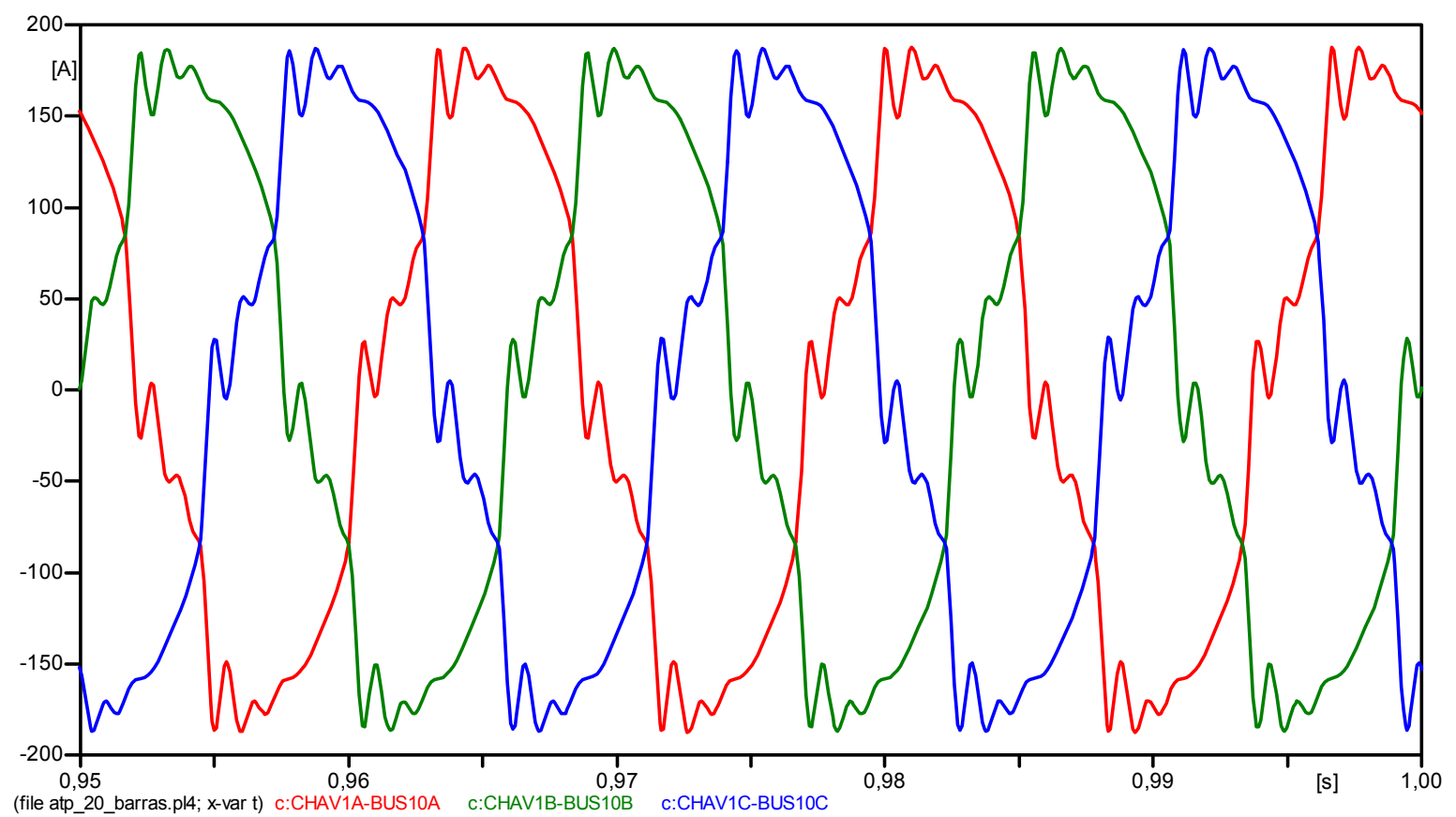

Figura 3.47 - Corrente instantânea trifásica (fase-terra) medida na subestação para o estudo de caso 6 (dado histórico).

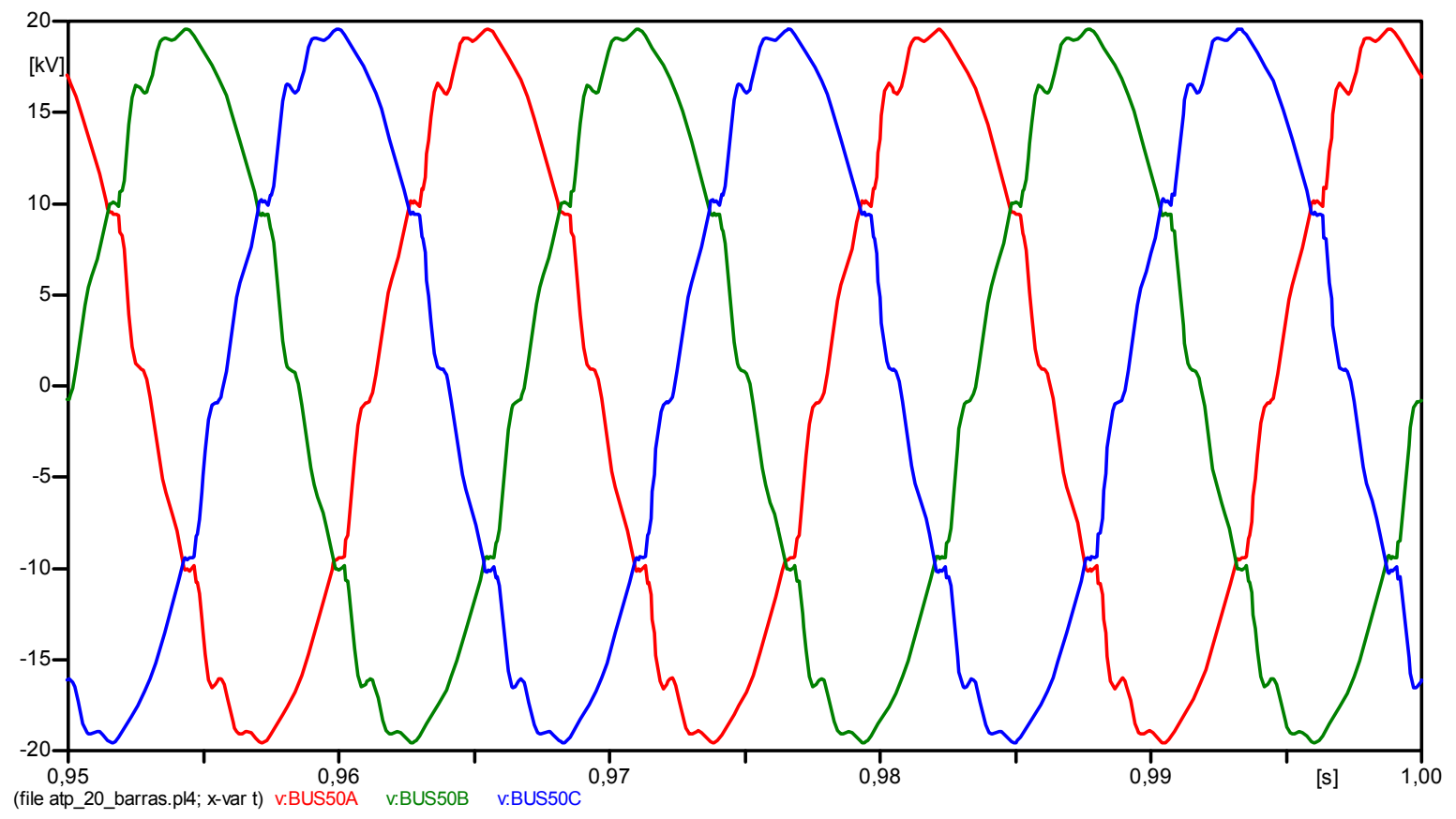

Figura 3.48 - Tensão instantânea trifásica (fase-terra) medida no final do alimentador para o estudo de caso 6 (dado histórico). 


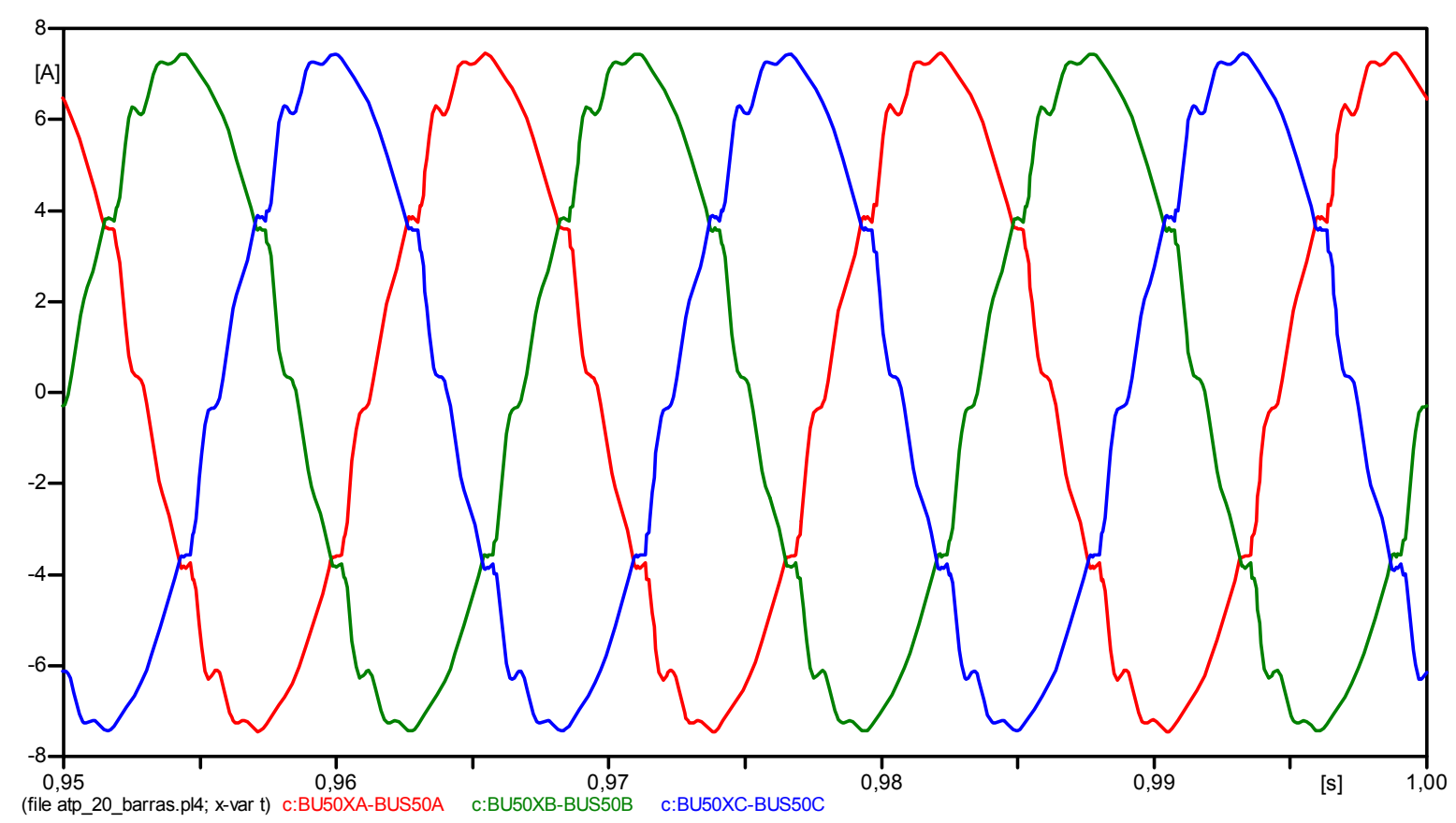

Figura 3.49 - Corrente instantânea trifásica (fase-terra) medida no final do alimentador para o estudo de caso 6 (dado histórico).

Obtidas as medidas de tensão da subestação, verificou-se então que suas DHTs foram de 3,58\% (fase A), 3,56\% (fase B) e 3,49\% (fase C).

A simulação que representa o estado atual deste estudo de caso conta com uma carga não linear (retificador) alocada na barra 42. Este retificador foi alocado no sistema para alimentar uma carga RL parametrizada com $1200 \Omega$ e $400 \mathrm{mH}$. Desta forma, foram medidas as correntes fundamental e harmônicas na entrada do retificador, as quais podem ser visualizadas por meio da Tabela 3.19. 
Tabela 3.19 - Assinatura harmônica de corrente da carga não linear alocada na barra 42 para o estudo de caso 6.

\begin{tabular}{|c|c|c|c|}
\hline Fundamental e Harmônicas & $\begin{array}{c}\text { Amplitude (Ipico) } \\
\text { Fase A [A] }\end{array}$ & $\begin{array}{c}\text { Amplitude (Ipico) } \\
\text { Fase B [A] }\end{array}$ & $\begin{array}{c}\text { Amplitude (Ipico) } \\
\text { Fase C [A] }\end{array}$ \\
\hline 1 & 29,65 & 30,029 & 29,71 \\
\hline 3 & 0,27716 & 0,43734 & 0,16215 \\
\hline 5 & 6,5488 & 6,269 & 6,4888 \\
\hline 7 & 2,9737 & 3,3319 & 2,961 \\
\hline 9 & 0,22478 & 0,35548 & 0,16201 \\
\hline 11 & 2,2789 & 2,1265 & 2,2631 \\
\hline 13 & 1,4375 & 1,6915 & 1,3557 \\
\hline
\end{tabular}

Além disso, para a obtenção dos dados atuais deste estudo de caso, a tensão nominal da fonte foi variada em $+4 \%$ na fase $A,+2 \%$ na fase $B$ e $+2 \%$ na fase C. Os dados atuais também contam com variações no carregamento da rede e, desta forma, as variações percentuais nas impedâncias de determinadas barras podem ser visualizadas na Tabela 3.20.

Tabela 3.20 - Barras que sofreram variações de impedância durante a simulação dos dados que representam o estado atual da rede para o estudo de caso 6.

\begin{tabular}{|c|c|c|c|}
\hline Barra & Fase A & Fase B & Fase C \\
\hline 41 & $+8 \%$ & $-8 \%$ & $+8 \%$ \\
\hline 53 & $-15 \%$ & sem variação & sem variação \\
\hline 33 & sem variação & sem variação & $-7 \%$ \\
\hline 34 & $-10 \%$ & $+15 \%$ & $-4 \%$ \\
\hline
\end{tabular}

De forma breve, pode-se dizer que o estado atual deste estudo de caso conta com variações no carregamento e tensão da rede, além de uma carga não linear alocada na barra 42. As formas de onda medidas tanto na subestação como no final do alimentador puderam ser obtidas e são mostradas nas Figuras de 3.50 a 3.53. 


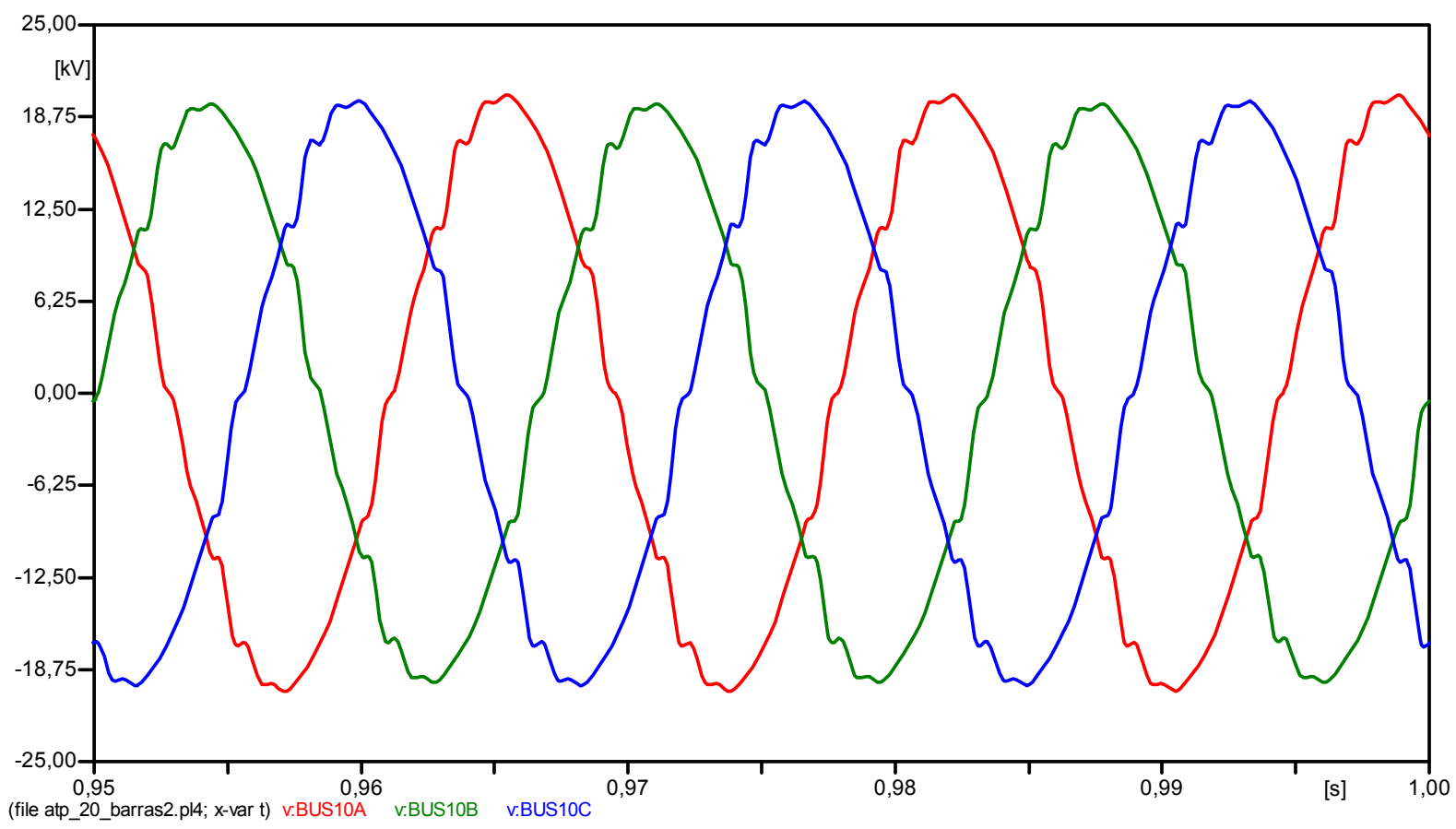

Figura 3.50 - Tensão instantânea trifásica (fase-terra) medida na subestação para o estudo de caso 6 (dado atual).

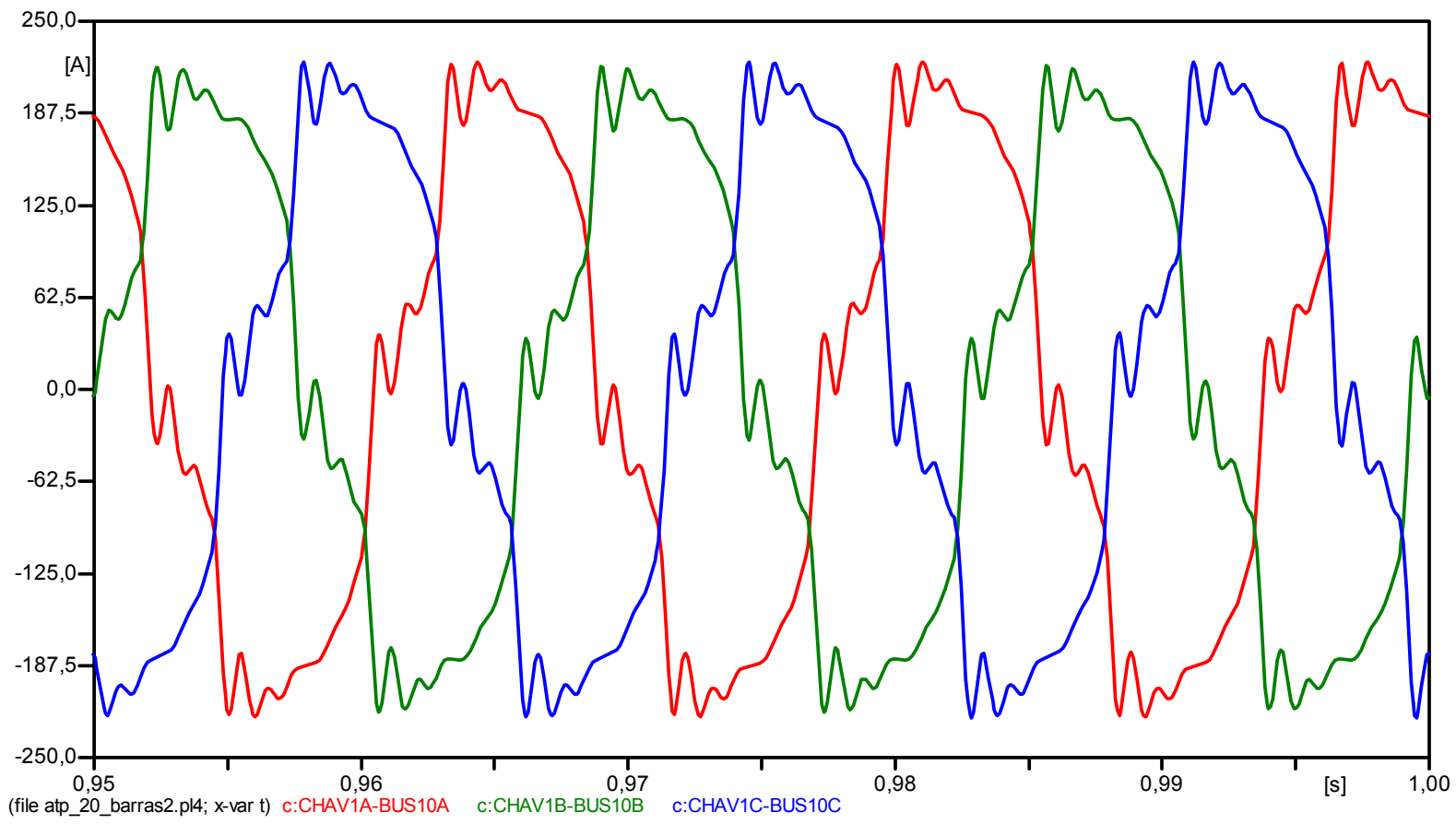

Figura 3.51 - Corrente instantânea trifásica (fase-terra) medida na subestação para o estudo de caso 6 (dado atual). 


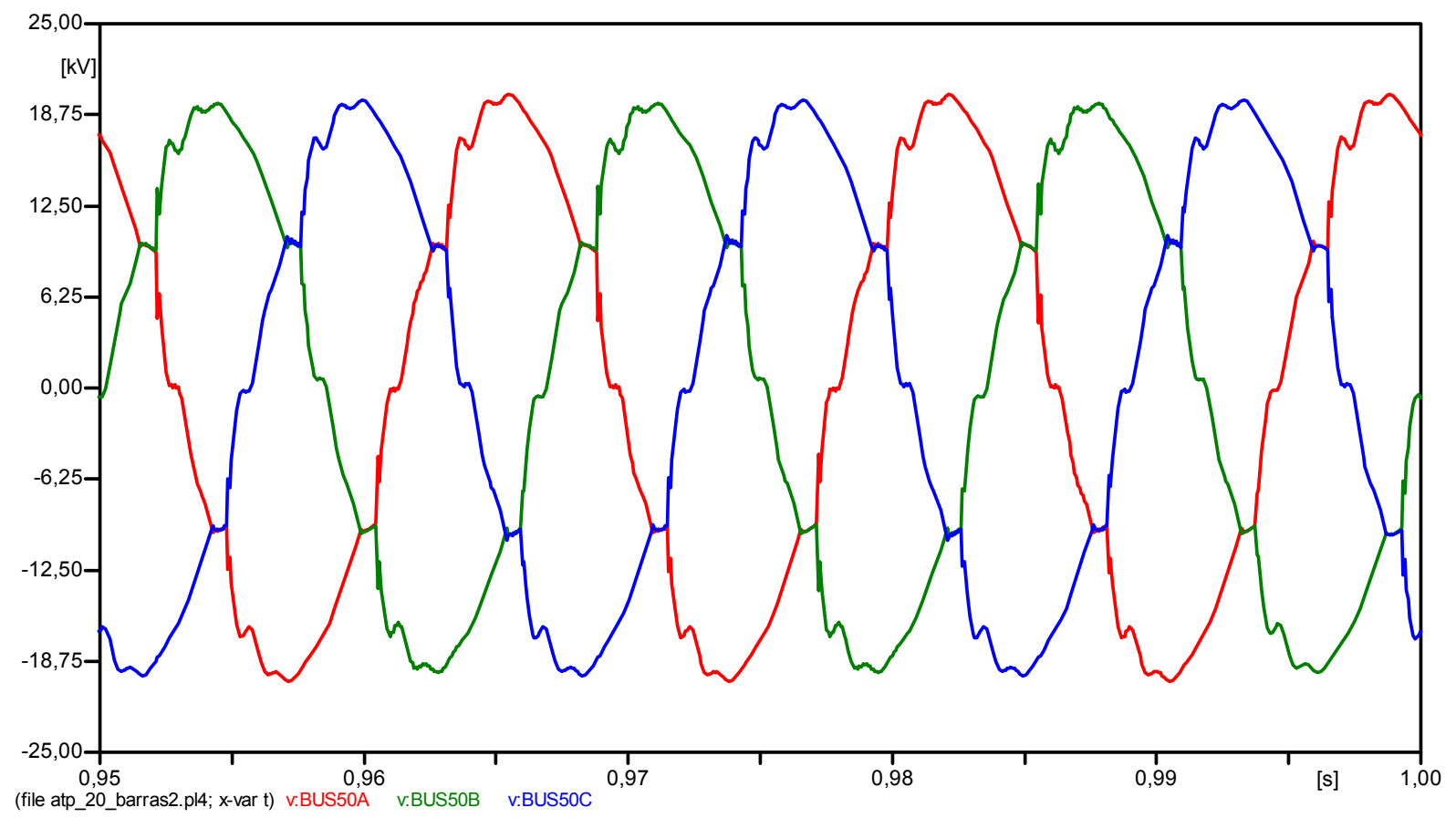

Figura 3.52 - Tensão instantânea trifásica (fase-terra) medida no final do alimentador para o estudo de caso 6 (dado atual).

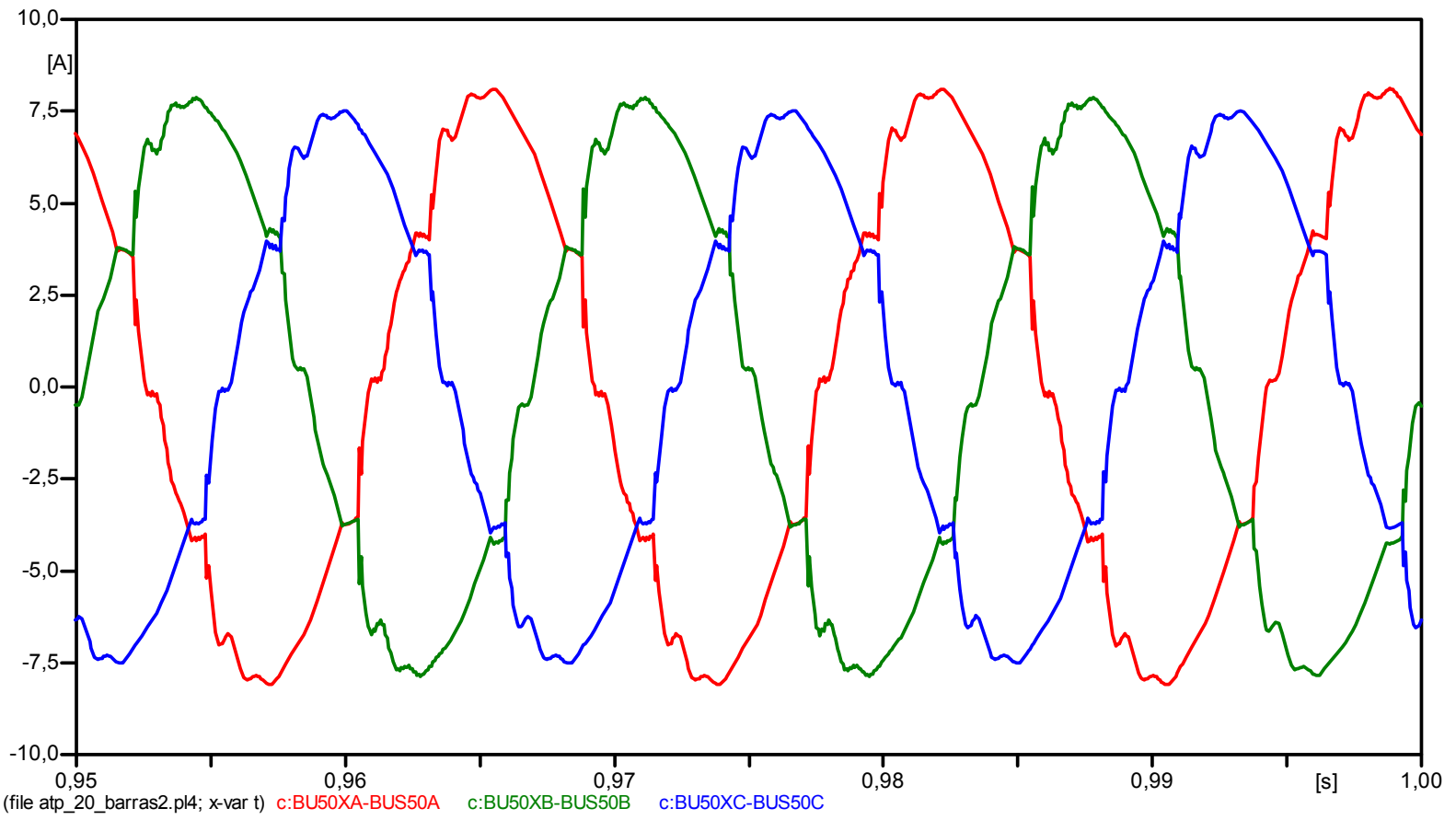

Figura 3.53 - Corrente instantânea trifásica (fase-terra) medida no final do alimentador para o estudo de caso 6 (dado atual).

Frente ao estudo de caso 6 , verificou-se que as DHTs calculadas para as tensões medidas na subestação durante o estado atual da rede foram de $4,24 \%$ 
(fase A), 4,20\% (fase B) e 4,17\% (fase C). A seguir, apresenta-se a Tabela 3.21, onde são mostrados os níveis de tensão tanto da fundamental como das harmônicas (somente ímpares até $13^{a}$ ordem) medidas na subestação para cada uma das fases.

Tabela 3.21 - Componentes fundamental e harmônicas de tensão medidas na subestação para o estudo de caso 6.

\begin{tabular}{|c|c|c|c|}
\hline Fundamental e Harmônicas & $\begin{array}{c}\text { Amplitude (Vpico) } \\
\text { Fase A [V] }\end{array}$ & $\begin{array}{c}\text { Amplitude (Vpico) } \\
\text { Fase B [V] }\end{array}$ & $\begin{array}{c}\text { Amplitude (Vpico) } \\
\text { Fase C [V] }\end{array}$ \\
\hline 1 & 20016 & 19489 & 19632 \\
\hline 3 & 29,574 & 60,428 & 34,177 \\
\hline 5 & 258,96 & 304,86 & 290,59 \\
\hline 7 & 233,88 & 224,24 & 213,88 \\
\hline 9 & 21,953 & 4,5806 & 25,789 \\
\hline 11 & 300,3 & 317,49 & 330,05 \\
\hline 13 & 400,42 & 318,65 & 358,48 \\
\hline
\end{tabular}

\subsection{Estudos de Caso Gerados para o Sistema de 90 Barras}

Esta Seção é destinada a apresentar os estudos de caso gerados sobre o sistema real de 90 barras. As cargas não lineares alocadas nestes estudos de caso serão também baseadas nos retificadores modelados e previamente comentados na Seção 3.4. Cabe comentar aqui que, para o sistema de 90 barras, foram gerados quatro estudos de caso que serão devidamente apresentados nas Subseções de 3.6.1 a 3.6.4.

Ressalta-se que as mesmas nomenclaturas adotadas durante as explanações dos estudos de caso gerados para o sistema fictício de 20 barras serão mantidas.

\subsubsection{Estudo de Caso 1}

Conforme pode ser verificado nas Figuras de 3.3 a 3.5, quatro medidores foram alocados, sendo 2 para tensão e 2 para corrente. Portanto, a partir deste 
momento os medidores de tensão (na barra B01) e de corrente (entre P01 e a barra B01) serão referidos como medidores da subestação. Já os medidores de tensão (em P02) e de corrente (entre P02 e a barra B19) serão tratados como medidores de ramificação, visto que estes foram alocados de forma aleatória e se encontram numa das ramificações da rede. Estas nomenclaturas serão empregadas para todos os casos que se referem ao sistema real de 90 barras.

Neste primeiro estudo de caso, o sistema de 90 barras foi simulado para se ter medidas históricas com distorções harmônicas. A fim de se gerar os dados que correspondem ao histórico da rede, um retificador foi alocado na barra B90, o qual era responsável por alimentar uma carga $\mathrm{RL}$ com $1600 \Omega$ e $200 \mathrm{mH}$. As formas de onda das tensões e correntes históricas medidas na subestação e pelos medidores de ramificação podem ser visualizadas por meio das Figuras de 3.54 a 3.57.

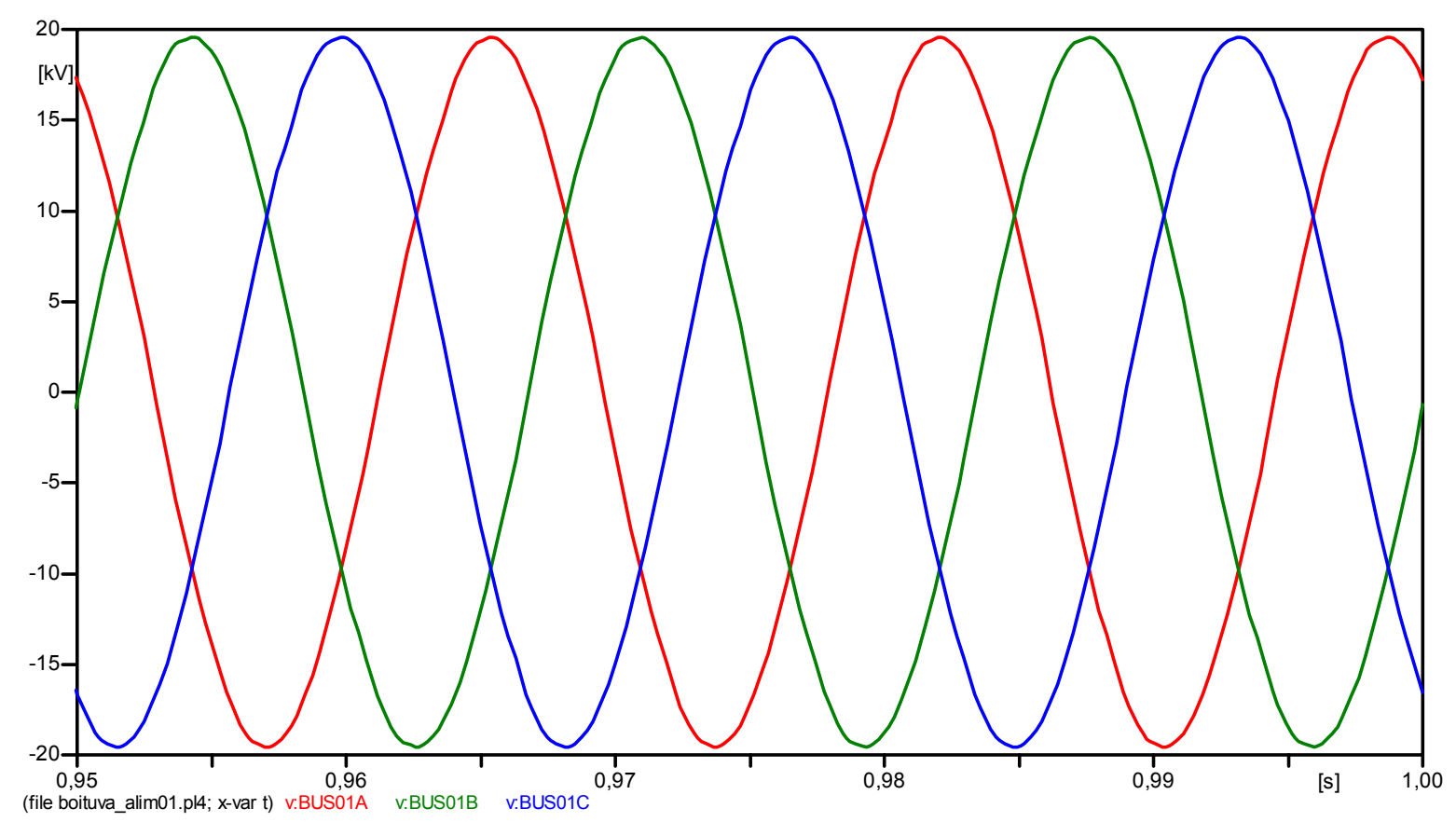

Figura 3.54 - Tensão instantânea trifásica (fase-terra) medida na subestação para o estudo de caso 1 (dado histórico). 


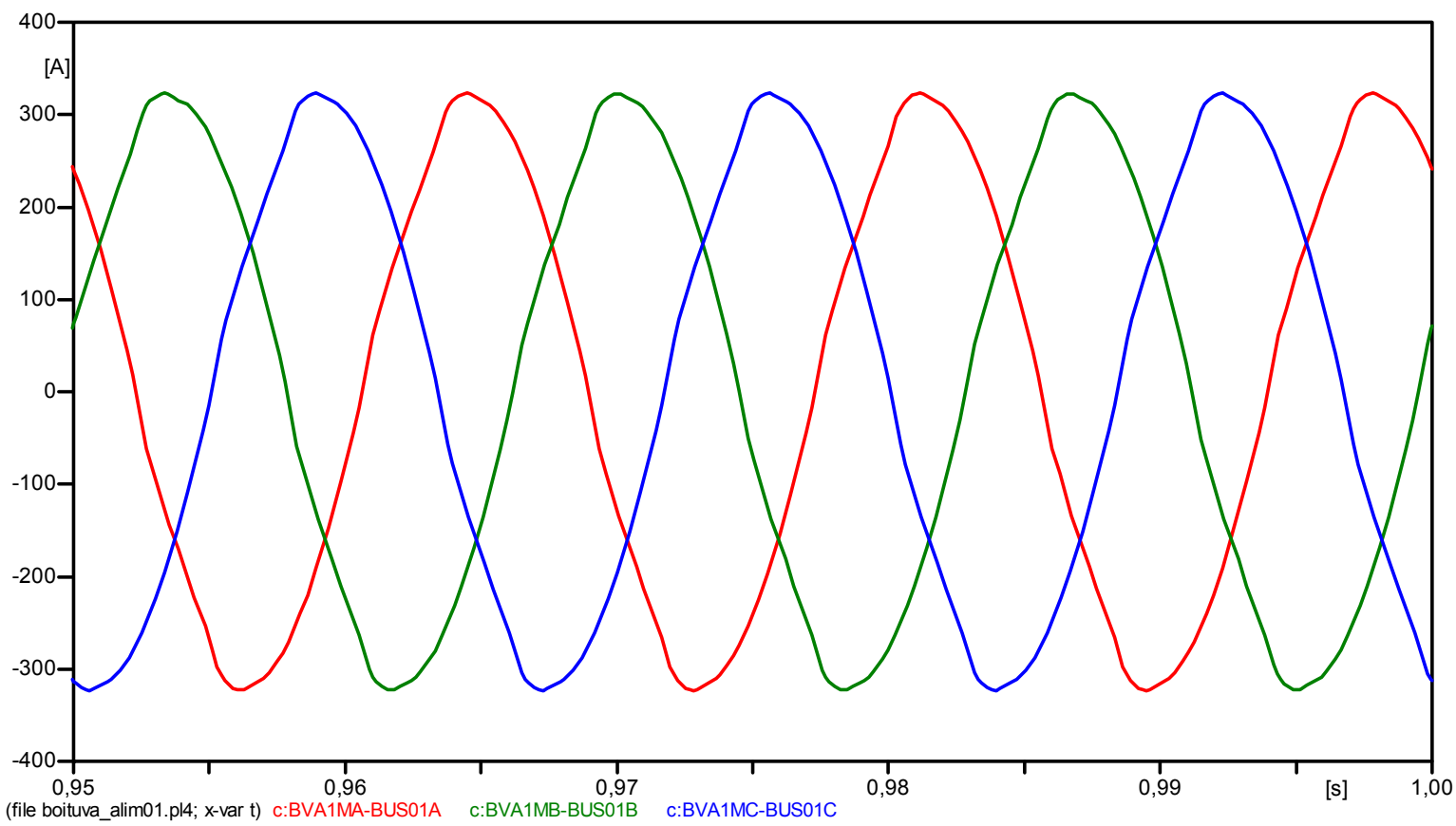

Figura 3.55 - Corrente instantânea trifásica (fase-terra) medida na subestação para o estudo de caso 1 (dado histórico).

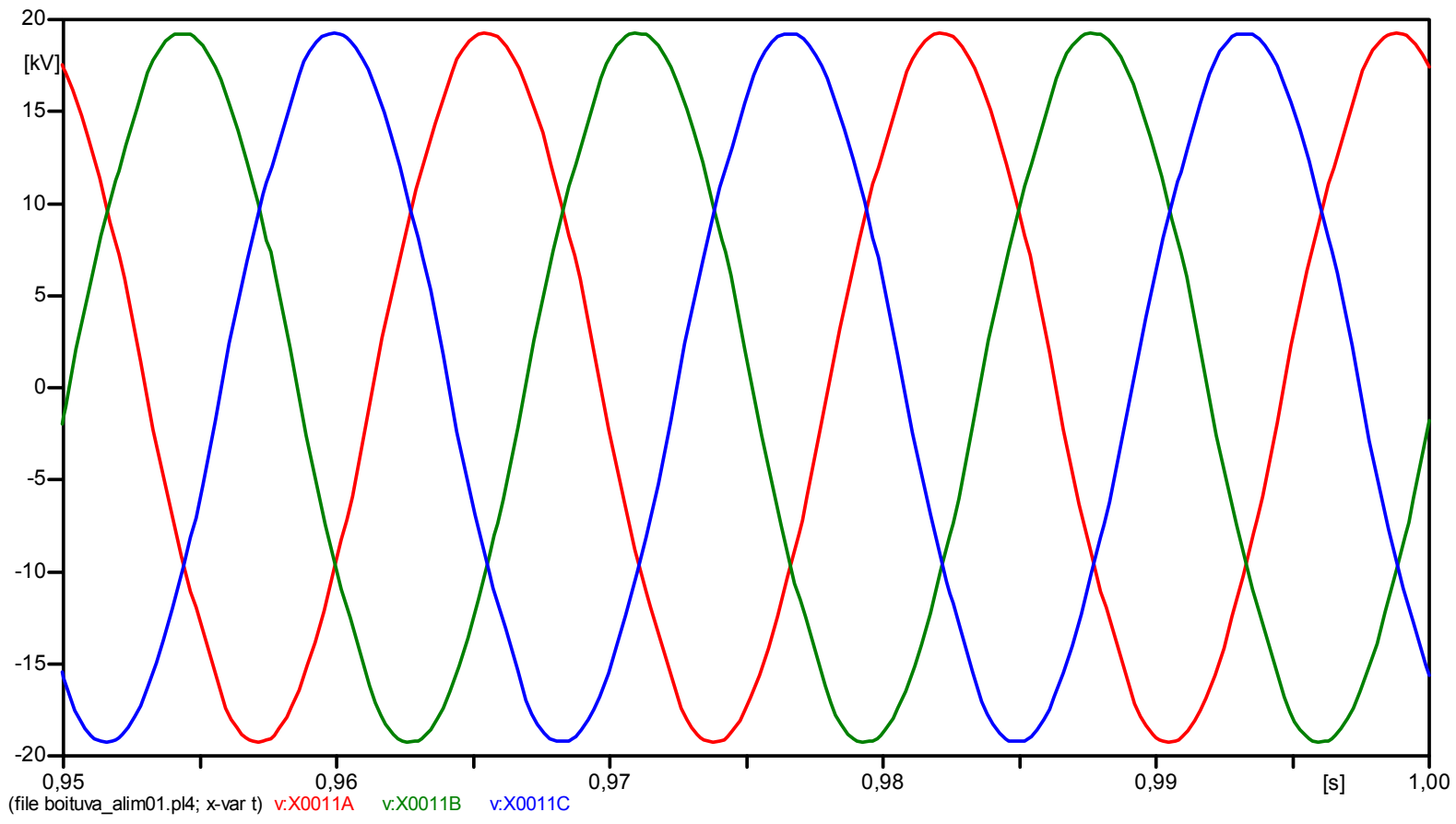

Figura 3.56 - Tensão instantânea trifásica (fase-terra) obtida pelo medidor de ramificação para o estudo de caso 1 (dado histórico). 


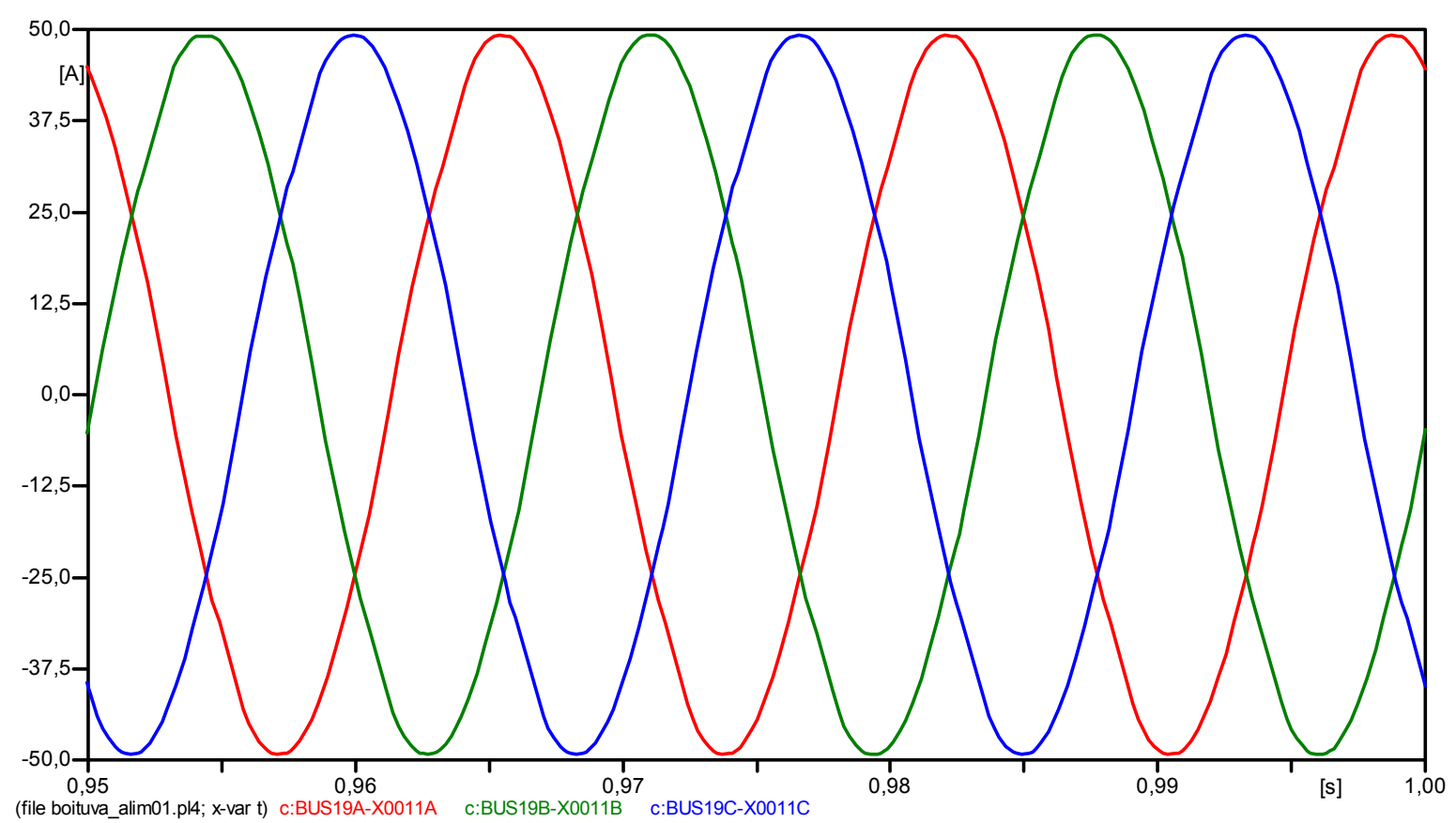

Figura 3.57 - Corrente instantânea trifásica (fase-terra) obtida pelo medidor de ramificação para o estudo de caso 1 (dado histórico).

Após obtidas as medidas de tensão da subestação, verificou-se que suas DHTs foram de $0,84 \%$ (fase A), $1,13 \%$ (fase B) e $0,91 \%$ (fase C).

Já a simulação que representa o estado atual deste estudo de caso conta com uma carga não linear (retificador) alocada na barra B45. Este retificador foi alocado no sistema para alimentar uma carga $R L$ parametrizada com $1100 \Omega$ e 200 $\mathrm{mH}$. Desta forma, foram medidas as correntes fundamental e harmônicas na entrada do retificador, as quais podem ser visualizadas por meio da Tabela 3.22. 
Tabela 3.22 - Assinatura harmônica de corrente da carga não linear alocada na barra B45 para o estudo de caso 1.

\begin{tabular}{|c|c|c|c|}
\hline Fundamental e Harmônicas & $\begin{array}{c}\text { Amplitude (Ipico) } \\
\text { Fase A [A] }\end{array}$ & $\begin{array}{c}\text { Amplitude (Ipico) } \\
\text { Fase B [A] }\end{array}$ & $\begin{array}{c}\text { Amplitude (Ipico) } \\
\text { Fase C [A] }\end{array}$ \\
\hline 1 & 30,977 & 31,061 & 31,056 \\
\hline 3 & 0,11382 & 0,068057 & 0,046173 \\
\hline 5 & 6,8708 & 6,8169 & 6,8267 \\
\hline 7 & 3,2001 & 3,3136 & 3,2896 \\
\hline 9 & 0,099694 & 0,068582 & 0,034293 \\
\hline 11 & 2,5056 & 2,4595 & 2,4727 \\
\hline 13 & 1,7448 & 1,8436 & 1,837 \\
\hline
\end{tabular}

Além disso, para a obtenção dos dados atuais deste estudo de caso, nenhuma variação em tensão ou carregamento foi gerada. Assim, as formas de onda medidas tanto na subestação como na ramificação puderam ser obtidas e são mostradas nas Figuras de 3.58 a 3.61.

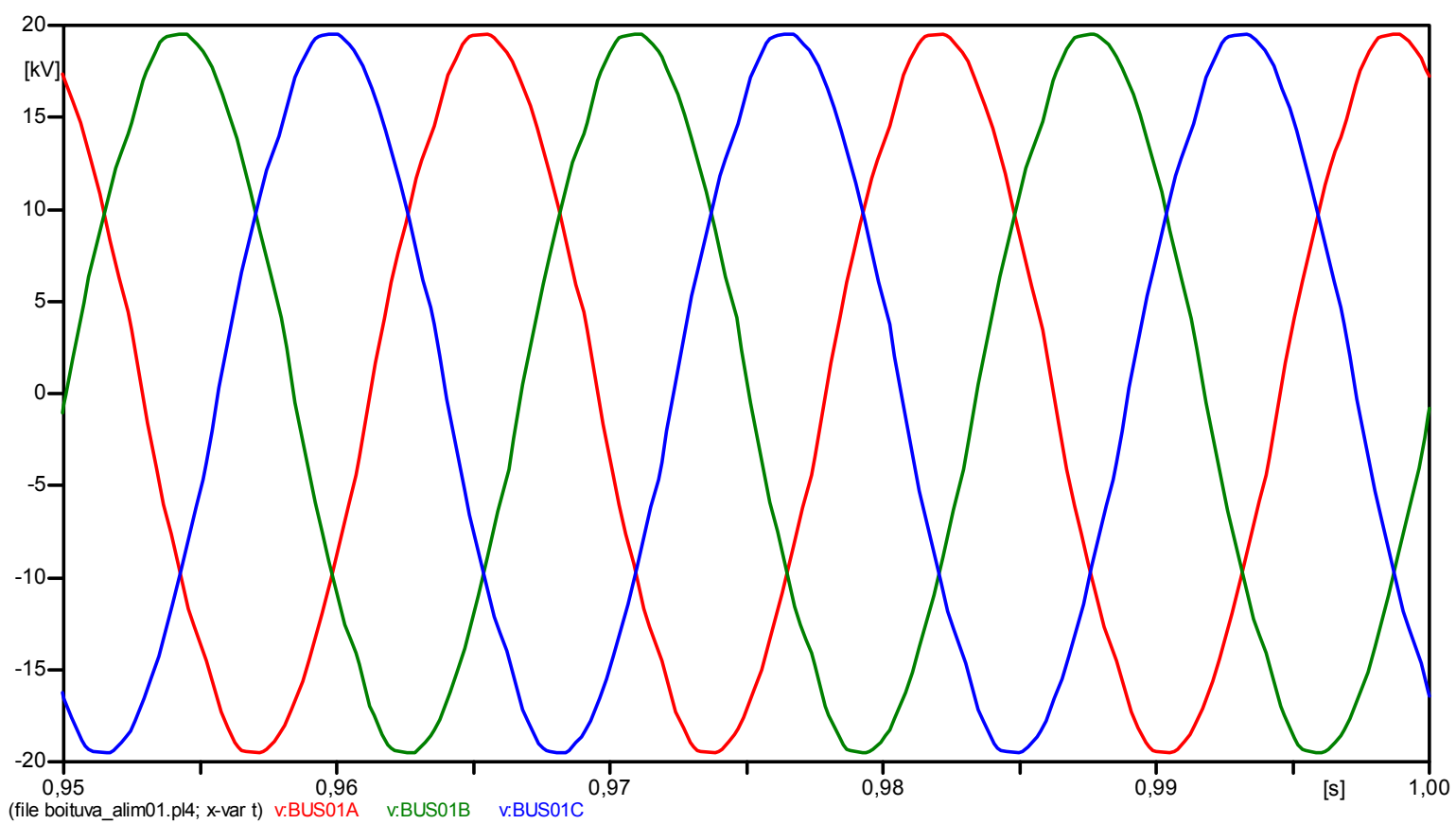

Figura 3.58 - Tensão instantânea trifásica (fase-terra) medida na subestação para o estudo de caso 1 (dado atual). 


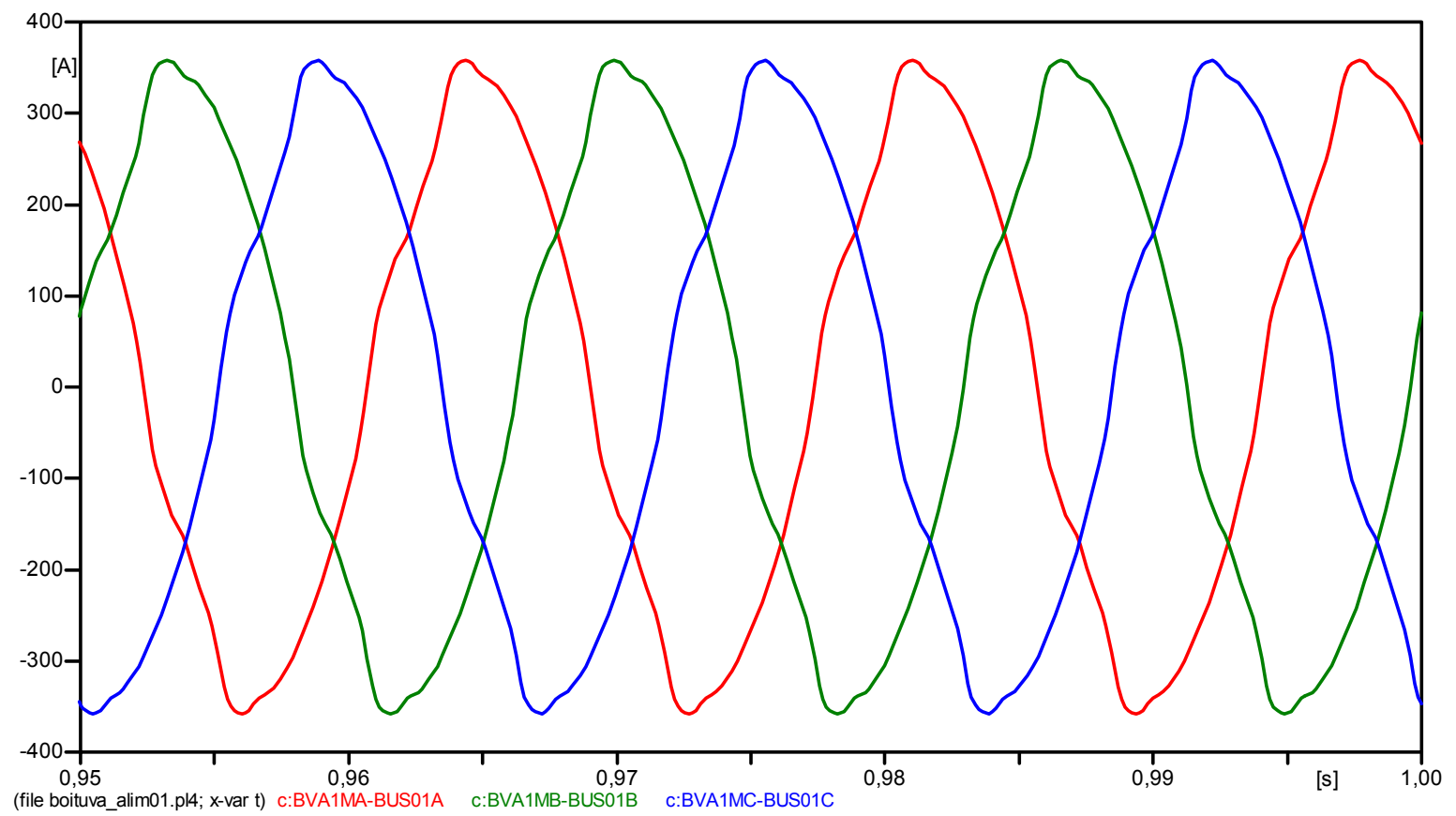

Figura 3.59 - Corrente instantânea trifásica (fase-terra) medida na subestação para o estudo de caso 1 (dado atual).

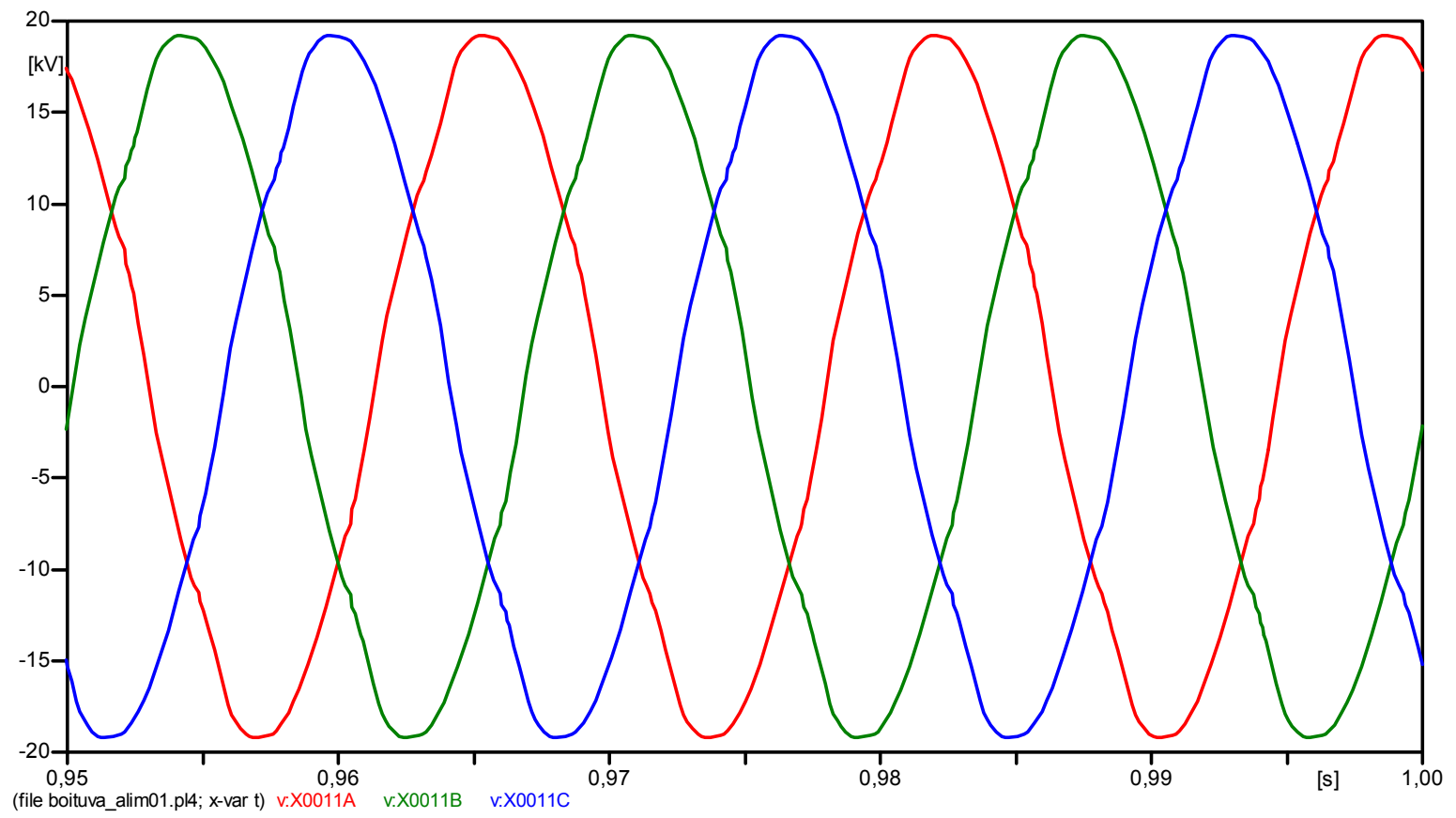

Figura 3.60 - Tensão instantânea trifásica (fase-terra) obtida pelo medidor de ramificação para o estudo de caso 1 (dado atual). 


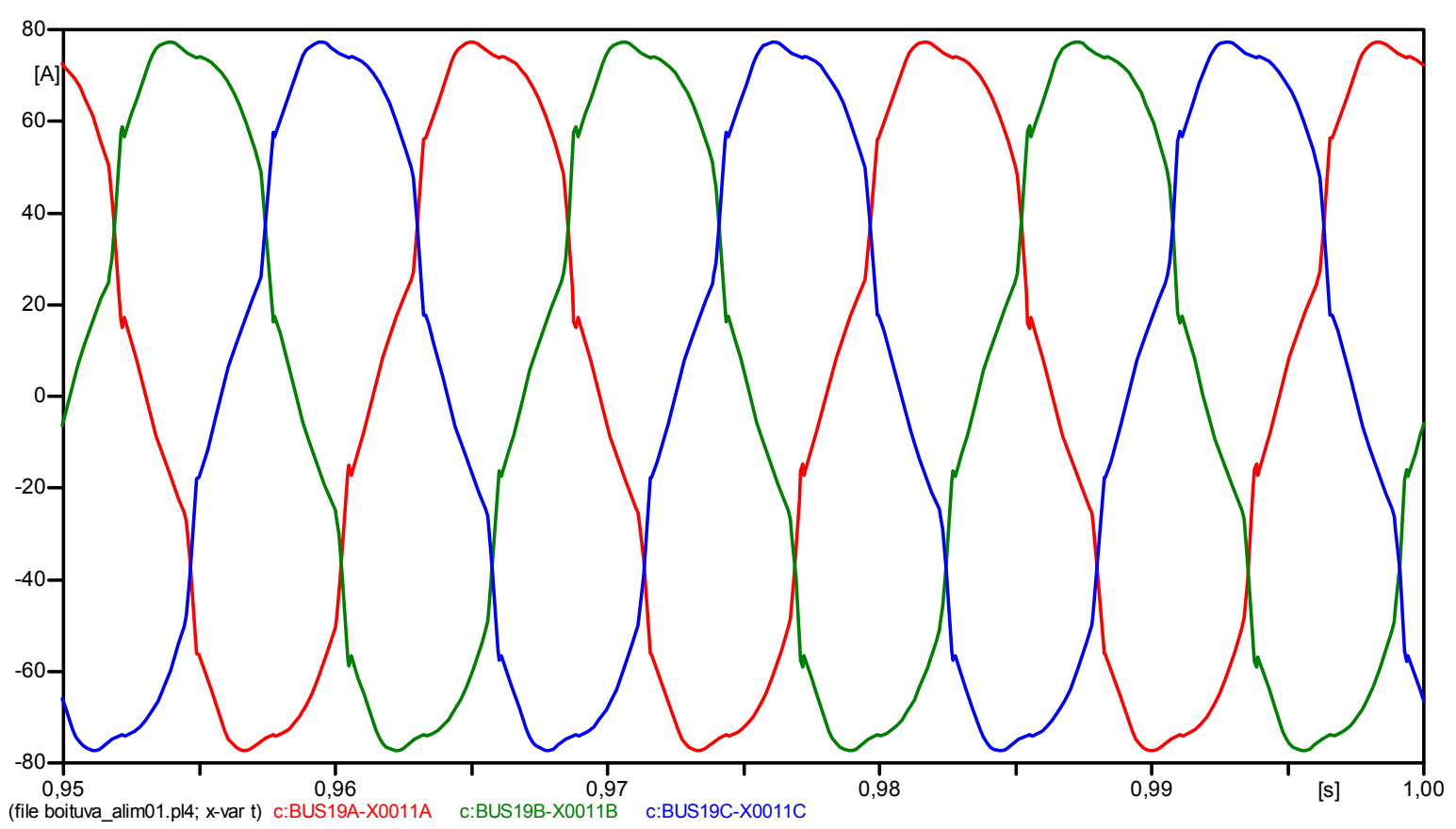

Figura 3.61 - Corrente instantânea trifásica (fase-terra) obtida pelo medidor de ramificação para o estudo de caso 1 (dado atual).

Em relação ao estudo de caso 1, verificou-se que as DHTs calculadas para as tensões medidas na subestação durante o estado atual da rede foram de 1,65\% (fase A), $1,90 \%$ (fase B) e 1,71\% (fase C). Desta forma, apresenta-se a Tabela 3.23, onde são mostrados os níveis de tensão tanto da fundamental como das harmônicas (somente ímpares até $13^{a}$ ordem) medidas na subestação para cada uma das fases.

Tabela 3.23 - Componentes fundamental e harmônicas de tensão medidas na subestação para o estudo de caso 1.

\begin{tabular}{|c|c|c|c|}
\hline Fundamental e Harmônicas & $\begin{array}{c}\text { Amplitude (Vpico) } \\
\text { Fase A [V] }\end{array}$ & $\begin{array}{c}\text { Amplitude (Vpico) } \\
\text { Fase B [V] }\end{array}$ & $\begin{array}{c}\text { Amplitude (Vpico) } \\
\text { Fase C [V] }\end{array}$ \\
\hline 1 & 19498 & 19555 & 19501 \\
\hline 3 & 31,098 & 54,029 & 33,036 \\
\hline 5 & 199,32 & 225,09 & 198,66 \\
\hline 7 & 174,41 & 193,41 & 189,58 \\
\hline 9 & 7,6485 & 18,546 & 13,002 \\
\hline 11 & 107,96 & 121,38 & 112,65 \\
\hline 13 & 68,201 & 83,327 & 73,175 \\
\hline
\end{tabular}




\subsubsection{Estudo de Caso 2}

O segundo estudo de caso também apresenta medidas históricas com distorções harmônicas; portanto, para se gerar os dados que correspondem ao histórico da rede, um retificador foi alocado na barra B90. Este retificador foi responsável por alimentar uma carga RL parametrizada com $1600 \Omega$ e $200 \mathrm{mH}$. Além dessa carga não linear alocada na barra B90, os bancos de capacitores alocados nas barras B05 e B47 foram retirados da rede. As formas de onda das tensões e correntes históricas medidas na subestação e pelos medidores de ramificação podem ser visualizadas por meio das Figuras de 3.62 a 3.65.

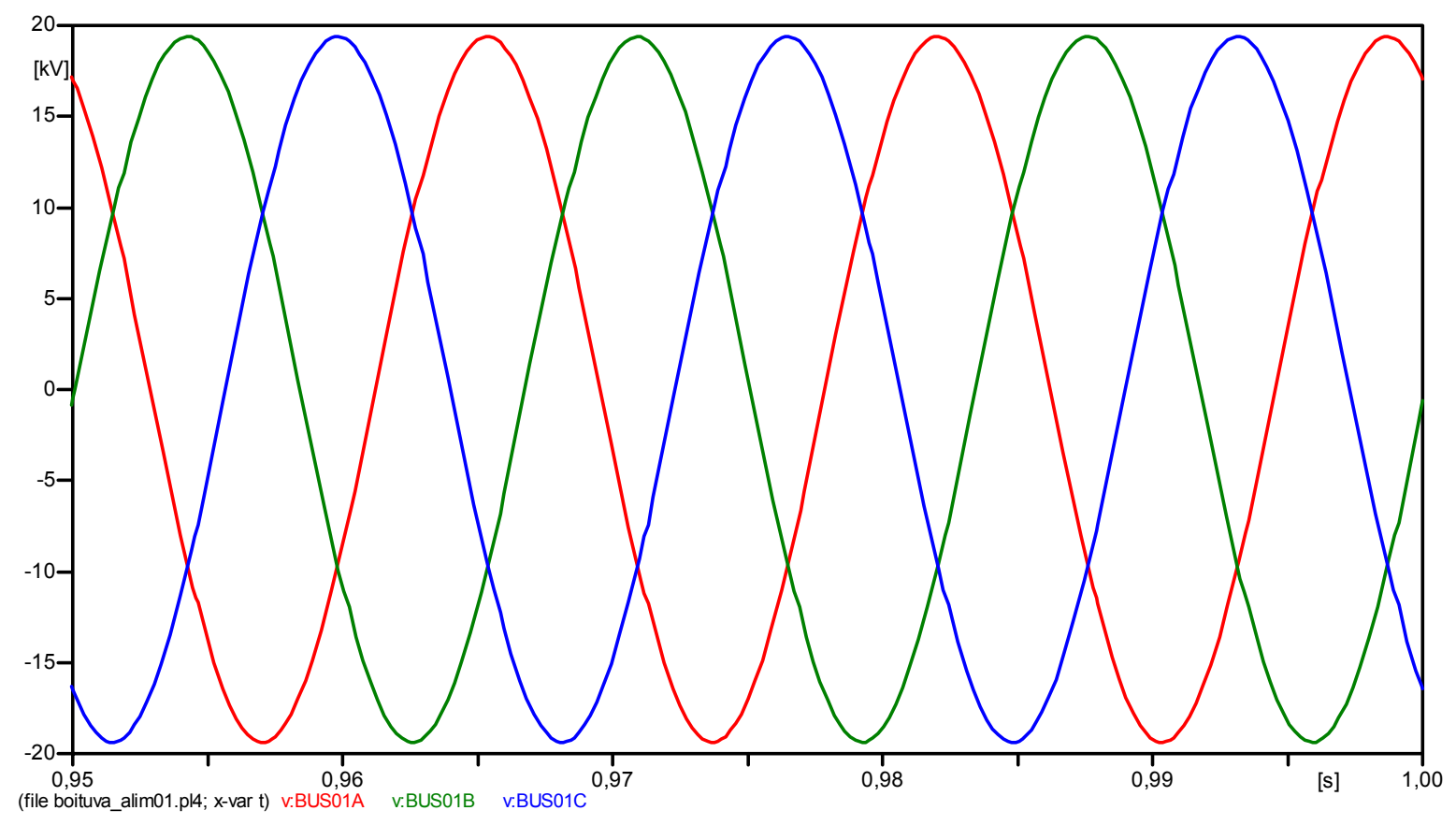

Figura 3.62 - Tensão instantânea trifásica (fase-terra) medida na subestação para o estudo de caso 2 (dado histórico). 


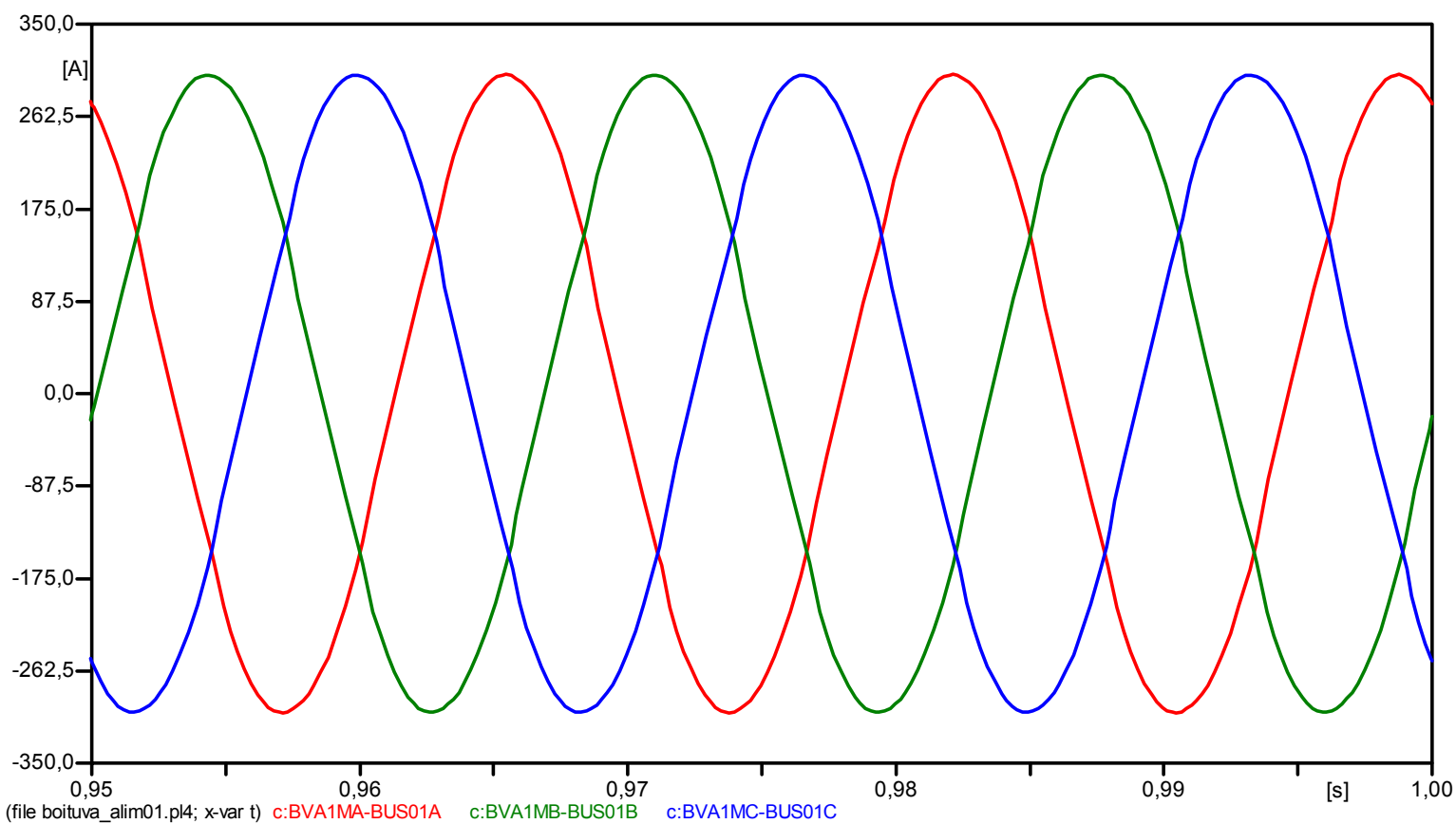

Figura 3.63 - Corrente instantânea trifásica (fase-terra) medida na subestação para o estudo de caso 2 (dado histórico).

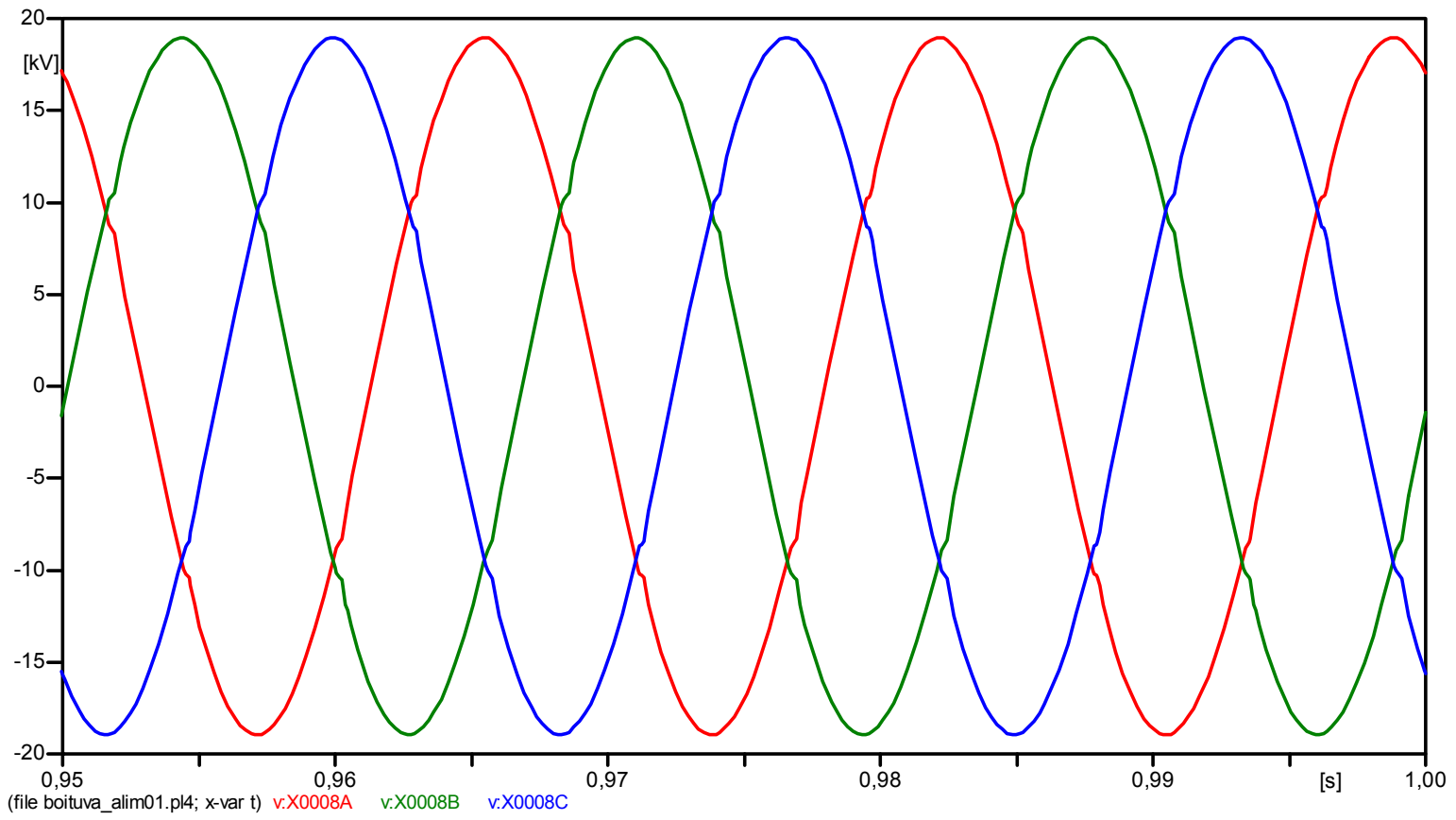

Figura 3.64 - Tensão instantânea trifásica (fase-terra) obtida pelo medidor de ramificação para o estudo de caso 2 (dado histórico). 


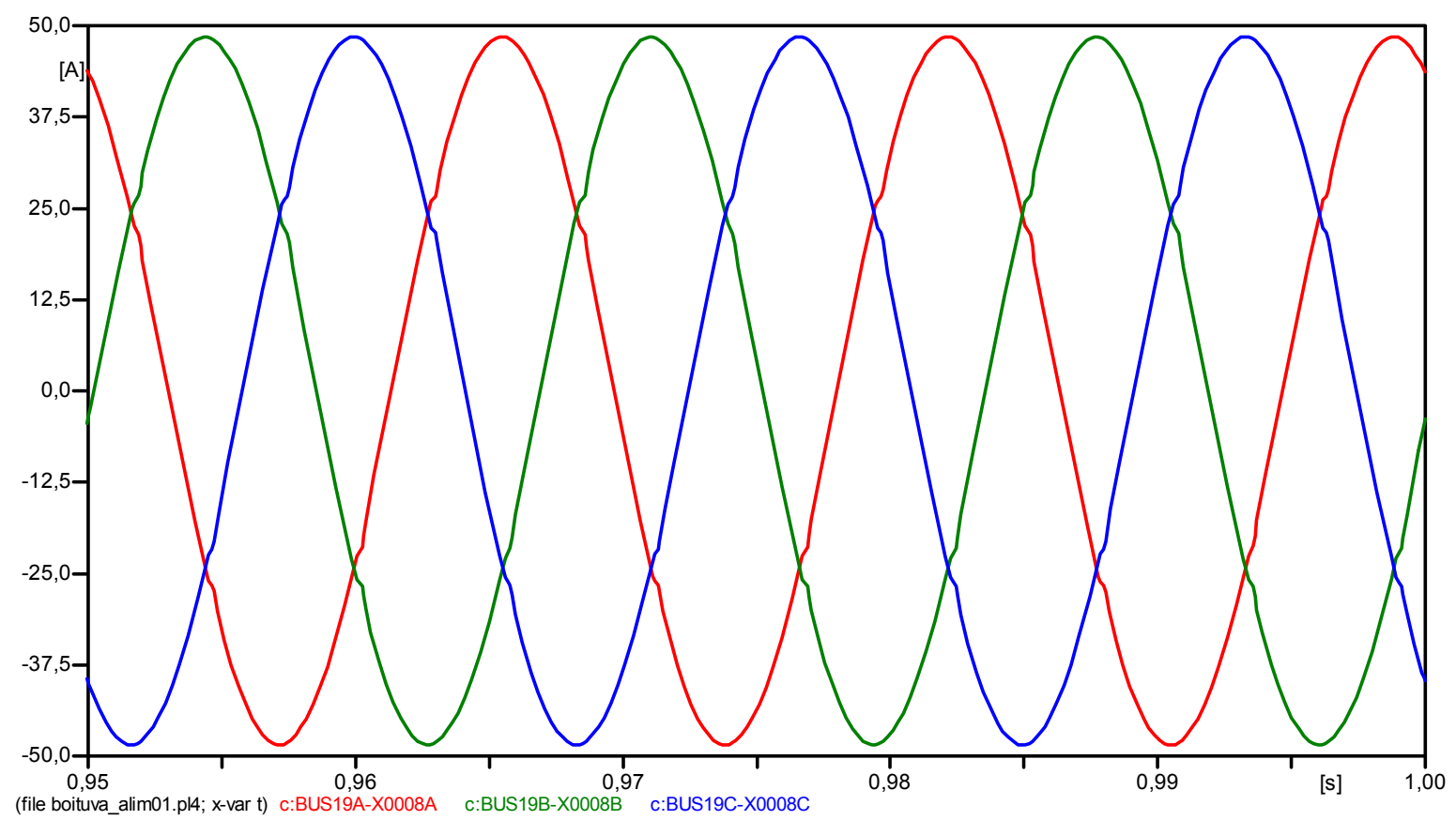

Figura 3.65 - Corrente instantânea trifásica (fase-terra) obtida pelo medidor de ramificação para o estudo de caso 2 (dado histórico).

Após obtidas as medidas de tensão da subestação, verificou-se que suas DHTs foram de $0,62 \%$ (fase A), $0,89 \%$ (fase B) e $0,66 \%$ (fase $C$ ).

Já a simulação que representa o estado atual deste estudo de caso conta com uma carga não linear (retificador) alocada na barra B49. Este retificador foi alocado no sistema a fim de alimentar uma carga $\mathrm{RL}$, sendo esta parametrizada com $1100 \Omega$ e $200 \mathrm{mH}$. Desta forma, foram medidas as correntes de fase fundamental e harmônicas na entrada do retificador, as quais podem ser visualizadas por meio da Tabela 3.24. 
Tabela 3.24 - Assinatura harmônica de corrente da carga não linear alocada na barra B49 para o estudo de caso 2.

\begin{tabular}{|c|c|c|c|}
\hline Fundamental e Harmônicas & $\begin{array}{c}\text { Amplitude (Ipico) } \\
\text { Fase A [A] }\end{array}$ & $\begin{array}{c}\text { Amplitude (Ipico) } \\
\text { Fase B [A] }\end{array}$ & $\begin{array}{c}\text { Amplitude (Ipico) } \\
\text { Fase C [A] }\end{array}$ \\
\hline 1 & 31,87 & 31,988 & 31,855 \\
\hline 3 & 0,066211 & 0,15487 & 0,08912 \\
\hline 5 & 7,1454 & 7,0581 & 7,1521 \\
\hline 7 & 3,4965 & 3,617 & 3,4547 \\
\hline 9 & 0,064781 & 0,15026 & 0,085507 \\
\hline 11 & 2,8198 & 2,7278 & 2,8131 \\
\hline 13 & 2,0621 & 2,174 & 1,9999 \\
\hline
\end{tabular}

Além disso, para a obtenção dos dados atuais deste estudo de caso, nenhuma variação em tensão ou carregamento foi gerada. Assim, as formas de onda medidas tanto na subestação como na ramificação puderam ser obtidas e são mostradas nas Figuras de 3.66 a 3.69.

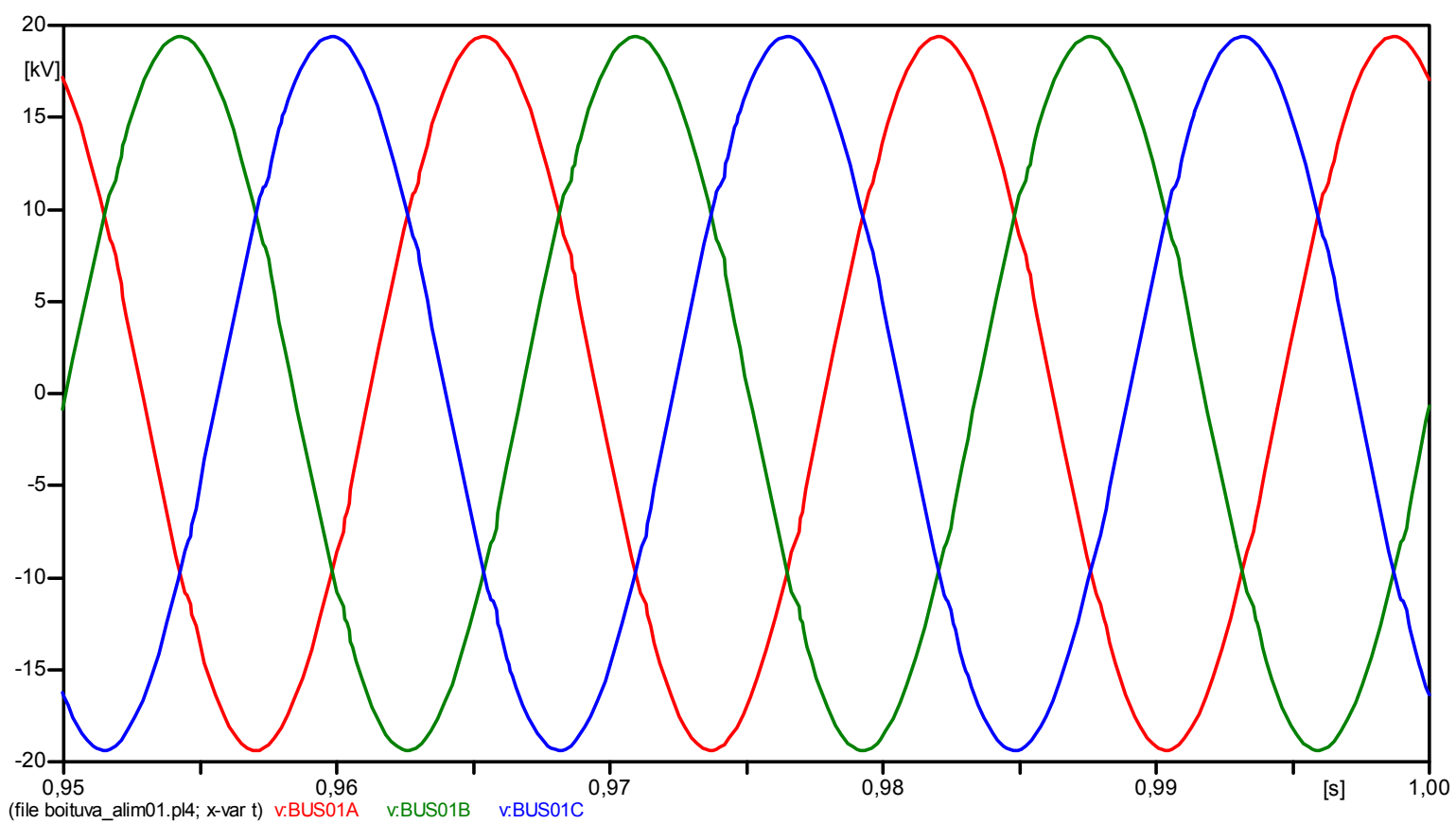

Figura 3.66 - Tensão instantânea trifásica (fase-terra) medida na subestação para o estudo de caso 2 (dado atual). 


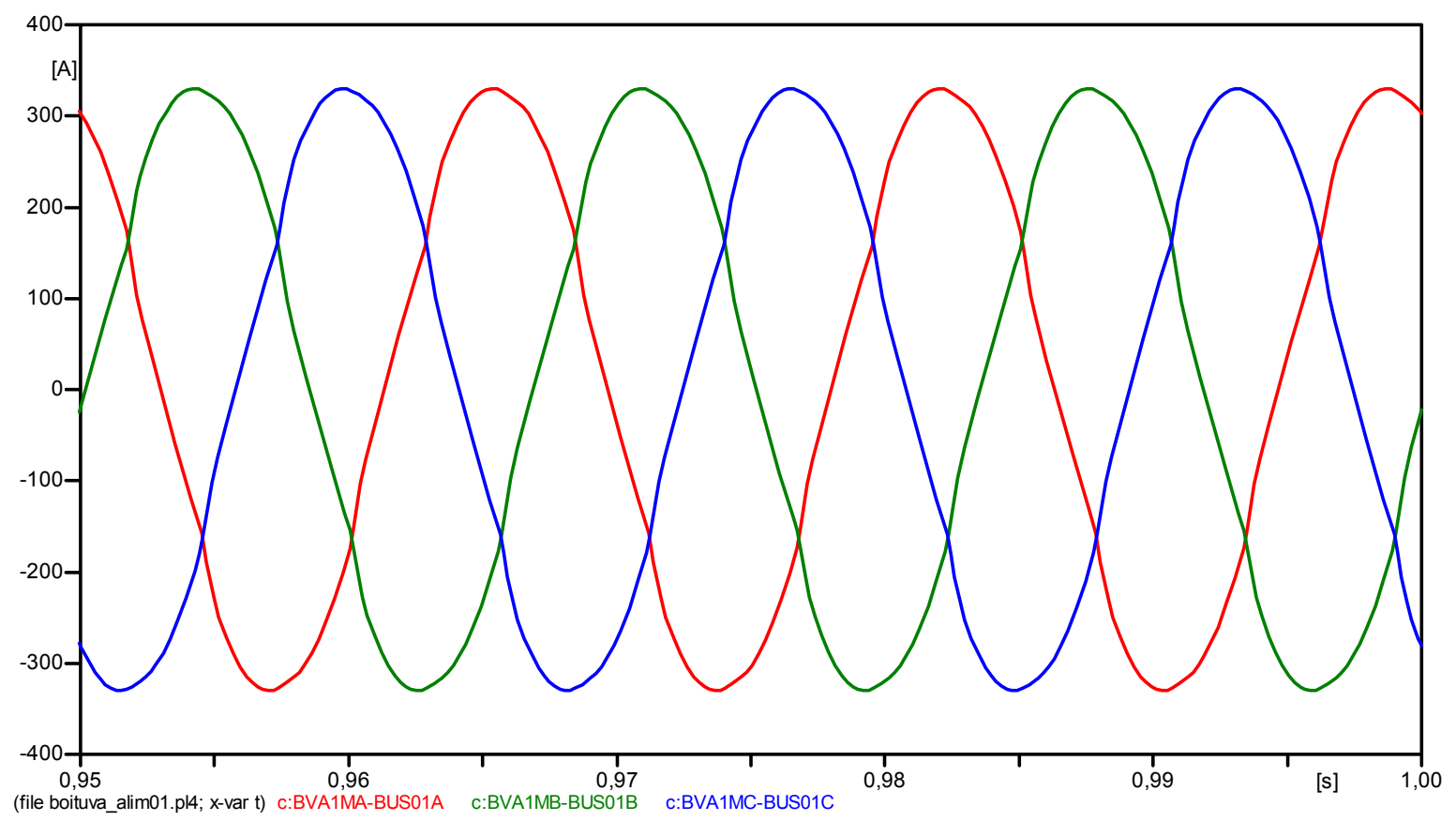

Figura 3.67 - Corrente instantânea trifásica (fase-terra) medida na subestação para o estudo de caso 2 (dado atual).

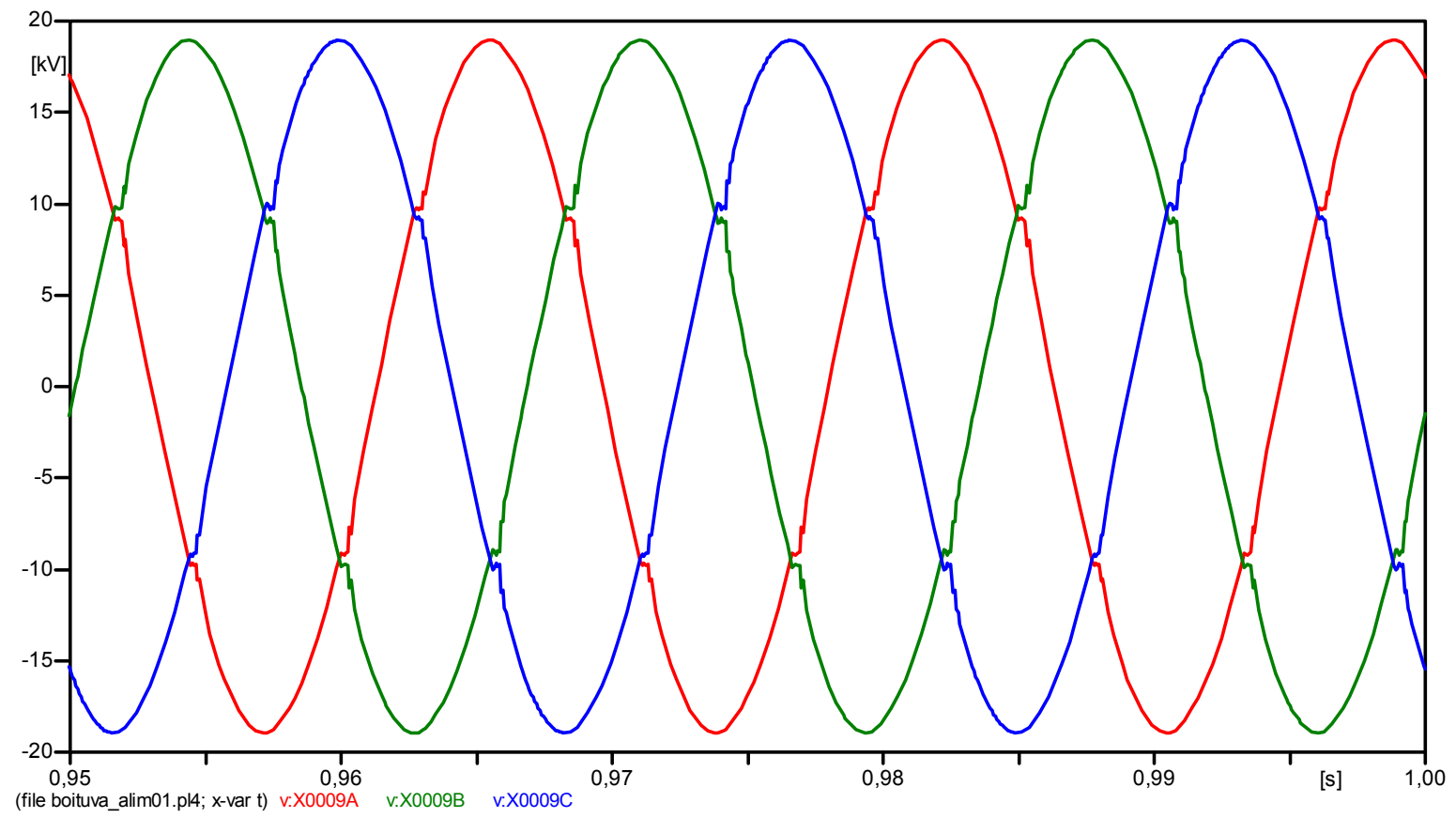

Figura 3.68 - Tensão instantânea trifásica (fase-terra) obtida pelo medidor de ramificação para o estudo de caso 2 (dado atual). 


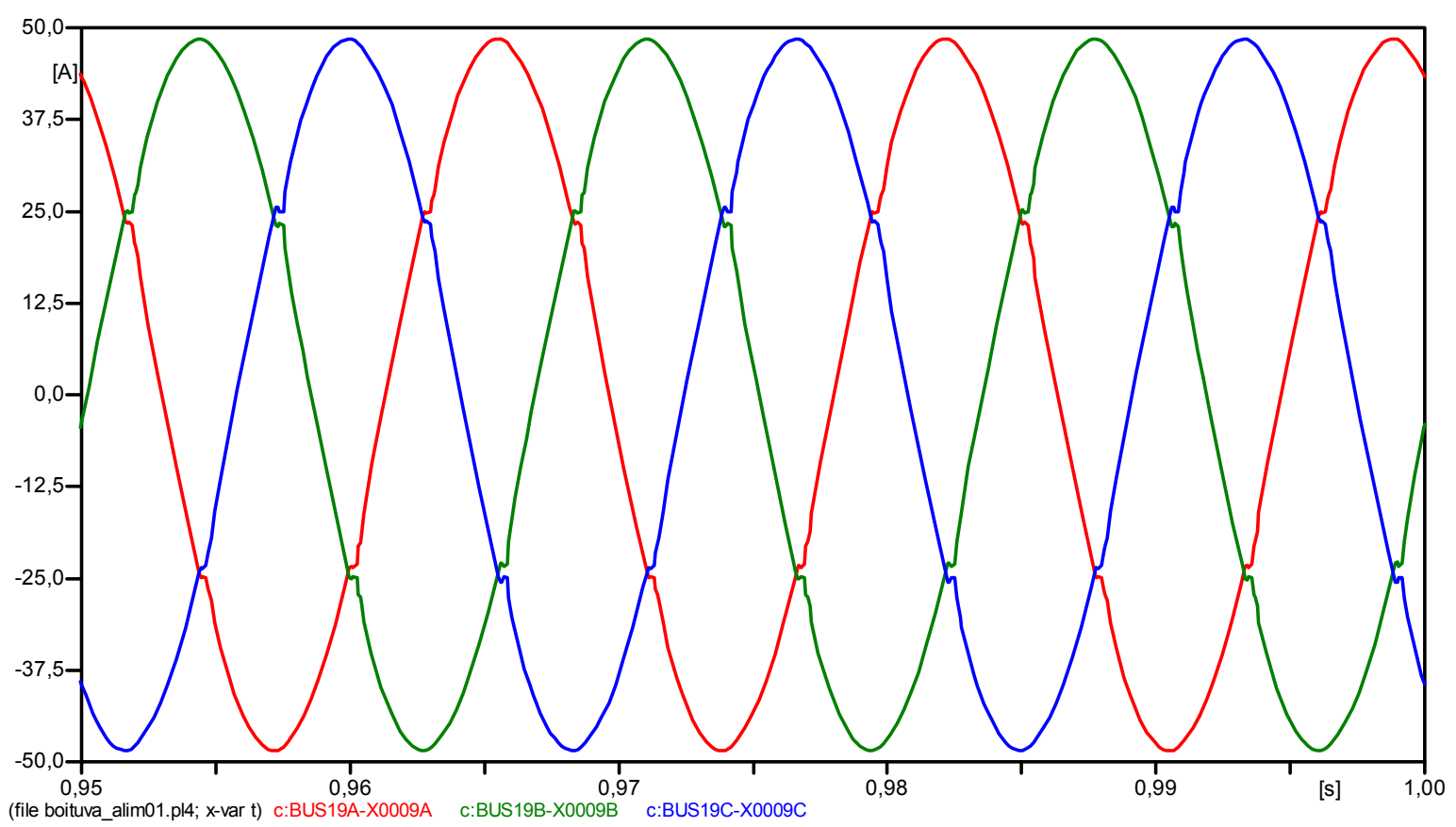

Figura 3.69 - Corrente instantânea trifásica (fase-terra) obtida pelo medidor de ramificação para o estudo de caso 2 (dado atual).

Frente ao estudo de caso 2, verificou-se que as DHTs das tensões medidas na subestação durante o estado atual da rede foram de 1,14\% (fase $A$ ), 1,35\% (fase B) e $1,18 \%$ (fase C). Na Tabela 3.25 são mostrados os níveis de tensão tanto da fundamental como das harmônicas (somente ímpares até $13^{a}$ ordem) medidas na subestação para cada uma das fases.

Tabela 3.25 - Componentes fundamental e harmônicas de tensão medidas na subestação para o estudo de caso 2.

\begin{tabular}{|c|c|c|c||}
\hline Fundamental e Harmônicas & $\begin{array}{c}\text { Amplitude (Vpico) } \\
\text { Fase A [V] }\end{array}$ & $\begin{array}{c}\text { Amplitude (Vpico) } \\
\text { Fase B [V] }\end{array}$ & $\begin{array}{c}\text { Amplitude (Vpico) } \\
\text { Fase C [V] }\end{array}$ \\
\hline 1 & 19309 & 19365 & 19311 \\
\hline 3 & 31,189 & 54,15 & 32,03 \\
\hline 5 & 121,24 & 151,16 & 134,06 \\
\hline 7 & 85,868 & 101,58 & 85,479 \\
\hline 9 & 9,9959 & 19,835 & 9,9922 \\
\hline 11 & 78,284 & 72,464 & 87,192 \\
\hline 13 & 66,113 & 62,609 & 56,56 \\
\hline
\end{tabular}




\subsubsection{Estudo de Caso 3}

O terceiro estudo de caso também apresenta medidas históricas com distorções harmônicas. Desta forma, para se gerar os dados que correspondem ao histórico da rede, dois retificadores foram alocados nas barras B49 e B90. Ambos os retificadores alimentam cargas $\mathrm{RL}$, sendo a primeira parametrizada com $1700 \Omega \mathrm{e}$ $400 \mathrm{mH}$ (retificador da barra B49) e a segunda parametrizada com $1600 \Omega$ e $200 \mathrm{mH}$ (retificador da barra B90). Além dessas cargas não lineares alocadas nas barras B49 e B90, os bancos de capacitores alocados nas barras B05 e B47 foram retirados da rede. As formas de onda das tensões e correntes históricas medidas na subestação e pelos medidores de ramificação podem ser visualizadas por meio das Figuras de 3.70 a 3.73 .

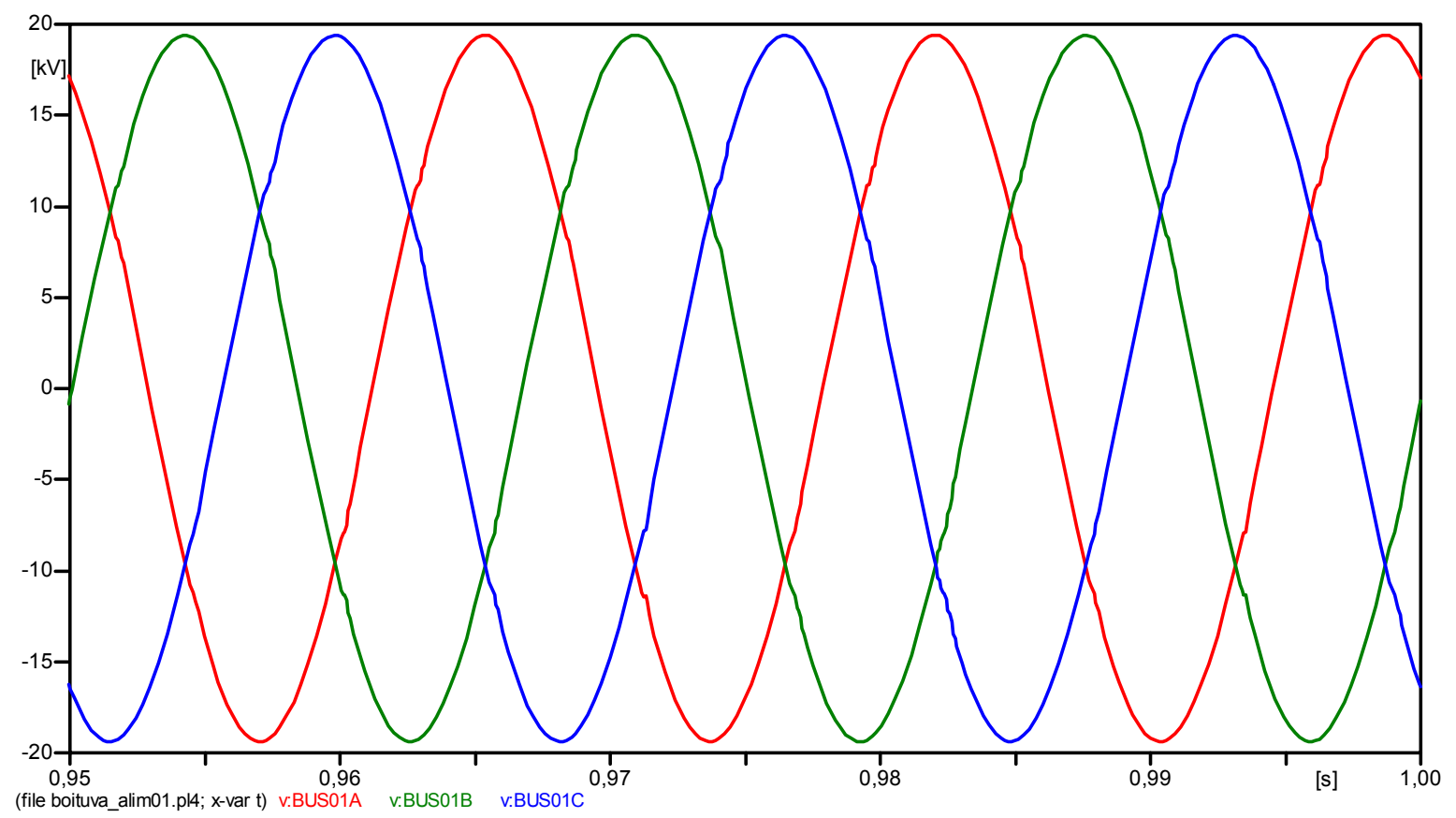

Figura 3.70 - Tensão instantânea trifásica (fase-terra) medida na subestação para o estudo de caso 3 (dado histórico). 


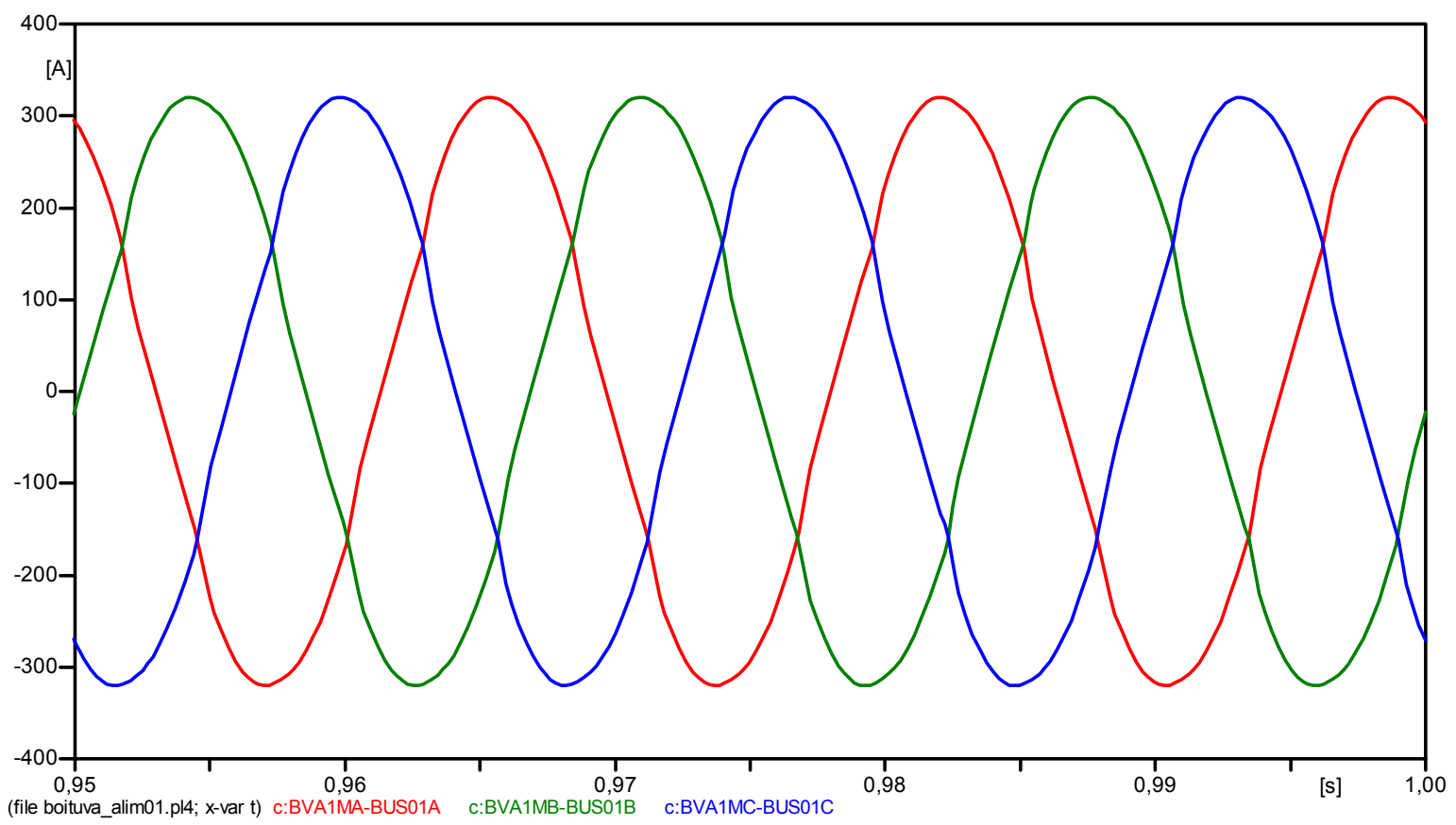

Figura 3.71 - Corrente instantânea trifásica (fase-terra) medida na subestação para o estudo de caso 3 (dado histórico).

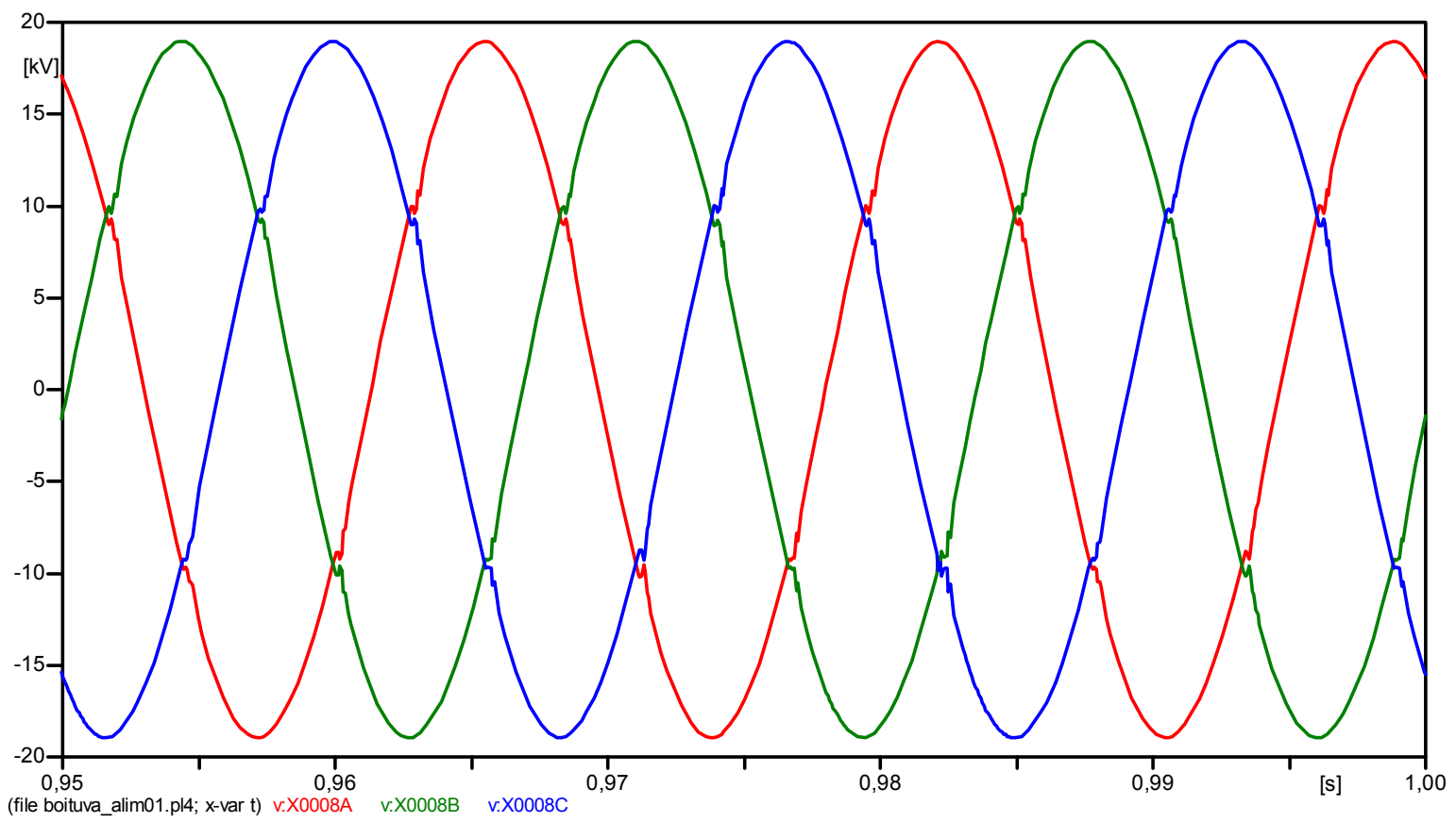

Figura 3.72 - Tensão instantânea trifásica (fase-terra) obtida pelo medidor de ramificação para o estudo de caso 3 (dado histórico). 


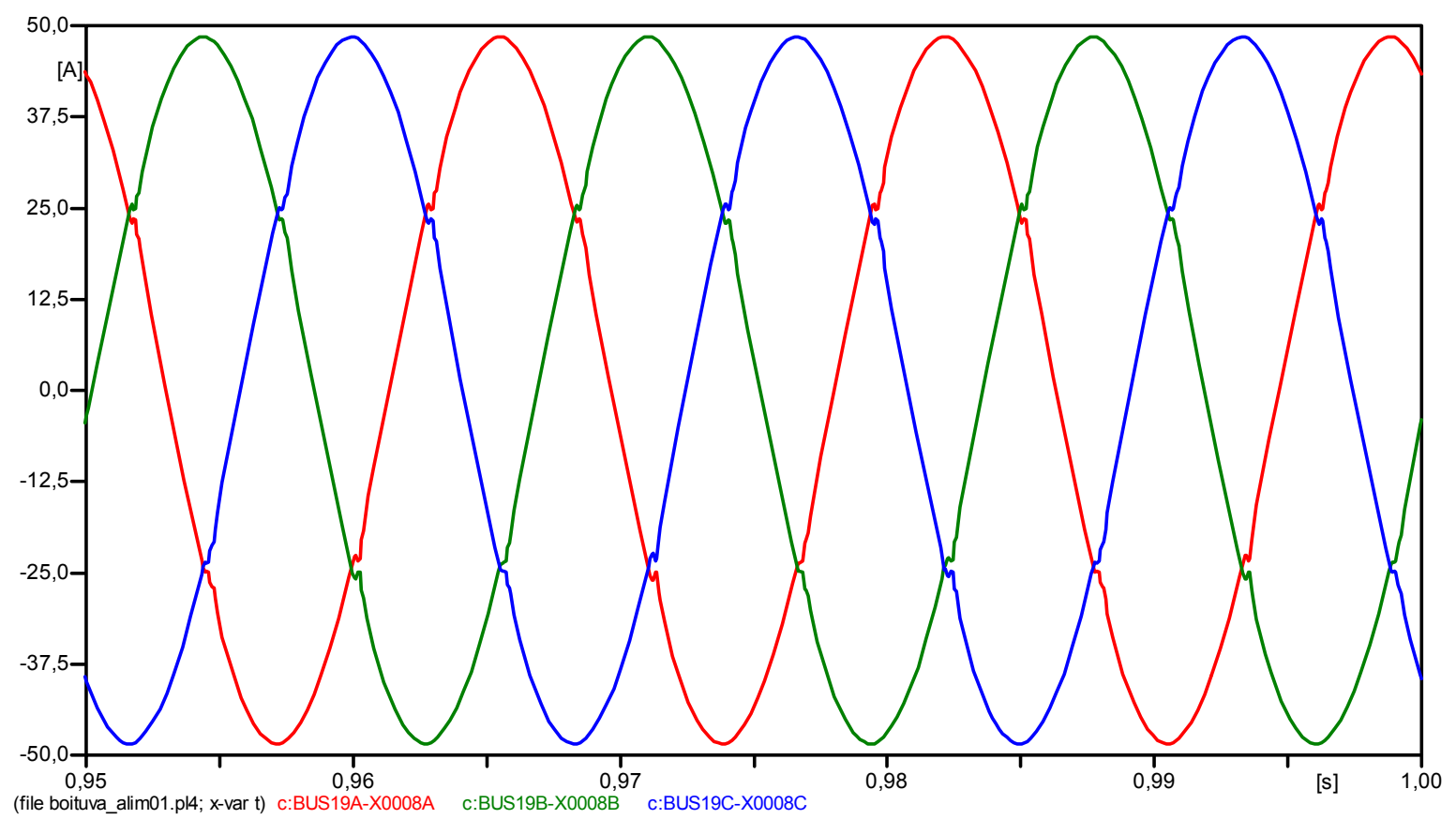

Figura 3.73 - Corrente instantânea trifásica (fase-terra) obtida pelo medidor de ramificação para o estudo de caso 3 (dado histórico).

Após obtidas as medidas de tensão da subestação, verificou-se que suas DHTs foram de $0,97 \%$ (fase A), $1,16 \%$ (fase B) e $0,99 \%$ (fase C).

A simulação que representa o estado atual deste estudo de caso conta com uma carga não linear (retificador) alocada na barra B14. Este retificador foi alocado no sistema para alimentar uma carga RL parametrizada com $1100 \Omega$ e $100 \mathrm{mH}$. Desta forma, foram medidas as correntes fundamental e harmônicas na entrada do retificador, as quais podem ser visualizadas por meio da Tabela 3.26. 
Tabela 3.26 - Assinatura harmônica de corrente da carga não linear alocada na barra B14 para o estudo de caso 3.

\begin{tabular}{|c|c|c|c|}
\hline Fundamental e Harmônicas & $\begin{array}{c}\text { Amplitude (Ipico) } \\
\text { Fase A [A] }\end{array}$ & $\begin{array}{c}\text { Amplitude (Ipico) } \\
\text { Fase B [A] }\end{array}$ & $\begin{array}{c}\text { Amplitude (Ipico) } \\
\text { Fase C [A] }\end{array}$ \\
\hline 1 & 32,103 & 31,694 & 31,594 \\
\hline 3 & 0,64738 & 0,28725 & 0,36201 \\
\hline 5 & 6,8504 & 7,3522 & 7,3735 \\
\hline 7 & 3,6606 & 3,3363 & 3,1991 \\
\hline 9 & 0,62327 & 0,30228 & 0,33304 \\
\hline 11 & 2,4541 & 3,0199 & 2,9518 \\
\hline 13 & 2,1858 & 1,8867 & 1,7828 \\
\hline
\end{tabular}

Além disso, para a obtenção dos dados atuais deste estudo de caso, nenhuma variação em tensão ou carregamento foi gerada. Assim, as formas de onda medidas tanto na subestação como na ramificação puderam ser obtidas e são ilustradas nas Figuras de 3.74 a 3.77.

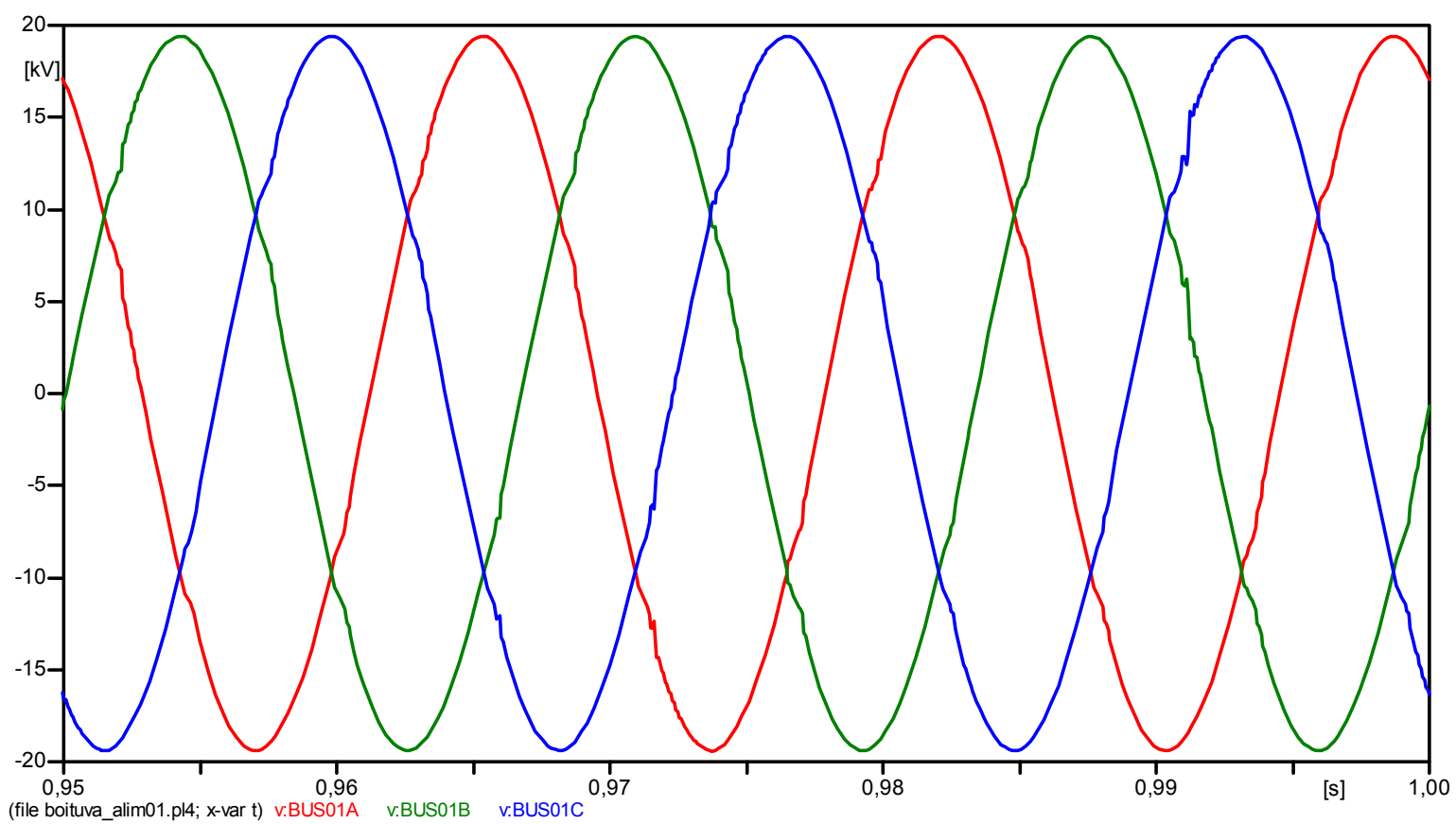

Figura 3.74 - Tensão instantânea trifásica (fase-terra) medida na subestação para o estudo de caso 3 (dado atual). 


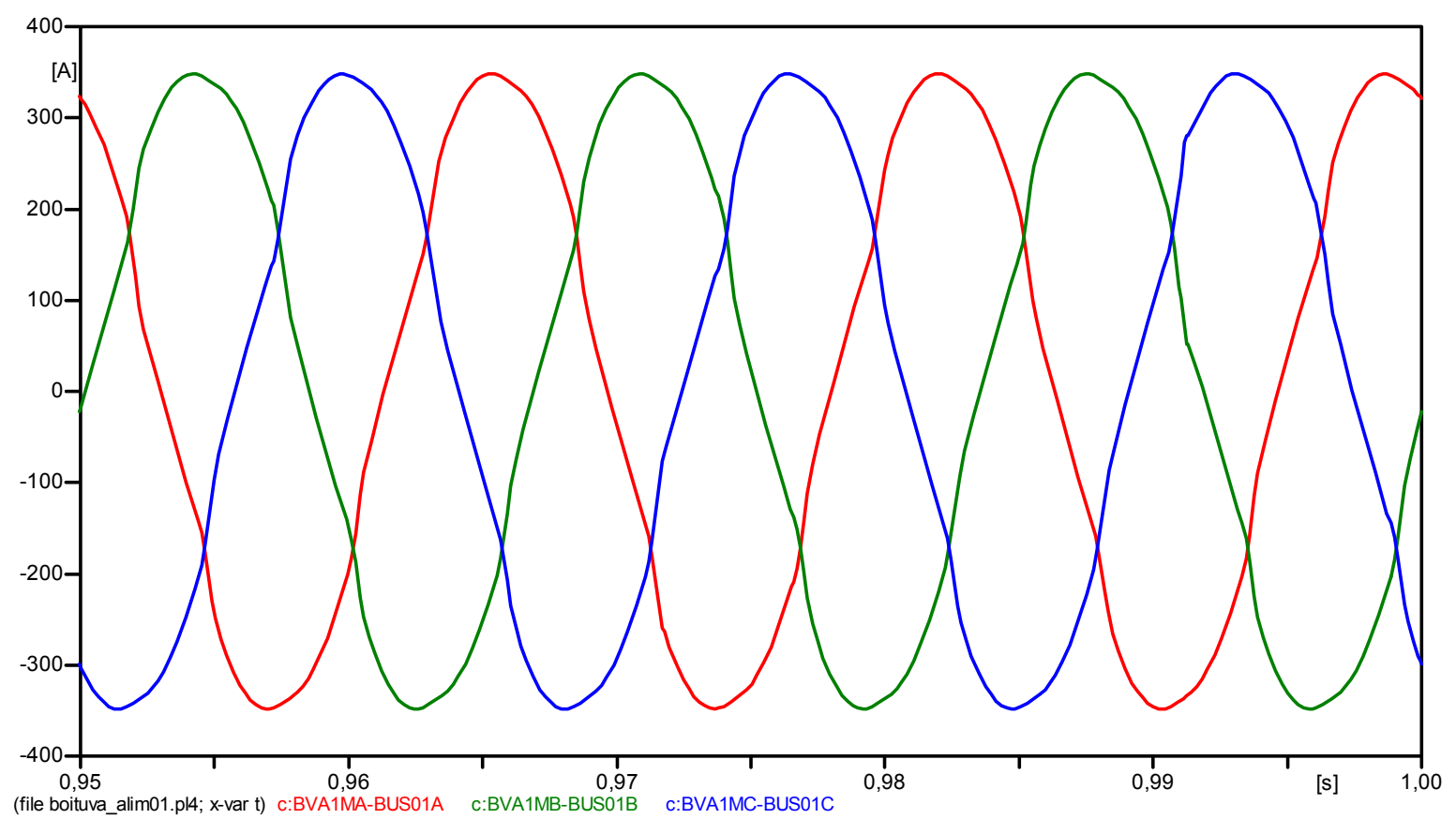

Figura 3.75 - Corrente instantânea trifásica (fase-terra) medida na subestação para o estudo de caso 3 (dado atual).

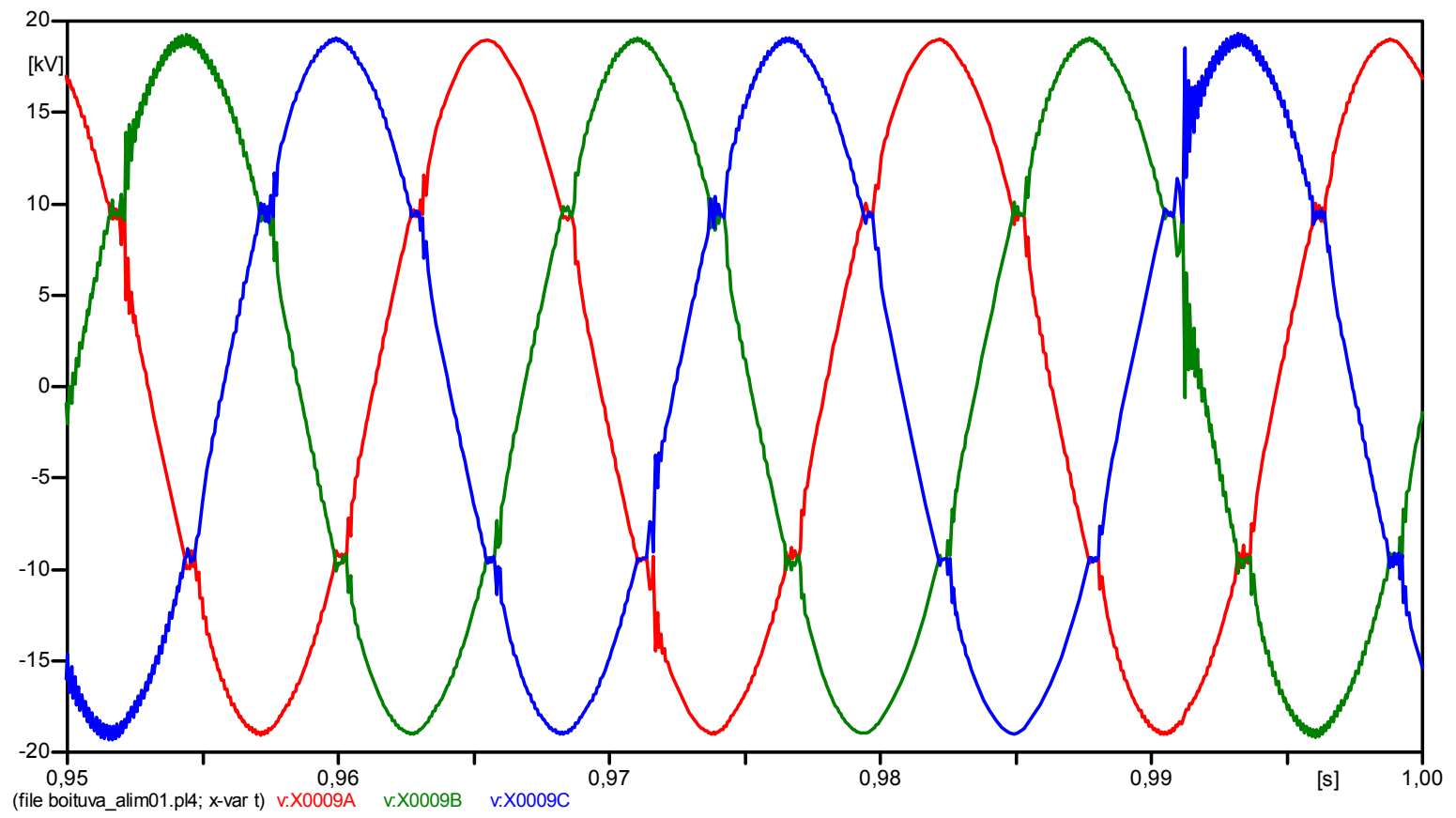

Figura 3.76 - Tensão instantânea trifásica (fase-terra) obtida pelo medidor de ramificação para o estudo de caso 3 (dado atual). 


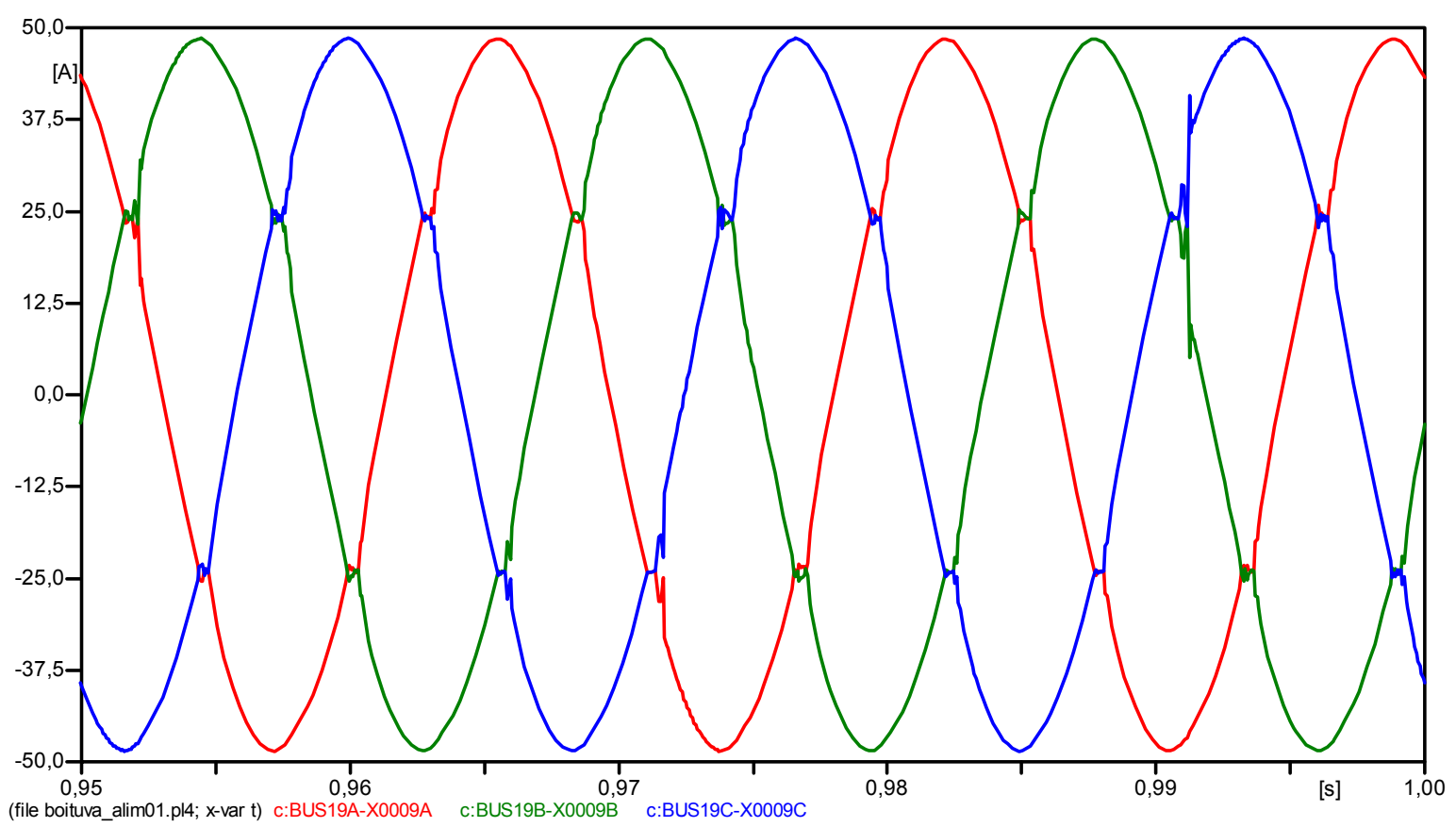

Figura 3.77 - Corrente instantânea trifásica (fase-terra) obtida pelo medidor de ramificação para o estudo de caso 3 (dado atual).

Em relação ao estudo de caso 3, verificou-se que as DHTs calculadas para as tensões medidas na subestação durante o estado atual da rede foram de $1,53 \%$ (fase A), 1,76\% (fase B) e 1,61\% (fase C). A seguir, apresenta-se a Tabela 3.27, onde são mostrados os níveis de tensão tanto da fundamental como das harmônicas (somente ímpares até $13^{a}$ ordem) medidas na subestação para cada uma das fases.

Tabela 3.27 - Componentes fundamental e harmônicas de tensão medidas na subestação para o estudo de caso 3.

\begin{tabular}{|c|c|c|c|}
\hline Fundamental e Harmônicas & $\begin{array}{c}\text { Amplitude (Vpico) } \\
\text { Fase A [V] }\end{array}$ & $\begin{array}{c}\text { Amplitude (Vpico) } \\
\text { Fase B [V] }\end{array}$ & $\begin{array}{c}\text { Amplitude (Vpico) } \\
\text { Fase C [V] }\end{array}$ \\
\hline 1 & 19291 & 19346 & 19294 \\
\hline 3 & 32,358 & 54,102 & 27,91 \\
\hline 5 & 168,24 & 200,95 & 187,21 \\
\hline 7 & 118,8 & 134,87 & 114,6 \\
\hline 9 & 4,7747 & 22,555 & 17,953 \\
\hline 11 & 109,88 & 110,87 & 128,83 \\
\hline 13 & 94,915 & 95,45 & 84,396 \\
\hline
\end{tabular}




\subsubsection{Estudo de Caso 4}

Por fim, neste quarto estudo de caso, as medidas históricas também apresentam distorções harmônicas. Desta forma, para se gerar os dados que correspondem ao histórico da rede, dois retificadores foram alocados nas barras B49 e B90. Os retificadores alimentavam cargas $\mathrm{RL}$, sendo ambas as cargas parametrizadas com $800 \Omega$ e $200 \mathrm{mH}$. Além dessas cargas não lineares alocadas nas barras B49 e B90, os bancos de capacitores são mantidos nas barras B05 e B47. As formas de onda das tensões e correntes históricas medidas na subestação e pelos medidores de ramificação podem ser visualizadas por meio das Figuras de 3.78 a 3.81 .

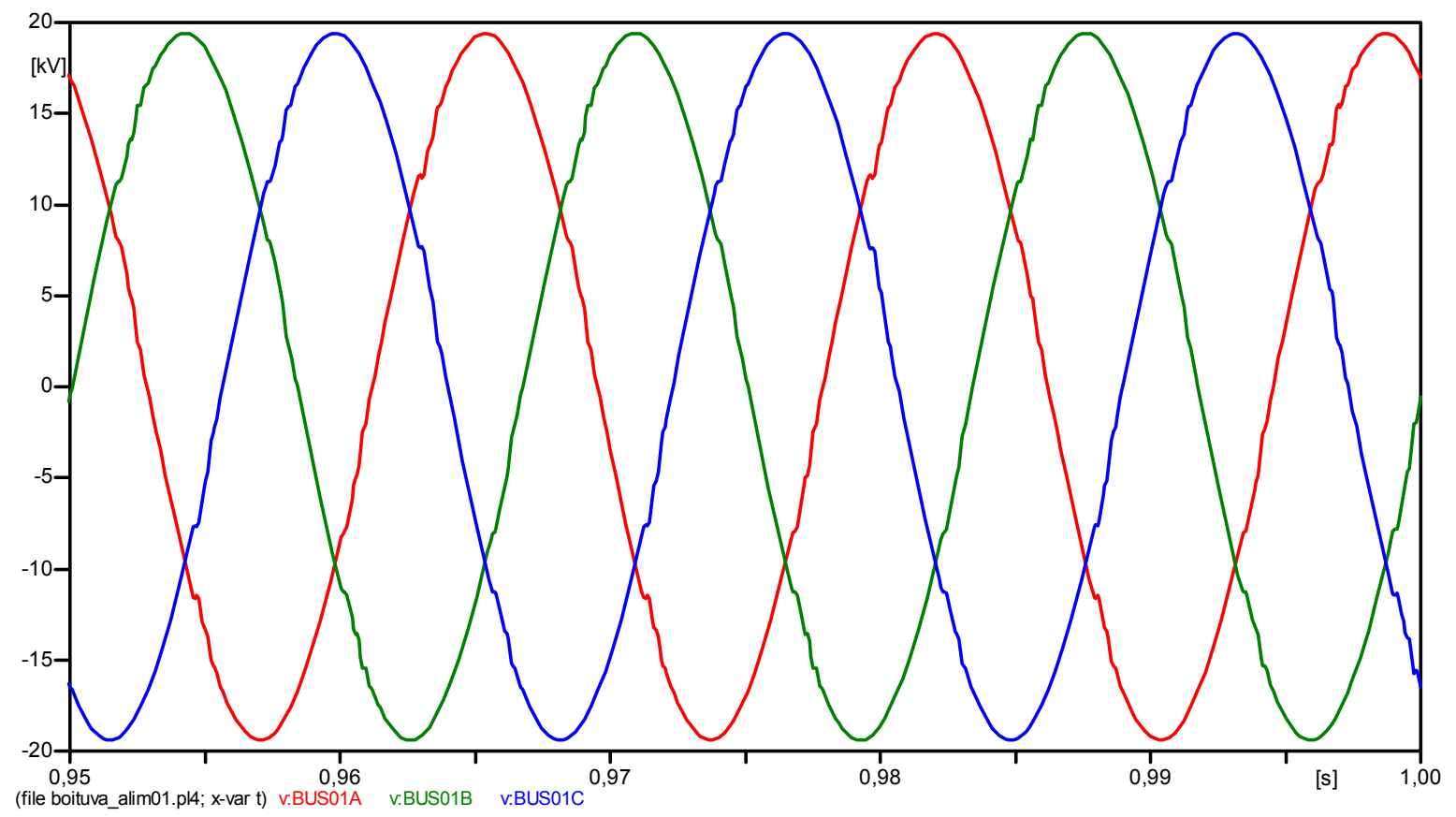

Figura 3.78 - Tensão instantânea trifásica (fase-terra) medida na subestação para o estudo de caso 4 (dado histórico). 


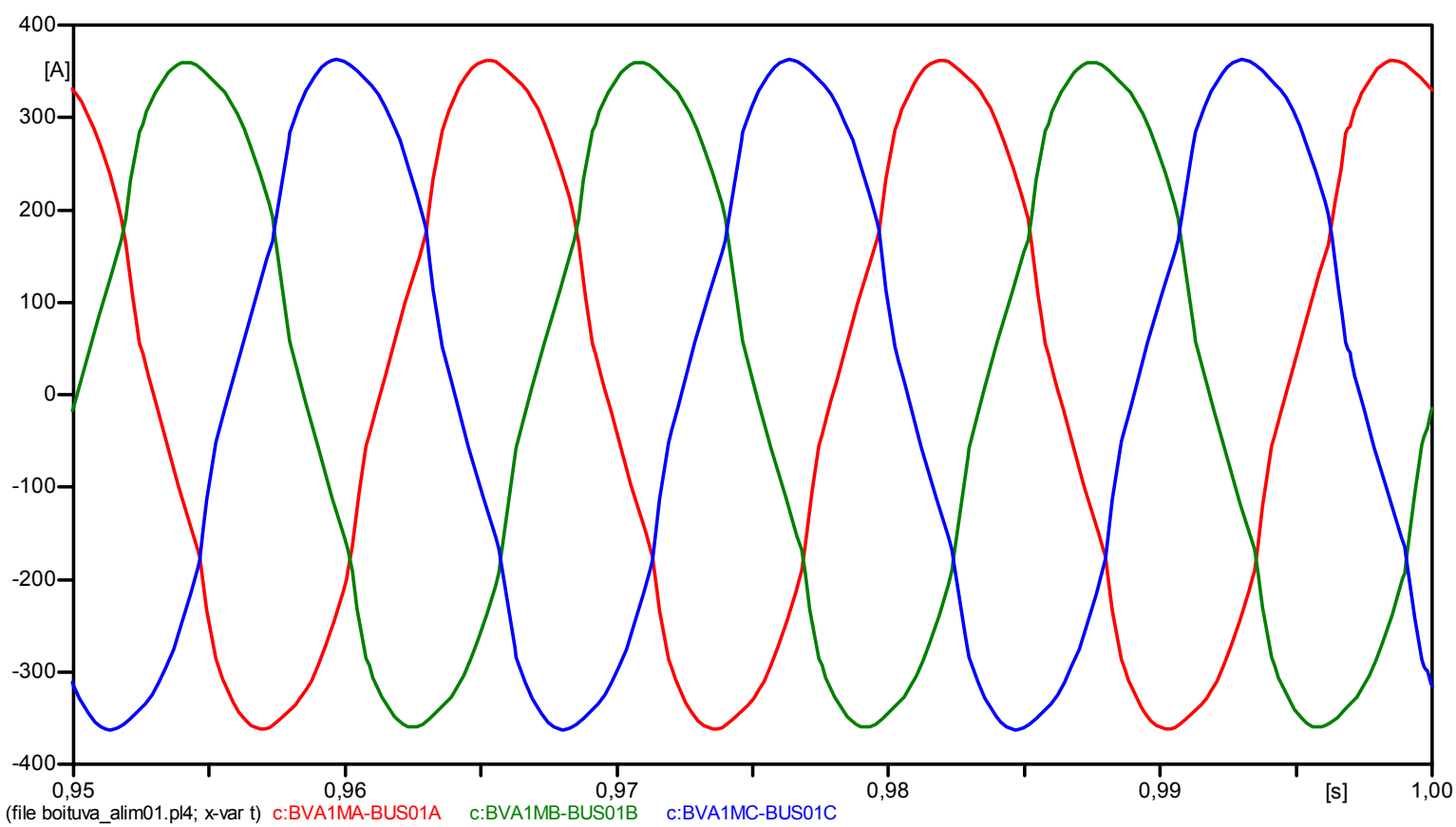

Figura 3.79 - Corrente instantânea trifásica (fase-terra) medida na subestação para o estudo de caso 4 (dado histórico).

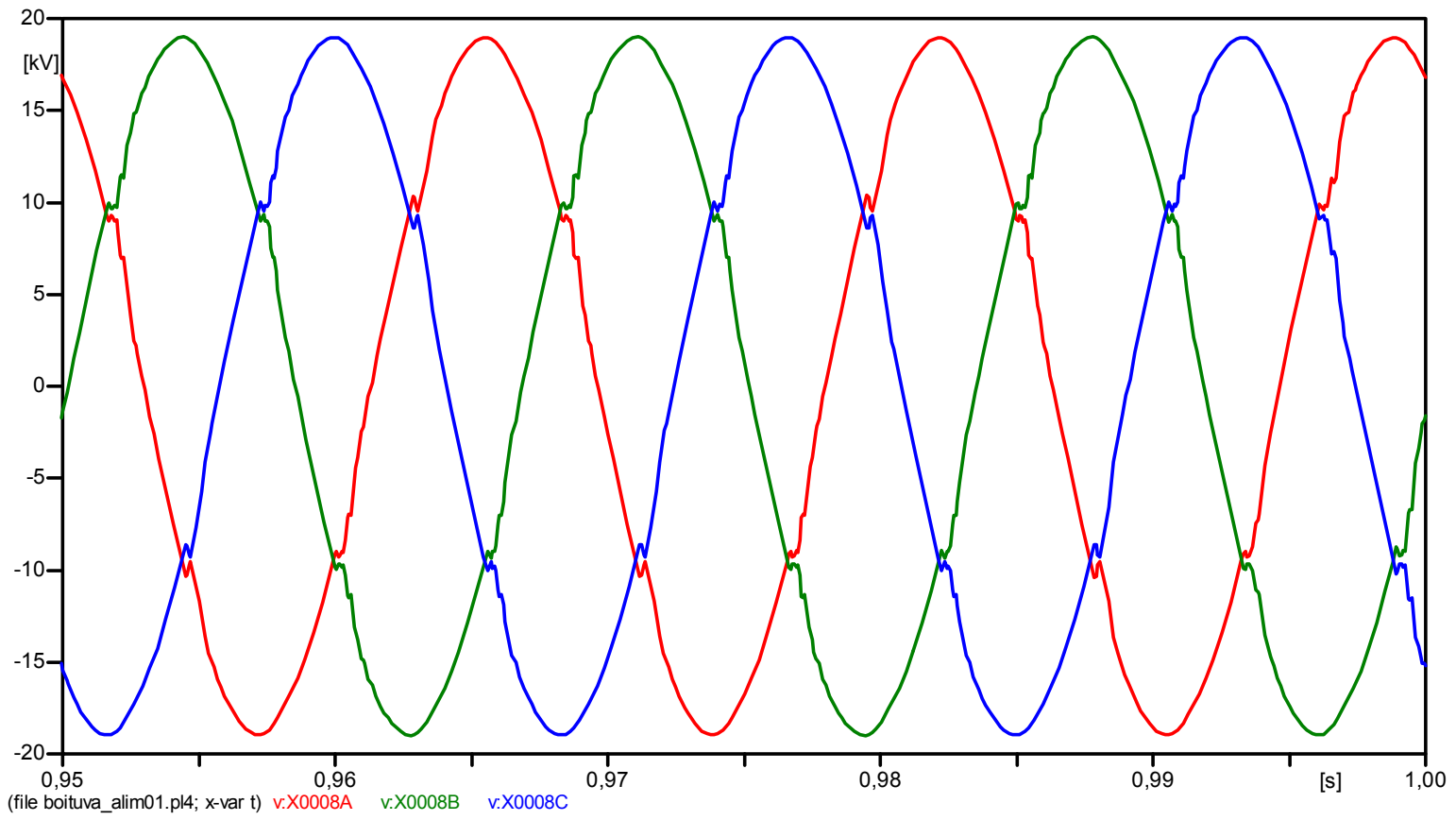

Figura 3.80 - Tensão instantânea trifásica (fase-terra) obtida pelo medidor de ramificação para o estudo de caso 4 (dado histórico). 


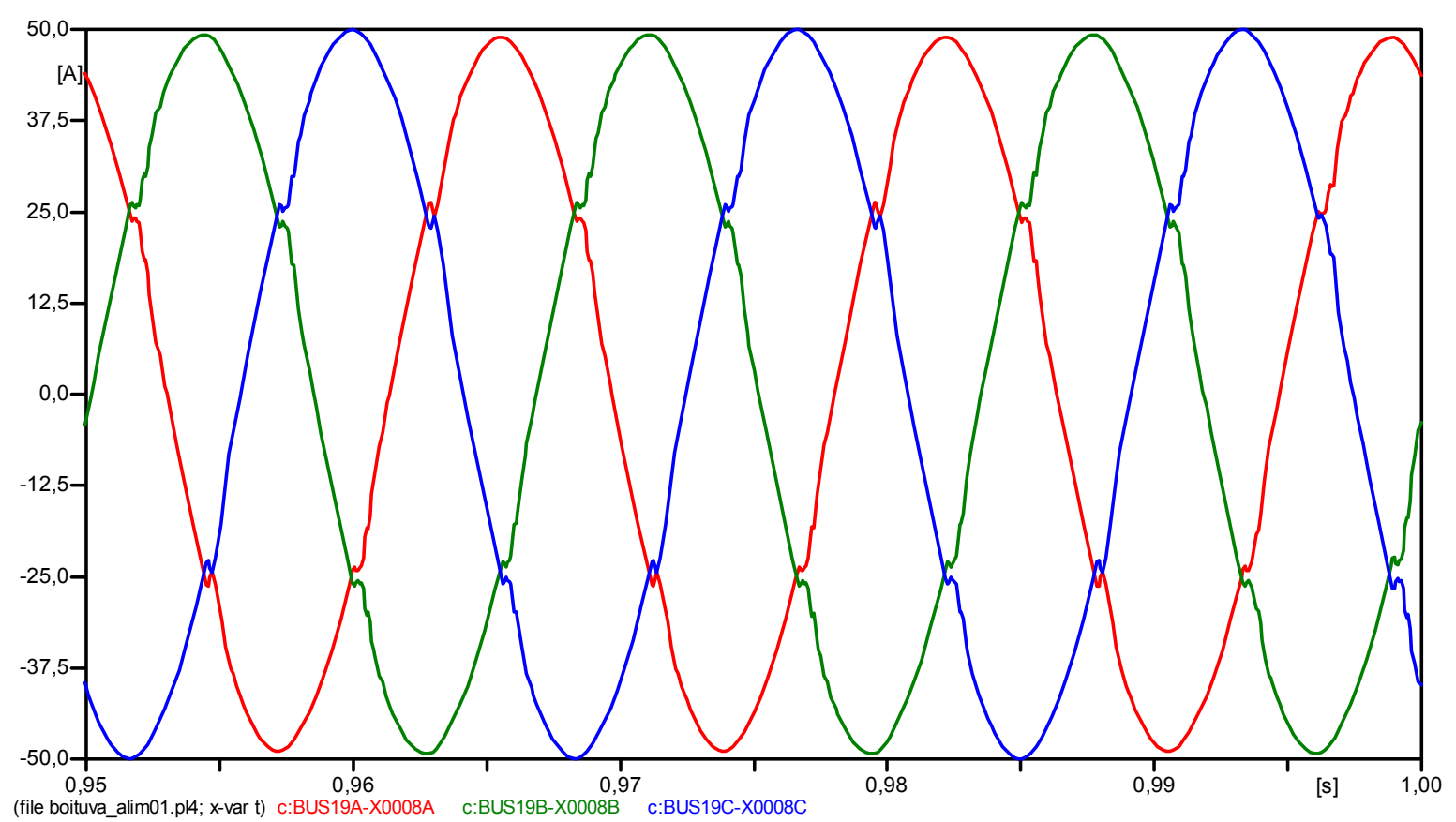

Figura 3.81 - Corrente instantânea trifásica (fase-terra) obtida pelo medidor de ramificação para o estudo de caso 4 (dado histórico).

Após obtidas as medidas de tensão da subestação, verificou-se que suas DHTs foram de $1,68 \%$ (fase A), 1,86\% (fase B) e 1,66\% (fase C).

Já a simulação que representa o estado atual deste estudo de caso conta com uma carga não linear (retificador) alocada na barra B05. Este retificador foi alocado no sistema a fim de alimentar uma carga $\mathrm{RL}$, sendo esta parametrizada com $1600 \Omega$ e $200 \mathrm{mH}$. Desta forma, foram medidas as correntes fundamental e harmônicas na entrada do retificador, as quais podem ser visualizadas por meio da Tabela 3.28. 
Tabela 3.28 - Assinatura harmônica de corrente da carga não linear alocada na barra B05 para o estudo de caso 4.

\begin{tabular}{|c|c|c|c|}
\hline Fundamental e Harmônicas & $\begin{array}{c}\text { Amplitude (Ipico) } \\
\text { Fase A [A] }\end{array}$ & $\begin{array}{c}\text { Amplitude (Ipico) } \\
\text { Fase B [A] }\end{array}$ & $\begin{array}{c}\text { Amplitude (Ipico) } \\
\text { Fase C [A] }\end{array}$ \\
\hline 1 & 22,334 & 22,34 & 22,386 \\
\hline 3 & 0,031102 & 0,071249 & 0,047756 \\
\hline 5 & 4,9293 & 4,9925 & 5,0112 \\
\hline 7 & 2,92 & 3,0475 & 3,0558 \\
\hline 9 & 0,095168 & 0,19462 & 0,10015 \\
\hline 11 & 2,3823 & 2,4073 & 2,546 \\
\hline 13 & 1,8862 & 2,118 & 2,0806 \\
\hline
\end{tabular}

Além disso, para a obtenção dos dados atuais deste estudo de caso, variações de tensão e carregamento foram geradas. Quanto às tensões, estas foram variadas em $-4 \%$ na fase $A,+10 \%$ na fase $B$ e $-7 \%$ na fase $C$. As variações de carregamento podem ser verificadas na Tabela 3.29.

Tabela 3.29 - Barras que sofreram variações de impedância durante a simulação dos dados que representam o estado atual da rede para o estudo de caso 4.

\begin{tabular}{|c|c|c|c|}
\hline Barra & Fase A & Fase B & Fase C \\
\hline B12 & $+5 \%$ & $+15 \%$ & $-15 \%$ \\
\hline B16 & $+10 \%$ & $+10 \%$ & $-10 \%$ \\
\hline B33 & $+5 \%$ & $+5 \%$ & $+5 \%$ \\
\hline B41 & $+8 \%$ & $+8 \%$ & $-8 \%$ \\
\hline B44 & $-3 \%$ & $-12 \%$ & $-7 \%$ \\
\hline B51 & $+12 \%$ & $-13 \%$ & $+14 \%$ \\
\hline B85 & $-8 \%$ & $-2 \%$ & $+5 \%$ \\
\hline
\end{tabular}

Assim, as formas de onda medidas tanto na subestação como na ramificação puderam ser obtidas e são mostradas nas Figuras de 3.82 a 3.85 . 


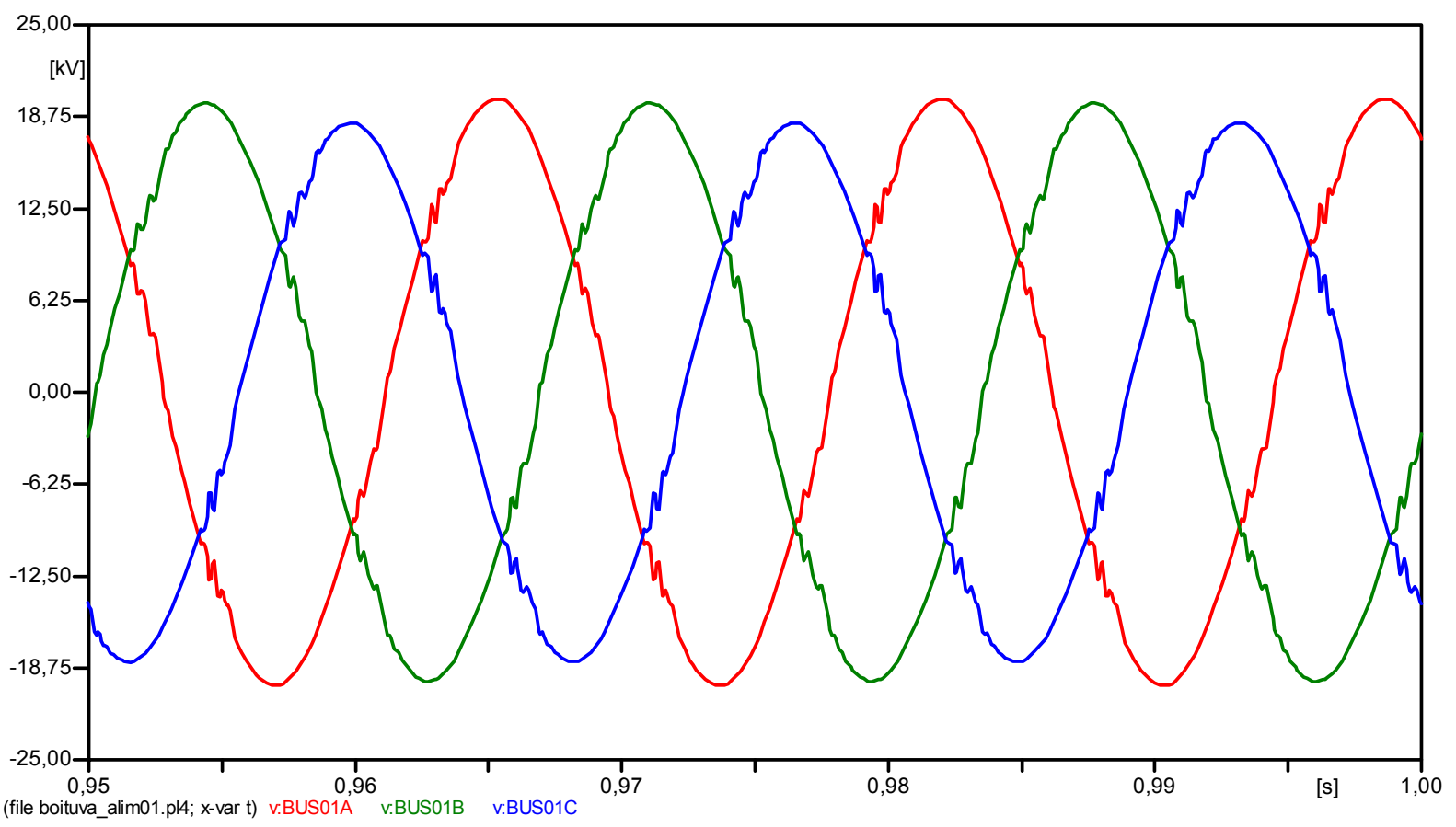

Figura 3.82 - Tensão instantânea trifásica (fase-terra) medida na subestação para o estudo de caso 4 (dado atual).

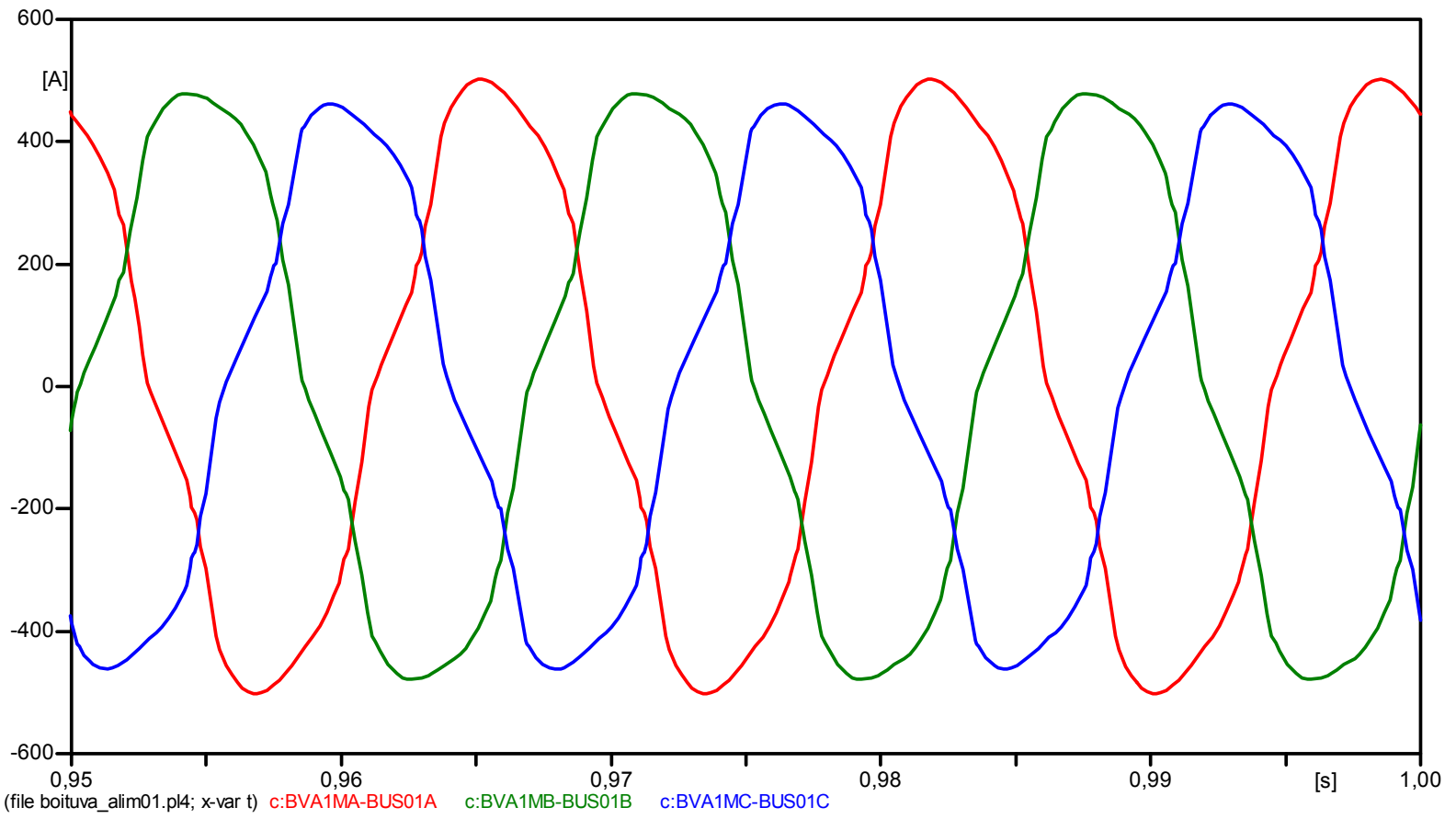

Figura 3.83 - Corrente instantânea trifásica (fase-terra) medida na subestação para o estudo de caso 4 (dado atual). 


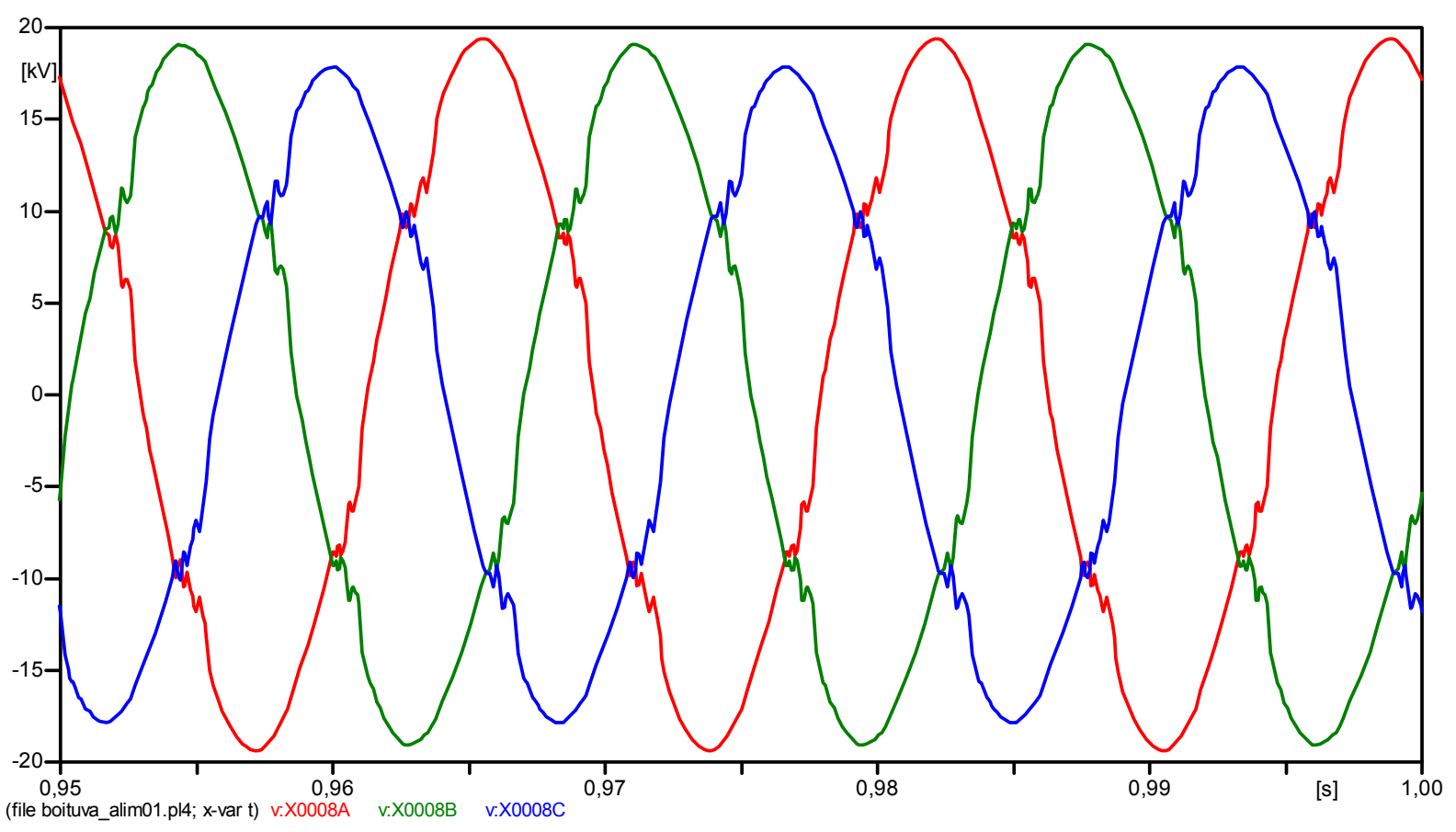

Figura 3.84 - Tensão instantânea trifásica (fase-terra) obtida pelo medidor de ramificação para o estudo de caso 4 (dado atual).

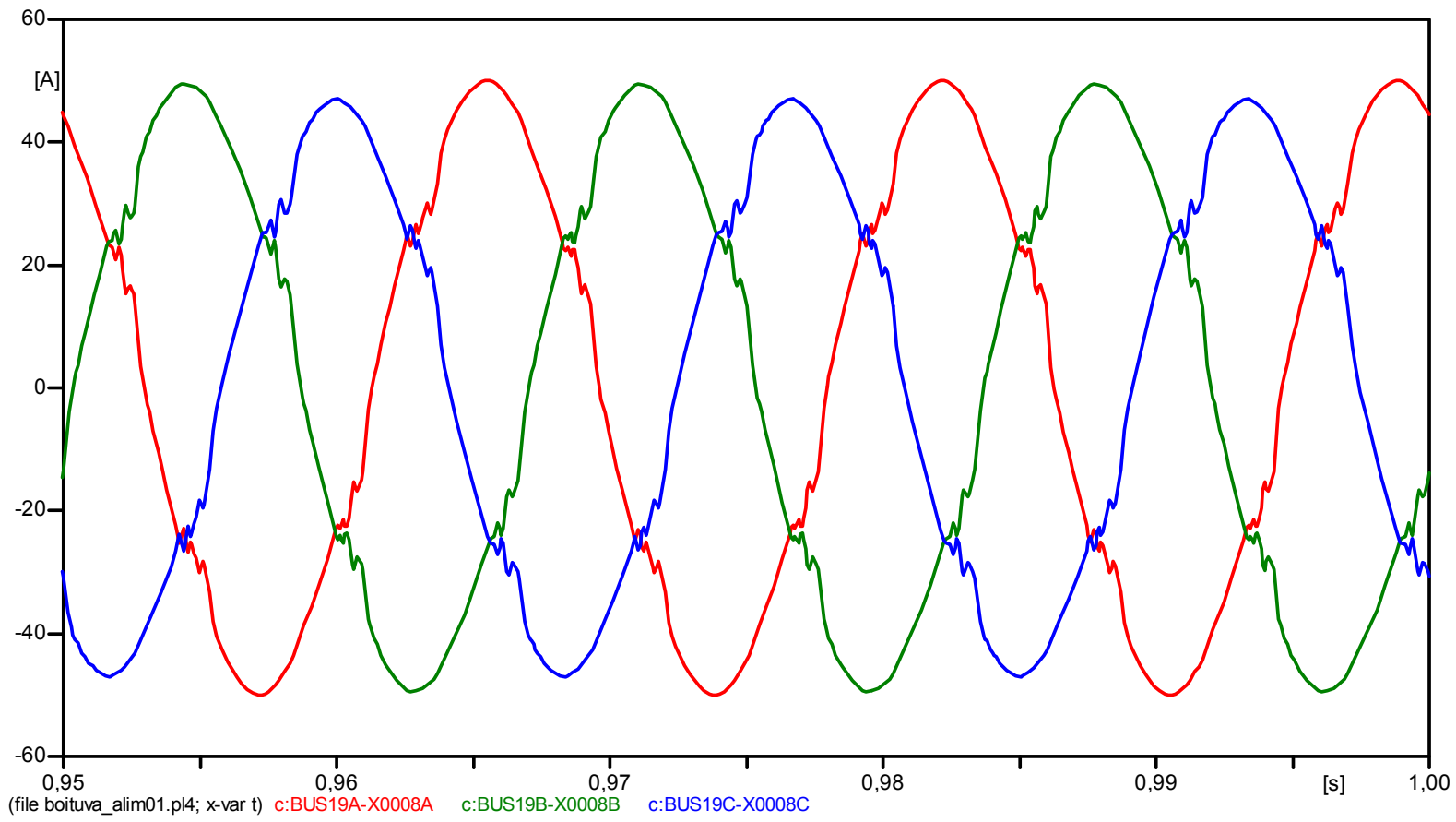

Figura 3.85 - Corrente instantânea trifásica (fase-terra) obtida pelo medidor de ramificação para o estudo de caso 4 (dado atual).

Frente ao estudo de caso 4, verificou-se que as DHTs calculadas para as tensões medidas na subestação durante o estado atual da rede foram de $2,76 \%$ 
(fase A), 3,00\% (fase B) e 3,09\% (fase C). A seguir, apresenta-se a Tabela 3.30, onde são mostrados os níveis de tensão tanto da fundamental como das harmônicas (somente ímpares até $13^{a}$ ordem) medidas na subestação para cada uma das fases.

Tabela 3.30 - Componentes fundamental e harmônicas de tensão medidas na subestação para o estudo de caso 4.

\begin{tabular}{|c|c|c|c|}
\hline Fundamental e Harmônicas & $\begin{array}{c}\text { Amplitude (Vpico) } \\
\text { Fase A [V] }\end{array}$ & $\begin{array}{c}\text { Amplitude (Vpico) } \\
\text { Fase B [V] }\end{array}$ & $\begin{array}{c}\text { Amplitude (Vpico) } \\
\text { Fase C [V] }\end{array}$ \\
\hline 1 & 19735 & 19511 & 18104 \\
\hline 3 & 70,327 & 61,205 & 19,529 \\
\hline 5 & 396,88 & 424,94 & 450,51 \\
\hline 7 & 285,62 & 286,75 & 194,64 \\
\hline 9 & 36,016 & 52,954 & 88,924 \\
\hline 11 & 101,43 & 123,41 & 154,17 \\
\hline 13 & 118,06 & 117,86 & 60,272 \\
\hline
\end{tabular}

\subsection{Aspectos Normativos}

Apenas como comentário adicional, é importante ressaltar que todas as distorções harmônicas geradas em cada um dos estudos de caso foram realizadas de forma a apresentarem DHTs dentro dos limites impostos tanto pelo IEEE (IEEE Standard 519-1992, 1992) quanto pelos Procedimentos de Distribuição de Energia Elétrica no Sistema Elétrico Nacional (ANEEL, 2010). Os limites recomendados pelo IEEE podem ser visualizados por meio da Tabela 3.31. Já os limites impostos pelo PRODIST (Procedimentos de Distribuição de Energia Elétrica no Sistema Elétrico Nacional), estes podem ser verificados tanto na Tabela 3.32 (distorções harmônicas individuais de tensão) como na Tabela 3.33 (distorções harmônicas totais de tensão). 
Tabela 3.31 - Limites recomendados pelo IEEE para distorções harmônicas individuais e totais de tensão.

\begin{tabular}{|c|c|c|}
\hline Tensão Nominal do Barramento (Vn) & $\begin{array}{c}\text { Distorção Harmônica } \\
\text { Individual (\%) }\end{array}$ & $\begin{array}{c}\text { Distorção Harmônica } \\
\text { Total (\%) }\end{array}$ \\
\hline $\mathrm{Vn} \leq 69 \mathrm{kV}$ & 3 & 5 \\
\hline $69 \mathrm{kV}<\mathrm{Vn} \leq 161 \mathrm{kV}$ & 1,5 & 2,5 \\
\hline $\mathrm{Vn}>161 \mathrm{kV}$ & 1 & 1,5 \\
\hline
\end{tabular}

Fonte: (IEEE Standard 519-1992, 1992)

Tabela 3.32 - Limites fornecidos pelo PRODIST para as distorções harmônicas individuais de tensão.

\begin{tabular}{|c|c|c|c|c|c|}
\hline & \multirow{2}{*}{$\begin{array}{c}\text { Ordem } \\
\text { Harmônica }\end{array}$} & \multicolumn{4}{|c|}{ Distorção Harmônica Individual de Tensão (\%) } \\
\hline & & $\mathrm{Vn} \leq 1 \mathrm{kV}$ & $1 \mathrm{kV}<\mathrm{Vn} \leq 13,8 \mathrm{kV}$ & $13,8 \mathrm{kV}<\mathrm{Vn} \leq 69 \mathrm{kV}$ & $69 \mathrm{kV}<\mathrm{Vn} \leq 230 \mathrm{kV}$ \\
\hline \multirow{9}{*}{ 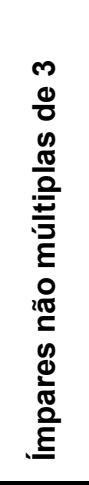 } & 5 & 7,5 & 6 & 4,5 & 2,5 \\
\hline & 7 & 6,5 & 5 & 4 & 2 \\
\hline & 11 & 4,5 & 3,5 & 3 & 1,5 \\
\hline & 13 & 4 & 3 & 2,5 & 1,5 \\
\hline & 17 & 2,5 & 2 & 1,5 & 1 \\
\hline & 19 & 2 & 1,5 & 1,5 & 1 \\
\hline & 23 & 2 & 1,5 & 1,5 & 1 \\
\hline & 25 & 2 & 1,5 & 1,5 & 1 \\
\hline & $>25$ & 1,5 & 1 & 1 & 0,5 \\
\hline \multirow{5}{*}{ 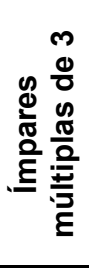 } & 3 & 6,5 & 5 & 4 & 2 \\
\hline & 9 & 2 & 1,5 & 1,5 & 1 \\
\hline & 15 & 1 & 0,5 & 0,5 & 0,5 \\
\hline & 21 & 1 & 0,5 & 0,5 & 0,5 \\
\hline & $>21$ & 1 & 0,5 & 0,5 & 0,5 \\
\hline \multirow{7}{*}{$\frac{\mathscr{0}}{\frac{0}{\pi}}$} & 2 & 2,5 & 2 & 1,5 & 1 \\
\hline & 4 & 1,5 & 1 & 1 & 0,5 \\
\hline & 6 & 1 & 0,5 & 0,5 & 0,5 \\
\hline & 8 & 1 & 0,5 & 0,5 & 0,5 \\
\hline & 10 & 1 & 0,5 & 0,5 & 0,5 \\
\hline & 12 & 1 & 0,5 & 0,5 & 0,5 \\
\hline & $>12$ & 1 & 0,5 & 0,5 & 0,5 \\
\hline
\end{tabular}

Fonte: (ANEEL, 2010) 
Tabela 3.33 - Limites fornecidos pelo PRODIST para as distorções harmônicas totais de tensão.

\begin{tabular}{|c|c|}
\hline Tensão Nominal do Barramento $(\mathbf{V n})$ & DHT de Tensão (\%) \\
\hline $\mathrm{Vn} \leq 1 \mathrm{kV}$ & 10 \\
\hline $1 \mathrm{kV}<\mathrm{Vn} \leq 13,8 \mathrm{kV}$ & 8 \\
\hline $13,8 \mathrm{kV}<\mathrm{Vn} \leq 69 \mathrm{kV}$ & 6 \\
\hline $69<\mathrm{Vn} \leq 230 \mathrm{kV}$ & 3 \\
\hline
\end{tabular}

Fonte: (ANEEL, 2010) 


\section{Método Proposto para Localização da Fonte Consumidora de Potências Harmônicas}

Este capítulo tem como objetivo apresentar, em detalhes, os aspectos do método desenvolvido para a localização da fonte consumidora de potências harmônicas. Por este motivo, no Capítulo 3, foram devidamente mostrados os estudos de caso que têm como função validar a metodologia proposta. Portanto, na sequência, são explanados com o auxílio de diagramas de blocos os aspectos fundamentais do sistema de localização (Seção 4.1). Após fornecidos os detalhes do localizador, os resultados obtidos pelo mesmo são reportados (Seção 4.2).

\subsection{Aspectos do Sistema de Localização}

O sistema de localização da fonte consumidora de potências harmônicas foi desenvolvido com o intuito de localizar uma fonte causadora de distorções harmônicas, tendo-se como base somente duas medidas (histórica e atual), as quais foram realizadas pelos medidores da subestação e, também, por medidores alocados no final do alimentador (no sistema de 20 barras) ou em alguma ramificação da rede (no sistema de 90 barras). Cabe comentar que este método, apesar de ser compacto, possui um alto esforço computacional, pois depende da simulação de uma diversidade de casos para que a fonte seja localizada. 0 mecanismo de funcionamento do localizador é ilustrado por intermédio da Figura 4.1, a qual será explanada em maior nível de detalhamento. 


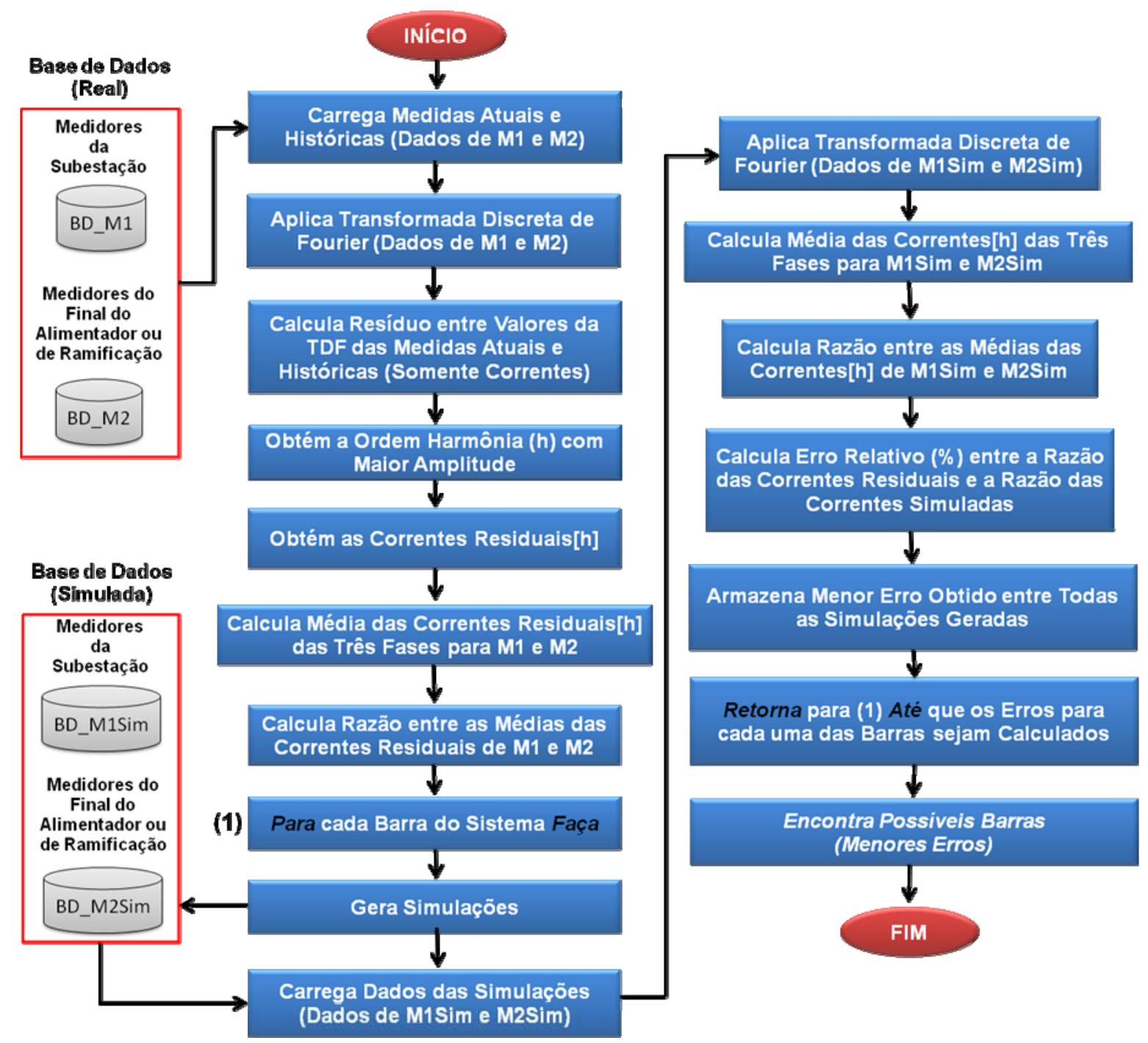

Figura 4.1 - Mecanismo de funcionamento do localizador de fonte consumidora de potências harmônicas.

Mediante a análise da Figura 4.1 nota-se que os dados gerados em cada um dos estudos de caso são armazenados em bases de dados, onde tais dados são fornecidos como entrada para o sistema de localização. Desta forma, após carregados os dados históricos e os dados que representam o estado atual do sistema, calcula-se a TDF sobre estes sinais/dados. Posteriormente, os resultados obtidos pela aplicação da TDF (fundamental e harmônicas) são utilizados para calcular os resíduos entre as medidas históricas e atuais (nesta etapa são consideradas somente as correntes), isto é, realiza-se uma operação de subtração 
entre as medidas atuais e históricas, tendo-se aqui o intuito de se retirar da análise as possíveis cargas não lineares que já estiverem presentes na rede quando da obtenção dos dados históricos.

Calculados os resíduos, é possível dizer que um novo conjunto de dados é obtido (dados residuais), sendo que este conjunto de dados conta agora com os resíduos das tensões e correntes dos medidores da subestação e também daqueles medidores do final do alimentador (sistema de 20 barras) ou de ramificação (sistema de 90 barras).

Analisando-se os resíduos das tensões da subestação, faz-se uma verificação sobre qual é a harmônica com maior amplitude e, desta forma, a ordem desta harmônica de maior amplitude é conhecida. Na sequência, são selecionadas as correntes harmônicas residuais referentes à ordem harmônica previamente obtida.

Tendo em mãos as correntes residuais para a ordem harmônica obtida, calcula-se então a média das três fases para estas correntes harmônicas residuais. Por fim, são obtidos os dados que servem como referência para o método de localização, onde se calcula a razão entre as médias das correntes residuais.

A partir deste estágio, o algoritmo inicializa um laço de repetição (loop) até que cada barra do sistema tenha sido testada. Dentro deste laço, uma grande quantidade de simulações é gerada (Figura 4.2). Estas simulações são geradas com base numa tabela de amplitudes que pode ser mais bem compreendida por meio da Figura 4.2. 


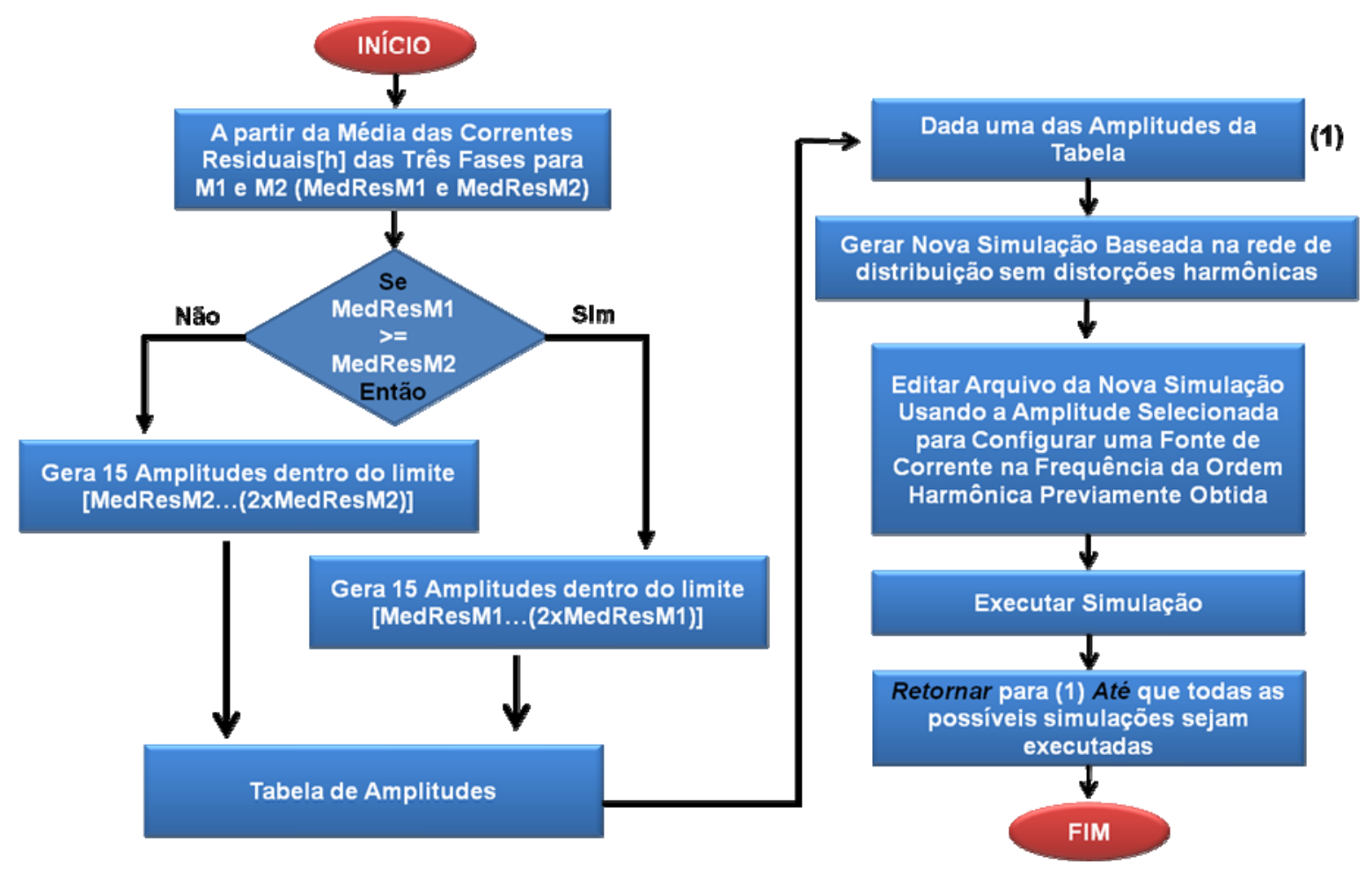

Figura 4.2 - Mecanismo de funcionamento do bloco "Gera Simulações".

Cada uma das 15 amplitudes geradas configuram uma simulação; no entanto, esta quantidade de amplitudes é variável e quanto mais amplitudes forem geradas, maior será também a precisão do sistema de localização. Adotou-se a quantidade de 15 amplitudes devido ao custo computacional para gerar esta quantidade de simulações e também pelo fato deste número possibilitar uma boa resposta do método de localização. Nesta etapa do algoritmo, é importante compreender que para cada simulação, aloca-se uma fonte de corrente com amplitude proveniente da tabela previamente comentada e com frequência correspondente à ordem harmônica obtida antes da inicialização do laço de repetição. É importante comentar que esta amplitude pode representar em alguns casos uma aproximação grosseira à amplitude da corrente harmônica da carga (somente a corrente da ordem harmônica previamente selecionada), pois, a mesma não é conhecida. 
Para que cada um dos 15 casos sejam gerados, um arquivo que representa a configuração base do sistema (rede conforme conhecida sem distorções harmônicas, isto é, somente com as cargas RL e bancos de capacitores) é editado para que cada uma das simulações possa ser executada, como mostrado na Figura 4.2.

Desta forma, conforme a Figura 4.1, uma nova base de dados contendo somente os dados simulados é obtida e armazenada. Assim, as medidas de M1Sim (medidas da subestação) e M2Sim (medidas do final do alimentador ou de ramificação) que representam os dados simulados são carregadas, onde as mesmas são direcionadas ao cálculo da TDF a fim de que as componentes fundamentais e harmônicas das medidas de tensão e corrente sejam obtidas.

Calcula-se então a média das correntes harmônicas para as três fases (somente para a ordem harmônica obtida no início do algoritmo de localização). Na sequência, é calculada a razão entre as médias das correntes harmônicas obtidas para as medidas da subestação e para aquelas medidas do final do alimentador ou da ramificação. Obtidas estas razões para cada uma das 15 simulações geradas, verifica-se então qual delas apresenta o menor erro absoluto quando comparadas à razão calculada para as medidas atuais e históricas da rede (razão de referência). Assim, a simulação que apresentar o menor erro é eleita como uma possível solução para a localização da fonte consumidora de potências harmônicas. Entretanto, para cada barra do sistema, deve-se então eleger uma possível solução, isto é, a solução que apresentou o menor erro.

Finalizado o laço de repetição e obtidos os menores erros para cada uma das barras que compõem a rede, gera-se uma lista das barras com seus respectivos 
erros. Assim, a barra com menor erro é tida como provável posição da fonte consumidora de potências harmônicas.

\subsection{Resultados Obtidos pelo Localizador para Cada Estudo de Caso}

Conforme previamente comentado, o localizador fornece uma lista das barras junto com seus respectivos erros absolutos. Assim, as Tabelas de 4.1 a 4.6 mostram estas listas obtidas para cada um dos seis estudos de caso relacionados ao sistema fictício de 20 barras, destacando-se a barra de menor erro e também aquela barra a ser localizada, isto é, a barra onde a fonte consumidora de potências harmônicas encontra-se devidamente alocada.

Tabela 4.1 - Erros obtidos para cada uma das barras no estudo de caso 1 do sistema de 20 barras.

\begin{tabular}{|c|c|c|c|c|}
\hline Barras & Erros & Barras & Erros & $\begin{array}{l}\text { Barra a ser } \\
\text { Localizada }\end{array}$ \\
\hline 10 & 12,71 & 34 & 12,30 & \multirow{10}{*}{21} \\
\hline 20 & 2,74 & 40 & 31,13 & \\
\hline 21 & 2,75 & 41 & 31,33 & \\
\hline 22 & 2,74 & 42 & 31,34 & \\
\hline 23 & 2,75 & 43 & 31,13 & \\
\hline 24 & 2,75 & 44 & 31,13 & \\
\hline 30 & 12,30 & 50 & 4118,40 & \\
\hline 31 & 12,30 & 51 & 4118,34 & \\
\hline 32 & 12,30 & 52 & 4118,32 & \\
\hline 33 & 12,30 & 53 & 4118,31 & \\
\hline
\end{tabular}


Tabela 4.2 - Erros obtidos para cada uma das barras no estudo de caso 2 do sistema de 20 barras.

\begin{tabular}{|c|c||c|c||c||}
\hline Barras & Erros & Barras & Erros & $\begin{array}{c}\text { Barra a ser } \\
\text { Localizada }\end{array}$ \\
\hline 10 & 21,10 & 34 & 5,67 \\
\hline 20 & 13,21 & 40 & 13,95 \\
\hline 21 & 13,21 & 41 & 14,04 \\
\hline 22 & 13,22 & 42 & 14,04 \\
\hline 23 & 13,22 & 43 & 13,95 & \\
\hline 24 & 13,22 & 44 & 13,95 & \multirow{3}{*}{30} \\
\hline 30 & 5,66 & 50 & 3227,54 & \\
\hline 31 & 5,67 & 51 & 3227,49 & \\
\hline 32 & 5,67 & 52 & 3227,48 \\
\hline 33 & 5,67 & 53 & 3227,47 & \\
\hline
\end{tabular}

Tabela 4.3 - Erros obtidos para cada uma das barras no estudo de caso 3 do sistema de 20 barras.

\begin{tabular}{|c|c||c|c||c||}
\hline Barras & Erros & Barras & Erros & $\begin{array}{c}\text { Barra a ser } \\
\text { Localizada }\end{array}$ \\
\hline 10 & 26,00 & 34 & 1,96 \\
\hline 20 & 15,50 & 40 & 23,18 \\
\hline 21 & 15,50 & 15,50 & 41 & 23,17 \\
\hline 22 & 15,50 & 42 & 23,18 \\
\hline 23 & 15,50 & 43 & 23,18 \\
\hline 24 & 1,96 & 44 & 23,18 \\
\hline 30 & 1,96 & 50 & 465,68 \\
\hline 31 & 1,96 & 51 & 465,67 \\
\hline 32 & 1,96 & 52 & 465,67 \\
\hline 33 & 53 & 465,67 \\
\hline
\end{tabular}


Tabela 4.4 - Erros obtidos para cada uma das barras no estudo de caso 4 do sistema de 20 barras.

\begin{tabular}{|c|c||c|c||c|}
\hline Barras & Erros & Barras & Erros & $\begin{array}{c}\text { Barra a ser } \\
\text { Localizada }\end{array}$ \\
\hline 10 & 49,86 & 34 & 49,70 \\
\hline 20 & 49,69 & 40 & 49,51 \\
\hline 21 & 49,69 & 41 & 49,51 \\
\hline 22 & 49,69 & 42 & 49,51 \\
\hline 23 & 49,69 & 43 & 49,51 \\
\hline 24 & 49,69 & 44 & 49,51 \\
\hline 30 & 49,70 & 50 & 0,42 \\
\hline 31 & 49,70 & 51 & $\mathbf{0 , 4 2}$ \\
\hline 32 & 49,70 & $\mathbf{5 2}$ & $\mathbf{0 , 4 2}$ \\
\hline 33 & 49,70 & $\mathbf{5 3}$ & $\mathbf{0 , 4 2}$ \\
\hline
\end{tabular}

Tabela 4.5 - Erros obtidos para cada uma das barras no estudo de caso 5 do sistema de 20 barras.

\begin{tabular}{|c|c|c|c|c|}
\hline Barras & Erros & Barras & Erros & $\begin{array}{l}\text { Barra a ser } \\
\text { Localizada }\end{array}$ \\
\hline 10 & 50,06 & 34 & 49,63 & \multirow{10}{*}{52} \\
\hline 20 & 49,81 & 40 & 49,50 & \\
\hline 21 & 49,81 & 41 & 49,50 & \\
\hline 22 & 49,81 & 42 & 49,50 & \\
\hline 23 & 49,81 & 43 & 49,50 & \\
\hline 24 & 49,81 & 44 & 49,50 & \\
\hline 30 & 49,62 & 50 & 0,50 & \\
\hline 31 & 49,63 & 51 & 0,50 & \\
\hline 32 & 49,63 & 52 & 0,50 & \\
\hline 33 & 49,63 & 53 & 0,50 & \\
\hline
\end{tabular}


Tabela 4.6 - Erros obtidos para cada uma das barras no estudo de caso 6 do sistema de 20 barras.

\begin{tabular}{|c|c|c|c|c|}
\hline Barras & Erros & Barras & Erros & $\begin{array}{l}\text { Barra a ser } \\
\text { Localizada }\end{array}$ \\
\hline 10 & 44,55 & 34 & 41,09 & \multirow{10}{*}{42} \\
\hline 20 & 42,77 & 40 & 37,75 & \\
\hline 21 & 42,77 & 41 & 37,75 & \\
\hline 22 & 42,77 & 42 & 37,75 & \\
\hline 23 & 42,78 & 43 & 37,75 & \\
\hline 24 & 42,78 & 44 & 37,75 & \\
\hline 30 & 41,09 & 50 & 363,19 & \\
\hline 31 & 41,09 & 51 & 363,18 & \\
\hline 32 & 41,09 & 52 & 363,18 & \\
\hline 33 & 41,09 & 53 & 363,18 & \\
\hline
\end{tabular}

Analisando os resultados obtidos pelo método de localização, somente o estudo de caso 2 apresentou um resultado preciso para a localização da fonte consumidora de potências harmônicas.

Para o estudo de caso 1, o método de localização apresenta duas possíveis soluções, onde é possível verificar que nenhuma delas representa a real posição da carga. Entretanto, são posições muito próximas à carga, visto que a barra 21 encontra-se a $100 \mathrm{~m}$ da barra 20 e a apenas $50 \mathrm{~m}$ da barra 22. Portanto, diz-se que o método de localização apresentou para este estudo de caso um erro na faixa de 50 a 100 metros de distância.

No estudo de caso 3, o localizador elege um conjunto de barras maior (barras 30, 31, 32, 33 e 34). Neste caso, verifica-se que a barra 34 (posição real da carga) encontra-se na lista de possíveis soluções. Ainda com relação ao estudo de caso 4, pode-se dizer que o erro apresentado pelo método de localização está na faixa de 0 a 2350 metros de distância. 
Já no estudo de caso 4 , o localizador de fontes consumidoras de potências harmônicas elege as barras 50, 51, 52 e 53. Assim, é possível notar que a barra 53 (posição real da carga) também está na lista de possíveis soluções. Para este estudo de caso foi constatado um erro que varia entre 0 e 300 metros de distância.

Assim como no estudo de caso 4, para o estudo de caso 5, as barras 50,51, 52 e 53 foram novamente eleitas; entretanto, para este estudo de caso, a carga encontra-se alocada na barra 52. Desta forma, foi possível obter um erro que varia entre 0 e 300 metros de distância.

Por fim, para o estudo de caso 6 , as barras $40,41,42,43$ e 44 foram eleitas como possíveis soluções. No entanto, a carga não linear encontra-se alocada na barra 42. Portanto, o erro variou entre 0 e 1300 metros de distância.

Na sequência deste capítulo, os resultados do método de localização obtidos para os quatro estudos de caso realizados para o sistema real composto por 90 barras serão apresentados por meio das Tabelas de 4.7 a 4.10 . 
Tabela 4.7 - Erros obtidos para cada uma das barras no estudo de caso 1 do sistema de 90 barras.

\begin{tabular}{|c|c|c|c|c|c|c|c|c|}
\hline Barras & Erros & Barras & Erros & Barras & Erros & Barras & Erros & $\begin{array}{l}\text { Barra a ser } \\
\text { Localizada }\end{array}$ \\
\hline 01 & 47,08 & 24 & 4,68 & 47 & 45,13 & 70 & 45,61 & \multirow{23}{*}{ B45 } \\
\hline 02 & 47,71 & 25 & 4,68 & 48 & 45,17 & 71 & 45,67 & \\
\hline 03 & 48,63 & 26 & 4,68 & 49 & 45,17 & 72 & 45,67 & \\
\hline 04 & 47,68 & 27 & 4,67 & 50 & 45,25 & 73 & 45,69 & \\
\hline 05 & 47,05 & 28 & 4,65 & 51 & 45,25 & 74 & 45,70 & \\
\hline 06 & 46,80 & 29 & 4,65 & 52 & 45,30 & 75 & 45,70 & \\
\hline 07 & 46,71 & 30 & 4,64 & 53 & 45,32 & 76 & 45,71 & \\
\hline 08 & 46,09 & 31 & 4,63 & 54 & 45,37 & 77 & 45,71 & \\
\hline 09 & 45,96 & 32 & 4,62 & 55 & 45,42 & 78 & 45,71 & \\
\hline 10 & 46,00 & 33 & 4,62 & 56 & 45,42 & 79 & 45,71 & \\
\hline 11 & 47,51 & 34 & 4,61 & 57 & 45,42 & 80 & 45,72 & \\
\hline 12 & 46,39 & 35 & 4,61 & 58 & 45,42 & 81 & 45,75 & \\
\hline 13 & 45,99 & 36 & 4,61 & 59 & 45,42 & 82 & 45,76 & \\
\hline 14 & 45,79 & 37 & 4,61 & 60 & 45,42 & 83 & 45,76 & \\
\hline 15 & 45,79 & 38 & 4,60 & 61 & 45,42 & 84 & 45,76 & \\
\hline 16 & 45,79 & 39 & 4,60 & 62 & 45,42 & 85 & 45,76 & \\
\hline 17 & 45,75 & 40 & 4,60 & 63 & 45,42 & 86 & 45,76 & \\
\hline 18 & 45,68 & 41 & 4,60 & 64 & 45,42 & 87 & 45,78 & \\
\hline 19 & 45,59 & 42 & 4,60 & 65 & 45,57 & 88 & 45,77 & \\
\hline 20 & 4,68 & 43 & 4,60 & 66 & 45,57 & 89 & 45,90 & \\
\hline 21 & 4,68 & 44 & 4,59 & 67 & 45,57 & 90 & 45,95 & \\
\hline 22 & 4,68 & 45 & 4,59 & 68 & 45,59 & & & \\
\hline 23 & 4,68 & 46 & 45,48 & 69 & 45,59 & & & \\
\hline
\end{tabular}


Tabela 4.8 - Erros obtidos para cada uma das barras no estudo de caso 2 do sistema de 90 barras.

\begin{tabular}{|c|c|c|c|c|c|c|c|c|}
\hline Barras & Erros & Barras & Erros & Barras & Erros & Barras & Erros & $\begin{array}{l}\text { Barra a ser } \\
\text { Localizada }\end{array}$ \\
\hline 01 & 31,39 & 24 & 56,46 & 47 & 0,25 & 70 & 0,82 & \multirow{23}{*}{ B49 } \\
\hline 02 & 29,96 & 25 & 56,46 & 48 & 0,25 & 71 & 0,93 & \\
\hline 03 & 27,93 & 26 & 56,46 & 49 & 0,25 & 72 & 0,93 & \\
\hline 04 & 23,47 & 27 & 56,27 & 50 & 0,25 & 73 & 0,97 & \\
\hline 05 & 22,36 & 28 & 56,15 & 51 & 0,25 & 74 & 0,98 & \\
\hline 06 & 21,48 & 29 & 56,10 & 52 & 0,26 & 75 & 0,98 & \\
\hline 07 & 21,17 & 30 & 56,02 & 53 & 0,30 & 76 & 1,00 & \\
\hline 08 & 19,03 & 31 & 55,94 & 54 & 0,39 & 77 & 1,01 & \\
\hline 09 & 17,84 & 32 & 55,75 & 55 & 0,47 & 78 & 1,01 & \\
\hline 10 & 17,75 & 33 & 55,73 & 56 & 0,47 & 79 & 1,01 & \\
\hline 11 & 6,01 & 34 & 55,71 & 57 & 0,47 & 80 & 1,01 & \\
\hline 12 & 1,49 & 35 & 55,70 & 58 & 0,48 & 81 & 1,08 & \\
\hline 13 & 0,26 & 36 & 55,64 & 59 & 0,47 & 82 & 1,09 & \\
\hline 14 & 3,94 & 37 & 55,60 & 60 & 0,48 & 83 & 1,09 & \\
\hline 15 & 3,93 & 38 & 55,56 & 61 & 0,48 & 84 & 1,09 & \\
\hline 16 & 3,93 & 39 & 55,56 & 62 & 0,48 & 85 & 1,09 & \\
\hline 17 & 4,65 & 40 & 55,54 & 63 & 0,48 & 86 & 1,09 & \\
\hline 18 & 5,84 & 41 & 55,52 & 64 & 0,48 & 87 & 1,12 & \\
\hline 19 & 7,48 & 42 & 55,48 & 65 & 0,74 & 88 & 1,12 & \\
\hline 20 & 56,47 & 43 & 55,47 & 66 & 0,74 & 89 & 1,35 & \\
\hline 21 & 56,47 & 44 & 55,36 & 67 & 0,75 & 90 & 1,45 & \\
\hline 22 & 56,47 & 45 & 55,36 & 68 & 0,78 & & & \\
\hline 23 & 56,46 & 46 & 0,25 & 69 & 0,79 & & & \\
\hline
\end{tabular}


Tabela 4.9 - Erros obtidos para cada uma das barras no estudo de caso 3 do sistema de 90 barras.

\begin{tabular}{|c|c|c|c|c|c|c|c|c|}
\hline Barras & Erros & Barras & Erros & Barras & Erros & Barras & Erros & $\begin{array}{l}\text { Barra a ser } \\
\text { Localizada }\end{array}$ \\
\hline 01 & 32,71 & 24 & 52,70 & 47 & 3,61 & 70 & 4,13 & \multirow{23}{*}{ B14 } \\
\hline 02 & 31,39 & 25 & 52,70 & 48 & 3,61 & 71 & 4,24 & \\
\hline 03 & 29,51 & 26 & 52,70 & 49 & 3,61 & 72 & 4,24 & \\
\hline 04 & 25,38 & 27 & 52,52 & 50 & 3,61 & 73 & 4,28 & \\
\hline 05 & 24,34 & 28 & 52,40 & 51 & 3,61 & 74 & 4,29 & \\
\hline 06 & 23,52 & 29 & 52,36 & 52 & 3,60 & 75 & 4,29 & \\
\hline 07 & 23,22 & 30 & 52,29 & 53 & 3,64 & 76 & 4,32 & \\
\hline 08 & 21,21 & 31 & 52,21 & 54 & 3,72 & 77 & 4,32 & \\
\hline 09 & 20,09 & 32 & 52,03 & 55 & 3,80 & 78 & 4,32 & \\
\hline 10 & 19,99 & 33 & 52,02 & 56 & 3,80 & 79 & 4,32 & \\
\hline 11 & 9,01 & 34 & 52,00 & 57 & 3,80 & 80 & 4,33 & \\
\hline 12 & 4,78 & 35 & 51,99 & 58 & 3,81 & 81 & 4,39 & \\
\hline 13 & 3,62 & 36 & 51,93 & 59 & 3,80 & 82 & 4,40 & \\
\hline 14 & 0,33 & 37 & 51,90 & 60 & 3,81 & 83 & 4,40 & \\
\hline 15 & 0,33 & 38 & 51,86 & 61 & 3,81 & 84 & 4,40 & \\
\hline 16 & 0,33 & 39 & 51,86 & 62 & 3,81 & 85 & 4,40 & \\
\hline 17 & 1,00 & 40 & 51,83 & 63 & 3,81 & 86 & 4,40 & \\
\hline 18 & 2,11 & 41 & 51,82 & 64 & 3,81 & 87 & 4,43 & \\
\hline 19 & 3,63 & 42 & 51,79 & 65 & 4,06 & 88 & 4,43 & \\
\hline 20 & 52,71 & 43 & 51,78 & 66 & 4,07 & 89 & 4,65 & \\
\hline 21 & 52,71 & 44 & 51,66 & 67 & 4,07 & 90 & 4,75 & \\
\hline 22 & 52,70 & 45 & 51,66 & 68 & 4,10 & & & \\
\hline 23 & 52,70 & 46 & 3,62 & 69 & 4,11 & & & \\
\hline
\end{tabular}


Tabela 4.10 - Erros obtidos para cada uma das barras no estudo de caso 4 do sistema de 90 barras.

\begin{tabular}{|c|c|c|c|c|c|c|c|c|}
\hline Barras & Erros & Barras & Erros & Barras & Erros & Barras & Erros & $\begin{array}{l}\text { Barra a ser } \\
\text { Localizada }\end{array}$ \\
\hline 01 & 27,04 & 24 & 464,17 & 47 & 3,85 & 70 & 2,94 & \multirow{23}{*}{ B05 } \\
\hline 02 & 25,37 & 25 & 464,16 & 48 & 3,77 & 71 & 2,83 & \\
\hline 03 & 23,03 & 26 & 464,17 & 49 & 3,77 & 72 & 2,83 & \\
\hline 04 & 20,38 & 27 & 462,60 & 50 & 3,62 & 73 & 2,79 & \\
\hline 05 & 19,46 & 28 & 461,54 & 51 & 3,62 & 74 & 2,78 & \\
\hline 06 & 18,73 & 29 & 461,16 & 52 & 3,52 & 75 & 2,77 & \\
\hline 07 & 18,47 & 30 & 460,52 & 53 & 3,48 & 76 & 2,75 & \\
\hline 08 & 19,75 & 31 & 459,89 & 54 & 3,39 & 77 & 2,75 & \\
\hline 09 & 18,41 & 32 & 458,29 & 55 & 3,30 & 78 & 2,74 & \\
\hline 10 & 18,82 & 33 & 458,15 & 56 & 3,30 & 79 & 2,74 & \\
\hline 11 & 5,42 & 34 & 457,96 & 57 & 3,30 & 80 & 2,74 & \\
\hline 12 & 2,20 & 35 & 457,87 & 58 & 3,29 & 81 & 2,67 & \\
\hline 13 & 2,22 & 36 & 457,37 & 59 & 3,30 & 82 & 2,66 & \\
\hline 14 & 4,83 & 37 & 457,08 & 60 & 3,30 & 83 & 2,66 & \\
\hline 15 & 4,83 & 38 & 456,76 & 61 & 3,29 & 84 & 2,66 & \\
\hline 16 & 4,83 & 39 & 456,73 & 62 & 3,30 & 85 & 2,66 & \\
\hline 17 & 5,35 & 40 & 456,54 & 63 & 3,30 & 86 & 2,66 & \\
\hline 18 & 6,19 & 41 & 456,43 & 64 & 3,30 & 87 & 2,63 & \\
\hline 19 & 7,36 & 42 & 456,11 & 65 & 3,02 & 88 & 2,63 & \\
\hline 20 & 464,24 & 43 & 456,02 & 66 & 3,02 & 89 & 2,39 & \\
\hline 21 & 464,23 & 44 & 455,04 & 67 & 3,01 & 90 & 2,29 & \\
\hline 22 & 464,19 & 45 & 455,04 & 68 & 2,98 & & & \\
\hline 23 & 464,17 & 46 & 3,18 & 69 & 2,97 & & & \\
\hline
\end{tabular}

Após obtidos resultados do localizador quando aplicado ao sistema real de 90 barras, pôde-se observar que para o estudo de caso 1, o método de localização elege as barras B44 e B45 como possíveis soluções. Desta forma, verifica-se que a posição real da carga (barra B45) encontra-se na lista de soluções e, portanto, podese dizer que o erro relacionado à distância está na faixa de 0 e 70,8 metros.

Para o estudo de caso 2, observou-se que o localizador forneceu como resposta uma lista com as barras $46,47,48,49,50$ e 51. Desta forma, o erro da distância está entre 0 e 1957,6 metros. 
Já para o estudo de caso 3, verificou-se que as barras B14, B15 e B16 foram eleitas como possíveis soluções e, desta forma, constatou-se um erro para a distância na faixa de 0 a 637,8 metros.

Analisando-se a resposta do método de localização quando aplicado ao estudo de caso 4, o método de localização apresentou solução única, onde neste caso verificou-se um erro relacionado à distância entre a barra B12 (solução do localizador) e a barra B05 (posição real da carga) de 5364,1 metros.

É importante notar que somente o resultado obtido pelo método de localização para o estudo de caso 4 apresentou um erro maior. Além disso, este erro pode ter sido acarretado devido a este estudo de caso apresentar maiores variações no carregamento da rede.

Obtidos todos os resultados para cada um dos dez estudos de caso, no próximo capítulo apresentar-se-á a metodologia de identificação da composição harmônica da carga, bem como os resultados obtidos nesta etapa.

Cabe comentar que, de forma aleatória, uma das barras eleitas pelo método de localização foi tida como suposta posição da carga para que o método de identificação pudesse ser executado. Entretanto, após a identificação da composição harmônica da carga, para cada um dos estudos de caso, todas as barras eleitas pelo localizador são utilizadas pelo método de ajuste/sintonia do localizador para que o mesmo possa refinar os resultados até então obtidos pelo método de localização de fontes consumidoras de potências harmônicas. 


\section{Método Proposto para Identificação da Fonte Consumidora de Potências Harmônicas}

Realizada a localização das barras que podem conter a fonte consumidora de potências harmônicas, torna-se então possível identificar as componentes harmônicas desta fonte. Seguindo esta premissa, para cada um dos 10 estudos de caso apresentados nesta tese, somente a barra com menor erro encontrada pelo método de localização foi utilizada durante o processo de estimação das amplitudes das componentes harmônicas de corrente das fontes consumidoras de potências harmônicas. Estas barras contendo o menor erro foram previamente mostradas e podem ser conferidas por meio das Tabelas de 4.1 a 4.10 .

Seguindo o contexto acima delineado, o Capítulo 5 é designado a apresentar em detalhes o funcionamento do método desenvolvido para a identificação da fonte consumidora de potências harmônicas, identificação esta que visa estimar as amplitudes das correntes harmônicas da fonte. Assim, este capítulo foi dividido em duas partes, sendo a primeira destinada às explanações relacionadas ao método, bem como seus aspectos intrínsecos (Seção 5.1), ao passo que a segunda parte é responsável por apresentar os resultados obtidos pelas estimações para cada um dos estudos de caso (Seção 5.2).

\subsection{Aspectos do Sistema de Identificação}

O sistema de identificação da fonte consumidora de potências harmônicas foi desenvolvido segundo o diagrama de blocos mostrado na Figura 5.1. 


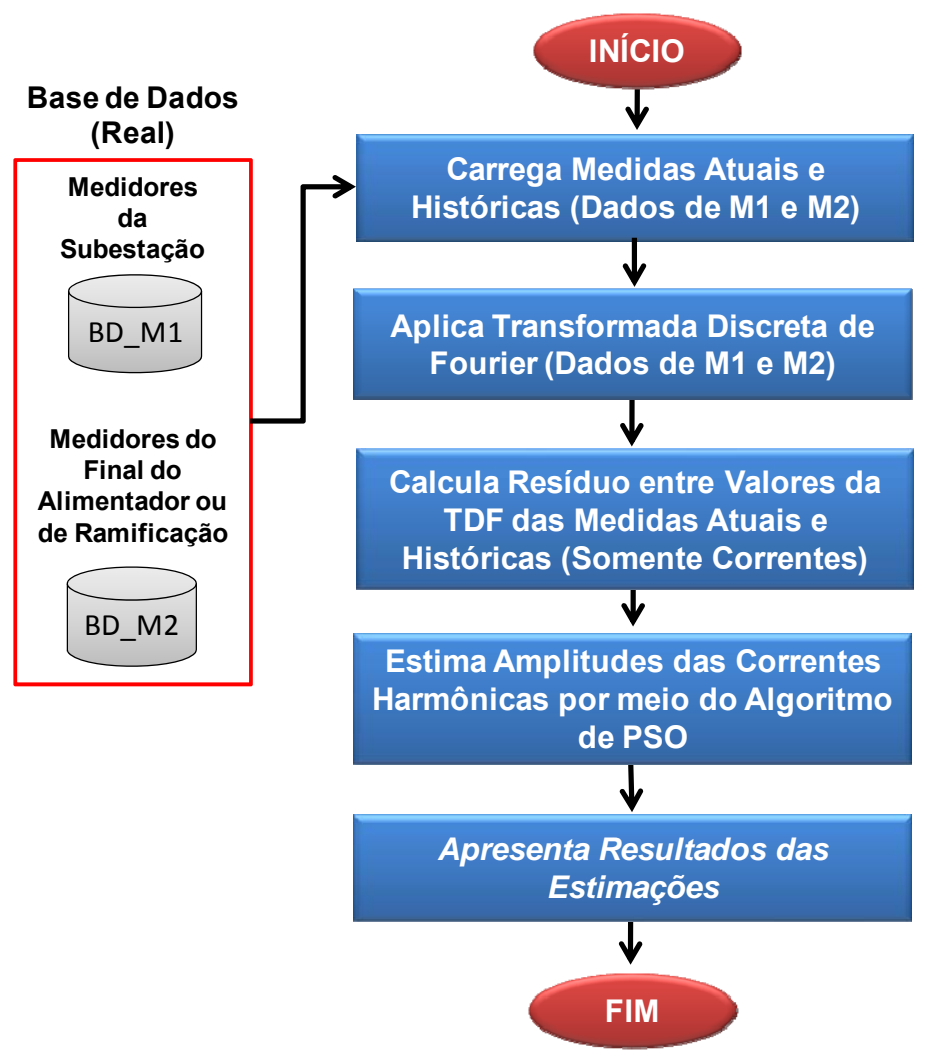

Figura 5.1 - Mecanismo de funcionamento do método de identificação da fonte consumidora de potências harmônicas.

Nota-se que, por meio da Figura 5.1, o método de identificação é inicializado pela entrada dos dados referentes às simulações históricas e atuais do estudo de caso sob análise. Seguindo a mesma métrica adotada pelo método de localização, a identificação também necessita que a TDF seja calculada para os dados de entrada (histórico e atual). Além disso, também deve ser calculado o resíduo entre as medidas de corrente históricas e atuais.

Após estas primeiras etapas, o método de identificação emprega algoritmos de PSO (Particle Swarm Optimization), também conhecidos como enxame de partículas, para estimar as amplitudes das correntes harmônicas absorvidas pela carga não linear (fonte consumidora de potências harmônicas). Este processo de estimação é ilustrado por meio da Figura 5.2. 


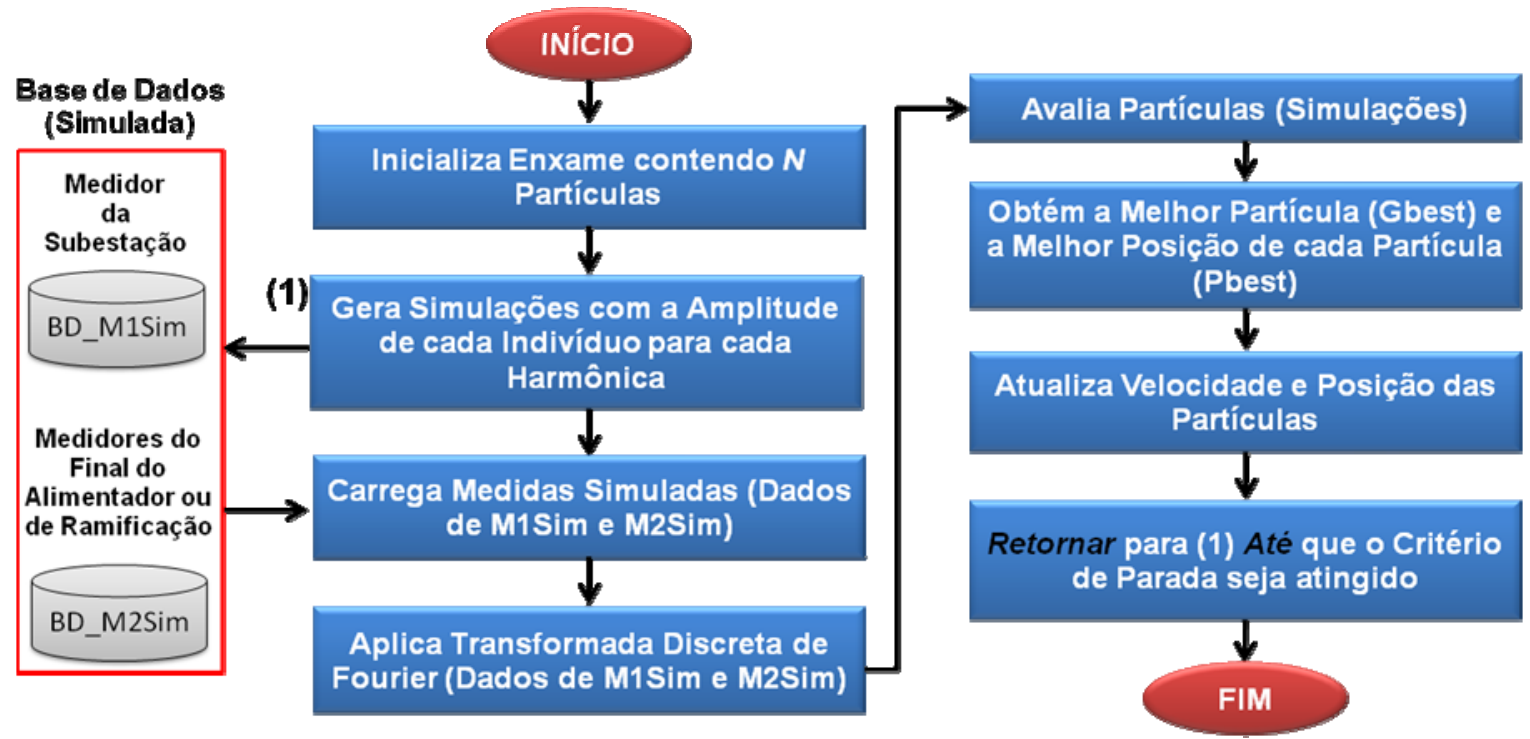

Figura 5.2 - Diagrama representativo da otimização realizada por PSO para estimação das amplitudes das harmônicas.

Conforme a Figura 5.2, a princípio, o algoritmo inicializa um enxame contendo $N$ partículas. Para esta tese considerou-se um total de 15 partículas. No entanto, cada partícula representa uma simulação e, para que cada partícula seja avaliada e "rankeada" conforme sua aptidão, faz-se necessário que o arquivo contendo o sistema base seja aberto e então inserida uma fonte de corrente harmônica parametrizada com o valor da amplitude determinado por cada partícula, bem como com o valor da frequência da corrente harmônica a ser estimada. Nota-se que 15 simulações são geradas, as quais representam cada uma das 15 partículas.

É importante comentar que cada partícula representa somente a amplitude de uma harmônica e, portanto, este mesmo procedimento deve ser realizado para cada harmônica a ser estimada. Geradas e executadas as simulações, os dados simulados são armazenados e então carregados, onde calcula-se então a TDF para tais dados. Assim, cada partícula já pode ser avaliada, sendo esta avaliação realizada por meio do cálculo do erro entre o resíduo previamente calculado e as medidas simuladas, sendo que, quanto menor for o erro, mais apta é a partícula. 
Depois de obtidas as aptidões de cada uma das partículas, o algoritmo de PSO armazena a melhor partícula e a melhor posição de cada partícula. $\mathrm{Na}$ sequência, são atualizados os valores de velocidade e posição de cada partícula. Assim, o algoritmo continua realizando estes procedimentos de avaliação das partículas e atualização das suas velocidades e posições de forma iterativa até que o critério de parada seja atingido. Como critério de parada, adotou-se um limite máximo de gerações igual a 10. Ao final da execução do algoritmo de PSO, para cada harmônica a ser estimada, uma lista de amplitudes é obtida.

Os conceitos fundamentais do PSO, bem como as equações que o regem podem ser comtempladas na Seção 5.2.

\subsection{Otimização por Enxame de Partículas (PSO)}

Nesta tese de doutorado empregou-se como método de identificação da fonte consumidora de potências harmônicas, o algoritmo de PSO, o qual foi responsável por estimar as amplitudes das componentes harmônicas de corrente da carga não linear. O algoritmo de PSO foi empregado em seu formato mais básico, conforme proposto por Kennedy e Eberhart (1995). Desta forma, verifica-se que, em sua forma mais básica, o algoritmo de PSO não possui muitos parâmetros livres a serem configurados; portanto, há de se ajustar somente a quantidade de partículas que irão compor o enxame, o critério de parada e os componentes cognitivo $\left(\varphi_{1}\right)$ e social $\left(\varphi_{2}\right)$ responsáveis por acelerar a partícula durante o processo de busca pela solução ótima. Ambos os componentes (cognitivo e social) foram aqui ajustados para 0,1 .

Seguindo este contexto, inicializa-se o algoritmo de PSO, com suas $N$ partículas que irão possuir valores iniciais aleatórios e com velocidades iniciais 
iguais a zero. Desta forma, na sequência, cada partícula é avaliada por uma função objetivo que fornecerá a aptidão da partícula, isto é, se a partícula apresenta uma solução satisfatória para o problema de otimização a ser resolvido. Avaliadas cada uma das partículas, obtém-se o valor da melhor partícula do enxame $\left(g_{\text {best }}\right)$ e a melhor posição (até o momento) obtida por cada partícula $\left(p_{\text {best }}\right)$. Após esta etapa, as velocidades das partículas são atualizadas conforme a expressão 5.1.

$$
v_{i}(t+1)=v_{i}(t)+\varphi_{1} \times\left(p_{\text {best }}-x_{i}(t)\right)+\varphi_{2} \times\left(g_{\text {best }}-x_{i}(t)\right)
$$

onde, $i$ representa cada partícula da população e $t$ representa o estado atual das posições e velocidades das partículas. Portanto, após atualizadas as velocidades, deve-se atualizar também as posições das partículas por meio da expressão 5.2.

$$
x_{i}(t+1)=x_{i}(t)+v_{i}(t+1) .
$$

Cabe lembrar que tanto as velocidades quanto as posições das partículas devem ter valores limites inferiores e superiores, garantindo-se assim que a partícula não apresente uma solução que esteja fora do espaço de busca. Assim, todos os procedimentos supracitados são repetidos até que o critério de parada seja atingido.

\subsection{Resultados Obtidos pelo Método de Identificação}

Na sequência, serão mostrados os resultados obtidos pelo método de identificação; portanto, partindo-se da barra selecionada pelo método de localização em cada estudo de caso (o quadro resumo das barras selecionadas durante a localização pode ser visualizado por meio da Tabela 5.1), aplicou-se o método de identificação que fornece como resposta as amplitudes estimadas. 
Tabela 5.1 - Quadro resumo dos resultados obtidos pelo método de localização para os sistemas de 20 e 90 barras.

\begin{tabular}{|c|c|}
\hline $\begin{array}{c}\text { Estudo de Caso } \\
\text { Sistema de 20 barras }\end{array}$ & Barras \\
\hline 1 & $\mathbf{2 0 / 2 2}$ \\
\hline 2 & $\mathbf{3 0}$ \\
\hline 3 & $\mathbf{3 0 / 3 1 / 3 2 / 3 3 / 3 4}$ \\
\hline 4 & $\mathbf{5 0 / 5 1 / 5 2 / 5 3}$ \\
\hline 5 & $\mathbf{5 0 / 5 1 / 5 2 / 5 3}$ \\
\hline 6 & $\mathbf{4 0 / 4 1 / 4 2 / 4 3 / 4 4}$ \\
\hline \multicolumn{2}{|c|}{} \\
\hline $\begin{array}{c}\text { Estudo de Caso } \\
\text { Sistema de 90 barras }\end{array}$ & Barras \\
\hline 1 & $\mathbf{4 4 / 4 5}$ \\
\hline 2 & $\mathbf{4 6 / 4 7 / 4 8 / 4 9 / 5 0 / 5 1}$ \\
\hline 3 & $14 / 15 / 16$ \\
\hline 4 & $\mathbf{1 2}$ \\
\hline
\end{tabular}

Cabe aqui também informar que somente as barras em destaque na Tabela 5.1 foram utilizadas para se identificar a composição harmônica da carga em cada estudo de caso. As respostas do método de identificação quando aplicado aos seis estudos de caso relacionados ao sistema de 20 barras podem ser conferidas por meio das Tabelas de 5.2 a 5.7 .

Tabela 5.2 - Resultados obtidos pelo método de identificação para a estimação das amplitudes das correntes harmônicas da carga no estudo de caso 1.

\begin{tabular}{|c|c|c|c|c|}
\hline Harmônica & $\begin{array}{c}\text { Amplitude Média } \\
\text { Estimada [A] }\end{array}$ & $\begin{array}{c}\text { Amplitude } \\
\text { Fase A [A] }\end{array}$ & $\begin{array}{c}\text { Amplitude } \\
\text { Fase B [A] }\end{array}$ & $\begin{array}{c}\text { Amplitude } \\
\text { Fase C [A] }\end{array}$ \\
\hline 1 & 64,46422 & 59,935 & 60,165 & 59,922 \\
\hline 3 & 0,013656 & 0,14789 & 0,26817 & 0,12101 \\
\hline 5 & 13,38659 & 13,332 & 13,183 & 13,316 \\
\hline 7 & 7,172088 & 6,8956 & 7,1166 & 6,799 \\
\hline 9 & 0,056021 & 0,15505 & 0,24416 & 0,12224 \\
\hline 11 & 0,862661 & 5,3141 & 5,2254 & 5,275 \\
\hline 13 & 0,932048 & 4,055 & 4,2602 & 3,9178 \\
\hline
\end{tabular}


Tabela 5.3 - Resultados obtidos pelo método de identificação para a estimação das amplitudes das correntes harmônicas da carga no estudo de caso 2.

\begin{tabular}{|c|c|c|c|c|}
\hline Harmônica & $\begin{array}{c}\text { Amplitude Média } \\
\text { Estimada [A] }\end{array}$ & $\begin{array}{c}\text { Amplitude Real } \\
\text { Fase A [A] }\end{array}$ & $\begin{array}{c}\text { Amplitude Real } \\
\text { Fase B [A] }\end{array}$ & $\begin{array}{c}\text { Amplitude Real } \\
\text { Fase C [A] }\end{array}$ \\
\hline 1 & 43,75045 & 40,183 & 40,495 & 40,276 \\
\hline 3 & 1,001237 & 0,26221 & 0,34026 & 0,078471 \\
\hline 5 & 8,283988 & 8,4262 & 8,1579 & 8,3561 \\
\hline 7 & 6,01795 & 5,2202 & 5,5296 & 5,2661 \\
\hline 9 & 1,008492 & 0,25976 & 0,33712 & 0,087809 \\
\hline 11 & 1,795214 & 3,717 & 3,4775 & 3,6429 \\
\hline 13 & 0,122602 & 2,8919 & 3,2209 & 2,9527 \\
\hline
\end{tabular}

Tabela 5.4 - Resultados obtidos pelo método de identificação para a estimação das amplitudes das correntes harmônicas da carga no estudo de caso 3.

\begin{tabular}{|c|c|c|c|c|}
\hline Harmônica & $\begin{array}{c}\text { Amplitude Média } \\
\text { Estimada [A] }\end{array}$ & $\begin{array}{c}\text { Amplitude Real } \\
\text { Fase A [A] }\end{array}$ & $\begin{array}{c}\text { Amplitude Real } \\
\text { Fase B [A] }\end{array}$ & $\begin{array}{c}\text { Amplitude Real } \\
\text { Fase C [A] }\end{array}$ \\
\hline 1 & 27,35373 & 27,922 & 28,085 & 27,96 \\
\hline 3 & 0,025613 & 0,083991 & 0,17505 & 0,093931 \\
\hline 5 & 6,225405 & 6,2727 & 6,1661 & 6,2899 \\
\hline 7 & 3,102865 & 3,0053 & 3,1771 & 3,0538 \\
\hline 9 & 0,024512 & 0,094306 & 0,18167 & 0,091193 \\
\hline 11 & 2,430665 & 2,5111 & 2,4162 & 2,5642 \\
\hline 13 & 1,658056 & 1,686 & 1,8692 & 1,7534 \\
\hline
\end{tabular}

Tabela 5.5 - Resultados obtidos pelo método de identificação para a estimação das amplitudes das correntes harmônicas da carga no estudo de caso 4.

\begin{tabular}{|c|c|c|c|c||}
\hline Harmônica & $\begin{array}{c}\text { Amplitude Média } \\
\text { Estimada [A] }\end{array}$ & $\begin{array}{c}\text { Amplitude Real } \\
\text { Fase A [A] }\end{array}$ & $\begin{array}{c}\text { Amplitude Real } \\
\text { Fase B [A] }\end{array}$ & $\begin{array}{c}\text { Amplitude Real } \\
\text { Fase C [A] }\end{array}$ \\
\hline 1 & 79,75212 & 44,446 & 45,61 & 44,898 \\
\hline 3 & 1,437426 & 0,35875 & 0,44443 & 0,7948 \\
\hline 5 & 20,62902 & 21,303 & 21,523 & 21,765 \\
\hline 7 & 9,6307 & 10,675 & 10,304 & 10,4 \\
\hline 9 & 0,140279 & 0,43704 & 0,14895 & 0,45499 \\
\hline 11 & 4,031414 & 3,6088 & 3,7039 & 3,8396 \\
\hline 13 & 2,39775 & 2,481 & 2,4422 & 2,457 \\
\hline
\end{tabular}


Tabela 5.6 - Resultados obtidos pelo método de identificação para a estimação das amplitudes das correntes harmônicas da carga no estudo de caso 5.

\begin{tabular}{|c|c|c|c|c||}
\hline Harmônica & $\begin{array}{c}\text { Amplitude Média } \\
\text { Estimada [A] }\end{array}$ & $\begin{array}{c}\text { Amplitude Real } \\
\text { Fase A [A] }\end{array}$ & $\begin{array}{c}\text { Amplitude Real } \\
\text { Fase B [A] }\end{array}$ & $\begin{array}{c}\text { Amplitude Real } \\
\text { Fase C [A] }\end{array}$ \\
\hline 1 & 28,27979 & 25,762 & 25,801 & 25,852 \\
\hline 3 & 0,019142 & 0,084949 & 0,022207 & 0,08719 \\
\hline 5 & 5,304299 & 5,5588 & 5,5617 & 5,5175 \\
\hline 7 & 2,792369 & 2,8655 & 2,9506 & 2,9904 \\
\hline 9 & 0,00911 & 0,076775 & 0,066179 & 0,085823 \\
\hline 11 & 1,97929 & 2,1524 & 2,176 & 2,15 \\
\hline 13 & 1,442157 & 1,541 & 1,647 & 1,6853 \\
\hline
\end{tabular}

Tabela 5.7 - Resultados obtidos pelo método de identificação para a estimação das amplitudes das correntes harmônicas da carga no estudo de caso 6.

\begin{tabular}{|c|c|c|c|c|}
\hline Harmônica & $\begin{array}{c}\text { Amplitude Média } \\
\text { Estimada [A] }\end{array}$ & $\begin{array}{c}\text { Amplitude Real } \\
\text { Fase A [A] }\end{array}$ & $\begin{array}{c}\text { Amplitude Real } \\
\text { Fase B [A] }\end{array}$ & $\begin{array}{c}\text { Amplitude Real } \\
\text { Fase C [A] }\end{array}$ \\
\hline 1 & 38,2348 & 29,65 & 30,029 & 29,71 \\
\hline 3 & 2,184549 & 0,27716 & 0,43734 & 0,16215 \\
\hline 5 & 6,169165 & 6,5488 & 6,269 & 6,4888 \\
\hline 7 & 3,677516 & 2,9737 & 3,3319 & 2,961 \\
\hline 9 & 0,484453 & 0,22478 & 0,35548 & 0,16201 \\
\hline 11 & 2,204912 & 2,2789 & 2,1265 & 2,2631 \\
\hline 13 & 1,325106 & 1,4375 & 1,6915 & 1,3557 \\
\hline
\end{tabular}

A seguir, são também apresentados os resultados das estimações de amplitudes das correntes harmônicas obtidas para os estudos de caso relacionados ao sistema de 90 barras. Estes resultados podem ser visualizados por meio das Tabelas de 5.8 a 5.11 . 
Tabela 5.8 - Resultados obtidos pelo método de identificação para a estimação das amplitudes das correntes harmônicas da carga no estudo de caso 1.

\begin{tabular}{|c|c|c|c|c|}
\hline Harmônica & $\begin{array}{c}\text { Amplitude Média } \\
\text { Estimada [A] }\end{array}$ & $\begin{array}{c}\text { Amplitude Real } \\
\text { Fase A [A] }\end{array}$ & $\begin{array}{c}\text { Amplitude Real } \\
\text { Fase B [A] }\end{array}$ & $\begin{array}{c}\text { Amplitude Real } \\
\text { Fase C [A] }\end{array}$ \\
\hline 1 & 33,2461 & 30,977 & 31,061 & 31,056 \\
\hline 3 & 0,022874 & 0,11382 & 0,068057 & 0,046173 \\
\hline 5 & 6,858473 & 6,8708 & 6,8169 & 6,8267 \\
\hline 7 & 3,306624 & 3,2001 & 3,3136 & 3,2896 \\
\hline 9 & 0,031477 & 0,099694 & 0,068582 & 0,034293 \\
\hline 11 & 2,512649 & 2,5056 & 2,4595 & 2,4727 \\
\hline 13 & 1,854389 & 1,7448 & 1,8436 & 1,837 \\
\hline
\end{tabular}

Tabela 5.9 - Resultados obtidos pelo método de identificação para a estimação das amplitudes das correntes harmônicas da carga no estudo de caso 2.

\begin{tabular}{|c|c|c|c|c|}
\hline Harmônica & $\begin{array}{c}\text { Amplitude Média } \\
\text { Estimada [A] }\end{array}$ & $\begin{array}{c}\text { Amplitude Real } \\
\text { Fase A [A] }\end{array}$ & $\begin{array}{c}\text { Amplitude Real } \\
\text { Fase B [A] }\end{array}$ & $\begin{array}{c}\text { Amplitude Real } \\
\text { Fase C [A] }\end{array}$ \\
\hline 1 & 33,85237 & 31,87 & 31,988 & 31,855 \\
\hline 3 & 0,0128 & 0,066211 & 0,15487 & 0,08912 \\
\hline 5 & 6,9732 & 7,1454 & 7,0581 & 7,1521 \\
\hline 7 & 3,109333 & 3,4965 & 3,617 & 3,4547 \\
\hline 9 & 0,019467 & 0,064781 & 0,15026 & 0,085507 \\
\hline 11 & 2,0485 & 2,8198 & 2,7278 & 2,8131 \\
\hline 13 & 1,315367 & 2,0621 & 2,174 & 1,9999 \\
\hline
\end{tabular}

Tabela 5.10 - Resultados obtidos pelo método de identificação para a estimação das amplitudes das correntes harmônicas da carga no estudo de caso 3.

\begin{tabular}{|c|c|c|c|c|}
\hline Harmônica & $\begin{array}{c}\text { Amplitude Média } \\
\text { Estimada [A] }\end{array}$ & $\begin{array}{c}\text { Amplitude Real } \\
\text { Fase A [A] }\end{array}$ & $\begin{array}{c}\text { Amplitude Real } \\
\text { Fase B [A] }\end{array}$ & $\begin{array}{c}\text { Amplitude Real } \\
\text { Fase C [A] }\end{array}$ \\
\hline 1 & 33,67736 & 32,103 & 31,694 & 31,594 \\
\hline 3 & 0,038726 & 0,64738 & 0,28725 & 0,36201 \\
\hline 5 & 7,097149 & 6,8504 & 7,3522 & 7,3735 \\
\hline 7 & 3,141346 & 3,6606 & 3,3363 & 3,1991 \\
\hline 9 & 0,048442 & 0,62327 & 0,30228 & 0,33304 \\
\hline 11 & 2,171704 & 2,4541 & 3,0199 & 2,9518 \\
\hline 13 & 1,413447 & 2,1858 & 1,8867 & 1,7828 \\
\hline
\end{tabular}


Tabela 5.11 - Resultados obtidos pelo método de identificação para a estimação das amplitudes das correntes harmônicas da carga no estudo de caso 4.

\begin{tabular}{|c|c|c|c|c||}
\hline Harmônica & $\begin{array}{c}\text { Amplitude Média } \\
\text { Estimada [A] }\end{array}$ & $\begin{array}{c}\text { Amplitude Real } \\
\text { Fase A [A] }\end{array}$ & $\begin{array}{c}\text { Amplitude Real } \\
\text { Fase B [A] }\end{array}$ & $\begin{array}{c}\text { Amplitude Real } \\
\text { Fase C [A] }\end{array}$ \\
\hline 1 & 168,9054 & 22,334 & 22,34 & 22,386 \\
\hline 3 & 0,177733 & 0,031102 & 0,071249 & 0,047756 \\
\hline 5 & 20,81817 & 4,9293 & 4,9925 & 5,0112 \\
\hline 7 & 5,7821 & 2,92 & 3,0475 & 3,0558 \\
\hline 9 & 0,075867 & 0,095168 & 0,19462 & 0,10015 \\
\hline 11 & 3,3567 & 2,3823 & 2,4073 & 2,546 \\
\hline 13 & 2,537133 & 1,8862 & 2,118 & 2,0806 \\
\hline
\end{tabular}

Por meio das estimações obtidas pelo método de identificação, é então possível verificar que são estimadas as amplitudes médias das correntes harmônicas das cargas, pois, as cargas não lineares foram todas modeladas de forma equilibrada.

Verifica-se também que a estimação das amplitudes das harmônicas apresenta uma maior discrepância quando estimados os valores das componentes harmônicas com menores amplitudes (principalmente $3^{a}$ e $9^{a}$ ordens).

É importante destacar que os estudos de caso 4 tanto do sistema de 20 barras quanto do sistema de 90 barras apresentaram amplitudes das correntes harmônicas e fundamental com altos níveis de distinção das amplitudes reais das correntes absorvidas pelas cargas. No entanto, um fator a ser ponderado é a quantidade de partículas e gerações parametrizadas para os algoritmos de PSO (15 partículas e 10 gerações), pois, a intenção era de se obter um equilíbrio entre bons resultados e esforço computacional. 


\section{Método Proposto para Ajuste/Sintonia do Localizador de Fonte Consumidora de Potências Harmônicas}

Depois de realizadas as etapas de localização e identificação da fonte consumidora de potências harmônicas, por fim, tenta-se aperfeiçoar o seu ajuste ou sintonia a fim de melhorar o resultado obtido pelo método de localização. Assim, empregando-se tanto as barras previamente selecionadas durante a etapa de localização da fonte como as amplitudes estimadas durante a fase de identificação, um algoritmo para ajuste/sintonia da localização é também proposto nesta tese de doutorado. Portanto, é importante que o leitor tenha em mente aqueles resultados já apresentados nos Capítulos 4 e 5 .

O método de ajuste/sintonia foi implementado conforme o diagrama de blocos mostrado na Figura 6.1. Neste diagrama, algumas características que se assemelham aos algoritmos de localização e identificação podem ser notadas, como por exemplo, os três primeiros blocos, os quais são responsáveis por carregar as medidas históricas e atuais, calcular a TDF para os dados recebidos como entrada e calcular o resíduo entre os valores da TDF obtidos para os dados que representam a condição atual e histórica do sistema. É importante frisar que este cálculo do resíduo leva em consideração somente os dados correspondentes às correntes medidas. Outro aspecto deste algoritmo que também possui certo grau de similaridade com os algoritmos de localização e identificação é a geração de simulações. No entanto, estas simulações são realizadas somente para as barras eleitas pelo método de 
localização. Nota-se que uma nova base de dados contendo os dados simulados é criada e que logo após as simulações, tais dados são carregados. Portanto, calculase novamente a TDF, neste caso para os dados simulados, sendo obtidos em seguida o erro entre o resíduo das simulações e o resíduo obtido entre os dados atuais e históricos. Cabe comentar que neste caso, nenhuma harmônica foi selecionada e, portanto, considerou-se para tanto as correntes fundamentais e harmônicas até a $13^{\mathrm{a}}$ ordem (somente as de ordem ímpar). Por fim, partindo-se dos erros dos resíduos obtidos para cada uma das barras eleitas, bem como para cada corrente fundamental e harmônica, torna-se possível verificar e calcular uma probabilidade de determinada carga estar alocada nas respectivas barras eleitas pelo método de localização. Por exemplo, supondo que o método de localização obteve como as barras $\mathrm{X}$ e $\mathrm{Y}$ como possíveis soluções, após a aplicação do método de identificação e do ajuste/sintonia da localização verificou-se que para a corrente fundamental o menor erro obtido se refere à barra $X$, no entanto, para as demais correntes harmônicas $\left(5^{\mathrm{a}}, 7^{\mathrm{a}}, 9^{\mathrm{a}}, 11^{\mathrm{a}}\right.$ e $\left.13^{\mathrm{a}}\right)$ os menores erros se referem à barra $\mathrm{Y}$. Desta forma, pode-se dizer que de um total de 6 medidas de erro, somente uma delas se refere à barra $\mathrm{X} e$ as outras cinco se referem à barra $\mathrm{Y}$ e, portanto, tem-se uma probabilidade de $16,7 \%$ de a carga estar alocada na barra $\mathrm{X}$ e $83,3 \%$ de chances de a carga estar alocada na barra Y.

Desta forma, o algoritmo apresenta como resultado a probabilidade de a carga encontrar-se alocada em uma determinada barra (dentre aquelas barras eleitas). 


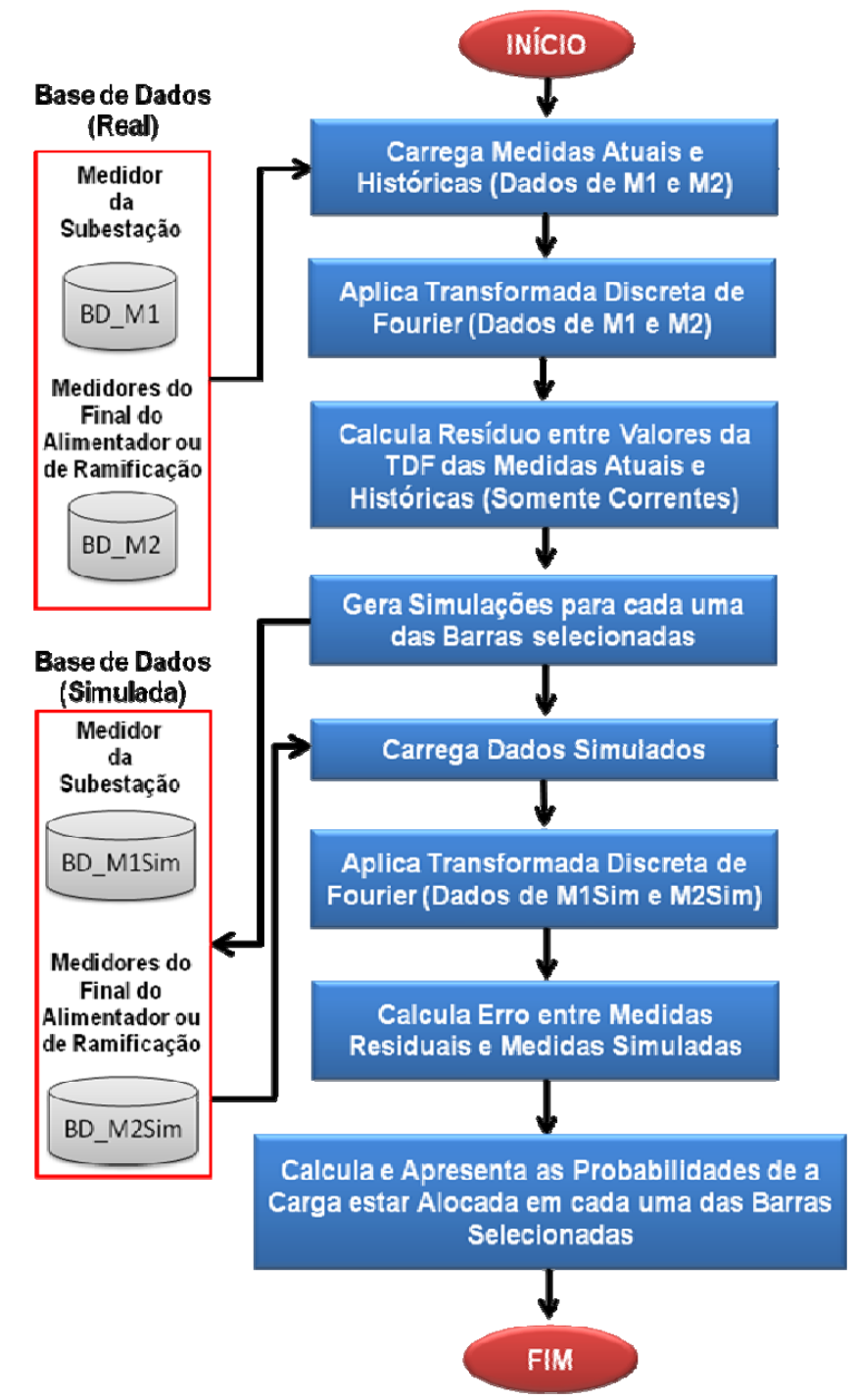

Figura 6.1 - Mecanismo de funcionamento do método de ajuste/sintonia da localização da fonte consumidora de potências harmônicas.

Os resultados obtidos pelo método de ajuste/sintonia para os estudos de caso relacionados ao sistema de 20 barras, os quais tiveram mais de uma barra selecionada, podem ser conferidos por meio das Tabelas de 6.1 a 6.5 , onde são mostradas as barras selecionadas e as respectivas probabilidades de a carga estar alocada. 
Tabela 6.1 - Probabilidades de a carga estar alocada em cada barra selecionada para o estudo de caso 1 do sistema de 20 barras.

\begin{tabular}{|c|c|c|}
\hline $\begin{array}{c}\text { Barra } \\
\text { Selecionada }\end{array}$ & Probabilidades (\%) & Barra Desejada \\
\hline 20 & 100 & 21 \\
\hline 22 & 0 & 21 \\
\hline
\end{tabular}

Tabela 6.2 - Probabilidades de a carga estar alocada em cada barra selecionada para o estudo de caso 3 do sistema de 20 barras.

\begin{tabular}{|c|c|c|}
\hline $\begin{array}{c}\text { Barra } \\
\text { Selecionada }\end{array}$ & Probabilidades (\%) & Barra Desejada \\
\hline 30 & 57,14 & \\
\hline 31 & 0 & \multirow{2}{*}{34} \\
\hline 32 & 0 & \\
\hline 33 & 0 & \\
\hline 34 & 42,86 & \\
\hline
\end{tabular}

Tabela 6.3 - Probabilidades de a carga estar alocada em cada barra selecionada para o estudo de caso 4 do sistema de 20 barras.

\begin{tabular}{|c|c|c|}
\hline $\begin{array}{c}\text { Barra } \\
\text { Selecionada }\end{array}$ & Probabilidades (\%) & Barra Desejada \\
\hline 50 & 28,57 & \\
\hline 51 & 0 & \multirow{2}{*}{53} \\
\hline 52 & 0 & \\
\hline 53 & 71,43 & \\
\hline
\end{tabular}

Tabela 6.4 - Probabilidades de a carga estar alocada em cada barra selecionada para o estudo de caso 5 do sistema de 20 barras.

\begin{tabular}{|c|c|c|}
\hline $\begin{array}{c}\text { Barra } \\
\text { Selecionada }\end{array}$ & Probabilidades (\%) & Barra Desejada \\
\hline 50 & 57,14 & \\
\hline 51 & 0 & \multirow{2}{*}{52} \\
\hline 52 & 14,29 & \\
\hline 53 & 28,57 & \\
\hline
\end{tabular}


Tabela 6.5 - Probabilidades de a carga estar alocada em cada barra selecionada para o estudo de caso 6 do sistema de 20 barras.

\begin{tabular}{|c|c|c|}
\hline $\begin{array}{c}\text { Barra } \\
\text { Selecionada }\end{array}$ & Probabilidades (\%) & Barra Desejada \\
\hline 40 & 71,43 & \\
\hline 41 & 14,285 & \multirow{2}{*}{42} \\
\hline 42 & 14,285 & \\
\hline 43 & 0 & \\
\hline 44 & 0 & \\
\hline
\end{tabular}

Realizados os procedimentos necessários para a execução do algoritmo de ajuste/sintonia do método de localização, verificou-se por meio de seus resultados que, frente ao estudo de caso 1, o ajuste/sintonia restringe a solução do problema à barra 20 que se encontra a 100 metros da barra 21 (posição real da carga). Entretanto, este erro de 100 metros é satisfatório devido ao baixo erro para a distância.

Com relação ao estudo de caso 3, é possível notar que das 5 barras (30, 31,32, 33 e 34) previamente selecionadas pelo localizador, somente duas delas foram consideradas pelo algoritmo de ajuste/sintonia do localizador, onde neste caso são tidas como possíveis soluções do problema as barras 30 e 34 . É possível notar também que há maior probabilidade de a carga estar alocada na barra 30 , entretanto, a barra 34 (posição real da carga) foi admitida como uma possível solução. Desta forma, constata-se que o erro relacionado à distância está numa faixa de 0 a 1300 metros ao invés da faixa de 0 a 2350 metros previamente obtida pelo método de localização. Desta forma, observa-se que o algoritmo de ajuste/sintonia do localizador apresenta uma resposta mais restrita e com menor erro. 
No estudo de caso 4, são então obtidas como possíveis soluções as barras 50 e 53. Além disso, é possível verificar que a barra 53 (posição real da carga) apresenta uma probabilidade em torno de $71 \%$ de a carga estar alocada nesta posição. Em contrapartida, verifica-se que a barra 50 apresenta uma probabilidade em torno de $29 \%$. Assim, diz-se que para este estudo de caso, pode ser obtida uma faixa de erro que varia entre 0 e 300 metros.

Já para o estudo de caso 5, pode-se verificar que, das 4 barras previamente selecionadas $(50,51,52$ e 53), somente 3 delas $(50,52$ e 53) foram tidas como possíveis soluções. Desta forma, observou-se que o erro para a distância varia entre 0 e 300 metros.

Analisando-se o estudo de caso 6 , nota-se que das 5 barras $(40,41,42,43$ e 44) previamente selecionadas pelo localizador, somente 3 barras $(40,41$ e 42) foram mantidas como soluções. Assim, constatou-se que o erro da distância encontra-se ente 0 e 400 metros, ao invés da faixa de erro de 0 a 1300 metros que foi obtida pelo localizador.

Por meio das análises feitas para o sistema de 20 barras, verificou-se assim que o algoritmo de ajuste/sintonia consegue, em alguns casos, restringir o erro da distância, além de apresentar probabilidades mais adequadas para se tomar a decisão sobre qual barra deve ser monitorada a priori.

Na sequência, os resultados obtidos para o sistema de 90 barras (Tabelas de 6.6 a 6.8) são apresentados. 
Tabela 6.6 - Probabilidades de a carga estar alocada em cada barra selecionada para o estudo de caso 1 do sistema de 90 barras.

\begin{tabular}{|c|c|c|}
\hline $\begin{array}{c}\text { Barra } \\
\text { Selecionada }\end{array}$ & Probabilidades (\%) & Barra Desejada \\
\hline 44 & 57,14 & B45 \\
\hline 45 & 42,86 & \\
\hline
\end{tabular}

Tabela 6.7 - Probabilidades de a carga estar alocada em cada barra selecionada para o estudo de caso 2 do sistema de 90 barras.

\begin{tabular}{|c|c|c|}
\hline $\begin{array}{c}\text { Barra } \\
\text { Selecionada }\end{array}$ & Probabilidades (\%) & Barra Desejada \\
\hline 46 & 85,71 & \\
\hline 47 & 0 \\
\hline 48 & 0 & \multirow{2}{*}{ B49 } \\
\hline 49 & 0 & \\
\hline 50 & 0 & \\
\hline 51 & 14,29 & \\
\hline
\end{tabular}

Tabela 6.8 - Probabilidades de a carga estar alocada em cada barra selecionada para o estudo de caso 3 do sistema de 90 barras.

\begin{tabular}{|c|c|c|}
\hline $\begin{array}{c}\text { Barra } \\
\text { Selecionada }\end{array}$ & Probabilidades (\%) & Barra Desejada \\
\hline 14 & 71,43 & \multirow{2}{*}{ B14 } \\
\hline 15 & 0 & \\
\hline 16 & 28,57 & \\
\hline
\end{tabular}

Por meio dos resultados obtidos para o sistema de 90 barras, observou-se para o estudo de caso 1 que as barras B44 e B45 são possíveis soluções. No entanto, a barra B44 apresenta uma maior probabilidade de a carga estar alocada nesta posição ao invés de estar alocada na barra B45 (posição real da carga). Ainda assim, é possível constatar que o erro para a distância é de 70,8 metros, implicandose num erro muito baixo e, portanto, pode ser considerado como satisfatório. 
No estudo de caso 2, constatou-se que somente as barras B46 e B51 foram obtidas como soluções. Desta forma, diz-se que o erro para a distância se encontra entre 1413 e 1957,6 metros.

Por fim, no estudo de caso 3, verificou-se que, das 3 barras eleitas (14, 15 e 16), somente 2 delas (14 e 16) são soluções. Assim, observou-se que a faixa de erro encontra-se entre 0 e 637,8 metros.

Em resumo, um método de ajuste/sintonia da localização foi proposto, onde pôde-se verificar que o método consegue restringir as soluções para a localização da fonte consumidora de potências harmônicas. Portanto, a aplicação deste método é imprescindível à metodologia de localização da fonte consumidora de potências harmônicas proposta nesta tese. 


\section{Discussões e Conclusões}

Nesta tese de doutorado foi apresentada uma nova proposta para localização de fonte consumidora de potências harmônicas de forma que a mesma fosse viável de ser aplicada ao sistema elétrico brasileiro.

Assim, nota-se que a metodologia proposta emprega somente dois medidores, sendo um alocado na subestação e outro no final do alimentador ou em alguma ramificação da rede, o que implica num baixo custo quando da aquisição de tais equipamentos. Portanto, pode-se dizer que o método aqui proposto diverge das metodologias convencionais, as quais baseiam-se em estimadores de estados e, desta maneira, empregam uma grande quantidade de medidores que devem ser alocados no sistema. Além disso, uma proposta para a identificação das componentes harmônicas de corrente da carga foi também desenvolvida, onde o algoritmo de PSO é responsável por estimar as amplitudes das correntes harmônicas da carga.

Por meio dos resultados apresentados pelo método de identificação, verificase que o mesmo ainda necessita de um refinamento e maior investigação. Entretanto, o método de identificação foi capaz de apresentar, na maior parte dos estudos de caso, resultados coerentes. Além dos métodos de localização e identificação propostos, verificou-se também aqui a necessidade de utilizar um algoritmo para ajuste/sintonia da localização. Assim, em grande parte dos casos, o 
ajuste/sintonia foi capaz de apresentar resultados que corrigissem e/ou restringissem as soluções apresentadas pelo método de localização.

Outro aspecto a ser ressaltado é o fato de que cada um dos 10 estudos de caso mostrados nesta tese fez uso tanto de um sistema fictício (20 barras) como de um sistema real (90 barras). Além disso, para cada caso, a dinâmica do sistema foi alterada com o intuito de verificar se os métodos de localização, identificação e ajuste/sintonia propostos seriam capazes de fornecer bons resultados frente a estas variações na dinâmica do sistema. Tratam-se, como alterações na dinâmica do sistema, as variações de posição da carga não linear, entrada de cargas não lineares que não estavam presentes nos dados históricos, variações no carregamento e na tensão da rede. Portanto, a cada estudo de caso, complexidade e incertezas foram inseridas a fim de verificar o desempenho do método proposto, o qual apresentou resultados bem promissores mesmo em meio a toda esta dinâmica que pode ser encontrada em sistemas de distribuição de energia elétrica.

Ademais, esta tese de doutorado pretende fornecer lastro para futuras pesquisas que sejam realizadas na mesma área, bem como para aquelas pesquisas que visem identificar a contribuição tanto da concessionária quanto do consumidor para a distorção harmônica da rede de distribuição.

Como trabalhos futuros, as seguintes frentes de investigações poderiam ser contempladas:

- Determinação dos parâmetros ótimos a serem utilizados no PSO a fim de melhorar ainda mais os resultados obtidos;

- Aplicação de outras arquiteturas de sistemas inteligentes, tais como aquelas híbridas, com o intuito de refinar as soluções obtidas; 
- Realizar análises de sensibilidade da metodologia proposta com relação à variação da carga;

- Otimização da alocação de medidores. 



\section{Referências Bibliográficas}

ALAMMARI, R. A., SOLIMAN, S. A. e EL-HAWARY, M. E. (2004). Identification of Individual Types of Harmonic Loads in an Electric Power System Bus. Electrical Power and Energy Systems, Vol. 26, pp. 545-548.

AL-KANDARI, A. M. e EL-NAGGAR, K. M. (2006). Recursive Identification of Harmonic Loads in Power Systems. Electrical Power and Energy Systems, Vol. 28, pp. 531-536.

ANEEL (2010). PRODIST (Procedimentos de Distribuição de Energia Elétrica no Sistema Elétrico Nacional) - Módulo 8: Qualidade da Energia Elétrica, Rev. 2, pp. $1-69$.

ARRUDA, E. F., KAGAN, N. e RIBEIRO, P. F. (2010). Harmonic Distortion State Estimation Using an Evolutionary Strategy. IEEE Transactions on Power Delivery, Vol. 25, No. 2, pp. 831-842.

BARBARO, P. V., CATALIOTTI, A., COSENTINO, V. e NUCCIO, S. (2007). A Novel Approach Based on Nonactive Power for the Identification of Disturbing Loads in Power Systems. IEEE Transactions on Power Delivery, Vol. 22, No. 3, pp. $1782-$ 1789.

BATISTA, F. A. B. (2006). Modulação Vetorial Aplicada a Retificadores Trifásicos PWM Unidirecionais. Tese de Doutorado. Universidade Federal de Santa Catarina, Florianópolis. 
CHANG, G. W., CHEN, C. -I. e LIU, Y. -J. (2010). A Neural-Network-Based Method of Modeling Electric Arc Furnace Load for Power Engineering Study. IEEE Transactions on Power Systems, Vol. 25, No. 1, pp. 138-146.

CHEN, C., LIU, X., KOVAL, D., XU, W. e TAYJASANANT, T. (2004). Critical Impedance Method - A New Detecting Harmonic Sources Method in Distribution Systems. IEEE Transactions on Power Delivery, Vol. 19, No. 1, pp. 288-297.

CRISTALDI, L. e FERRERO, A. (1994). A Digital Method for the Identification of the Source of Distortion in Electric Power Systems. IEEE Transactions on Instrumentation and Measurement, Vol. 44, No. 1, pp. 14-18.

CRONJE, W. S. T. e RENS, A. P. J. (2004). Investigating the Validity of Applying Artificial Neural Networks to Localise Harmonic Distortion Sources. Proc. of the IEEE Africon, pp. 645-650.

D'ANTONA, G., MUSCAS, C. e SULIS, S. (2009). State Estimation for the Localization of Harmonic Sources in Electric Distribution Systems. IEEE Transactions on Instrumentation and Measurement, Vol. 58, No. 5, pp. 14621470.

DU, Z. P., ARRILLAGA, J., WATSON, N. R. e CHEN, S. (1999). Identification of Harmonic Sources of Power Systems Using State Estimation. IEE Proc. -Gener. Transm. Distrib., Vol. 146, No. 1, pp. 7-12.

FARACH, J. E., GRADY, W. M. e ARAPOSTATHIS, A. (1993). An Optimal Procedure for Placing Sensors and Estimating the Locations of Harmonic Sources in Power Systems. IEEE Transactions on Power Delivery, Vol. 8, No. 3, pp. 13031310.

FARHOODNEA, M., MOHAMED, A. e SHAREEF, H. (2011). A Single Point Measurement Method for Evaluating Harmonic Contributions of Utility and 
Customer in Power Distribution Systems. Journal of Applied Sciences, Vol. 11, No. 2, pp. 257-265.

FERNANDES, R. A. S., SILVA, I. N., e OLESKOVICZ, M. (2010). Identificação de cargas lineares e não-lineares em sistemas elétricos residenciais usando técnicas para seleção de atributos e redes neurais artificiais. Revista SBA: Controle \& Automação, Vol. 21, No. 4, pp. 389-405.

FERRERO, A., SALICONE, S, e TODESCHINI, G. (2007). A Fuzzy Method for the Identification of the Sources Reducing Harmonic Pollution in the Electric Network. Proc. of the Instrumentation and Measurement Technology Conference (IMTC), pp. 1-6.

GOHR JR., R. e PERIN, A. J. (1991). Three-Phase Rectifier Filter Analysis. Proc. of Brazilian Power Electronics Conference (COBEP), pp. 281-283.

GURSOY, E. e NIEBUR, D. (2005). Impact of Sample Size on ICA-Based Harmonic Source Estimation. Proc. of the IEEE Int. Conf. on Intelligent System Application to Power System (ISAP), pp. 123-127.

GURSOY, E. e NIEBUR, D. (2009). Harmonic Load Identification Using Complex Independent Component Analysis. IEEE Transactions on Power Delivery, Vol. 24, No. 1 , pp. $285-292$.

HAMZAH, N., MOHAMED, A. e HUSSAIN, A. (2003). Methods for Determining Utility and Customer Harmonic Contributions at the Point of Common Coupling. Proc. of the National Power and Energy Conference (PECon), pp. 167-171.

HAMZAH, N., MOHAMED, A. e HUSSAIN, A. (2004). Harmonic Source Location at the Point of Common Coupling Based on Voltage Magnitude. Proc. of the IEEE Region 10 TENCON, pp. 220-223. 
HARTANA, R. K. e RICHARDS, G. G. (1993). Constrained Neural Network-Based Identification of Harmonic Sources. IEEE Transactions on Industry Applications, Vol. 29, No. 1, pp. 202-208.

HARTANA, R. K. e RICHARDS, G. G. (1990). Harmonic Source Monitoring and Identification Using Neural Networks. IEEE Transactions on Power Systems, Vol. 5, No. 4, pp. 1098-1104.

HEYDT, G. T. (1989). Identification of Harmonic Sources by a State Estimation Technique. IEEE Transactions on Power Delivery, Vol. 4, No. 1, pp. 569-576.

HONG, Y. -Y. e CHEN, Y. -C. (1999). Application of Algorithms and ArtificialIntelligence Approach for Locating Multiple Harmonics in Distribution Systems. IEE Proc. -Gener. Transm. Distrib., Vol. 146, No. 3, pp. 325-329.

HONG, Y. -Y., LIN, J. -S. e LIU, C. -H. (2000). Fuzzy Harmonic Power Flow Analyses. Proc. of the Int. Conf. on Power System Technology (PowerCon), pp. $121-125$

IEEE DISTRIBUTION PLANNING WORKING GROUP REPORT. (1991). Radial Distribution Test Feeders, IEEE Transactions on Power Systems, Vol. 6, No. 3, pp. 975-985.

IEEE STANDARD 519-1992. (1992). Recommended Practices and Requirements for Harmonic Control in Electrical Power Systems.

IEEE TASK FORCE ON HARMONIC IMPACTS. (1993). Effects of the Harmonics on Equipment, IEEE Transactions on Power Delivery, Vol. 8, No. 2, pp. 672-680. IEEE TASK FORCE ON HARMONICS MODELING AND SIMULATION. (1996a). Modeling and Simulation of the Propagation of Harmonics in Electric Power Networks - Part I: Samples Systems and Examples, IEEE Transactions on Power Delivery, Vol. 11, No. 1, pp. 452-465. 
IEEE TASK FORCE ON HARMONICS MODELING AND SIMULATION. (1996b). Modeling and Simulation of the Propagation of Harmonics in Electric Power Networks - Part II: Samples Systems and Examples, IEEE Transactions on Power Delivery, Vol. 11, No. 1, pp. 466-474.

ISLAM, K. M. S. e SAMRA, A. H. (1997). Identification of Harmonic Sources in Power Distribution Systems. Proc. of the IEEE Southeastcon, pp. 301-303.

KENNEDY, J. e EBERHART, R. C. (1995). Particle Swarm Optimization. Proceedings of IEEE International Conference on Neural Networks, pp. 19421948.

KENNEDY, J., EBERHART, R. C. e SHI, Y. (2001). Swarm Intelligence, Morgan Kaufmann/Academic Press.

KUMAR, A., DAS, B. e SHARMA, J. (2004). Determination of Location of Multiple Harmonic Sources in a Power System. Electrical Power and Energy Systems, Vol. 26, pp. 73-78.

KUMAR, A., DAS, B. e SHARMA, J. (2005a). Genetic Algorithm-Based Meter Placement for Static Estimation of Harmonic Sources. IEEE Transactions on Power Delivery, Vol. 20, No. 2, pp. 1088-1096.

KUMAR, A., DAS, B. e SHARMA, J. (2005b). Simple Technique for Placement of Meters for Estimation of Harmonics in Electric Power System. IEE Proc. -Gener. Transm. Distrib., Vol. 152, No. 1, pp. 67-78.

LI, C., XU, W., e TAYJASANANT, T. (2004). A "Critical Impedance"-Based Method for Identifying Harmonic Sources. IEEE Transactions on Power Delivery, Vol. 19, No. 2, pp. 671-678. 
LIMA, L. T. G., SEMLYEN, A. e IRAVANI, M. R. (2003). Harmonic domain periodic steady state modeling of power electronics apparatus: SVC and TCSC. IEEE Transactions on Power Delivery, Vol. 18, No. 3, pp. 960-967.

LIN, W., LIN, C., TU, K. e WU, C. (2005). Multiple Harmonic Source Detection and Equipment Identification with Cascade Correlation Network. IEEE Transactions on Power Delivery, Vol. 20, No. 3, pp. 2166-2173.

MA, H e GIRGIS, A. A. (1996). Identification and Tracking of Harmonic Sources in a Power System Using a Kalman Filter. IEEE Transactions on Power Delivery, Vol. 11, No. 3, pp. 1659-1665.

MANNIKOFF, A. e NILSSON, H. (2009). Sweden - 'Reaching 100\% Smart Meters 1 July, 2009', IEEE Power \& Energy Society General Meeting, pp. 1-4.

MAYORDOMO, J. G., BEITES, L. F., ASENSI, R., ORZAEZ, F., IZZEDDINE, M. e ZABALA, L. (1998). A contribution for modeling controlled and uncontrolled AC/DC converters in harmonic power flows. IEEE Transactions on Power Delivery, Vol. 13, No. 4, pp. 1501-1508.

MELIOPOULOS, A. P. S., ZHANG, F. e ZELINGHER, S. (1994). Power system harmonic state estimation. IEEE Transactions on Power Delivery, Vol. 9, No. 3, pp. 1701-1709.

MOHAMED, A., HUSSAIN, A., UMEH, K. e MOHAMED, R. (2006). A Rule Based Expert System for Identification of Harmonics Originating from Single Phase Nonlinear Loads. International Journal of Emerging Electric Power Systems, Vol. 7, No. 2, pp. 1-14.

MORIMOTO, K., KONISHI, K., MIKI, T., NAGAOKA, N. e AMETANI, A. (2007). Harmonic Source Identification by Simultaneous-Multipoint Harmonic 
Measurements. Proc. of the Universities Power Engineering Conference (UPEC), pp. 322-327.

NAJJAR, M. e HEYDT, G. T. (1991). A Hybrid Nonlinear - Least Square Estimation of Harmonic Signal Levels in Power Systems. IEEE Transactions on Power Delivery, Vol. 6, No. 1, pp. 282-288.

NGUYEN, M. T. e LEE, W. (2000). An Approach to Enhance the Harmonic Sources Identification Process. IEEE Industrial and Commercial Power Systems Technical Conference, pp. 127-132.

NIEKERK, C. R., RENS, A. P. J. e HOFFMAN, A. J. (2002). Identification of Types of Distortion Sources in Power Systems by Applying Neural Networks. Proc. of the IEEE Africon, pp. 829-834.

PFAJFAR, T., BLAZIC, B e PAPIC, I. (2008). Harmonic Contributions Evaluation with the Harmonic Current Vector Method. IEEE Transactions on Power Delivery, Vol. 23, No. 1, pp. 425-433.

PLATA, E. A. C. e TACCA, H. E. (2005). Arc Furnace Modeling in ATP-EMTP. Proc. of the Int. Conf. on Power Systems Trasients (IPST), pp. 1-6.

PYZALSKI, T., LUKOMSKI, R. e WILKOSZ, K. (2004). Utilization of the Voltage Rate to Localization of Harmonic Sources in a Power System. Proc. of the IEEE MELECON, pp. 1091-1094.

RENS, A. P. J. e SWART, P. H. (2001). On Technique for the Localisation of Multiple Distortion Sources in Three-Phase Networks: Time Domain Verification. European Transactions on Electrical Power, Vol. 11, No. 5, pp. 317-322. ROSA, F. C. (2006). Harmonic and Power Systems, CRC Press. 
SAHNI, M. e LEE, W. -J. (2004). Optimal Sensor Placement Technique for Locating Multiple Harmonics Sources on a Radial Distribution Feeder. Proc. of the IEEE Industry Applications Society Annual Meeting, pp. 2140-2145.

SANKARAN, C. (2002). Power Quality, CRC Press.

SANTOS, I. N., COSTA, F. H. e OLIVEIRA, J. C. (2009). Avaliação do Desempenho das Metodologias para a Representação de Consumidores Visando o Compartilhamento das Distorções Harmônicas. Conferência Brasileira sobre Qualidade da Energia Elétrica, pp. 1-6.

SCHAU, H. e NOVITSKIY, A. (2008). Identification of the Dominant Harmonic Source in the LV Network on the Base of Anomalous Power Flows Considerations. Proc. of the IEEE Power Tech, pp. 1-5.

SRINIVASAN, D., NG, W. S. e LIEW. A. C. (2006). Neural Network-Based Signature Recognition for Harmonic Source Identification. IEEE Transactions on Power Delivery, Vol. 21, No. 1, pp. 398-405.

SUMNeR, M., PAlethorpe, B., ThOMAS, D. W. P., ZANChetTA, P. e DI PIAZZA. M. A. (2002). A Technique for Power Supply Harmonic Impedance Estimation Using a Controlled Voltage Disturbance. IEEE Transactions on Power Electronics, Vol. 17, No. 2, pp. 207-215.

SUN, Y., ZHANG, G., XU, W. e MAYORDOMO, J. G. (2007). A harmonically coupled admittance matrix model for AC/DC converters. IEEE Transactions on Power System, Vol. 22, No. 4, pp. 1574 - 1582.

SUN, Y., ZHANG, G., XU, W. e MAYORDOMO, J. G. (2008). A Non-iterative Harmonic Power Flow Method for Accurate Harmonic Calculations. Proc. of the $13^{\text {th }}$ Int. Conf. on Harmonics and Quality of Power (ICHQP), pp. 1-6. 
TENG, J. -H e CHANG. C. -Y. (2007). Backward/Forward Sweep-Based Harmonic Analysis Method for Distribution Systems. IEEE Transactions on Power Delivery, Vol. 22, No. 3, pp. 1665-1672.

TESHOME, A. (1991). Harmonic Source and Type Identification in a Radial Distribution System. Proc. of the IEEE Industry Applications Society Annual Meeting, pp. 1605-1609.

THUNBERG, E. e SODER. L. (1999). A Norton Approach to Distribution Network Modeling for Harmonic Studies. IEEE Transactions on Power Delivery, Vol. 14, No. 1, pp. 272-277.

UMEH, K. e MOHAMED, A. (2004). A Rule-Based Expert System for Harmonic Load Recognition. Proc. of the National Power and Energy Conference (PECon), pp. 19-24.

UMEH, K. e MOHAMED, A. (2005). Intelligent System for Identification of Harmonics Originating from Single Phase Nonlinear Loads. Proc. of the IEEE Southeastcon, pp. 137-142.

VARADAN, S. e MAKRAM, E. B. (1994). Practical considerations in the application of neural networks to the identification of harmonic loads. Electrical Power Systems Research, Vol. 30, pp. 103-106.

VARADAN, S. e MAKRAM, E. B. (1996). Harmonic load identification and determination of load composition using a least squares method. Electrical Power Systems Research, Vol. 37, pp. 203-208.

VARIZ, A. M., CARNEIRO JR., S., PEREIRA, J. L. R. e BARBOSA, P. G. (1996). Cálculo do Fluxo de Harmônicos em Sistemas de Potência Trifásicos Utilizando o Método de Injeção de Correntes com Solução Iterativa. Revista SBA: Controle \& Automação, Vol. 19, No. 2, pp. 178-198. 
VLAHINIC, S., VLAHINIC, I e BRNOBIC, D. (2004). A Simple Measurement for Harmonic Source Localization. Proc. of the IEEE MELECON, pp. 991-994.

WILKOSZ, K. (2007). Harmonic Sources Localization: Comparison of Methods Utilizing the Voltage Rate or the Current Rate. Proc. of the $9^{\text {th }}$ Int. Conf. Electrical Power Quality and Utilisation, pp. 1-6.

WON, D. -J., CHUNG, I. -Y., KIM, J. -M., MOON, S. -I., SEO, J. -C. e CHOE, J. -W. (2006). A New Algorithm to Locate Power-Quality Event Source with Improved Realization of Distributed Monitoring Scheme. IEEE Transactions on Power Delivery, Vol. 21, No. 3, pp. 1641-1647.

XU, W., AHMED, E. E., ZHANG, X. e LIU, X. (2002). Measurement of Network Harmonic Impedances: Practical Implementation Issues and their Solutions. IEEE Transactions on Power Delivery, Vol. 17, No. 1, pp. 210-216.

XU, W., DRAKOS, J. E., MANSOUR, Y. e CHANG, A. (1994), A three-phase converter model for harmonic analysis of HVDC systems. IEEE Transactions on Power Delivery, Vol. 9, No. 3, pp. 1724-1731.

XU, W. e LIU, Y. (2000). A Method for Determining Customer and Utility Harmonic Contributions at the Point of Common Coupling. IEEE Transactions on Power Delivery, Vol. 15, No. 2, pp. 804-811.

XU, W., LIU, X. e LIU, Y. (2003). An Investigation on the Validity of Power-Direction Method for Harmonic Source Determination. IEEE Transactions on Power Delivery, Vol. 18, No. 1, pp. 214-219.

YAN, Y. H., CHEN, C. S., MOO, C. S. e HSU, C. T. (1994). Harmonic Analysis for Industrial Customers. IEEE Transactions on Industry Applications, Vol. 30, No. 2, pp. 462-468. 
YONGHAI, X., SHUN, H. e YINGYING, L. (2006). Intelligent System for Identification of Harmonics Originating from Single Phase Nonlinear Loads. Proc. of the Int. Conf. on Power System Technology, pp. 1-5.

ZHANG, X., AHMED, E. e XU, W. (1999). Determination of Network Harmonic Impedances Using Steady-State Measurements. Proc. of the IEEE Power Enginnering Society Summer Meeting, pp. 390-394.

ZHAO, Y., LI, J. e XIA, D. (2004). Harmonic Source Identification and Current Separation in Distribution Systems. Electrical Power and Energy Systems, Vol. 26, pp. 1-7.

ZIARI, I. e JALILIAN, A. (2004). Optimal Harmonic Power Flow Using an Ant Colony System-Based Algorithm. Proc. of the Universities Power Engineering Conference (UPEC), pp. 1-4. 


\section{Anexo A - Sistema IEEE de 13 Barras}

$\mathrm{O}$ arquivo que corresponde à modelagem do sistema IEEE de 13 barras feita por meio do software ATP é aqui mostrado por partes. Neste arquivo, são então configuradas as linhas de distribuição, cargas $R L$, bancos de capacitores, transformadores, dentre outros. É importante comentar que este arquivo foi desenvolvido com base no IEEE Task Force on Harmonics Modeling and Simulation (1996a, 1996b), em que disponibiliza um arquivo ATP referente ao sistema a ser modelado.

\section{A.1. Configurações iniciais do modelo}

BEGIN NEW DATA CASE POWER FREQUENCY 6.512E-5 0.1333060 $1 \quad 1 \quad 1$

(1)

1

\section{A.2. Algoritmo para injeção de corrente nas barras}

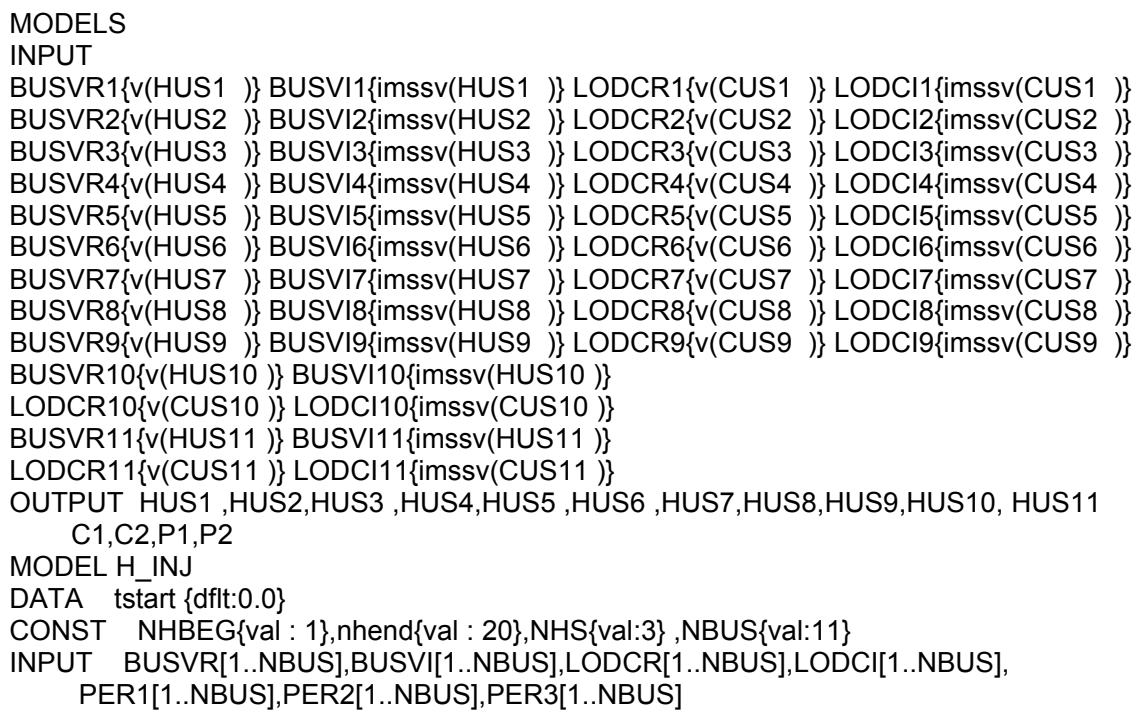


VAR OMEGA,I,J,

HSM1[1..nhend], HSA1[1..nhend],

HSM2[1..nhend], HSA2[1..nhend],

HSM3[1..nhend], HSA3[1..nhend],

Y[1..NBUS],G[1..NBUS], LINV[1..NBUS],

VMAG[1..NBUS],CMAG[1..NBUS],PHASEV[1..NBUS],

CINJ[1..NBUS], CINJT[1..NBUS],HS[1..NBUS],HX ,

HISTORY BUSVR[1..NBUS]\{dflt:0\}

OUTPUT HS , PHASEV, CINJT

INIT

HSM1[1..nhend]:=[ $1,0,0.542,0,0.152$,

$0,0.069,0,0.043,0$,

$0.036,0 \quad 0.029, \quad 0, \quad 0.025$

$0.000,0.018,0.000,0.014,0]$

HSA1[1..nhend]:=[ $-1.45,0,0.66,0,110.77$

$0,151.87,0,-95.02, \quad 0$.

$-13.91,0,95.2,0,-182.7$,

$0,-91.59,0,10.52,0$.

HSA1[1..nhend] := HSA1[1..nhend] ${ }^{*} \mathrm{PI} / 180$

HSM2[1..nhend]:=[ 1, 0, 0.192, 0, 0.107,

$0,0.021,0,0.014,0$

$0.009,0,0.006,0,0.005$,

$0.000,0.000,0.000,0.000,0$

HSA2[1..nhend]:=[ $-41.2,0,273.40,0,339.00$,

$0,137.67,0,263.20, \quad 0$.,

$39.80,0,182.4,0,287.00$,

$0,0,0,0,0$.

HSA2[1..nhend] := HSA2[1..nhend] ${ }^{*} \mathrm{Pl} / 180$

HSM3[1..nhend]:=[ $1,0,0.0074,0.0954,0.0017$,

$0.0832,0.00, \quad 0.0049,0, \quad 0$,

$0.0,0,0.0, \quad 0, \quad 0.0$

$0.000,0.0,0.000,0.0,0]$

HSA3[1..nhend]:=[ -35.0, 0, -105.8, -167.4, -275.5,

$-42.6,0,-247.8,0,0$.

$0,0,0,0,0$,

$0,-91.59,0,10.52$

HSA3[1..nhend] := HSA3[1..nhend] ${ }^{*} \mathrm{PI} / 180$

OMEGA: $=\left.2 *{ }^{*}\right|^{*} 60$

ENDINIT

EXEC

IF (t=tstart) THEN

$\mathrm{l}:=0$

WHILE I<NBUS DO

$\mathrm{I}:=\mid+1$

VMAG[I] := SQRT(BUSVR[I] $\left.{ }^{\star *} 2+B U S V I[]^{\star \star} 2\right)$

PHASEV[I] := ATAN2(BUSVI[I],BUSVR[I])

CMAG[I] := SQRT $(\text { LODCI[I] }]^{\star \star} 2+$ LODCR $\left.[I]^{\star \star} 2\right)^{\star} 1000$

$\mathrm{G}[\mathrm{I}] \quad:=\left(\mathrm{CMAG}[\mathrm{I} / \mathrm{VMAG}[\mathrm{I}])^{*}\left(\quad\right.\right.$ PER1[1] ${ }^{*} \mathrm{COS}(\mathrm{HSA} 1[1])$

+PER2[1]*COS(HSA2[1])

$\left.+\mathrm{PER} 3[1]^{*} \mathrm{COS}(\mathrm{HSA} 3[1])\right)$

LINV[I] := -OMEGA* $($ CMAG [I]/VMAG[I])*(PER1[I]*'SIN $($ HSA1[1])

+PER2[1] ${ }^{*}$ IIN(HSA2[1])

+ PER3[I] ${ }^{*}$ SIN(HSA3[1])

CINJ[I]:=VMAG[I]*COS(OMEGA*t+PHASEV[I]-PI/2)/OMEGA

integral(BUSVR[I]):=CINJ[I]

$\mathrm{HS}[1]:=0$

ENDWHILE

ELSE

$\mathrm{I}:=0$

WHILE I<NBUS DO

$\mathrm{I}:=\mid+1$

CINJ[l]:=integral(BUSVR[I])

ENDWHILE

ENDIF

$\mathrm{J}:=0$

WHILE J<NBUS DO

$\mathrm{J}:=\mathrm{J}+1$

CINJT[J]:=LINV[J]*CINJ[J] +G[J]*BUSVR[J]

$H X:=-C I N J T[J]$

FOR I := NHBEG TO NHEND

DO HX:=HX+

PER1[J]*CMAG[J]*HSM1[I] $\cos \left(I^{*}\right.$ OMEGA ${ }^{*} t+I^{*}$ PHASEV[J]+HSA1[I])+

PER2[J]* CMAG[J] ${ }^{*} \mathrm{HSM} 2[]^{*} \cos \left(I^{*} \mathrm{OMEGA}^{*} \mathrm{t}+\mathrm{I}^{*} \mathrm{PHASEV}[\mathrm{J}]+\mathrm{HSA} 2[\mathrm{I}]\right)+$

PER3[J]*CMAG[J] ${ }^{*} \mathrm{HSM} 3[\mathrm{I}]^{*} \cos \left(\mathrm{I}^{*} \mathrm{OMEGA}{ }^{*} \mathrm{t}+\mathrm{I}^{*} \mathrm{PHASEV}[\mathrm{J}]+\mathrm{HSA}[[\mathrm{l}])\right.$

ENDFOR

$\mathrm{HS}[\mathrm{J}]:=-\mathrm{HX}$ 
ENDWHILE

ENDEXEC

ENDMODel

USE H_INJ AS H_INJA

INPUT ${ }^{-}$BUSVR[1] := BUSVR1 BUSVI[1] := BUSVI1

LODCR[1] := LODCR1 LODCI[1] := LODCl1

PER1[1] := 0.0 PER2[1] := 0.2 PER3[1] := 0.2

BUSVR[2] := BUSVR2 BUSVI[2] := BUSVI2

LODCR[2] := LODCR2 LODCI[2] := LODCl2

PER1[2] := 0.0 PER2[2] := 0.2 PER3[2] := 0.2

BUSVR[3] := BUSVR3 BUSVI[3] := BUSVI3

LODCR[3] := LODCR3 LODCI[3] := LODCI3

PER1[3] := 0.1 PER2[3] := 0.1 PER3[3] := 0 .

BUSVR[4] := BUSVR4 BUSVI[4] := BUSVI4

LODCR[4] := LODCR4 LODCI[4] := LODCI4

PER1[4] := 0.0 PER2[4] := 0.3 PER3[4] := 0 .

BUSVR[5] := BUSVR5 BUSVI[5] := BUSVI5

LODCR[5] := LODCR5 LODCI[5] := LODCI5

PER1[5] := 0.0 PER2[5] := 0.3 PER3[5] := 0 .

BUSVR[6] := BUSVR6 BUSVI[6] := BUSVI6

LODCR[6] := LODCR6 LODCI[6] := LODCl6

PER1[6] := 0.0 PER2[6] $:=0.3$ PER3[6] $:=0$.

BUSVR[7] := BUSVR7 BUSVI[7] := BUSVI7

LODCR[7] := LODCR7 LODCI[7] := LODCl7

PER1[7] $:=0.0$ PER2[7] $:=0.15$ PER3[7] $:=0.2$

BUSVR[8] := BUSVR8 BUSVI[8] := BUSVI8

LODCR[8] $:=$ LODCR8 LODCI[8] := LODCI8

PER1[8] := 0.0 PER2[8] := 0.15 PER3[8] := 0.2

BUSVR[9] := BUSVR9 BUSVI[9] := BUSVI9

LODCR[9] := LODCR9 LODCI[9] := LODCI9

PER1[9] := 0.0 PER2[9] := 0.15 PER3[9] $:=0.2$

BUSVR[10] := BUSVR10 BUSVI[10] := BUSVI10

LODCR[10] := LODCR10 LODCI[10]:= LODCl10

PER1[10] := 0.0 PER2[10] :=0.15 PER3[10] := 0.2

BUSVR[11] := BUSVR11 BUSVI[11] := BUSVI11

LODCR[11] := LODCR11 LODCI[11] := LODCI11

PER1[11] := 0.0 PER2[11] $:=0.15$ PER3[11] $:=0.2$

OUTPUT HUS1 := HS[1] HUS2 := HS[2] HUS3 $:=\mathrm{HS}[3]$ HUS4 $:=\mathrm{HS}[4]$

HUS5 := HS[5] HUS6 := HS[6] HUS7 := HS[7] HUS8 := HS[8]

HUS9 := HS[9] HUS10:= HS[10] HUS11:= HS[11]

ENDUSE

RECORD H_INJA.HS[1] AS HS1

H INJA.HS[2] AS HS2

endmodels

$\begin{array}{ll}\text { CUS1 } & .001 \\ \text { HUS1 } & 9999 . \\ \text { CUS2 } & .001 \\ \text { HUS2 } & 9999 . \\ \text { CUS3 } & .001 \\ \text { HUS3 } & 9999 . \\ \text { CUS4 } & .001 \\ \text { HUS4 } & 9999 . \\ \text { CUS5 } & .001 \\ \text { HUS5 } & 9999 . \\ \text { CUS6 } & .001 \\ \text { HUS6 } & 9999 . \\ \text { CUS7 } & .001 \\ \text { HUS7 } & 9999 . \\ \text { CUS8 } & .001 \\ \text { HUS8 } & 9999 . \\ \text { CUS9 } & .001 \\ \text { HUS9 } & 9999 . \\ \text { CUS10 } & .001 \\ \text { HUS10 } & 9999 . \\ \text { CUS11 } & .001 \\ \text { HUS11 } & 9999 .\end{array}$




\section{A.3. Modelagem do sistema de distribuição}

\section{A.3.1. Impedância equivalente da fonte}

$\begin{array}{lll}\text { SOURCABUS50A } & 0 . & 11.1 \\ \text { SOURCBBUS50B } & 0 . & 11.1 \\ \text { SOURCCBUS50C } & 0 . & 11.1\end{array}$

\section{A.3.2. Bancos de capacitores}

$\begin{array}{ll}\text { BU911C } & 46.5 \\ \text { BUS75A } & 93.25 \\ \text { BUS75B } & 93.25 \\ \text { BUS75C } & 93.25\end{array}$

\section{A.3.3. Transformador da subestação}

$\begin{array}{cc}\text { TRANSFORMER } & \text { SA } \\ 9999 & \\ \text { 1BUS50ABUS50C } & .0010 .0115 . \\ \text { 2BU50XA } & .0346 .27692 .6218 \\ \text { TRANSFORMER } & \text { SB } \\ \text { 9999 } & .0010 .00115 . \\ \text { 1BUS50BBUS50A } & .0346 .27692 .5518 \\ \text { 2BU50XB } & \text { SC } \\ \text { TRANSFORMER } & \\ 9999 & .0010 .00115 . \\ \text { 1BUS50CBUS50B } & .0346 .27692 .5918 \\ \text { 2BU50XC } & \end{array}$

\section{A.3.4. Transformador entre as barras 33 e 34}

$\begin{array}{cc}\text { TRANSFORMER } & \text { DA } \\ 9999 & \\ \text { 1BUS33ABUS33C } & .0010 .04 .16 \\ \text { 2BU34XA } & .0051 .0092 .277 \\ \text { TRANSFORMER } & \text { DB } \\ 9999 & \\ \text { 1BUS33BBUS33A } & .0010 .004 .16 \\ \text { 2BU34XB } & .0051 .0092 .277 \\ \text { TRANSFORMER } & \text { DC } \\ \text { 9999 } & \\ \text { 1BUS33CBUS33B } & .0010 .004 .16 \\ \text { 2BU34XC } & .0051 .0092 .275\end{array}$

\section{A.3.5. Impedâncias das cargas não lineares}

$\begin{array}{lc}\text { BUS45BHMS45B } & 35.152 \\ \text { BUS45BHMS45B } & 47.922 \\ \text { BUS46BHMS46C } & 76.275 \\ \text { BUS46BHMS46C } & 133.06 \\ \text { BUS52AHMS52A } & 135.31\end{array}$




$\begin{array}{lc}\text { BUS52AHMS52A } & 201.72 \\ \text { BUS71AHMS71B } & 45.989 \\ \text { BUS71AHMS71B } & 80.226 \\ \text { BUS71BHMS71C } & 49.168 \\ \text { BUS71BHMS71C } & 85.772 \\ \text { BUS71CHMS71A } & 41.501 \\ \text { BUS71CHMS71A } & 72.399 \\ \text { BUS75AHMS75A } & 11.951 \\ \text { BUS75AHMS75A } & 30.720 \\ \text { BUS75BHMS75B } & 92.627 \\ \text { BUS75BHMS75B } & 104.34 \\ \text { BUS75CHMS75C } & 18.225 \\ \text { BUS75CHMS75C } & 24.847 \\ \text { BUS92CHMS92A } & 97.340 \\ \text { BUS92CHMS92A } & 109.65 \\ \text { BU911CHM911C } & 32.299 \\ \text { BU911CHM911C } & 68.219\end{array}$

\section{A.3.6. Impedâncias das cargas RL}

$\begin{array}{lc} & \\ \text { BU34XA } & 141.03 \\ \text { BU34XA } & 297.93 \\ \text { BUS32A } & 3993.1 \\ \text { BUS32A } & 6963.6 \\ \text { BUS32B } & 4155.1 \\ \text { BUS32B } & 7246.1 \\ \text { BUS32C } & 3749.6 \\ \text { BUS32C } & 6539.0 \\ \text { B71-0A } & 3993.1 \\ \text { B71_0A } & 6963.6 \\ \text { B71_0B } & 4155.1 \\ \text { B71_0B } & 7246.1 \\ \text { B71_0C } & 3749.6 \\ \text { B71_0C } & 6539.0 \\ \text { B71-1A } & 3993.1 \\ \text { B71_1A } & 6963.6 \\ \text { B71_1B } & 4155.1 \\ \text { B71_1B } & 7246.1 \\ \text { B71_1C } & 3749.6 \\ \text { B71_1C } & 6539.0 \\ \text { B71-2A } & 3993.1 \\ \text { B71_2A } & 6963.6 \\ \text { B71_2B } & 4155.1 \\ \text { B71_2B } & 7246.1 \\ \text { B71_2C } & 3749.6 \\ \text { B71_2C } & 6539.0 \\ \text { B71-3A } & 3993.1 \\ \text { B71_3A } & 6963.6 \\ \text { B71_3B } & 4155.1 \\ \text { B71_3B } & 7246.1 \\ \text { B71_3C } & 3749.6 \\ \text { B71_3C } & 6539.0 \\ \text { B71-4A } & 3993.1 \\ \text { B71_4A } & 6963.6 \\ \text { B71_4B } & 4155.1 \\ \text { B71_4B } & 7246.1 \\ \text { B71_4C } & 3749.6 \\ \text { B71_4C } & 6539.0 \\ \text { B71-5A } & 3993.1 \\ \text { B71_5A } & 6963.6 \\ \text { B71_5B } & 4155.1 \\ \text { B71_5B } & 7246.1 \\ \text { B71_5C } & 3749.6 \\ \text { B71_5C } & 6539.0 \\ \text { B71-6A } & 3993.1 \\ \text { B71_6A } & 6963.6 \\ \text { B71_6B } & 4155.1 \\ \text { B71_6B } & 7246.1 \\ \text { B71_6C } & 3749.6 \\ \text { B71_6C } & 6539.0 \\ \text { B71-7A } & 3993.1 \\ \text { B } & \\ & \end{array}$




$\begin{array}{lc}\text { B71_7A } & 6963.6 \\ \text { B71_7B } & 4155.1 \\ \text { B71_7B } & 7246.1 \\ \text { B71_7C } & 3749.6 \\ \text { B71_7C } & 6539.0 \\ \text { B71-8A } & 3993.1 \\ \text { B71_8A } & 6963.6 \\ \text { B71_8B } & 4155.1 \\ \text { B71_8B } & 7246.1 \\ \text { B71_8C } & 3749.6 \\ \text { B71_8C } & 6539.0 \\ \text { BUS71A } & 3993.1 \\ \text { BUS71A } & 6963.6 \\ \text { BUS71B } & 4155.1 \\ \text { BUS71B } & 7246.1 \\ \text { BUS71C } & 3749.6\end{array}$

\section{A.3.7. Impedâncias das linhas de distribuição}

\$VINTAGE, 1

1BU50XABUS32A

2BU50XBBUS32B

3BU50XCBUS32C

\$VINTAGE, 0

\$VINTAGE, 1

1BUS33ABUS32A

2BUS33BBUS32B

3BUS33CBUS32C

\$VINTAGE, 0

\$VINTAGE, 1

1BUS32BBUS45B

2BUS32CBUS45C

\$VINTAGE, 0

\$VINTAGE, 1

1BUS45BBUS46B

2BUS45CBUS46C

\$VINTAGE, 0

\$VINTAGE, 1

1BUS32ABUS71A

2BUS32BBUS71B

3BUS32CBUS71C

\$VINTAGE, 0

\$VINTAGE, 1

1BUS71ABU150A

2BUS71BBU150B

3BUS71CBU150C

\$VINTAGE, 0

\$VINTAGE, 1

1BUS71ABUS84A

2BUS71CBUS84C

\$VINTAGE, 0

\$VINTAGE, 1

1BUS92ABUS75A

2BUS92BBUS75B

3BUS92CBUS75C
1.31623009E-01 3.84794744E-01 6.27912024E-03 5.91462503E-02 1.81330876E-01 -1.77606864E-03 1.27712145E-01 3.97589069E-01 5.85889315E-03 5.99353790E-02 1.65552739E-01 -1.40269917E-03 $5.79943154 \mathrm{E}-02$ 1.46195369E-01 -7.50179764E-04 1.29206726E-01 3.92667398E-01 5.72960436E-03

7.13527342E-02 1.11601044E-01 1.42239621E-03 1.49838447E-02 4.13881846E-02 -3.00210228E-04 7.07486634E-02 1.13569208E-01 1.31369399E-03 1.47865626E-02 4.53327190E-02 -3.77647319E-04 1.44985789E-02 3.65488421E-02 -1.66546010E-04 7.03750183E-02 1.14799625E-01 1.33777374E-03

1.25854901E-01 1.27700830E-01 1.18385707E-03 1.95236562E-02 4.36168101E-02 -2.26197373E-04 1.25320174E-01 1.28633594E-01 1.17282372E-03

7.55126745E-02 7.66202281E-02 7.10311740E-04 1.17141525E-02 2.61699940E-02 -1.35717946E-04 7.51918399E-02 7.71798845E-02 7.03691755E-04

1.31623009E-02 3.84794744E-02 6.27912024E-04 5.91462503E-03 1.81330876E-02 -1.77606864E-04 1.27712145E-02 3.97589069E-02 5.85889315E-04 5.99353790E-03 1.65552739E-02 -1.40269917E-04 $5.79943154 \mathrm{E}-03$ 1.46195369E-02 -7.50179764E-05 1.29206726E-02 3.92667398E-02 5.72960436E-04

6.58115045E-02 1.92250055E-01 3.13956012E-03 2.95731251E-02 9.06654379E-02 -8.88034320E-04 6.38560726E-02 1.98647217E-01 2.92944657E-03 2.99676895E-02 8.27763693E-02 -7.01349585E-04 $2.89971577 \mathrm{E}-02 \quad 7.30976843 \mathrm{E}-02$-3.75089882E-04 $\begin{array}{lll}6.46033628 \mathrm{E}-02 & 1.96186382 \mathrm{E}-01 & 2.86480218 \mathrm{E}-03\end{array}$

7.51918399E-02 7.71798845E-02 7.03691755E-04 1.17141525E-02 2.61699940E-02 -1.35717946E-04 7.55126745E-02 7.66202281E-02 7.10311740E-04

7.56155303E-02 4.22159091E-02 2.37674825E-02 3.02178030E-02 $3.07765151 \mathrm{E}-03 \quad 0.00000000 \mathrm{E}-00$

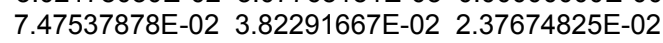
2.69696969E-02 -1.37311061E-03 0.00000000E-00 
\$VINTAGE, 0

3.02178030E-02 3.07765151E-03 0.00000000E-00

7.56155303E-02 4.22159091E-02 2.37674825E-02

\$VINTAGE, 1

1BUS84ABUS52A $\quad 1.49090909 \mathrm{E}-01 \quad 7.93787878 \mathrm{E}-02 \quad 5.33787477 \mathrm{E}-02$

\$VINTAGE, 0

\$VINTAGE, 1

1BUS71ABUS92A $\quad 0.00000000 \mathrm{E}-02 \quad 0.00000001 \mathrm{E}-01 \quad 0.00000000 \mathrm{E}-03$

2BUS71BBUS92B $\quad 0.00000000 \mathrm{E}-02 \quad 0.00000000 \mathrm{E}-02 \quad 0.00000000 \mathrm{E}-04$

$\begin{array}{lll}0.00000000 \mathrm{E}-02 & 0.00000001 \mathrm{E}-01 & 0.00000000 \mathrm{E}-03\end{array}$

$0.00000000 \mathrm{E}-02 \quad 0.00000000 \mathrm{E}-02 \quad 0.00000000 \mathrm{E}-04$

$0.00000000 \mathrm{E}-02 \quad 0.00000000 \mathrm{E}-02 \quad 0.00000000 \mathrm{E}-04$

$0.00000000 \mathrm{E}-02 \quad 0.00000001 \mathrm{E}-01 \quad 0.00000000 \mathrm{E}-03$

\$VINTAGE, 0

\$VINTAGE, 1

1BUS84CBU911C

7.54977632E-02 7.66465726E-02 6.81592959E-04

BLANK CARD ENDING BRANCHES

\section{A.3.8. Medidores de corrente}

\begin{tabular}{|c|c|}
\hline $\begin{array}{l}\text { BUS75ABSS75A } \\
\text { RUS75RSS75R }\end{array}$ & MEASURING \\
\hline BUS75BBSS75B & MEASURING \\
\hline BUS75CBSS75C & MEASURING \\
\hline
\end{tabular}

\section{A.3.9. Parâmetros da fonte}

$\begin{array}{llll}\text { 14SOURCA } & 93897 . & 60 . & 0 . \\ \text { 14SOURCB } & 93897 . & 60 . & -120 . \\ \text { 14SOURCC } & 93897 . & 60 . & 120 .\end{array}$

$-1$. $\begin{array}{rrrr}\text { 14SOURCB } & 93897 . & 60 . & -120 \\ \text { 14SOURCC } & 93897 . & 60 & 120\end{array}$

-1 .

\section{A.3.10. Barras com injeção de corrente harmônica}

$$
\begin{aligned}
& \text { 11BUS45B 1.E-18 } \\
& 18 \text { 1. HUS1 } \\
& \text { 11HMS45B 1.E-18 } \\
& 18 \text { 1. CUS1 } \\
& \text { 11BUS46B } 1 . \mathrm{E}-18 \\
& \text { 18BUS46C 1. HUS2 } \\
& \text { 11HMS46C 1.E-18 } \\
& \text { 18BUS46C 1. CUS2 } \\
& \text { 11BUS52A 1.E-18 } \\
& 18 \text { 1. HUS3 } \\
& \text { 11HMS52A 1.E-18 } \\
& 18 \text { 1. CUS3 } \\
& \text { 11BUS71A } 1 . E-18 \\
& \text { 18BUS71B 1. HUS4 } \\
& \text { 11HMS71B 1.E-18 } \\
& \text { 18BUS71B 1. CUS4 } \\
& \text { 11BUS71B } 1 . E-18 \\
& \text { 18BUS71C 1. HUS5 } \\
& \text { 11HMS71C 1.E-18 } \\
& \text { 18BUS71C 1. CUS5 } \\
& \text { 11BUS71C 1.E-18 } \\
& \text { 18BUS71A 1. HUS6 } \\
& \text { 11HMS71A 1.E-18 } \\
& \text { 18BUS71A 1. CUS6 } \\
& \text { 11BUS75A 1.E-18 } \\
& 18 \text { 1. HUS7 } \\
& \text { 11HMS75A 1.E-18 } \\
& 18 \text { 1. CUS7 } \\
& \text { 11BUS75B } 1 . \mathrm{E}-18 \\
& 18 \text { 1. HUS8 }
\end{aligned}
$$




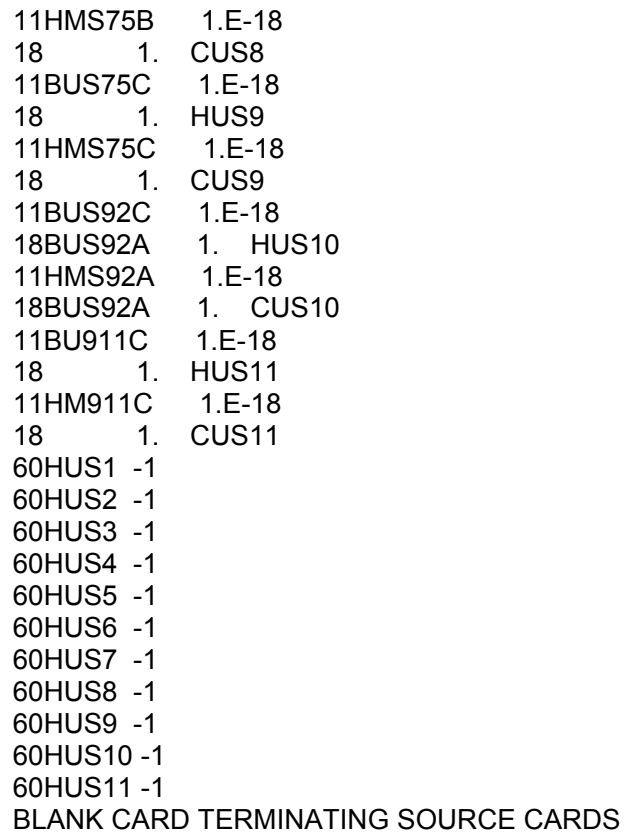

\section{A.3.11. Medidores de tensão}

BUS71ABUS71BBUS71CBU911CBUS75ABUS75BBUS75CBU50XABU50XBBU50XC BUS3MABUS3MBBUS3MCBUS3XABUS3XBBUS3XCOMEGA

BUS32ABUS32BBUS32CBUS45ABUS45BBUS45C

BLANK CARD TERMINATING NODE VOLTAGE OUTPUT CARDS 


\section{Anexo B - Sistema Fictício de 20 Barras}

Apresenta-se aqui o arquivo desenvolvido em ATP para modelar e simular o sistema fictício de 20 barras. Neste arquivo, são configuradas as linhas de distribuição, cargas RL, cargas não lineares, bancos de capacitores, transformadores, dentre outros.

\section{B.1. Configurações iniciais do modelo}

BEGIN NEW DATA CASE

POWER FREQUENCY

60.

$6.512 \mathrm{E}-51.06667$

$\begin{array}{lllllllll}500 & 1 & 1 & 1 & 1 & 0 & 0 & 1 & 0\end{array}$

\section{B.2. Impedâncias das linhas de distribuição}

\begin{tabular}{llc} 
/BRANCH & & \\
51BUS20ABUS23A & .10172 & 1.55575032 \\
52BUS20BBUS23B & .05245 & .28717716 \\
53BUS20CBUS23C & & \\
51BUS50ABUS51A & .08018 & 1.22634968 \\
52BUS50BBUS51B & .04135 & .22637284 \\
53BUS50CBUS51C & & \\
51BUS43ABUS44A & .19687 & 3.01106683 \\
52BUS43BBUS44B & .10152 & .555815165 \\
53BUS43CBUS44C & & \\
51BUS40ABUS43A & .19687 & 3.01106683 \\
52BUS40BBUS43B & .10152 & .555815165 \\
53BUS40CBUS43C & & \\
51BUS22ABUS20A & .02427 & .37113214 \\
52BUS22BBUS20B & .01289 & .06850757 \\
53BUS22CBUS20C & & \\
51BUS31ABUS32A & .02427 & .37113214 \\
52BUS31BBUS32B & .01289 & .06850757 \\
53BUS31CBUS32C & \multicolumn{2}{c}{} \\
51BUS41ABUS42A & .15789 & 2.4148628 \\
52BUS41BBUS42B & .08385 & .4457614 \\
53BUS41CBUS42C & & \\
51BUS42ABUS40A & .1103 & 1.68706544 \\
52BUS42BBUS40B & .05688 & .31141672 \\
53BUS42CBUS40C & \multicolumn{2}{|c}{} \\
51BUS30ABUS33A & .1103 & 1.68706544 \\
52BUS30BBUS33B & .05688 & .31141672 \\
53BUS30CBUS33C & & \\
51BU30YABUS40A & 1.1065 & 16.92295788 \\
52BU30YBBUS40B & .57057 & 3.12382194 \\
53BU30YCBUS40C & &
\end{tabular}


51BUS33ABUS34A 52BUS33BBUS34B 53BUS33CBUS34C 51BUS32ABUS30A 52BUS32BBUS30B 53BUS32CBUS30C 51BUS21ABUS22A 52BUS21BBUS22B 53BUS21CBUS22C 51BUS51ABUS53A 52BUS51BBUS53B 53BUS51CBUS53C 51BUS51ABUS52A 52BUS51BBUS52B 53BUS51CBUS52C 51BUS23ABUS24A 52BUS23BBUS24B 53BUS23CBUS24C 51BUS10ABU10XA 52BUS10BBU10XB 53BUS10CBU10XC 51BU10XABUS20A 52BU10XBBUS20B 53BU10XCBUS20C 51BU40XABU50XA 52BU40XBBU50XB 53BU 40XCBU50XC 51BUS40ABU40XA 52BUS40BBU40XB 53BUS40CBU40XC 51BUS20ABUS30A 52BUS20BBUS $30 \mathrm{~B}$ 53BUS20CBUS30C 51BUS30ABU30XA 52BUS30BBU30XB 53BUS30CBU30XC 51BU30XABU30YA 52BU30XBBU30YB 53BU30XCBU30YC
.428636 .55574044
.221031 .21012922
.428636 .55574044
.221031 .21012922
$.02427 \quad .37113214$
$.01289 \quad .06850757$
$.04849 \quad .74170786$
$.02575 \quad$ 13691243
$.04849 \quad .74170786$
$.02575 \quad .13691243$
$.27592 \quad 2.03517312$
$.21292 \quad .41281344$
.428636 .55574044
.221031 .21012922
.428636 .55574044
.221031 .21012922
$.42863 \quad 6.55574044$
.221031 .21012922
.428636 .55574044
.221031 .21012922
1.106516 .92295788
.570573 .12382194
.428636 .55574044
.221031 .21012922
$.42863 \quad 6.55574044$
.221031 .21012922

\section{B.3. Bancos de capacitores}

$\begin{array}{lll}X 0001 \mathrm{~A} & 5.9652 & 0 \\ \times 0001 \mathrm{~B} & 5.9652 & 0 \\ \mathrm{X0001C} & 5.9652 & 0\end{array}$

\section{B.4. Impedância equivalente da fonte}

$\begin{array}{lcc}\text { 51FONTEAT_PRIA } & 20.805 & 203.721 \\ \text { 52FONTEBT_PRIB } & 4.062 & 52.5397\end{array}$

\section{B.5. Transformador da subestação}

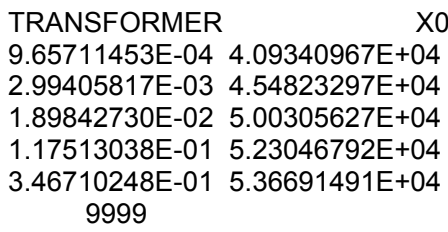




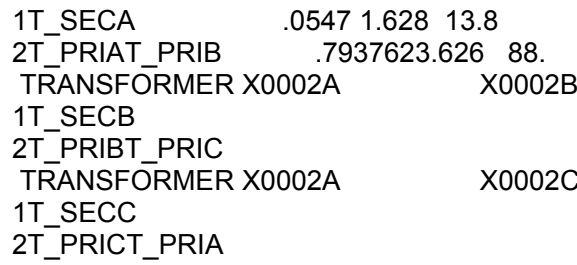

\section{B.6. Impedâncias das cargas $R L$}

$\begin{array}{ll}\text { BUS21ABUS21B } & 3272 . .0037 \\ \text { BUS21BBUS21C } & 3272 . .0037 \\ \text { BUS21CBUS21A } & 3272 . .0037 \\ \text { BUS23ABUS23B } & 3681 . .00416 \\ \text { BUS23BBUS23C } & 3681 . .00416 \\ \text { BUS23CBUS23A } & 3681 . .00416 \\ \text { BUS30ABUS30B } & 2454 . .00277 \\ \text { BUS30BBUS30C } & 2454 . .00277 \\ \text { BUS30CBUS30A } & 2454 . .00277 \\ \text { BUS33ABUS33B } & 4089.9 .00462 \\ \text { BUS33BBUS33C } & 4089.9 .00462 \\ \text { BUS33CBUS33A } & 4089.9 .00462 \\ \text { BUS34ABUS34B } & 11326 . .0128 \\ \text { BUS34BBUS34C } & 11326 . .0128 \\ \text { BUS34CBUS34A } & 11326 . .0128 \\ \text { BUS31ABUS31B } & 9815.9 .01109 \\ \text { BUS31BBUS31C } & 9815.9 .01109 \\ \text { BUS31CBUS31A } & 9815.9 .01109 \\ \text { BUS40ABUS40B } & 8179.9 .00924 \\ \text { BUS40BBUS40C } & 8179.9 .00924 \\ \text { BUS40CBUS40A } & 8179.9 .00924 \\ \text { BUS52ABUS52B } & 22042 . .02491 \\ \text { BUS52BBUS52C } & 22042 . .02491 \\ \text { BUS52CBUS52A } & 22042 . .02491 \\ \text { BUS53ABUS53B } & 12270 . .01387 \\ \text { BUS53BBUS53C } & 12270 . .01387 \\ \text { BUS53CBUS53A } & 12270 . .01387 \\ \text { BUS41ABUS41B } & 4927.6 .00557 \\ \text { BUS41BBUS41C } & 4927.6 .00557 \\ \text { BUS41CBUS41A } & 4927.6 .00557\end{array}$

\section{B.7. Chaves dos bancos de capacitores e seccionadoras}

$\begin{array}{lll}\text { ISWITCH } & & \\ \text { X0001ABUS42A } & -1 . & 1 . E 3 \\ \text { X0001BBUS42B } & -1 . & 1 . E 3 \\ \text { X0001CBUS42C } & -1 . & 1 . E 3 \\ \text { T_SECACHAV1A } & -1 . & 1 . E 3 \\ \text { T_SECBCHAV1B } & -1 . & 1 . E 3 \\ \text { T_SECCCHAV1C } & -1 . & 1 . E 3\end{array}$

\section{B.8. Medidores de corrente}

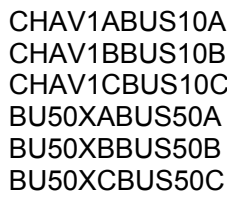

$\begin{array}{ll}\text { MEASURING } & 1 \\ \text { MEASURING } & 1 \\ \text { MEASURING } & 1 \\ \text { MEASURING } & 1 \\ \text { MEASURING } & 1 \\ \text { MEASURING } & 1\end{array}$




\title{
B.9. Parâmetros da fonte
}

ISOURCE

14FONTEA 071851.699

$\begin{array}{llll}60 . & -1 . & 1 . E 3 \\ 60 . & -120 . & -1 . & 1 . E 3\end{array}$

14FONTEB 071851.69

60. 120

$-1 . \quad 1 . E 3$

\section{B.10. Medidores de tensão}

\author{
/OUTPUT \\ BUS10ABUS10BBUS10CBUS50ABUS50BBUS50C \\ BLANK BRANCH \\ BLANK SWITCH \\ BLANK SOURCE \\ BLANK OUTPUT \\ BLANK PLOT \\ BEGIN NEW DATA CASE \\ BLANK
}

